\title{
SOIL CARBON SEQUESTRATION POTENTIAL AND LINKAGES WITH GENERAL FLOODING AND EROSION ISSUES, GISBORNE/EAST-CAPE REGION, NORTH ISLAND, NEW ZEALAND
}

\section{BRIDGET ELLEN O'LEARY}

\author{
A Thesis submitted to \\ Victoria University of Wellington \\ as partial fulfilment of the requirements for the \\ Master of Science Degree (Honours) \\ in \\ Physical Geography
}

School of Geography, Earth and Environmental Science

Victoria University of Wellington

October 2010 


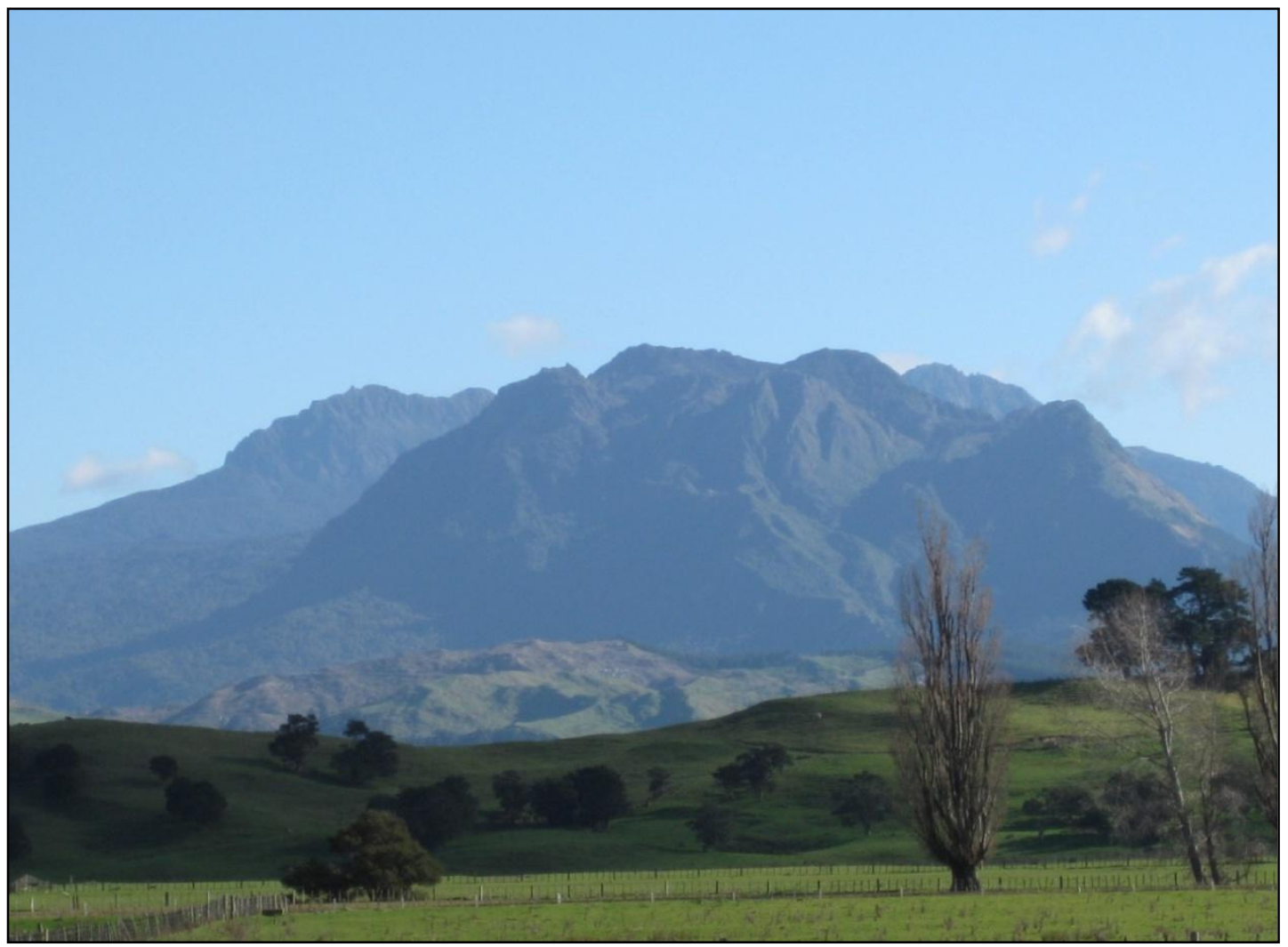

Looking west towards Mount Hikurangi (1752 m) (East-Cape), the highest nonvolcanic mountain located in New Zealand's North Island. 


\begin{abstract}
:
The global carbon cycle has been significantly modified by increased human demand and consumption of natural resources. Billions of tonnes of carbon moves between the Earth's natural spheres in any given year, with anthropogenic activities adding approximately 7.1 gigatonnes (Gt) of carbon (C) to this flux. On a global basis, the sum of $\mathrm{C}$ in living terrestrial biomass and soils is approximately three times greater than the carbon dioxide $\left(\mathrm{CO}_{2}\right)$ in the atmosphere; with the current soil organic carbon (OC) pool estimated at about $1500 \mathrm{Gt}$ (Falkowski et al. 2000). With total global emissions of $\mathrm{CO}_{2}$ from soils being acknowledged as one of the largest fluxes in the carbon cycle, ideas and research into mitigating this flux are now being recognised as extremely important in terms of climate change and the reduction of green house gases (GHG) in the future. Additional co-benefits of increasing carbon storage within the soil are improvements in a soil's structural and hydrological capacity. For example, increasing organic carbon generally increases infiltration and storage capacity of soil, with potential to reduce flooding and erosion. There are several management options that can be applied in order to increase the amount of carbon in the soil. Adjustments to land management techniques (e.g. ploughing) and also changes to cropping and vegetation type can increase organic carbon content within the subsurface (Schlesinger \& Andrews, 2000). If we are able to identify specific areas of the landscape that are prone to carbon losses or have potential to be modified to store additional carbon, we can take targeted action to mitigate and apply better management strategies to these areas. This research aims to investigate issues surrounding soil carbon and the more general sustainability issues of the Gisborne/East-Cape region, North Island, New Zealand. Maori-owned land has a large presence in the region. Much of this land is described as being "marginal" in many aspects. The region also has major issues in terms of flooding and erosion. Explored within this research are issues surrounding sustainability, (including flooding, erosion, and Maori land) with particular emphasis on carbon sequestration potential and the multiple co-benefits associated with increasing the amount of carbon in the soil. This research consists of a desktop study and field investigations focusing on differences in soil type and vegetation cover/land use and what effects these differences have on soil OC content within the subsurface. Soil chemical and physical analysis was undertaken with 220 soil samples collected from two case-study properties. Particle size analysis was carried out using a laser particle sizer (LPS) to determine textural characteristics and hydraulic capacity. Soil organic carbon (OC) content was determined following the colorimetric method, wet oxidation (Blakemore et al. 1987), with results identifying large difference in soil OC quantification between sampled sites. National scale data is explored and then compared with the results from this field investigation. The direct and indirect benefits resulting from more carbon being locked up in soil may assist in determining incentives for better landuse and land management practices in the Gisborne/East-Cape region. Potentially leading to benefits for the land-user, the environment and overall general sustainability.
\end{abstract}




\section{ACKNOWLEDGEMENTS:}

I acknowledge the valuable advice and support of my supervisor Dr. Bethanna Jackson. I thank Dr. Jackson for the encouragement, patience and the guidance she gave to me throughout this process. Without her valuable support and contribution this thesis would not have been possible.

Thanks also to Josephine (Gigi) Woods whose gracious assistance and sharing of her knowledge, in both the field and laboratory aspects of this research, proved extremely valuable.

My sincere thanks to the landowners and wider community for kindly allowing me access to their properties and for sharing local knowledge and history, ultimately allowing me insight into the 'East Coast way of life' and an appreciation of the beautiful landscape.

Thanks to all my family, friends and fellow classmates for the push to complete this research.

Special thanks to my parents (Neil and Kim 0'Leary) my brother (Reece O'Leary) and my trusty side-kick Bryn Margerison. Without their support, my sanity would have been seriously under threat. 
TABLE OF CONTENTS:

1.0 INTRODUCTION : ...............................................................................

1.1 CURRENT STATE OF KNOWLEDGE:

1.2 DATABASES, MONITORING SYSTEMS AND ASSOCIATED LIMITATIONS OR UNCERTAINTIES: ......................................................................................

1.3 A NEW ZEALAND PERSPECTIVE AND THE GISBORNE/EAST-CAPE

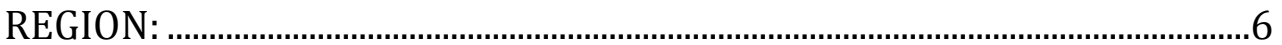

1.4 RESEARCH AIM AND OBJECTIVES:

2.0 BACKGROUND THEORY - SOIL CARBON AND SEQUESTRATION POTENTIAL: .......................................................................................... 11

2.1 INTERNATIONAL PERSPECTIVE:

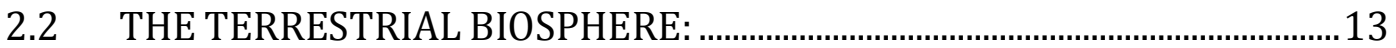

2.3 SOIL ORGANIC MATTER (OM), SOIL AGGREGATION AND STRUCTURAL STABILITY:

2.4 NEW ZEALAND'S TERRESTRIAL CARBON INVENTORY AND MONITORING SYSTEMS:

3.0 REGIONAL BACKGROUND AND INTRODUCTION TO CASE-STUDY SITES:

3.1 CULTURAL CONSIDERATIONS OF THE REGION : ...........................................

3.2 PHYSICAL CHARACTERISTICS:

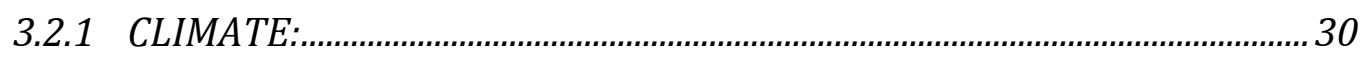

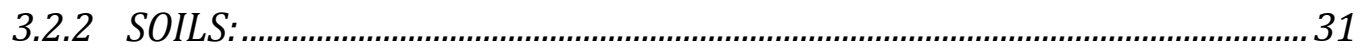

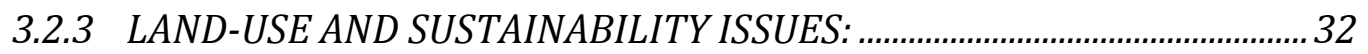

3.3 SITE 1: WILLOWBANK PROPERTY (UAWA CATCHMENT):..........................36

3.4 SITE 2: TIKITIKI PROPERTY (WAIAPU CATCHMENT): .................................40

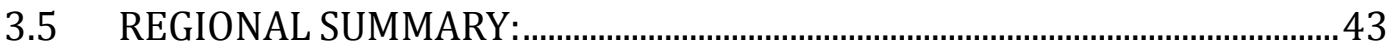

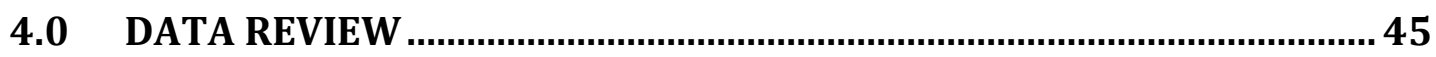

4.1 INTRODUCTION TO NEW ZEALAND'S SOIL CLASSIFICATION SCHEMES

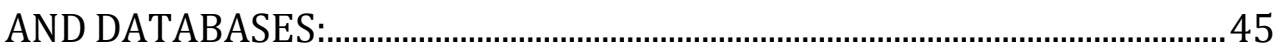

4.2 NEW ZEALAND'S FUNDAMENTAL SOIL LAYER (NZFSL): ...........................47

4.3 SUMMARY: 
5.0 METHODS:

5.1 FIELD SAMPLING TECHNIQUES:.....................................................................53

5.2 SOIL ANALYSIS: ................................................................................................ 54

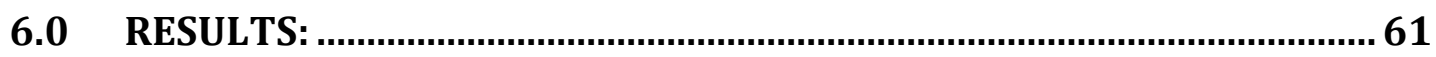

6.1 CHEMICAL RESULTS - SOIL ORGANIC CARBON: ..........................................62

6.2 MECHANICAL RESULTS - PARTICLE SIZE ANALYSIS AND TEXTURAL CHARACTERISTICS: .........................................................................................

7.0 INTERPRETATION, DISCUSSION AND CONCLUSIONS:..........................95

7.1 CONCLUSIONS: ................................................................................................100

7.2 IMPLICATIONS AND CONCLUDING STATEMENT: ......................................104

7.3 FURTHER RECOMMENDATIONS AND KEY RESEARCH

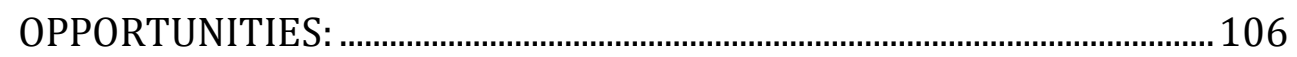

REFERENCES:_..........................................................................................................108

APPENDIX I: NEW ZEALAND SOIL CLASSIFICATION - SOIL ORDERS:................120

APPENDIX II: EXPLANATION OF CARBON ATTRIBUTE DATA FROM FSL:.......131

APPENDIX III: METHODS:

APPENDIX IV: TEXTURAL CLASSIFICATION AND SOIL WATER CHARACTERISTICS: 139

APPENDIX V: SOIL CHEMICAL ANALYSIS: ORGANIC CARBON RESULTS:.........145 


\section{LIST OF FIGURES:}

Figure 1. Photographs of recent flooding (June 2010) and associated consequences.

Figure 2. The Carbon cycle showing annual fluxes in gigatons (Gt) C/yr. 12

Figure 3. Soil aggregate size and impacts on soil OC turnover time. 15

Figure 4. Overview of LUCAS reporting process.

Figure 5. New Zealand Soil Carbon Monitoring System (CMS), Structure and Development.

Figure 6. Raukumara Peninsula, Gisborne/East-Cape, North Island, New Zealand 24

Figure 7. Geology of the Raukumara Peninsula. 29

Figure 8. Major climatic zones of the Raukumara Peninsula.. 30

Figure 9. Dominant soils and vegetation present at the Tikitiki case-study property (According to NZFSL and NZLRI). 35

Figure 10. Dominant soils and vegetation present at the Willowbank case-study property (According to NZFSL and NZLRI) 35

Figure 11. Aerial photograph case-study site 1: Willowbank 36

Figure 12. Soil Sample Locations: Willowbank Property 37

Figure 13. "Bottom Pasture" Sample Site 38

Figure 14. "River" Sample Site 38

Figure 15. "Kanuka" Sample Site. 38

Figure 16. "Top Pasture” Sample Site 38

Figure 17. Aerial photograph case-study property site 2: Tikitiki 40

Figure 18. Soil Sample Locations: Tikitiki Property 41

Figure 19. “Garden” Sample Site. 42 
Figure 20. "Gorse" Sample Site

Figure 21. "Flats" Sample Site 42

Figure 22. Soil samples in the laboratory air drying. .54

Figure 23. USDA Textural classification triangle. Source: .57

Figure 24. Beckman Coulter LS 13320 - Laser Particle Sizer. 59

Figure 25. Proportional decrease in soil OC (mg/g) with increasing sampling depth: Tikitiki.

Figure 26. Proportional decrease in soil OC (mg/g) with increasing sampling depth: Willowbank.

Figure 27. Stacked averages showing soil OC (mg/g) at each soil sample site 65

Figure 28. Depth integration results $(\leq 30 \mathrm{~cm})$

Figure 29. Averaged depth integration results $(\leq 30 \mathrm{~cm})$. 67

Figure 30. Depth integration results $(\leq 70 \mathrm{~cm})$ 69

Figure 31. Averaged depth integration results $(\leq 70 \mathrm{~cm})$. 69

Figure 32. \% soil OC comparison between "Gorse" vs. "Garden" 70

Figure 33. \% soil OC comparison between "Kanuka" vs. "Top Pasture". 71

Figure 34. \% soil OC comparison between "Top Pasture" vs. "Bottom Pasture"...... 72

Figure 35. \% soil OC comparison between "Flats" vs. "Bottom Pasture". 73

Figure 36. \% soil OC comparison between "Kanuka" vs. "Gorse". 74

Figure 37. Average Textural Proportions $(5-10 \mathrm{~cm}$ and $30-50 \mathrm{~cm})$ : Tikitiki casestudy property. 76

Figure 38. Average Textural Proportions $(<20 \mathrm{~cm}, 20-50 \mathrm{~cm}$ and $50-\mathrm{cm})$ :

Willowbank case-study property. 77

Figure 39. Ternary plots showing USDA textural classifications at each of the seven sample sites. 79 
Figure 40. Saturated Hydraulic Conductivity: Willowbank case-study property .... 81

Figure 41. Colour scheme produced using the polyscape tool .84

Figure 42. Soil carbon options layer Tikitiki case-study property .86

Figure 43. Soil carbon options layer Willowbank case-study property. .86

Figure 44. Farm impact/productivity layer Tikitiki case-study property. 88

Figure 45. Farm impact/productivity layer Willowbank case-study property.......... 88

Figure 46. Flood mitigation layer Tikitiki case-study property. 90

Figure 47. Flood mitigation layer Willowbank case-study property. 90

Figure 48. Hydrological worst case scenario layer Tikitiki case-study property.... 92

Figure 49. Hydrological worst case scenario layer Willowbank case-study property. 92 


\section{LIST OF TABLES:}

Table 1. New Zealand's Vegetation and Soil Carbon Reserves

Table 2. New Zealand's soil carbon stock $(0-0.3 \mathrm{~m})$ for land-use categories.

Table 3. Soil Orders from the revised New Zealand Soil Classification (NZSC)

Table 4. Soil Type (DOMNZSC), Vegetation, Land use and associated Carbon attributes at each of the seven sample sites

Table 5. Characteristics of soil C determination methods.

Table 6. Characteristics of the different methods followed to determine particle size distribution.

Table 7. Mean soil organic carbon (mg/g) (standard deviation): Tikitiki case-study property.

Table 8. Mean soil organic carbon (mg/g) (standard deviation): Willobank casestudy property.

Table 9. Table Showing Soil OC Depth Integration Results $(\leq 30 \mathrm{~cm})$ .66

Table 10. Table showing Soil OC Depth Integration Results $(\leq 70 \mathrm{~cm})$ 68

Table 11. Particle-size fractions according to the Standards Association of New Zealand (1986). 75

Table 12. Particle size fractions following the USDA soil standards 78

Table 13. Integrated soil OC $(\leq 20 \mathrm{~cm})$ results compared with attributes from the NZFSL: Tikitiki case-study property.

Table 14. Integrated soil OC $(\leq 20 \mathrm{~cm})$ results compared with attributes from the NZFSL: Willowbank case-study property. 


\section{LIST OF ACRONYMS:}

C - Carbon

CMS - Carbon Monitoring System

DEM Digital Elevation Model

ETS - Emissions Trading Scheme

FAO - Food and Agriculture Organization of the United Nations

GHG - Green House Gas

GIS - Geographic Information System

GPS - Global Positioning System.

Gt - Gigatons

IC - Inorganic Carbon

LRIS - Land Resource Information System

LUC - Land-Use Classification

LUCAS - Land-Use Carbon Analysis System

NSD - National Soils Database

NZCCC - New Zealand Climate Change Centre

NZFSL - New Zealand's Fundamental Soil Layer

NZG - New Zealand Genetic Soil Classification

NZLRI - New Zealand Land Resource Inventory

NZSC - New Zealand Soil Classification

OC - Organic Carbon

OM - Organic Matter

PTF - Pedo-Transfer Function

TOC - Total Organic Carbon

UNFCCC - United Nations Framework Convention on Climate Change 


\subsection{INTRODUCTION:}

The presently the topical subject of climate change, including consideration of its consequences, mitigation and adaptation strategies (including emissions trading schemes), has increased interest in carbon cycling at several spatial scales. There is particular interest in understanding the extent to which humans have impacted this critical global cycle to date, and the extent to which this will continue in the future. Future changes in the Earth's climate (whether natural or human induced) are expected to differ from region to region but increases in temperature and more extreme precipitation are predicted for most regions by most future climate scenario predictions (Denman et al. 2007). Soil carbon stocks (particularly organic matter) are sensitive to climate change, both directly (e.g. changes to precipitation patterns may increase the likelihood of erosion and increase leaching of dissolved organic carbon) and indirectly, as both carbon and climate changes can significantly modify other inherent soil properties such as structure, and overall soil stability. A flow-on effect to other elements of the global carbon cycle may follow if some of this stored soil carbon is taken up by the atmosphere. Soil conservation measures will become critical to allow sustainable land management and also as a means of mitigating some climate change impacts. Concerns surrounding soil carbon and changes to carbon dynamics (particularly soil carbon losses) are justified. Consequences of carbon being lost from the soil are widespread in terms of soil function and longer-term soil preservation. 
This research is concerned with addressing the extent to which increasing and/or conserving soil carbon stocks is beneficial, given the current predictions surrounding climate change. Specifically, it examines:

- To what degree can we avert some of the predicted climatic change? (through enhancing carbon sequestration)

- Given that not all change is likely to be averted, how might soil carbon management aid in managing the associated impacts? (increased flooding, erosion)

\subsection{CURRENT STATE OF KNOWLEDGE:}

\section{WHAT DOES CARBON SEQUESTRATION IN SOILS MEAN FOR OTHER SERVICES/RISKS?}

The term soil carbon sequestration is loosely defined as being:

"The removal of atmospheric $\mathrm{CO}_{2}$ by plants and storage of fixed carbon as soil organic matter" (Lal, 2004).

Although climate change has been the focus of a large body of research in past decades, the estimated numbers associated with individual stores and fluxes of carbon still vary greatly throughout literature. Globally soil ( $\leq 1$ metre depth) is estimated to contain about 2.5 times more organic carbon than contained in terrestrial vegetation (600Gt) (Batjes, 1996). Batjes (1996) estimated the global stock of organic carbon in the upper $100 \mathrm{~cm}$ of soil to be between 1462 and 1548 billion tons of carbon, making soil an extremely significant storage unit. Research concentrating on carbon within the subsurface is not new (Schlesinger, 1984; Batjes, 1996; Lal, 1999), but this element of the carbon cycle is still poorly understood in many respects. As there are many benefits associated with increases in soil carbon and potentially positive and negative feedbacks (Heimann \& Reichstein, 2008) to the global climate, greater focus should therefore be applied to soil carbon dynamics and research. Monitoring 
soil carbon losses or potential gains is important at all spatial scales (Preston et al. 2004).

Land-use change or conversion to cropping and agricultural farming has led to historic losses of soil carbon globally (FAO, 2001) including New Zealand through processes such as erosion (Preston et al. 2004; Trotter et al. 2004; Tate et al. 2003a \& 2000; Scott et al. 2002). The potential for increasing soil carbon has been realised by many (Lal, 1999; Post et al. 2000; Schlesinger, 1984; Trumbore et al. 1997), but because of the complexities surrounding soil carbon dynamics and particularly carbon turnover, knowledge gaps still exist. Increasing the soil organic carbon (OC) content of depleted or degraded soils can be a lengthy process needing high inputs of carbon to the soil. Raich \& Schlesinger (1992) estimated that the average global turnover time for soil OC (to $1 \mathrm{~m}$ depth) was about 32 years. However, results from their research suggested turnover varied from 14 years to 400 years depending on the type of ecosystem (Raich \& Schlesinger, 1992). Focus and research in carbon stocks and flows in the terrestrial environment should include identifying areas in the landscape that already have substantial carbon within the subsurface and the protection of these such areas. 'Target' management strategies such as reducing soil turnover for cropping purposes or the planting of a riparian strip that focus specifically on areas of high carbon stocks could be applied and therefore, potentially preventing carbon loses from the soil as a result of factors such as erosion.

Climate change and its associated impacts are not the only drivers for increased soil carbon sequestration, other environmental and socioeconomic realms can also benefit from increased carbon within the subsurface. Co-benefits for other services/risks mitigation include:

- Flood alleviation

- Increased water holding capacity
- Enhanced biodiversity in soil ecosystems

- Increased structural stability 
- Erosion alleviation

- Increased crop yields and plant biomass
- Increasing nutrient reserves

It is estimated that about $58 \%$ of soil organic matter (OM) is carbon (Post et al. 2001). Soil OM increases water retention and allows soils to release water more gradually. Increases in water storage and water transmitting capabilities can reduce the occurrence of rapid runoff and surface flooding on land. Streams and rivers benefit from increased water retention with the soil acting as a buffer slowing stream flow changes (Ghani et al. 2009) and, therefore, reducing flood peaks and drought periods, while retaining nutrients. The protection of $\mathrm{OM}$ therefore provides a multitude of benefits. This thesis focuses largely on the benefits of rural sustainability, particularly benefits surrounding flood alleviation and erosion mitigation. Additionally, it looks at the wider context of carbon sequestration and its importance with climate change.

\subsection{DATABASES, MONITORING SYSTEMS AND ASSOCIATED LIMITATIONS OR UNCERTAINTIES:}

There is potential to modify land-use and/or management practices to provide multiple co-beneficial outputs including increased sequestration potential, increased saturated hydraulic conductivity, plant available water and other ecosystem functions. However, for soil carbon sequestration to become a viable large-scale option in terms of reducing carbon emissions and therefore gaining the associated co-benefits that come with carbon sequestration in soil, steps need to be made to ensure models and monitoring systems are robust and applicable in many situations and at differing spatial scales. Falloon et al. (1998) recognised the crucial link between Geographic Information Systems (GIS) data, maps and carbon sequestration potential. GIS data provides an effective, easily visualised means of storing and transmitting spatially explicit information on specific parameters such as soils, land-use, and climate. This information, coupled with models or tools capable of identifying areas that have 
potential to sequester more carbon, could allow estimates of the impacts that land-use and climate changes have on overall carbon stocks (Falloon et al. 1998). Robust carbon modelling tools and supporting data will prove very powerful in identifying problematic areas of the landscape and areas that could possibly sequester more carbon, and potentially result in better landuse/management practices.

New Zealand is a signatory of the Kyoto Protocol, an international agreement that aims to mitigate and reduce the extent of climate change by reducing green house gas (GHG) emissions (UNFCCC, 2009). New Zealand, as a member, is obligated to reduce its greenhouse gas emissions to 1990 levels over the 20082012 commitment period, or pay financial penalties and purchase carbon credits on the international market for any emissions over these levels (Ministry for the Environment (MfE), 2010). New Zealand's ability to reduce GHG emissions, and the net costs of mitigation measures, depends largely on carbon uptake or release. This includes effects on soil carbon. Current legislation and initiatives surrounding emission reductions include the Emissions Trading Scheme (ETS), Permanent Forestry Sink Initiative and the Afforestation Grant Scheme, which focuses largely on using forestry as an offset to carbon emissions (NZCCC, 2010). In order to aid in meeting emission reduction targets, several monitoring systems and models have been developed to report on carbon stocks and flows in the New Zealand terrestrial environment. Differences in scope, methodology, and underlying assumptions surrounding carbon models and monitoring systems reflect the extreme difficulty encountered when attempting to quantify the complex and broad subject matter of terrestrial carbon. The New Zealand Soil Carbon Monitoring System (CMS) is one such system that has faced international scrutiny in the past (MfE, 2007). Uncertainties surround the assumption that soil carbon is at a steady state (When does carbon reach a 'steady state' within the soil?), and also uncertainties surrounding insufficient and outdated data (Tate et al. 2003c). This work does not attempt to critically review New Zealand's CMS or other carbon monitoring systems but rather examine the state of New Zealand's 
underlying data used to support systems such as New Zealand's CMS or other decision support tools.

\section{POLYSCAPE:}

Data support and research that surrounds decision support systems or tools that assist in the implementation of management strategies aimed at sustainability and co-beneficial environmental outcomes are crucial in terms of resource management. One such decision support system is the Geographic Information System (GIS) toolbox known as Polyscape. The Polyscape toolbox has been developed by researchers at Victoria University of Wellington and Bangor University in Wales and aims to assist with decisions surrounding additions, removal or protection of existing landscape features (Jackson et al. 2010). Polyscape was initially implemented in the UK evaluating trade-offs in changing land-use on hydrology, erosion and sediment transport, agriculture productivity and biodiversity. Tools such as Polyscape meet key research needs for models and visualisations that can be applied to any landscape at different spatial scales using readily available data for parameterisation (Jackson et al. 2010). However, data issues limit the applicability of such tools, even those that are designed for data-sparse environments. One of the objectives of this research will be to test the suitability of New Zealand's nationally available data for use with decision support tools such as Polyscape and inform an additional valuation layer on both existing and potential carbon storage and emissions in rural landscapes.

\subsection{A NEW ZEALAND PERSPECTIVE AND THE GISBORNE/EAST-CAPE REGION:}

New Zealand's soils are identified as being generally higher in soil OC (168 t/ha1 to $1 \mathrm{~m}$ ) than the mean global estimate of $130 \mathrm{t} / \mathrm{ha}^{-1}$ (Tate et al. 1997) This is largely attributed to the high proportion of pastoral land-use known to conserve carbon stocks in soils cleared of previous indigenous vegetation 

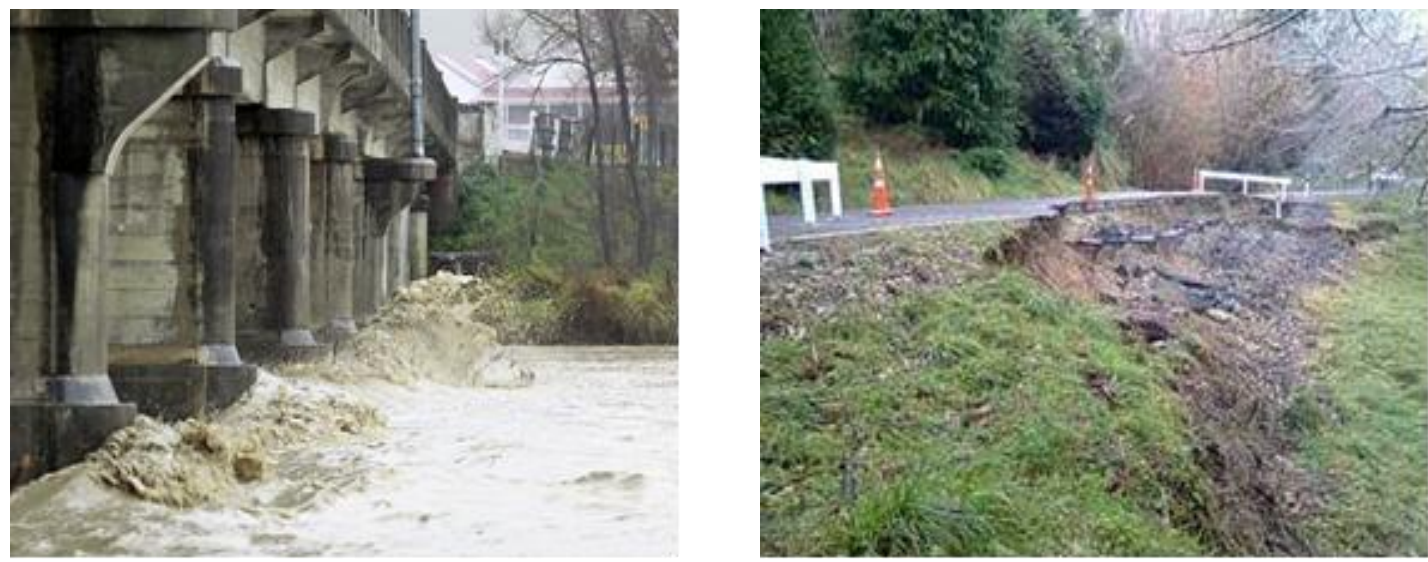

Figure 1. Photographs of recent flooding (June 2010) and associated consequences (increased erosions).

(Savage, 2006). Other contributing factors to higher soil OC also include New Zealand's temperate climate and fertile soils derived from volcanic ash (Schipper \& Sparling, 2009). Erosion is responsible for moving large amounts of terrestrial carbon into our oceans each year (Tate et al. 2004). Because the New Zealand landscape is subject to tectonic activity and high intensity rain storms, some erosion problems are inevitable but are severely exacerbated by humans. Anthromorphically enhanced soil erosion threatens to reduce New Zealand's naturally high carbon stocks and has been identified as one of the most pervasive forms of human induced degradation of terrestrial ecosystems, playing a dominant role in terms of the impact on New Zealand's national carbon budget (Tate et al. 2000). This generalisation is particularly true of the Gisborne/East-Cape region, North Island, New Zealand. Currently, the severe erosion and flooding issues influence land-use within the region with much of the land being considered as marginal and productivity at present being poor. However, a variety of opportunities for modification of land-use and management practices exist, with substantial potential for both environmental and socioeconomic gains. In this thesis, general sustainability issues within the Gisborne/East-Cape region are explored. Substantial focus is then given to two differing case-study properties in the East-Cape, one located west of Tolaga Bay and the other further north in the small township of Tikitiki. Results and conclusions are then discussed in the context of the wider East Cape region and in a national context. 


\subsection{RESEARCH AIM AND OBJECTIVES:}

The introduction provided a generalised overview of the issues and rationale behind this research. Below is a more defined research aim along with specific objectives of the work.

RESEARCH AIM: to investigate the issues surrounding general sustainability of rural land-use within the Gisborne/East-Cape, region, North Island, New Zealand with a particular emphasis on soil carbon sequestration and the associated co-benefits of increased carbon within soil.

OBJECTIVE ONE: determine both the environmental and socioeconomic sustainability issues the Gisborne/East-Cape region is facing at present, with a particular focus on the major erosion and flooding issues.

OBJECTIVE TWO: quantify soil OC and its variation with depth across a range of different soil types and land-uses within the Gisborne/East-Cape region.

OBJECTIVE THREE: review the available national scale soil data, both in a stand-alone sense and in comparison with the data collected in objective two. Then comment on data reliability and representativeness to inform its application with spatially explicit land management tools, using the geographic information system tool Polyscape as a 'test case'.

OBJECTIVE FOUR: comment on the results of objectives two and three with regards to how these results can be used to inform strategies to address the sustainability issues outlined in objective one. Objective four also looks at the application of results to the wider context of data support systems and assisting with overall sustainable land management decisions. 


\section{THESIS STRUCTURE:}

This thesis consists of seven primary chapters:

CHAPTER ONE: introduces the research topic.

CHAPTER TWO: is structured in two parts. Part one gives a generalised overview of the global carbon cycle, and reviews the role of terrestrial carbon. Part two looks at New Zealand's terrestrial carbon stocks primarily focusing on soil carbon reporting and monitoring strategies.

CHAPTER THREE: consists of a regional overview looking at both the physical and cultural characteristics of the Gisborne/East-Cape region. This chapter also looks at present sustainability issues and environmental value systems. Environmental and socio-economic consequences of flooding and erosion in the region are briefly discussed. To conclude the chapter features characterising the two case-study properties will be reviewed.

CHAPTER FOUR: provides a critical review of the available known published and unpublished national scale soil and land-use data and associated databases.

CHAPTER FIVE: outlines the methods followed along with justification as to why they were chosen.

CHAPTER SIX: presents summary results from both soil chemical and physical analysis looking at general trends evident within and between the two casestudy properties.

CHAPTER SEVEN: summarises the results and relationships presented in the previous chapter. A reintroduction of the aim and main objectives of this research and the conclusions that can be drawn from the presented results are stated. Further recommendations and research opportunities conclude the chapter. 
The appendices contain additional information relevant throughout.

APPENDIX I contains more information on the soil orders defined in the New Zealand soil classification.

APPENDIX II explains the carbon attribute data from New Zealand's Fundamental Soil Layer.

APPENDIX III outlines the methods and procedures followed throughout the research.

APPENDIX IV includes tables on textural classification and soil water characteristics at each of the seven sample sites.

APPENDIX V includes tables and data on soil chemical analysis (organic carbon results). 


\subsection{BACKGROUND THEORY - SOIL CARBON AND SEQUESTRATION POTENTIAL:}

Specific aspects of the carbon cycle need to be broken down into their component parts in order to understand the potential for sequestration in the various elements of this global cycle. The dynamics of carbon sequestration processes must be evaluated at several scales particularly in the context of local geological, soil, vegetation, climatic and land-use characteristics, with all the spatial variability and heterogeneity this entails. Understanding and predicting impacts on both the global and regional carbon cycles are fundamental research challenges. Throughout this chapter key processes governing soil carbon sequestration, and more generally carbon within the terrestrial biosphere are introduced and discussed. New Zealand's terrestrial carbon monitoring practices and the methodology behind the New Zealand soil carbon monitoring system are also briefly reviewed.

\subsection{INTERNATIONAL PERSPECTIVE:}

The Earth's climate is significantly influenced by $\mathrm{CO}_{2}$ concentrations and other green house gases (GHG) in the atmosphere, with the association of high $\mathrm{CO}_{2}$ concentrations and warm climates being indisputable (Schlesinger, 1998). Carbon moves through the Earth's environmental spheres (lithosphere, hydrosphere, biosphere and, atmosphere) and is controlled by a number of both natural and anthropogenic complex processes (Denman et al. 2007). Human actions have impacted this cycle significantly, most obviously through increased $\mathrm{CO}_{2}$ emissions. The following diagram (Figure 2) shows estimated natural annual carbon (C) fluxes (pre 1750) in black versus the anthropogenic in red. 


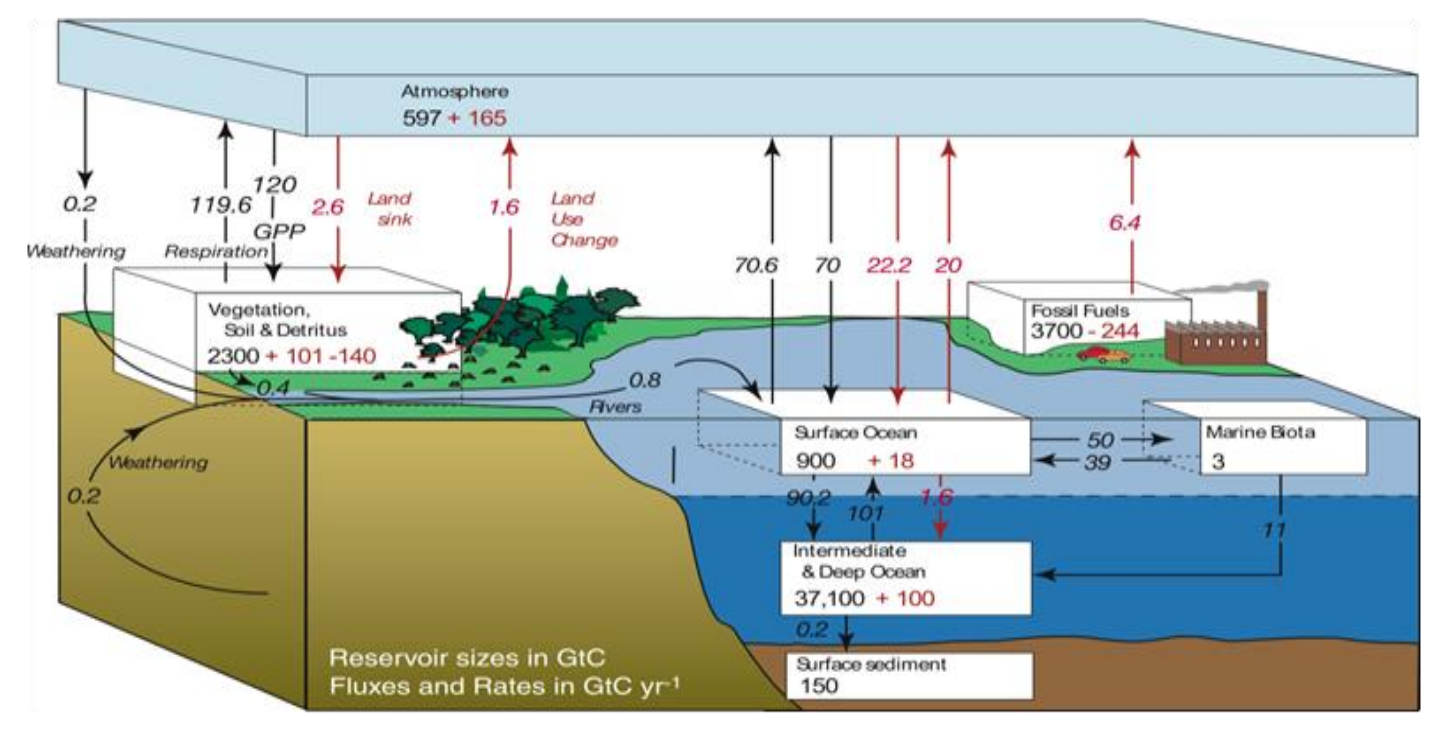

Figure 2. The Carbon cycle showing annual fluxes in gigatons (Gt) C/yr. Source: Denman et al. 2007

As shown in Figure 2, the Earth contains a number of large reservoirs that can at different times act as either a source or a sink of carbon. Natural $\mathrm{CO}_{2}$ sinks absorb about 55\% of all anthropogenic carbon emissions, and therefore have significant potential to slow down climate change (Le Quéré et al. 2009). The following are identified by Schlesinger (1998), as significant areas of carbon accumulation:

- organic molecules in living and dead organisms found in the biosphere,

- the gas carbon dioxide in the atmosphere,

- organic matter in soils,

- fossil fuels and sedimentary rock deposits in the lithosphere and,

- dissolved atmospheric carbon in the oceans (Schlesinger, 1998).

Presently $\mathrm{CO}_{2}$ levels within the atmosphere are around 383 parts per million (ppm), about 37\% higher than pre-industrial levels (Le Quéré et al. 2009). $\mathrm{CO}_{2}$ is considered a trace gas which contributes to the "greenhouse" effect and consequently global warming. Global consequences of high concentrations of $\mathrm{CO}_{2}$ in the atmosphere could prove dire to many ecosystems and ecosystem 
services and functions (Schimel, 1995). The threat of natural climate perturbations being exacerbated by these high concentrations of $\mathrm{CO}_{2}$ within the atmosphere has heightened interest in the study of carbon and carbon dynamics at both global and regional scales (Schlesinger, 1998).

\subsection{THE TERRESTRIAL BIOSPHERE:}

Terrestrial ecosystems gain carbon through the process of photosynthesis and lose $\mathrm{CO}_{2}$ through the process of respiration. However, the role the terrestrial biosphere plays in terms of the global carbon cycle is still difficult to quantify (Heimann \& Reichstein, 2008). Difficulties occur due to the complex biology and interactions underlying carbon storage, heterogeneity of vegetation and soils, and also the anthropogenic variations in land-use/management (Schimel, 1995). If changes in climate conditions (e.g. temperature, precipitation) and nutrient status are favourable productivity may increase and the amount of carbon sequestered from the atmosphere may be enhanced. However climatic change and/or an associated shift in ecosystems structure and dynamics can also have negative consequences decreasing soil carbon sequestration rates or increasing atmospheric $\mathrm{CO}_{2}$ emissions (Denman et al. 2007). Land-use change directly affects carbon fluxes at all spatial scales and as a result changes the amount of carbon stored in vegetation and soil (IPCC, 1996). For the scope of this research the below ground aspects of the carbon cycle and the associated soil functions will be the primary focus. Historically the major focus for carbon sequestration research has been primarily centred around vegetation and the above ground components of the carbon cycle (Raich \& Schlesinger, 1992). Carbon accumulations rates in vegetation are relatively well known. However, there is an increasing consensus soils may be as or more important as they are a major location of carbon storage and by far the largest pool in terrestrial ecosystems (Jobbagy \& Jackson, 2000). The global soil carbon pool consists of both soil organic carbon (OC) and soil inorganic carbon (IC). A global estimation of the total size of the soil carbon pool sits at about 2500 gigatons (Gt), with 1550 Gt of this being soil OC and the other 950 Gt soil IC (Lal, 2004). 
Residence times of soil OC can range from short (hours-days) to long (thousands of years) timeframes (Post \& Kwon, 2000). The size and long residence times associated with this carbon pool make it extremely important in the global carbon cycle. The global picture of subsurface interactions and resultant soil carbon changes are relatively unclear because both quantitative and qualitative techniques to interrogate change at large spatial scales are poorly developed (Tate et al. 2005). The quantity of soil OC present is dependent on several factors such as; soil texture, climate, vegetation, historical and current land-use, and land management practices in place (Milne, 2008). The interaction of such processes predominantly decides carbon transformations and transport in the soil resulting in either sequestration or even increased $\mathrm{CO}_{2}$ emissions (U.S. Department of Energy, 1999).

\subsection{SOIL ORGANIC MATTER (OM), SOIL AGGREGATION AND STRUCTURAL STABILITY:}

The four major constituents of soil are mineral components, soil water, air and organic matter (White, 2006). The relative proportions of each of these components can greatly influence soil characteristics and associated productivity potential. The combined processes of physical and chemical weathering, vegetation types, and microbial activity shape material into a series of horizons that constitute the soil profile (White, 2006). The location of these horizons can provide clues as to the major inputs, transformation, movements and losses of carbon from the soil (Ashman \& Puri, 2002).

Soil organic matter (OM) and the associated transformations and functions within the subsurface are recognised as one of the most important feature when it comes to carbon cycling in the soil. Essential functions include: biological functions, exchange functions, aggregation functions, and storage functions, contributing to differing carbon storage pools (Feller et al. 2000). It is generally agreed that there are at least three identifiable $\mathrm{C}$ pools within the subsurface. These are the 'active' pool; which includes the easily and rapidly decomposable 
aspects of fresh plant litter, the 'passive' pool; including stabilised OM that can remain in soils for several thousands of years and a 'slow' (or 'intermediate') pool; with turnover times ranging from years to centuries (Trumbore, 1997). However, there is still much debate surrounding turnover times and differing carbon fractions associated with the soil OC or soil OM pool (Post et al. 2001; Feller et al. 2000).

Carbon is generally the main element present in soil OM, comprising from $48 \%$ to $60 \%$ of the total weight (Rosell et al. 2000). Soil OM supports the formation and stabilization of soil structure, and is considered a reflection of the balance between carbon gains from plant residues and animal wastes and loss of carbon through decomposition (White, 2006). Accumulation of soil OM occurs throughout ecosystem development resulting from the interactions between biota and environmental controls (Post et al. 2001). As soil OM decomposition goes through the various stages, the organic particles within the soil combines with the soil matrix to form macroaggregates and microaggregates (BlancoCanqui \& Lal, 2004). Aggregation is also particularly important when it comes to a soils' hydraulic capacity and is key in preventing/reducing soil erosion.

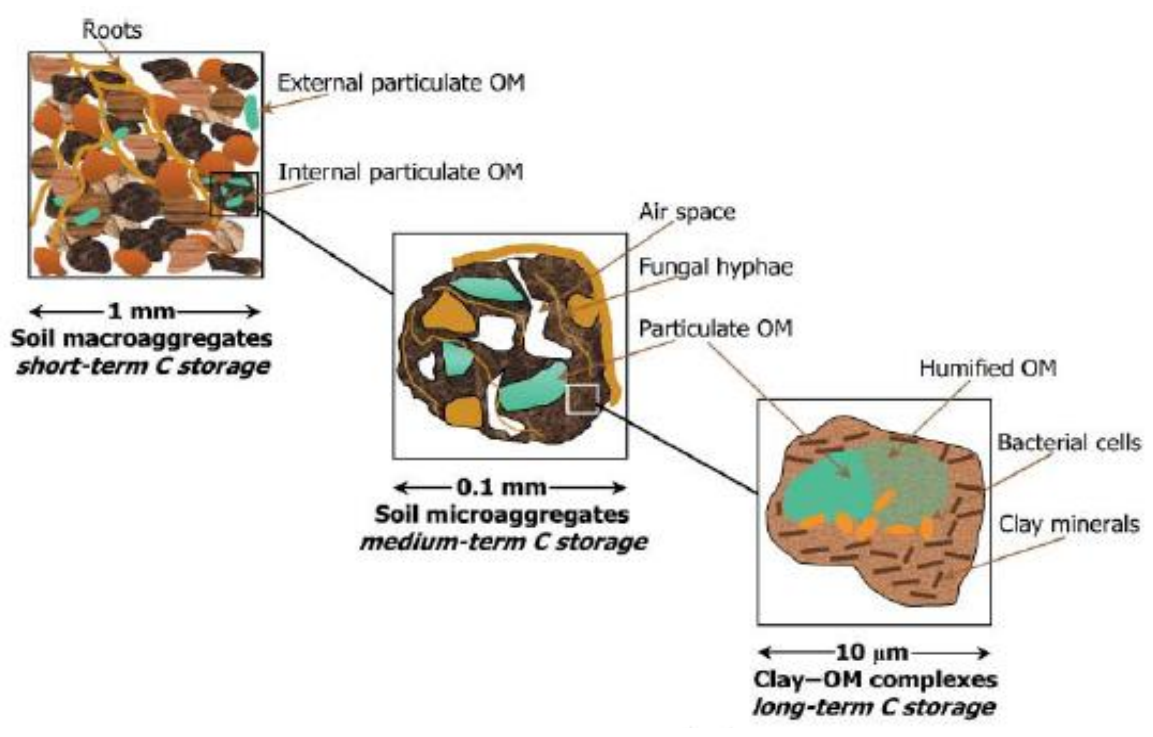

Figure 3. Soil aggregate size and impacts on soil OC turnover time. Source: Jones et al. 2004 
Aggregate organisation and the pore spaces in between constitute a soils structure (Tisdall, 1996). Soil structure predominantly controls the movement of water in the soil, and also significantly affects a soils strength and potential for plant growth, overall water storage, and soil OC storage. Soil structure is particularly sensitive to change. Processes and interactions between soil structure, texture, and OM therefore greatly influence the magnitude of the soil organic carbon pool (Blanco-Canqui \& Lal, 2004). Soil aggregation is crucial in terms of increasing overall soil OC. Improving depth distribution of soil OC and stabilising this $\mathrm{C}$ in terms of encapsulation within stable micro-aggregates (Figure 3) (Lal, 2004) will be beneficial in many aspects.

To recap, terrestrial carbon sequestration is complex. Estimates of the actual amount of carbon locked up, and in particular estimates of changes in these amounts are still inaccurate. Falloon et al. (1998) state that "soil carbon measurements are complex, laborious, and measurements taken at a few statistically unrepresentative sites are difficult to scale to larger areas". This is also recognised by Tate et al. (2005) who stated that currently predictions of soil $\mathrm{C}$ changes and associated implications are very uncertain largely because the techniques quantifying current and future soil $\mathrm{C}$ stocks and changes at differing spatial scales are inadequate. Importantly for soil $\mathrm{C}$ research then is the development of measurements and methods into usable techniques and research surrounding mitigation of this potentially negative soil C flux especially in terms of climate change and the reduction of green house gases (GHG) in the future. Approaches for sequestering carbon in terrestrial ecosystems can be divided into the following two categories:

- The manipulation approach of applying 'better' techniques to increase carbon sequestration beyond current conditions and,

- The protection approach, identifying areas that store carbon so that sequestration can be maintained or increased (Lal, 2003).

Both the manipulation and protection approaches are likely to be useful in the New Zealand context and to some extent have been already applied. The next 
section will look at New Zealand's approach to soil carbon monitoring. The underlying data supporting this system will be discussed in further chapters.

\subsection{NEW ZEALAND'S TERRESTRIAL CARBON INVENTORY AND MONITORING SYSTEMS:}

New Zealand's terrestrial carbon is predominantly found in vegetation, litter and soil OM (Tate et al. 1997). Tate et al. (1997) estimates of New Zealand's vegetation and soil $\mathrm{C}$ reserves can be seen in Table 1.

\begin{tabular}{|c|c|c|c|c|}
\hline \multirow{2}{*}{} & Area & \multicolumn{3}{|c|}{ Carbon Storage (Mt) } \\
\cline { 3 - 5 } & $\left(10^{3}\right.$ ha $)$ & Vegetation & Soil (0-1m) & $\begin{array}{c}\text { Total } \\
\text { (Vegetation C + Soil C, 0- } \\
1 \mathrm{~m})\end{array}$ \\
\hline North Island & 11440 & 990 & $\mathbf{1 9 6 0 \pm 7 0}$ & 2970 \\
\hline South Island & 15120 & 1390 & $\mathbf{2 2 7 0 \pm 1 6 0}$ & 3640 \\
\hline Stewart Island & 170 & 40 & $\mathbf{3 0 \pm 3}$ & 70 \\
\hline New Zealand & 26730 & 2420 & $\mathbf{4 2 6 0 \pm 1 9 0}$ & 6680 \\
\hline
\end{tabular}

Table 1. New Zealand's Vegetation and Soil Carbon Reserves. Source: Tate et al. (1997)

New Zealand's vegetation carbon equates to approximately $2420 \mathrm{Mt}$ C representing around $0.004 \%$ of global vegetation C estimates (Tate et al. 1997). As with much of the world, carbon in New Zealand's soils occurs mainly in the form of soil OM. Tate et al. (1997) estimated New Zealand's total soil carbon pool to be at approximately $4260 \mathrm{Mt} \mathrm{C}$, with a mean value of $168 \mathrm{t} \mathrm{ha}^{-1}$ of soil carbon to 1 meter depth and with most New Zealand soils containing around 50-150 tha-1 to $10 \mathrm{~cm}$ depth (Ghani et al. 2009). More recent estimates to three different depth increments (0-0.1, 0.1-0.3, and 0.3-1 m) are given by Scott et al. (2002) and are accordingly 1152 $\pm 44 \mathrm{Mt}(0-0.1 \mathrm{~m}), 1439 \pm 73 \mathrm{Mt}(0.1-0.3 \mathrm{~m})$, and $1602 \pm 167$ Mt $(0.3-1 \mathrm{~m})$ (mean \pm S.D). 


\section{LAND USE AND CARBON ANALYSIS SYSTEM (LUCAS):}

It is recognised that in the short term, if land-use practices remain constant, soil carbon tends also to remain constant (MfE, 2010). However, there is much debate around residence times and fluctuations in soil carbon stocks after a change in land-use has occurred. Post \& Kwon (2000) state that carbon losses as a result of natural vegetation conversion to cultivated use are well documented. Whether this decline or loss of carbon occurs rapidly or over a more gradual time scale is still debatable (Post et al. 2001).

New Zealand is using the system known as the Land Use and Carbon Analysis System (LUCAS) and the more recently developed Soil Carbon Monitoring system (CMS) to estimate soil carbon stocks for all land-uses and also, likely changes as a result of a land-use conversion (MfE, 2010). LUCAS, is a crossgovernment programme governed by the Ministry for the Environment (MfE) in cooperation with the Ministry of Agriculture and Forestry (MAF). LUCAS was established in 2005 to assist New Zealand in meeting its reporting and accounting obligations under Article 3.3 of the Kyoto Protocol for Land-Use, Land-Use Change and Forestry (LULUCF) and investigates land-use changes within New Zealand. The LUCAS system is predominantly a database and landuse mapping reporting system that includes data and calculations on: soils, natural forests and planted forests (MfE, 2010). The LUCAS database and monitoring system is the key reference source when determining changes in New Zealand's terrestrial carbon pool (MfE, 2010). System development, structure and relevance to international frameworks are outlined in Figure 4. 


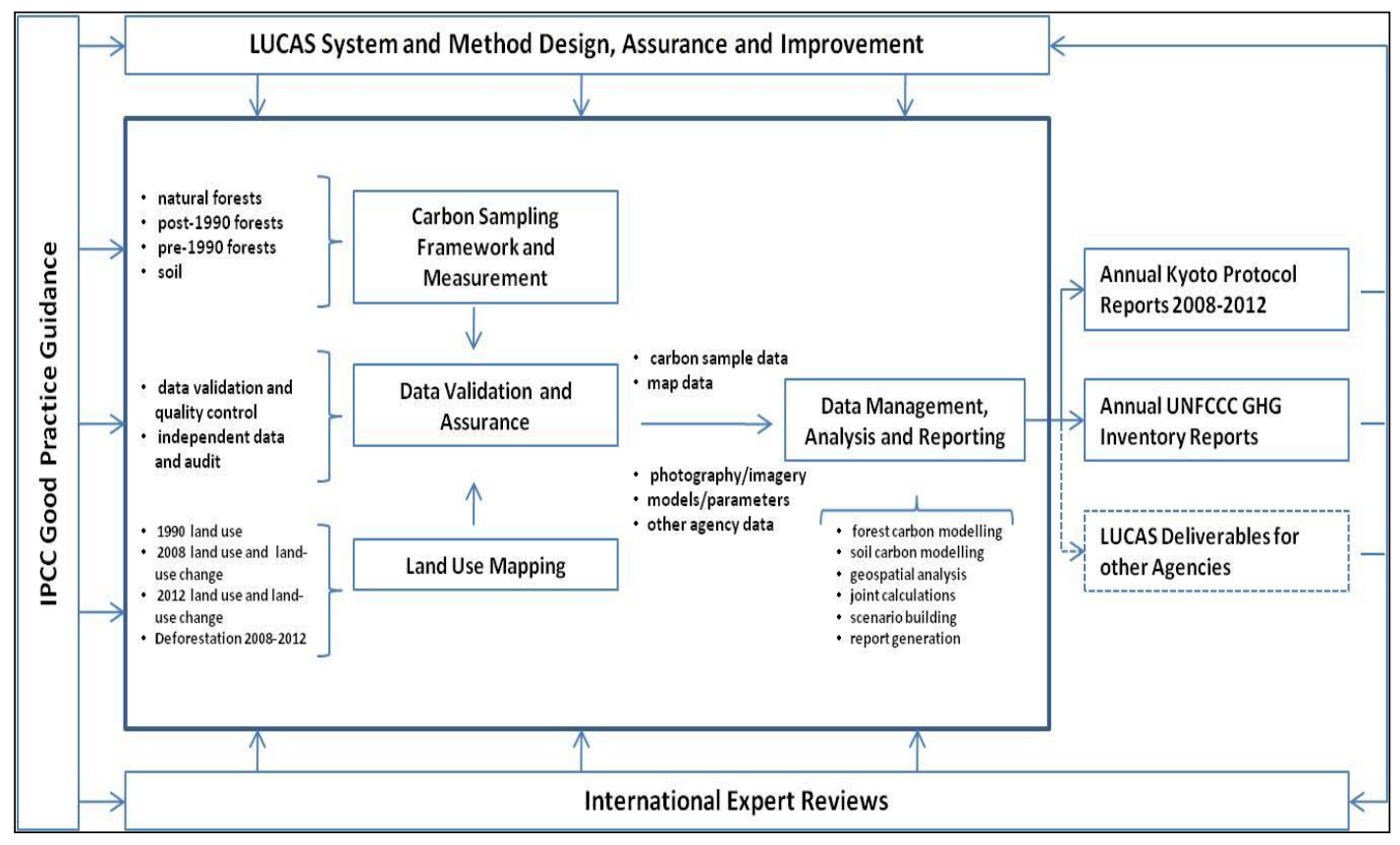

Figure 4. Overview of LUCAS reporting process. Source: Modified from the Ministry for the Environment.

LUCAS covers a wider spatial scale that is unlikely to include the smaller scale farm-level changes in soil carbon. The LUCAS system is very dependent on historic data especially when reporting on New Zealand's soil carbon pool. Data reliability and accuracy (to be discussed in further chapters) are questionable at many levels and estimates made through this system are heavily dependent on the underlying data being accurate.

\section{SOIL CARBON MONITORING SYSTEM (CMS):}

Soils are New Zealand's largest terrestrial C pool containing about $2500 \mathrm{Mt}$ of $\mathrm{C}$ to $0.25 \mathrm{~m}$ depth and $4260 \mathrm{Mt}$ of $\mathrm{C}$ to $1 \mathrm{~m}$ depth (Tate et al. 1997). As mentioned previously, this translates to a mean soil C for New Zealand to $1 \mathrm{~m}$ depth of 168 t/ha-1 (Tate et al. 1997). As New Zealand is one of the signatories of the Kyoto Protocol it has a commitment to reduce green house gas emissions. Under the Protocol, a reduction of about 7.5 $\mathrm{Mt}$ of $\mathrm{CO}_{2}$ equivalent will be required to meet New Zealand's assigned cap on emissions during the first commitment period, 2008-2012 (MfE, 2007). In 1996, the New Zealand Ministry for the 
Environment commissioned the development of a soil Carbon Monitoring System (CMS), focusing on reporting soil $\mathrm{CO}_{2}$ emissions as a result of different land-use changes (Tate et al. 2005). This programme has been developed in conjunction with other monitoring systems such as the indigenous forest and scrubland monitoring programmes with New Zealand following a more integrated approach to carbon monitoring and the associated impacts on the terrestrial carbon cycle (ICF International, 2008). The CMS contains actual soil carbon point data and national datasets comprised of soil type, climate information, vegetation and land-use information allowing estimates of soil carbon stocks for a particular land-use and also the ability to model likely changes to these stocks after a change in land-use (MAF, 2008). Currently, New Zealand's soil CMS (Figure 5) follows a similar framework proposed by the IPCC (1996) but uses national soil profile information (Tate et al. 2005). In general much of soil $C$ sequestration literature refers only to the soil surface $(0-10 \mathrm{~cm})$, with very little on total $\mathrm{C}$ storage in the soil profile or at greater depths. Schlesinger (1984) notes this depth range as being the most labile fraction in a typical soil profile and Tate et al. (1997) also state that this C within a soil profile is the most vulnerable to a land-use or climatic change. New Zealand, has adopted the IPCC internationally recognised reporting depths of $0-10 \mathrm{~cm}$, $10-20 \mathrm{~cm}$ and $20-30 \mathrm{~cm}$ (Tate et al. 2005). The soil CMS system is stratified by predominant factors that influence soil C changes over time (Scott et al. 2002).

Integrated in the system are nationally available New Zealand geographic information systems (GIS) data layers, which include data on:

- soil class,

- climate,

- land cover and,

- $\quad$ erosion index (slope x rainfall) (Tate et al. 2003a,b). 


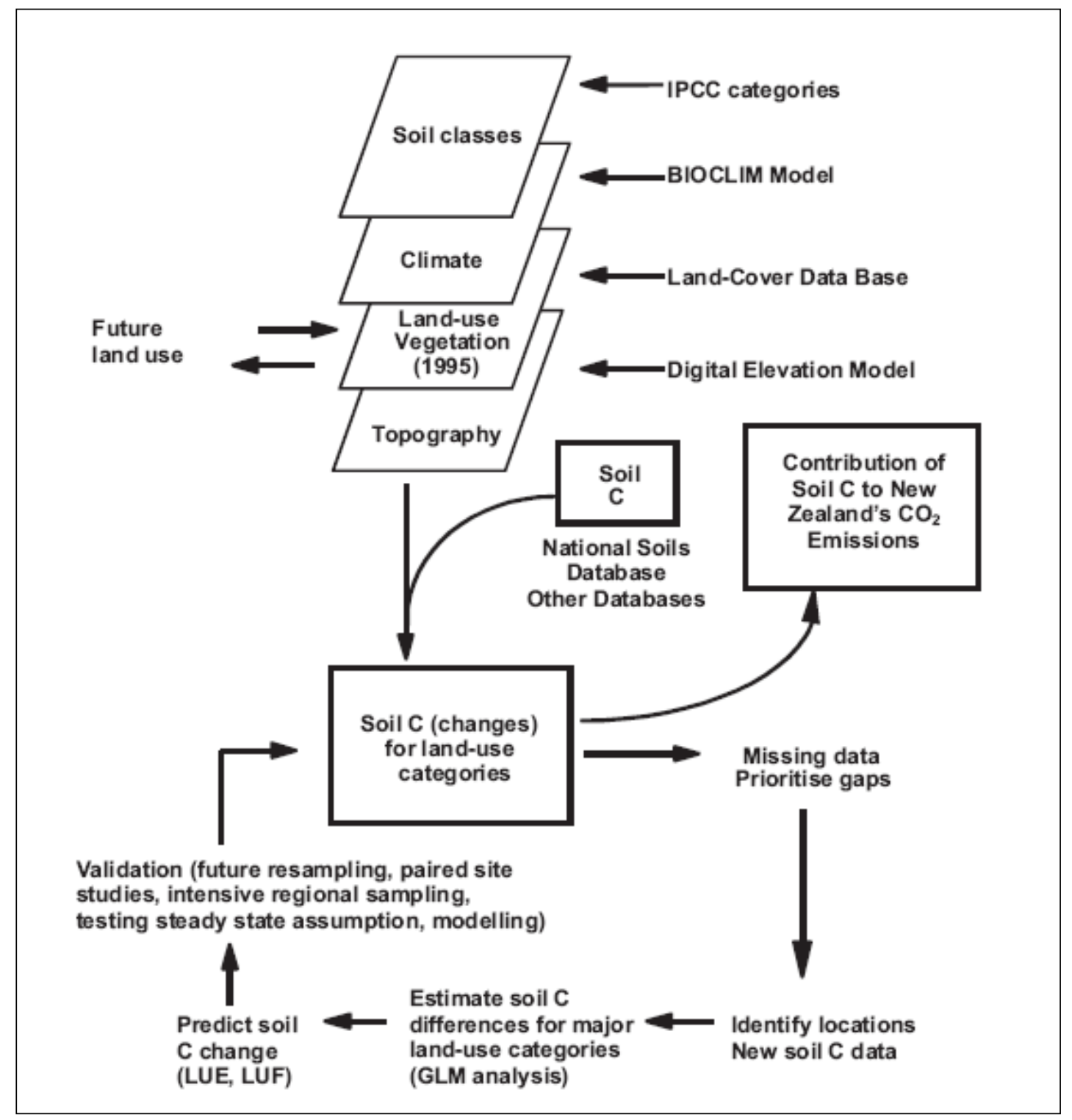

Figure 5. New Zealand Soil Carbon Monitoring System (CMS), Structure and Development. Source: Tate et al. 2004.

In terms of output an estimation of soil organic $\mathrm{C}$ for different combinations of soil class, climate and land-cover classes (Tate et al. 2005) is made using applicable national soil profile information and data. A more in depth overview of the theories behind the system as well as dominant processes governing soil C accumulation and transportation are given by Tate et al. 2005; 2003; 1997 and Scott et al. (2002).

The New Zealand CMS includes six IPCC (1996) soil classes with the addition of Podzols, which are extensive throughout much of New Zealand (Tate et al. 
2005). The soil classes within the systems are largely based on the concepts of soil texture and clay mineralogy playing a predominant role in the overall $\mathrm{OM}$ content. After all of the factors in the model are combined (soil class, climate, land cover, and erosion index) 39 resultant combinations of soil, climate and land cover units describe around $93 \%$ of New Zealand's landscape (Tate et al. 2005). Table 2 is an example of the results of the CMS and shows the soil C stock (t ha-1, 0-0.3 m) under several different land-uses.

\begin{tabular}{|l|c|}
\hline \multicolumn{1}{|c|}{ Land-use } & Soil Carbon Stock (t C ha-1 0-0.3m) \\
\hline Natural forest & $111.85 \pm 5.24$ \\
\hline Planted forest (pre-1990, post-1989) & $104.31 \pm 6.44$ \\
\hline Annual cropland & $118.27 \pm 22.47$ \\
\hline Perennial cropland & $114.91 \pm 13.22$ \\
\hline High-producing grassland & $114.93 \pm 3.56$ \\
\hline Low-producing grassland & $117.66 \pm 12.56$ \\
\hline Grassland with woody biomass & $111.57 \pm 4.29$ \\
\hline Wetlands & $104.62 \pm 19.92$ \\
\hline Settlements & $117.66 \pm 12.56$ \\
\hline Other land & 88 \\
\hline
\end{tabular}

Table 2. New Zealand's soil carbon stock (0-0.3m) for land-use categories.

Testing and validation of the model has occurred (e.g., Scott et al. 2002; Tate et al. 2005) with it also being published in international peer-reviewed journals (Scott et al. 2002; Tate et al. 2003a, b; Tate et al. 2005). However, the system is not without its flaws and several knowledge gaps and accuracy issues exist. The main sources of error identified include:

- the assumption that soil $\mathrm{C}$ is at a steady-state for all land-cover classes,

- lack of soil data for some soil/climate/land-use combinations,

- sampling collection and laboratory analysis,

- differences in information source and time periods,

- lack of data and soil carbon changes estimates below 0.3 metres, and

- $\quad$ effects of erosion (Scott et al. 2002; Tate et al. 2004; 2005). 
The use of a topography factor (slope $\mathrm{x}$ rainfall) is the only consideration made within the system surrounding erosion. The effects of soil erosion potentially could be much larger than direct land-use change effects but currently estimations are very uncertain (Tate et al. 2000). Erosion and the resulting redistribution of carbon in the landscape are areas of increased interest especially in New Zealand. The effects of erosion need to be considered more critically especially when considering the significance and the overall contribution to New Zealand's carbon budget.

\section{SUMMARY:}

This research focuses on soil carbon sequestration with a particular focus on how soil carbon affects more general landscape sustainability and the likelihood of flooding and erosion alleviation that comes with increasing carbon within the subsurface. Degraded landscapes or areas that are prone to erosion could have considerable potential for sequestration and other positive environmental gains with far reaching co-benefits. As mentioned previously, increasing the amount of OM or soil OC within the subsurface also has other associated potential cobenefits. Soils with higher quantities of organic carbon demonstrate improved nutrient absorption, increased water retention, improved texture and increased resistance to erosion. Nutrient absorption and water holding capacity are directly related to the soil $\mathrm{OM}$ content. Thus increasing the storage and amount of water flowing through the subsurface has benefits in terms of a reduction in overland flow and also a reduction of sediment or carbon being washed into waterways through processes such as erosion or mass movement. 


\subsection{REGIONAL BACKGROUND AND INTRODUCTION TO CASE-STUDY SITES:}

The Gisborne/East-Cape region of New Zealand's North Island (Figure 6) covers an area of about $8,852 \mathrm{~km}^{2}$ (Jessen et al. 1999). The region is located in the north-eastern corner of the North Island and is also referred to as 'Eastland', the East-Cape, or Raukumara Peninsula. The convention within this thesis is to refer to the region as the East-Cape.

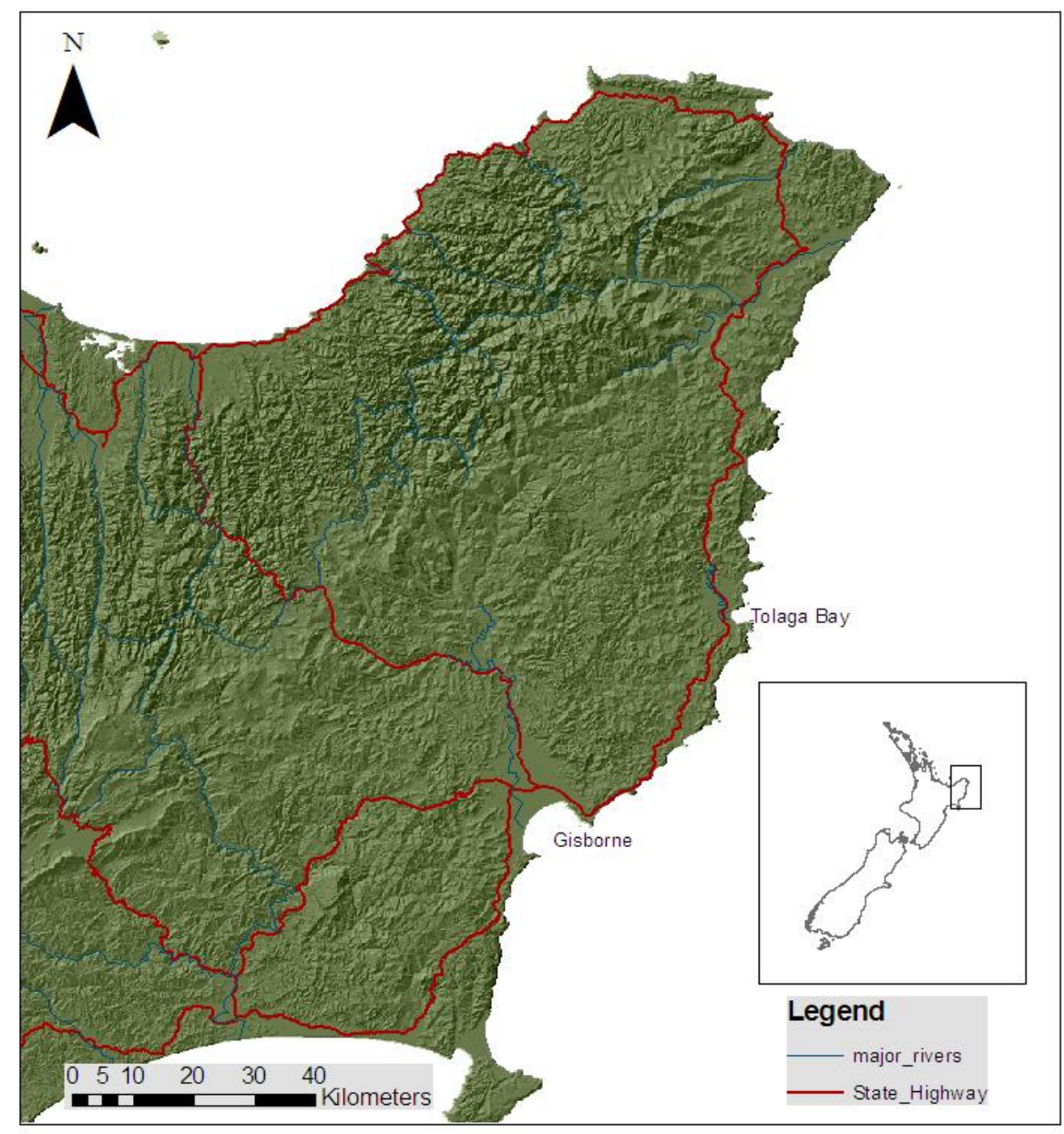

Figure 6. Raukumara Peninsula, Gisborne/East-Cape, North Island, New Zealand 
The Raukumara Range separates the region from neighbouring Bay of Plenty and the Central Plateau, with the highest peak reaching 5,753 ft (Mount Hikurangi- the highest non-volcanic mountain in the North Island). The EastCape is sparsely inhabited and is considered one of the most isolated areas of New Zealand with its few settlements generally situated within small bays along the coastline. The region is renowned for its beautiful beaches and rugged landscape. Deteriorated pastures present throughout the district, frequent flooding and accelerated soil erosion have led to the East-Cape being described as one of the most unstable landscapes in New Zealand (Molloy, 1988). This chapter consists of a general overview of both the cultural and physical aspects of the environment, with underlying geology and key geomorphological influences being explored. A brief insight into the history and land-use changes witnessed throughout the region is also given. Particular focus on some of the underlying causes that contribute to the sustainability issues such as increased flooding and erosion which hamper the region will be discussed. To conclude the two different case-study properties will be introduced looking at both predominant cultural and physical aspects of each of the properties.

\subsection{CULTURAL CONSIDERATIONS OF THE REGION:}

\section{SOCIO-ECONOMIC ISSUES AND OWNERSHIP COMPLEXITIES IN LAND TENURE:}

The East-Cape or Tairawhiti meaning, 'the coast upon which the sun shines across the water' is rich with Maori culture (Statistics New Zealand, 1999), and contains the highest percentage of Maori people of any region in New Zealand (Rhodes, 2001). The region is one of the few parts of the country where Maori still own large areas of land. Owners hold shares in land blocks and often manage the land through elected trustees (Funk \& Kerr, 2007). Maori land in the East-Cape region is governed under a variety of different organisations, such as trusts and incorporated societies. Most of the land in the region is registered under the Maori Land Court as part of the Tairawhiti Land District. The large Maori presence has meant the district maintains strong ties to Maori 
tradition. Through continual practice and knowledge sharing, traditional culture is still present within contemporary Maori society in the region. However over the past 140 years dramatic changes have occurred within the natural landscape, i.e., land-use changes that have largely affected not only the environment but also cultural, social and economic realms. Socio-economic issues and inequality experienced within the region in terms of health, high unemployment and housing quality have disadvantaged the community (Taylor, 1970). Environmental degradation (particularly increased erosion) from past land-use changes and poor management decisions affecting the very volatile soils of the region is considered one of the most if not the most important problem facing the Gisborne/East-Cape in terms of the natural environment (Taylor, 1970).

Research suggests that there is significant potential for carbon sequestration on Maori owned land (Funk \& Kerr, 2007). Large amounts of Maori owned land has been described as being marginal or 'underdeveloped' (Harmsworth et al. 2002), in many cases this is due in part to management constraints resulting from complex land ownership structures. Maori land in New Zealand, and in particular the East-Cape, has huge potential for both economic and environmental gains. To realise this potential, issues surrounding the ownership structures and land tenure must be resolved. Maori environmental perspectives and differences in values must also be appropriately incorporated in decision making processes to allow the advancement and development of many of these potential gains.

\section{LAND TENURE AND VALUE SYSTEMS:}

Maori people have a strong and intricate relationship with the land. Maori have the right to purchase and own 'general land', while also holding interests in their ancestral lands also known as Maori land (Kingi, 2008). Maori land is almost exclusively owned by the direct descendents of the original owners, passed down from generation to generation, with an understanding that land is 
permanent and human life is only temporary (Kingi, 2008). Kingi, (2008) describes Maori as tending to associate with land more in "terms of 'belonging to' rather than 'owning'” (Kingi, 2008:134). Cultural values tend to influence decisions surrounding land-management due largely to the fact that land is a source of identity and the centre of cultural pride (Kingi, 2008). Decisions regarding natural resources and the environment usually combine both economic considerations and cultural values and views.

At present it is estimated that Maori land makes up only 5.6 per cent of New Zealand's total land area of 26.9 million hectares (Kingi, 2008). One of the dominant problems in relation to Maori land is the current complexity of ownership, which often locks it out of the normal institutional mechanisms for use and development (Robertson, 2004). Issues surrounding multiple ownership structures often make it harder to manage the land to its full potential and pose substantial challenges in terms of socio-cultural, economic and environmental objectives.

\section{MAORI ENVIRONMENTAL VIEWS AND CONCEPTS:}

Like all societies, Maori people have their own values and belief systems which are observed in all aspects of life. Maori have a holistic viewpoint, considering everything to be connected; people, plants, air, water, animals and land. The natural environment is an extremely important part of Maori society, with land, mountains, valleys, rocks, water and the sea not only viewed as valuable resources, but, as the primary sources of collective identity (Whangapirita et al. 2003). Land is therefore not only valued for the practical uses but also for the close spiritual relationship that it holds. Land is regarded as a sacred trust and an asset of Maori people as a whole (Asher \& Naulls, 1987). Spiritual value is also given to many archaeological sites, and natural resource areas which include important types of vegetation, animal and bird life, and rock and mineral source areas. The term kaitiakitanga, or guardianship, is an important word highlighting how Maori place a high value on the land. Kaitiakitanga 
describes the relationship of Maori with the natural environment. Maori, as tangata whenua, are the kaitiaki of these ecosystems and have a self imposed responsibility to protect and enhance such ecosystems (New Zealand Biodiversity Strategy, 2007), they consider their relationship with nature as one of conservation and preservation for future generations. The idea of kaitiaki is also key to environmental decision making structure that is based on the concepts which govern the relationship of Maori and the environment. It is seen as the boundary between the spiritual and physical dimensions of natural resource management (James, 1993).

Maori people have developed detailed knowledge of local environmental features and processes that have been passed down from generation to generation. Both their traditional and contemporary knowledge is particularly important when it comes to sustainable development (Harmsworth, 2002). With an intricate understanding of local catchment and ecological processes, site-specific management frameworks and concepts are able to be developed that help promote the conservation of natural resources. Local knowledge also plays an important role in identifying and understanding spatial and temporal environmental change (Harmsworth et al. 2002).

\subsection{PHYSICAL CHARACTERISTICS:}

The East-Cape region is geologically complex with differing rock types and geomorphic controls producing a variety of landforms (Mazengarb et al. 2000). Past geological investigations of the Raukumara Peninsula have identified the landscape to be comprised of three main structural divisions, the Motu Block, the East Coast Allochthon, and the Neogene 'cover' (Moore \& Mazengarb, 1992). Significant research on the region has been carried out by the following authors: Jessen et al. (1999), Moore \& Mazengarb (1992), Isaac (1977). These references provide a comprehensive overview of the geological phenomena present. For the scope of this research, only a generalised overview of the geology of the region is given. 


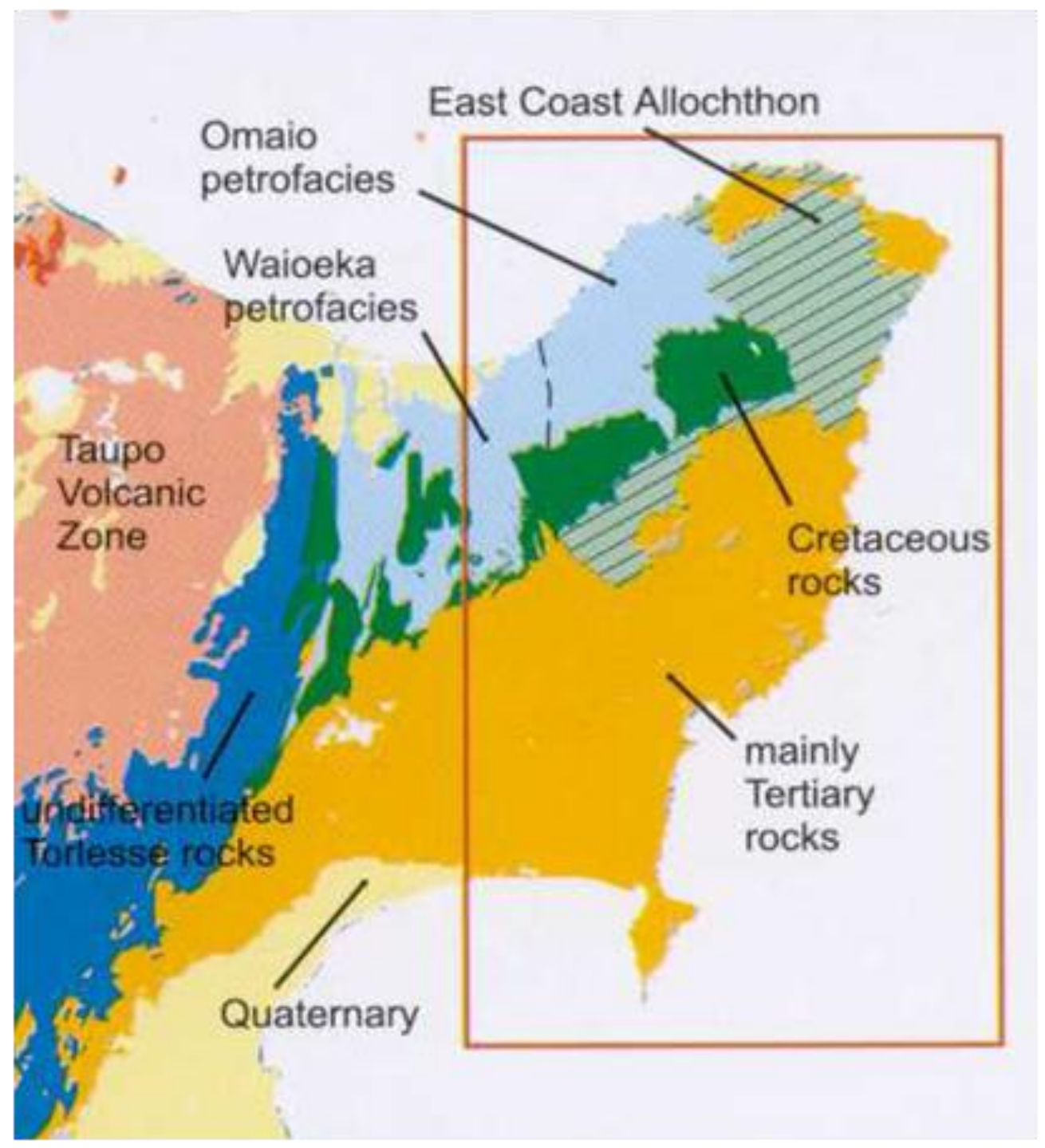

Figure 7. Geology of the Raukumara Peninsula. Source: Mazengarb \& Speden, 2000.

As throughout much of the New Zealand landscape, tectonic processes have played a dominant role in shaping the East-Cape region. Subduction at the boundary between the Indo-Australian and Pacific Plates has caused a rate of uplift of about $4 \mathrm{~mm} / \mathrm{yr}$ (Ota et al. 1992). From the western ranges toward the east coast, rocks become successively younger, are less compacted and show less tilt (Gibbs, 1959). Sedimentary rocks dominate varying from erosion resistant limestones and sandstones to easily erodible mudstones and argillites (Harris et al. 1964). Uplift and sea level fluctuations during the Quaternary have also caused widespread alluvial terrace development, floodplain deposits and uplifted marine terraces (Mazengarb \& Speden, 2000). 


\subsubsection{CLIMATE:}

An understanding of the surrounding climatic environment is crucial to gain a better perceptive of the interacting factors affecting soil and vegetation. Climate has a huge influence on soil processes and formation and shapes the ultimate land-uses within a region. The East-Cape region is considered a maritime climate with the Pacific Ocean playing a dominant role in the associated weather patterns (Hessell, 1980). The region often experiences huge contrasts in weather from year to year and is occasionally struck by severe cyclonic events, with one of the most significant in recent history being cyclone Bola (1988). Temperatures often surpass $30^{\circ} \mathrm{C}$ in the summer with droughts becoming more and more prevalent (Jessen, et al. 1999).

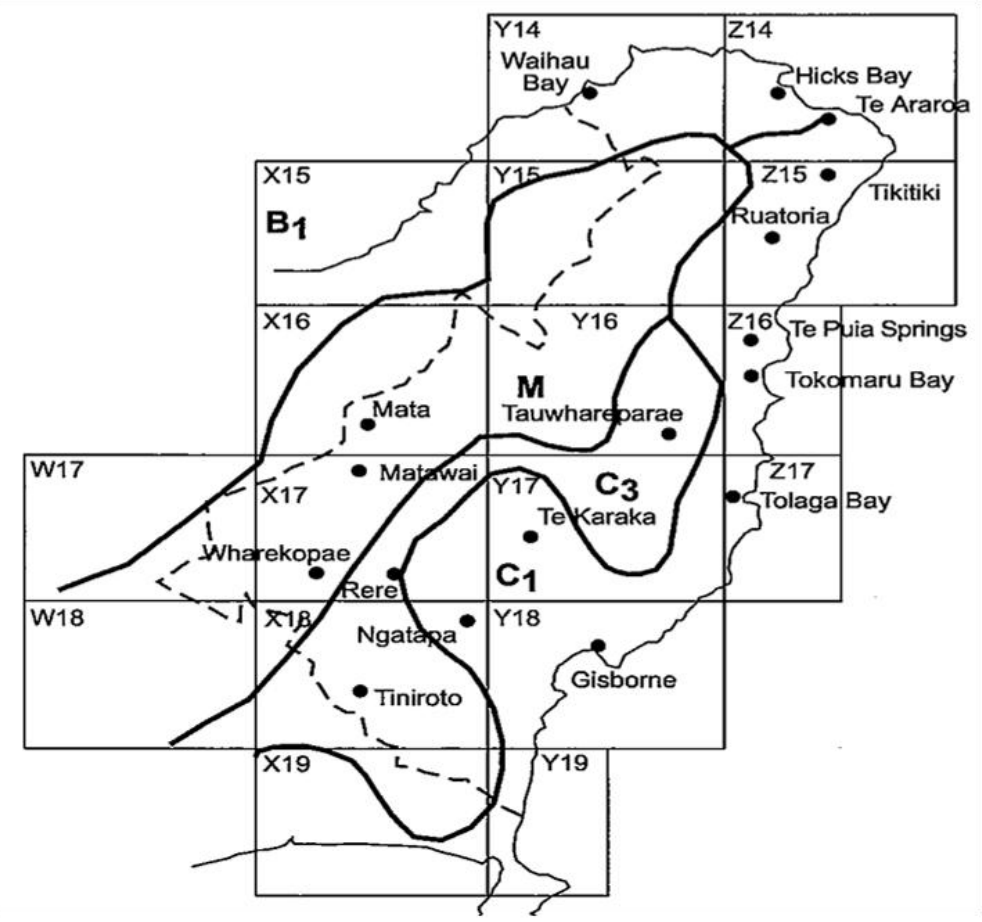

Figure 8. Major climatic zones of the Raukumara Peninsula. Source: Jessen et al, 1999.

There are significant spatial disparities in rainfall with average annual rainfall less than $1000 \mathrm{~mm} / \mathrm{yr}$ being recorded on the Poverty Bay flats and more than $4000 \mathrm{~mm} / \mathrm{yr}$ recorded in the Raukumara Range (Jessen et al. 1999). Jessen et al. (1999) have identified four main climatic areas within the peninsula denoted 
by C1, C3, M and B1 as seen in the Figure 8. The locations of the case-study properties where research was undertaken fall in the $\mathrm{C} 1$ and $\mathrm{C} 3$ zones. Zone $\mathrm{C} 1$ commonly experiences very warm summers, with annual rainfall totals generally between $1000-1500 \mathrm{~mm}$. Zone C3 experiences increased heavy rain from the south and south-east bringing annual rainfall generally to around 1500 - $2500 \mathrm{~mm}$ (Jessen et al. 1999). Extreme precipitation events tend to occur from the north from March through to May, with winter storms not as intense but lasting for a longer duration (Jessen, et al. 1999). High intensity convective storms throughout spring and summer are not uncommon. For example, just recently (January and June, 2010, during this project) wind and heavy rainfall caused communities to become completely isolated and led to the evacuation of many small townships within the peninsula. More generally, both storms and droughts regularly hamper the region, with the associated negative economic, social and environmental consequences being ongoing challenges. Such consequences have become the major catalysts for change and increased consideration of sustainability.

\subsubsection{SOILS:}

This section provides a generalised overview of soils present within the EastCape region, specific soils present within the two case-study properties are more thoroughly explained further on in this chapter and in the following chapter. In general, North Island soils are strongly influenced by volcanic ash (Schipper \& Sparling, 2009); this generalisation is true of the East-Cape region with factors such as rock type, tephra cover and rainfall defining the resultant soil pattern (McLeod et al. 1999). The range of soils within the region has been described as 'fairly small' (Gibbs, 1959) however, spatial variability has led to complex soil patterns. Soils within the region fall into the following broad soil orders which are the most generalised level of the revised New Zealand Soil Classification (NZSC) (Hewitt, 1998): 


\begin{tabular}{|l|l|}
\hline Soil Order: & Distribution: \\
\hline Pallic Soils & $\begin{array}{l}\text { tend to occur in areas of low rainfall in close } \\
\text { proximity to the coast. }\end{array}$ \\
\hline Brown Soils & $\begin{array}{l}\text { are the most widespread soil order found } \\
\text { throughout the region. }\end{array}$ \\
\hline Rare Podzols & $\begin{array}{l}\text { are associated with high annual rainfall } \\
(>2600 \mathrm{~mm} / \mathrm{yr})\end{array}$ \\
\hline Pumice Soils & tend to occur on gentle slopes and terraces \\
\hline Allophanic Soils & $\begin{array}{l}\text { occur with increasing rainfall. Their ability to } \\
\text { retain phosphorous is high }\end{array}$ \\
\hline Recent Soils & occur on steep hillslopes \\
\hline Raw Soils & $\begin{array}{l}\text { widely distributed throughout steep and/or } \\
\text { erosion-prone land }\end{array}$ \\
\hline Gley Soils & $\begin{array}{l}\text { are associated with wetness/saturation and tend } \\
\text { to occur on valley floors and alluvial plains }\end{array}$ \\
\hline
\end{tabular}

Table 3. Soil Orders from the revised New Zealand Soil Classification (NZSC). Source: Hewitt, 1998

For a more in-depth description of the soils listed in Table 3 refer to appendix (Appendix I). Pumice soils tend to dominate on the stable land towards the south-east of the region. An increase in rainfall towards the west results in the Pumice Soils grading into Allophanic Soils. Recent and Raw Soils are common on the steeper often unstable slopes in which soil is constantly being reworked by down-slope movement (McLeod et al. 1995). Alluvial plains present throughout consist of a sequence of Recent Soils with development varying with frequency of flooding and soil hydraulic properties (McLeod et al. 1999).

\subsubsection{LAND-USE AND SUSTAINABILITY ISSUES:}

The East Cape region is considered predisposed to erosion problems (MAF, 1998), problems being largely attributed to the underlying soils, steep slopes and climatic extremes discussed previously. Land-use change can exacerbate this predisposition and to a large extent has in the East Cape. Sedimentgenerating processes following a land-use change and the distribution of sediment is particularly important as degraded landscapes continue to redistribute the products of erosion, including nutrients and carbon. This could prove environmentally costly as the remobilisation of carbon being washed into waterways could result in loses back into the atmosphere. 
New Zealand has a history of rapid land-use change, with the first large-scale forest clearances taking place soon after Polynesian settlement (MAF, 1998). The impact of anthropogenic processes on vegetation was widespread with the stripping of native forests and conversion to agricultural pastures, increasing flooding within the already susceptible landscape and amplifying erosion (Smale et al. 1997). Heavy conversion pressures meant that much of the region was still being cleared of forests up to the 1920s (MfE, 1997). Soil erosion and the flow on effects such as loss of soil fertility and productivity are a major factor in the afore-mentioned economic decline and high unemployment rates within the region (Rhodes, 2001), along with isolation and land tenure complications.

Accelerated soil erosion has a major impact on the soil OC pool (Lal, 2004). Annually it is estimated that between 3 and 11 Mt of soil carbon is lost to New Zealand's coastal waters (Tate et al. 2000; Preston, et al. 2004). Without action terrestrial carbon losses of this magnitude will continue. Soil OM and associated soil functions aid in increasing overall soil structure. OM and the inherent physical functions of soils are also extremely important in influencing soil hydraulic properties (McLeod et al. 1999) with hydrological characteristics in turn regulating a number of soil properties and processes. For soil carbon in particular hydrology plays a key role when it comes to residence times and the transformation or storage of specific minerals and nutrients. Conversely, the amount of organic carbon in a soil modifies the hydrological properties and hence the carbon dynamics. A land-use change can lead to either positive or negative flow on effects. Negative changes include reducing the capacity of the land to retain and/or delay rainfall reaching the rivers, causing greater flood peaks, more intensive erosion, and changes in river systems, leading to more frequent and severe flooding (Watts et al. 2003). The East-Cape region is not exempt from such issues and is often making news headlines (One News, 2010) regarding flooding, land-sliding and erosion related phenomena, which can largely be contributed to the extensive land-use changes that have occurred within the region. The deteriorated pastures present throughout the region offer no adequate protection for the easily eroded rock denuded of its native 
forest cover. As a consequence of this the region is one of the worst affected by accelerated soil erosion and, frequent flooding (Gregg, 2009). The impact of anthropogenic processes on the native vegetation has been ruthless therefore increasing the susceptibility of the landscape to flooding and erosion (Smale et al. 1997).

\section{INTRODUCTION TO CASE-STUDY PROPERTIES:}

Case-study site selection and sample location steps primarily involved field investigations then accessing the majority of data through the New Zealand Land Resource Inventory (NZLRI). Access to the NZLRI is gained using a computer database, integrated through a Geographic Information System (GIS). GIS investigations looked into the dominant soils and vegetation types (Figure 9 and Figure 10) documented as present within the two properties. This underlying data and the associated databases will be discussed further in the following chapter. The New Zealand Land Resource Inventory (NZLRI) is a main source of information as is the Land Use Capability Classification of the Gisborne - East Cape region (Jessen et al. 1999). 


\section{SPECIFIC ATTRIBUTES FROM THE FUNDAMENTAL SOIL LAYER AND NEW ZEALANDS LAND RESOURCE INVENTORY:}
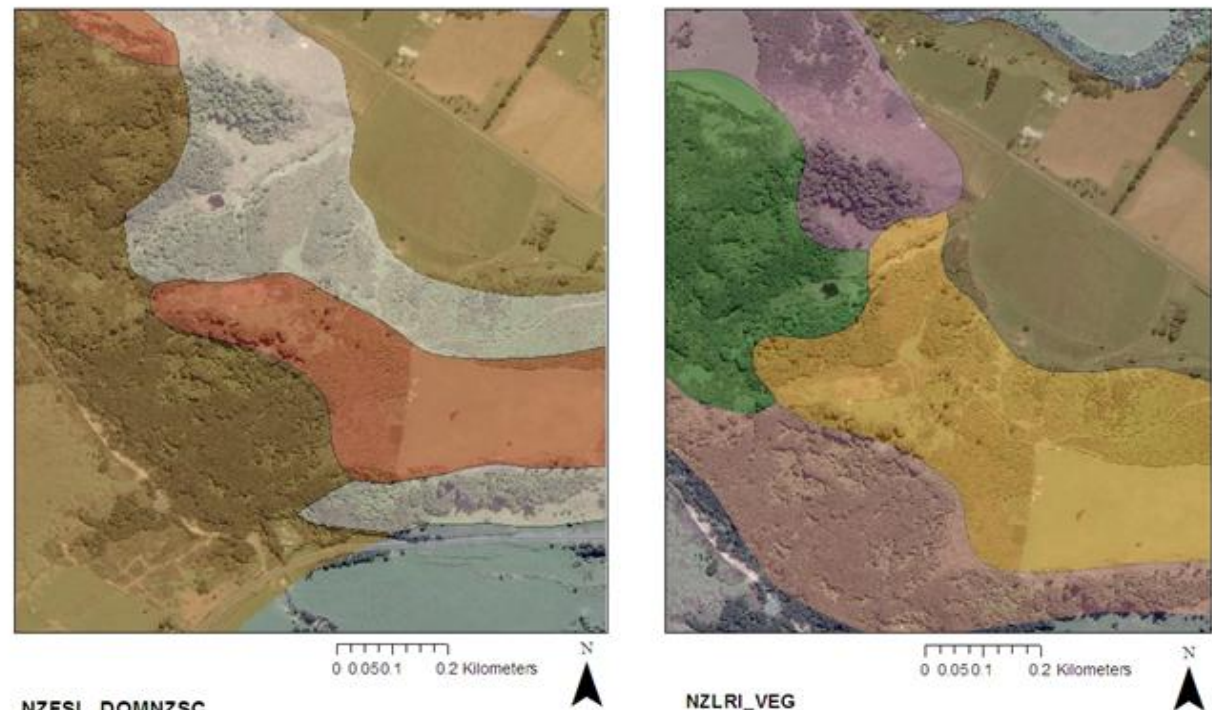

\section{NZFSL_DOMNZSC
Typic-Ortric Brown Soils}

NZLRI_VEG

Manuka. Kanuka $100 \%$ / Maxed indigenous sccub

Gorse 100\% / Semi-improved Pasture

Gorse $70 \%$ / Semi-improved Pasture $30 \%$

Improved Pasture 100\%

Figure 9. Dominant soils and vegetation present at the Tikitiki case-study property (According to NZFSL and NZLRI)

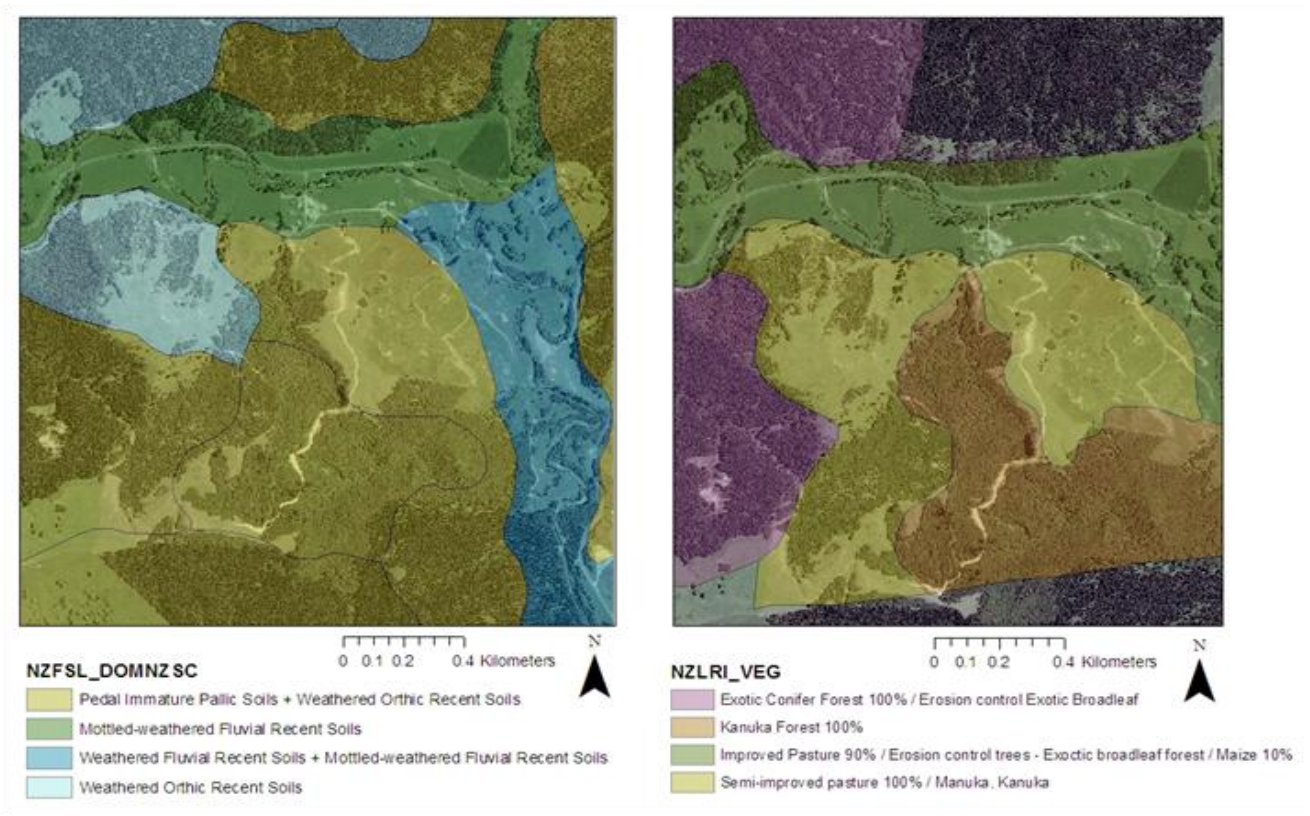

Figure 10. Dominant soils and vegetation present at the Willowbank case-study property (According to NZFSL and NZLRI) 


\subsection{SITE 1: WILLOWBANK PROPERTY (UAWA CATCHMENT):}

The Uawa catchment is located just north of Gisborne where the river exits to the sea at Tolaga Bay. The catchment covers an area of 51,500 hectares (McMillan, et al. 2010) and contains the property used as the first study site. This property is located west of Tolaga Bay at a place known as Tauwhareparae, Five Bridges. The property covers an area of about 158 hectares and borders the Mangaheia River.

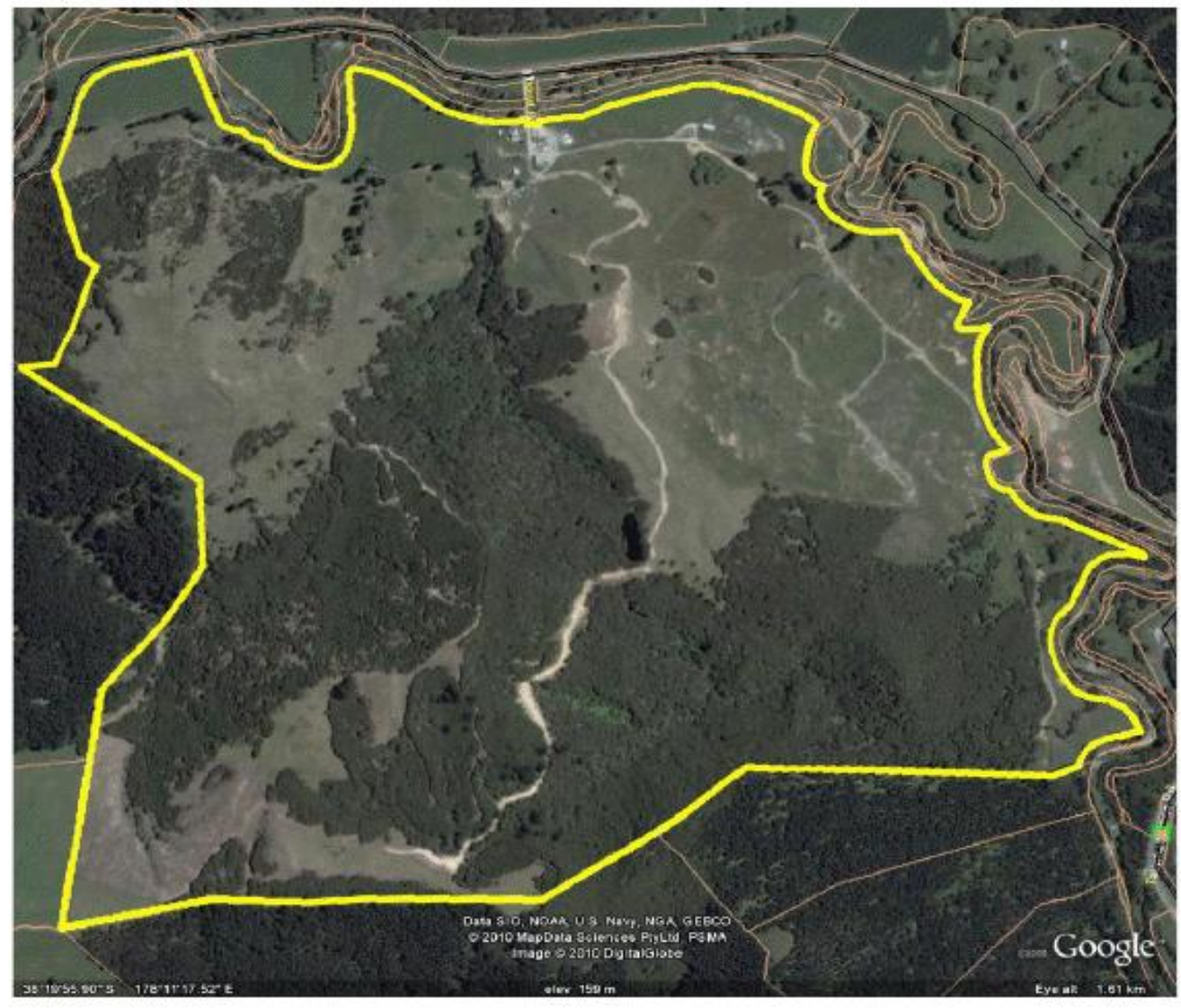

Figure 11 Aerial photograph case-study site 1: Willowbank 


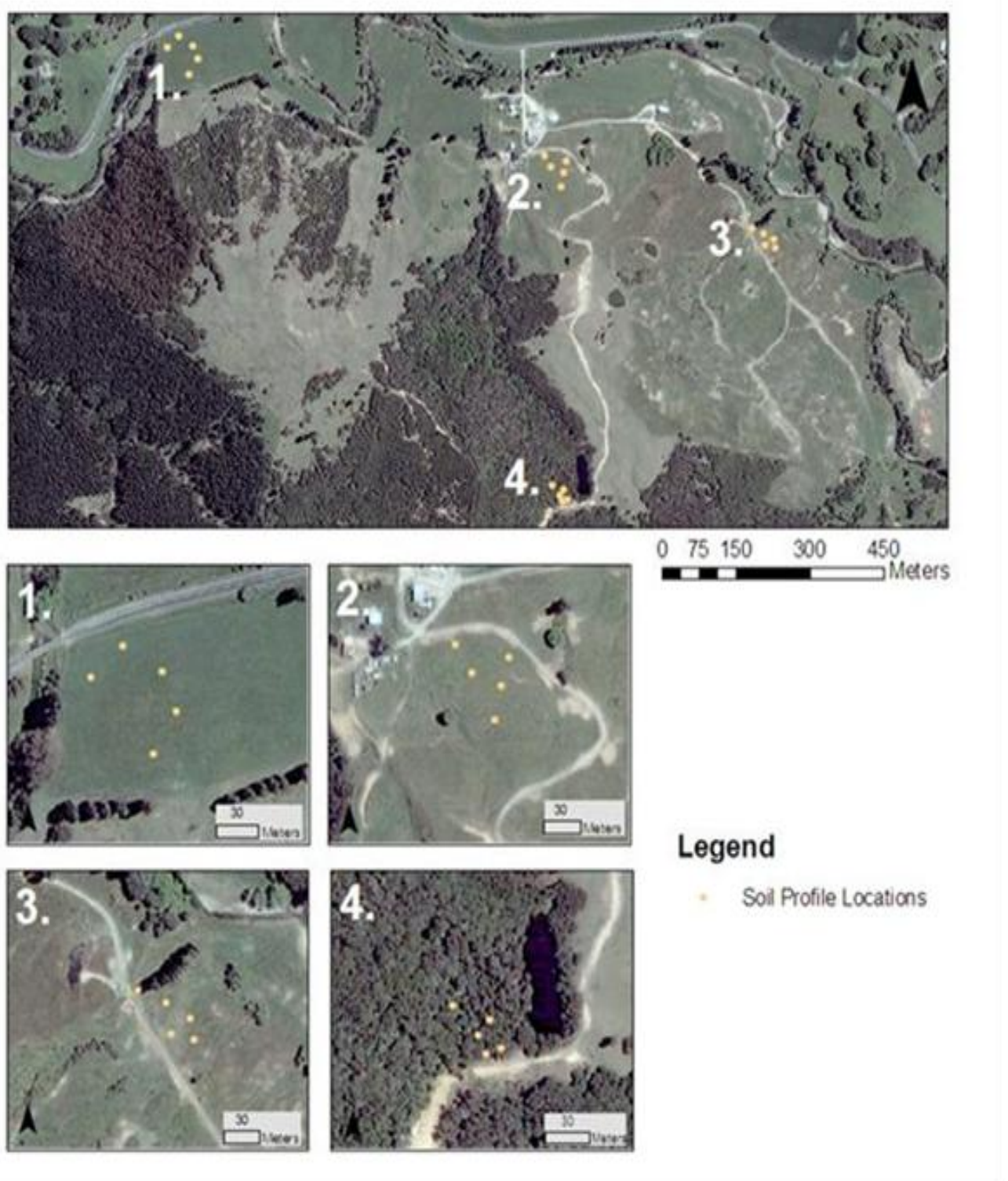

Figure 12. Soil Sample Locations: Willowbank Property

The Willowbank property is largely a family owned franchise with 11 family members working within a family contracting business run from the property. Like many properties within the Gisborne/East Cape region it shares a multiple ownership structure. The property is governed under a family trust with the majority of shares being held by two brothers. The brothers are fifth generation 'farmers' of the land and admit that the farm in the past came second to their contracting business. They now would like to shift their priority and focus towards sustainable farming practices. 


\section{PHYSICAL SETTING:}

Through New Zealand's Fundamental Soil Layer (NZFSL) and the New Zealand Land Resource Inventory (NZLRI) (accessed through ArcGIS) differences in dominant soil types and vegetation classes were identified (Figure 10, Table 4) Four sites were then identified for further investigations and sampling, these are referred to as;

- "Bottom pasture",

- "Top Pasture",
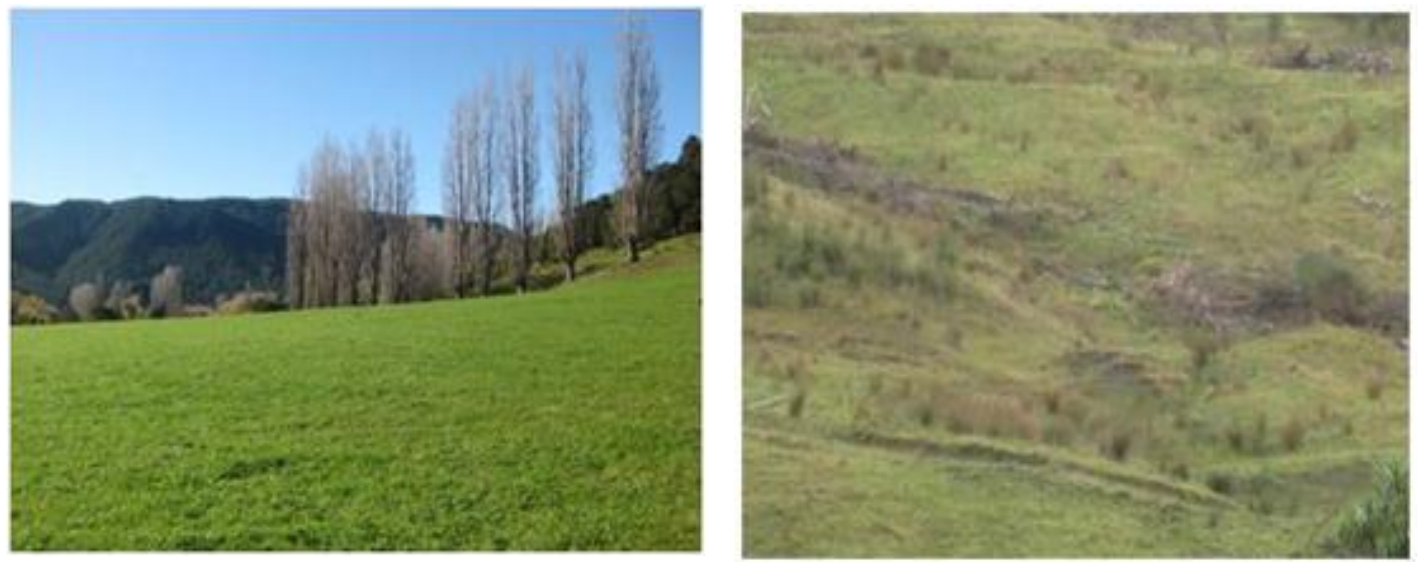

Figure 13. "Bottom Pasture" Sample Site

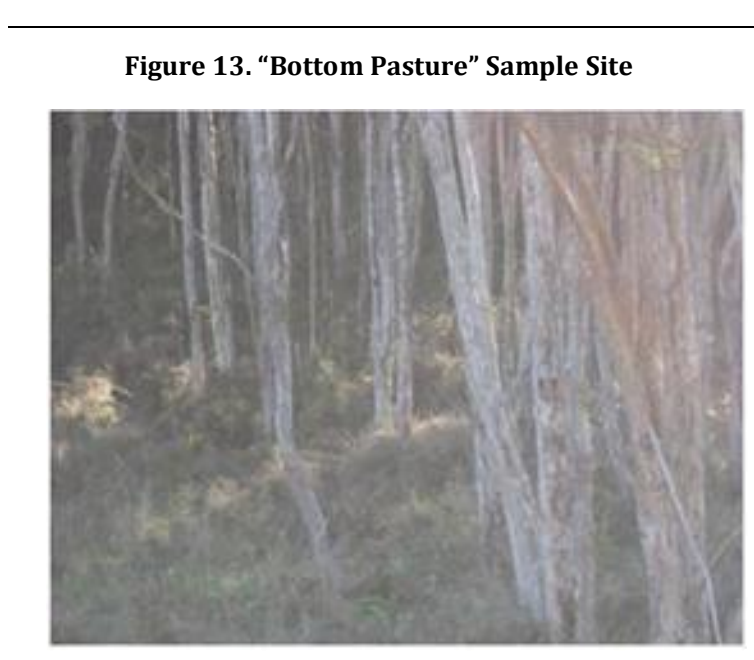

Figure 15. “Kanuka” Sample Site
- "River"

- "Kanuka".
Figure 14. "River" Sample Site

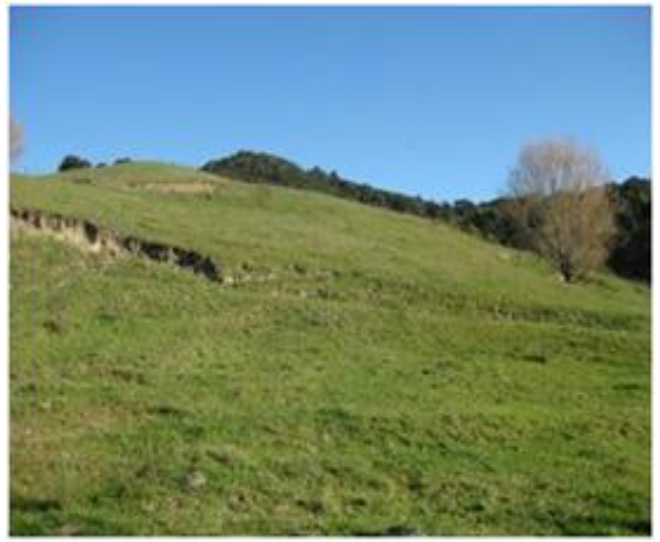

Figure 16. “Top Pasture” Sample Site 
The purpose of this section is to outline the physical characteristics of each of the sample sites within the property. The Willowbank property is located within a small river valley and contains several landscape features. Two of the sample locations, referred to as "Bottom Pasture" and "River", are located at the bottom of the property (with an elevation of 35 meters a.s.l.) in close proximity to the Mangaheia River which borders the property. Soil at the "Bottom Pasture" location at the time appeared to be free draining, however, discussions with the land manager revealed that during large rainfall events the paddock floods. The "River" site was located about $1 \mathrm{~km}$ east of the "Bottom Pasture" site and was more saturated with the presence of vascular plants. Further up the property at an elevation of 65 meters (a.s.l.) is the third sample location referred to as "Top Pasture". At the time of sampling this site was the driest of all seven sample sites and evidence of erosion scars were scattered throughout this part of the property. The area was dry except for one part that showed evidence of a higher water table. The site was also fenced off and was currently being used to graze cattle. The final sample site at the Willowbank property is referred to as "Kanuka" (at an elevation of 150 meters) this site had free draining soils that were particularly porous to touch. The "Kanuka" site was well sheltered with a north facing aspect. Vegetation is predominantly pasture at the lower three sample sites with large Kanuka and native forest located at the top of the property. 


\subsection{SITE 2: TIKITIKI PROPERTY (WAIAPU CATCHMENT):}

Located two hours north of Gisborne and just north of Ruatoria is the small East-Cape township of Tikitiki, in which the second property studied is located. Tikitiki is situated within the Waiapu catchment which has been described as highly degraded and modified (Harmsworth, 2002), contributing to serious erosion issues. The catchment is drained by the Waiapu river which like the nearby Waipaoa is known for the size of its sediment yields, with an average suspended sediment yield of 36 106 t/yr (Hicks, et al. 2004). A combination of unstable lithologies and anthropogenic stimuli is the cause of such high yields.

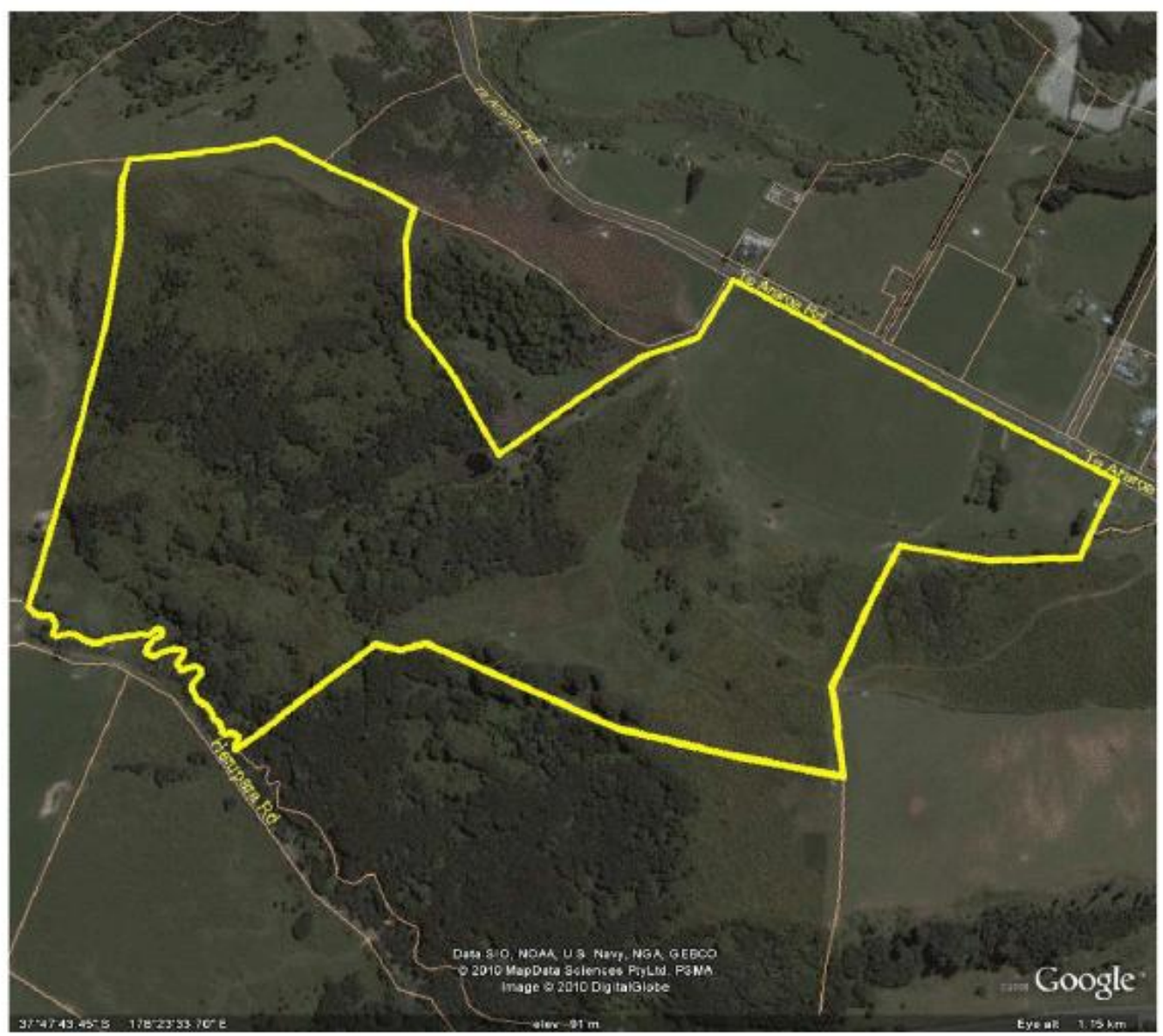

Figure 17. Aerial photograph case-study property site 2: Tikitiki 


\section{SOIL SAMPLE LOCATIONS - TIKITIKI:}
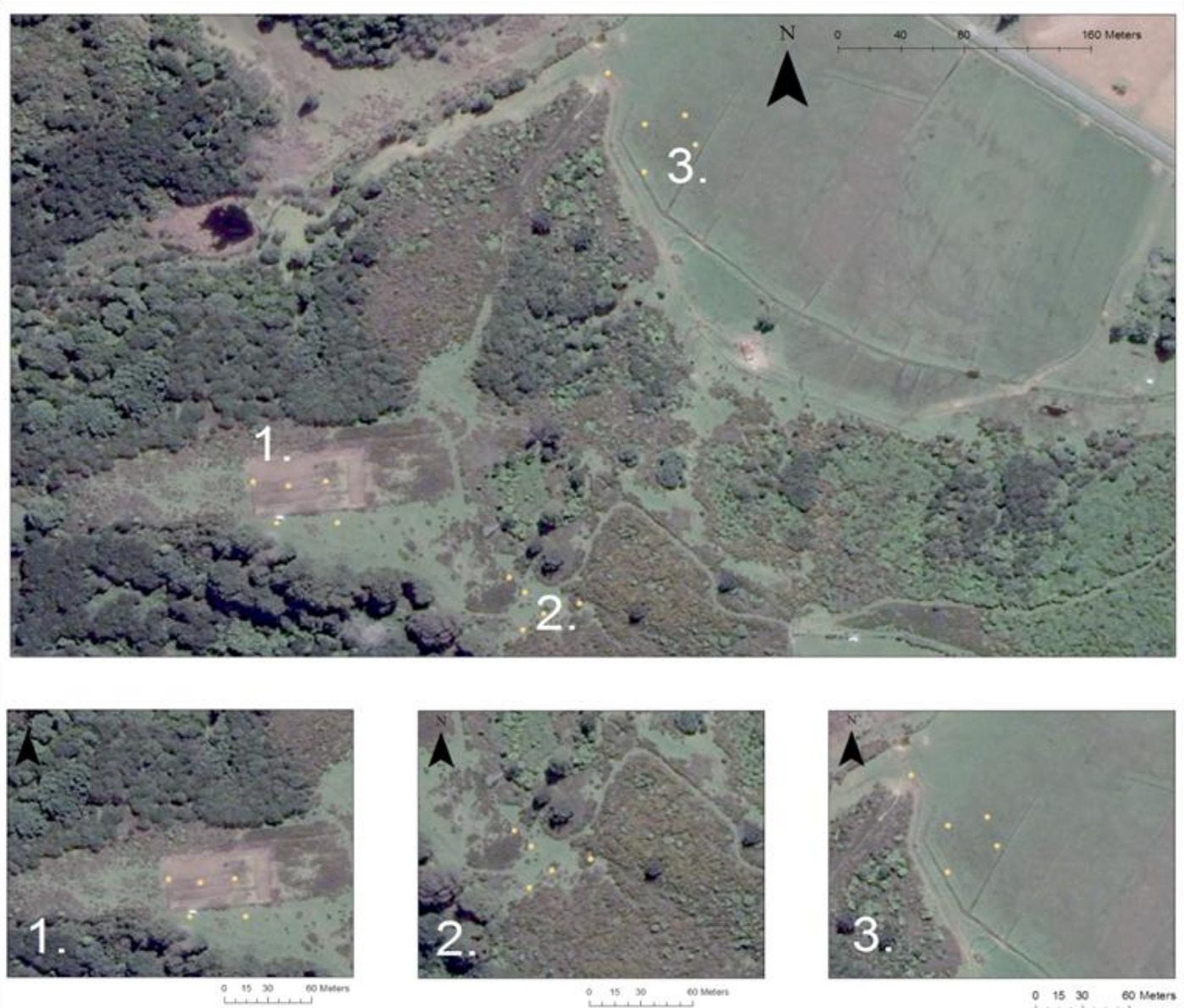

\section{Legend}

Soil Profile Locations

Figure 18. Soil Sample Locations: Tikitiki Property

The family block and site where soil samples were taken follows a multiple ownership structure governed by a family trust. The land block has over 100 trustees making management and coming to decisions regarding the land sometimes difficult. 


\section{PHYSICAL SETTING:}

Data from NZFSL at the Tikitiki case-study property showed three dominant soil types covering the area of interest. Differences in vegetation were again identified through the NZLRI (Figure 9, Table 4). Three different sites were then further identified as sites where soil sampling would be undertaken, these are referred to as:

- "Garden"

- "Gorse"
- "Flats"

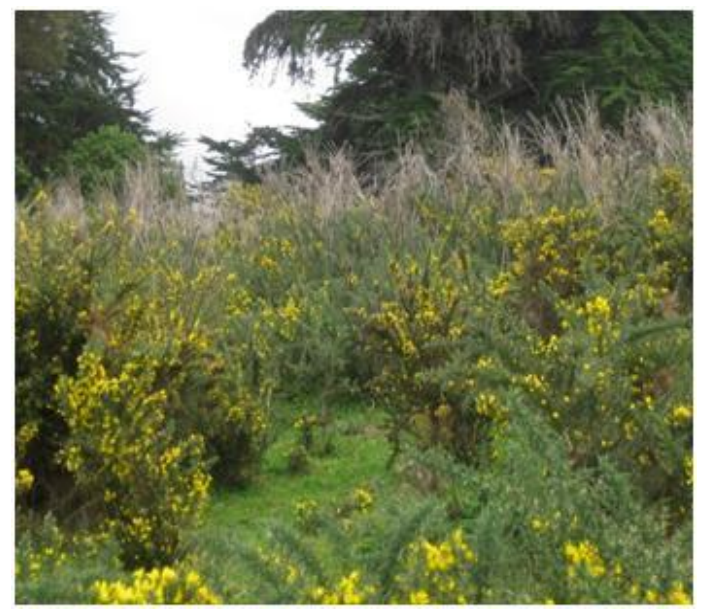

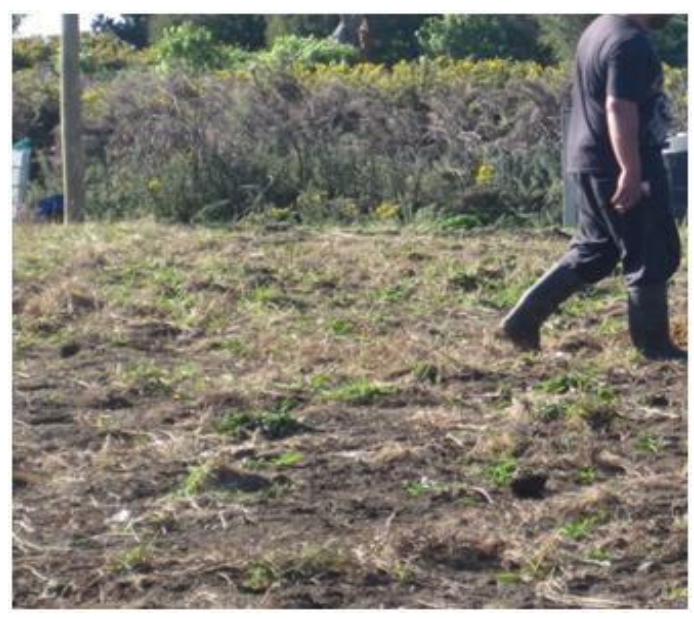

Figure 20. “Gorse” Sample Site

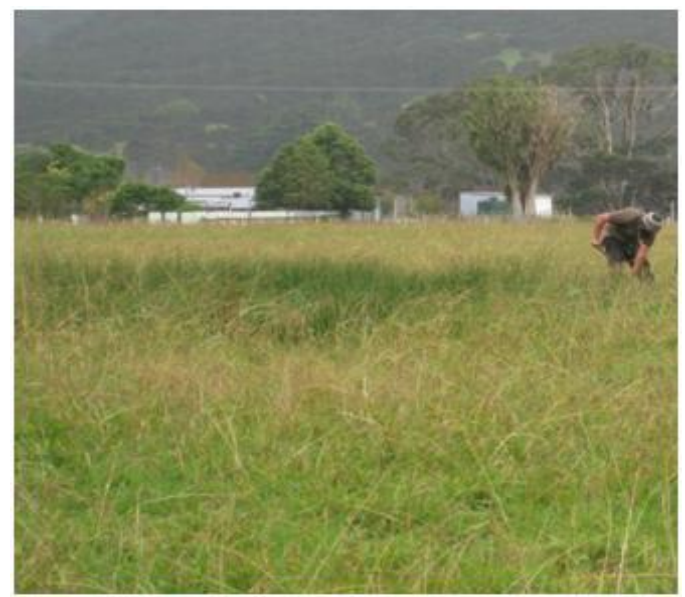

Figure 21. "Flats" Sample Site 
The second study site covers an area of about 48 ha. The property is made up of three dominant landscape features; the bottom flats, the top garden, and the relatively gently sloping surrounding hills. The sample location referred to as "Flats" is located at the bottom of the property with an elevation of about 30 meters. It is predominantly pasture, used for stock grazing. At the time the soil samples were taken (mid May 2009) the area was waterlogged and boggy with vascular plants thriving as a result of the saturated conditions. The site consisted of predominately waterlogged gleyed soils with iron mottles present throughout the soil profile. Located further up the property at an elevation of about 90 meters are the sites referred to as "Gorse" and "The Garden". The soil at these two sites was free draining with no evidence to suggest excess saturation. The soil was also quite friable. The property consists predominantly pasture and scrub;- the scrub in this case being Ulex europaeus (more commonly known as gorse). The land block is largely overgrown with gorse however, after discussions with the landowners this was not always the case as and prior to about the 1960 s the property was predominantly grassland. The land still has a high capacity for production, with a large organic garden located at the top of the property where traditional methods are being followed to grow kumara, potatoes and several other vegetables.

\subsection{REGIONAL SUMMARY:}

The need for environmental protection, with multiple positive outcomes and the encouragement of sustainability is a strong focus for the local governing bodies, Maori and the rural community. Land, water and air to Maori people are extremely special with the use and management of such resources requiring special care and attention. Maori have an expectation that they will participate when it comes to environmental decisions, however, historically their participation has not been facilitated, therefore values and interests have been significantly unrepresented (James, 1993). Having an understanding of Maori attitudes and values towards the environment is particularly important in terms of management decisions and avoiding conflict. Land-use changes 
witnessed over the past decade within the region have had impacts both culturally and environmentally. Because the Gisborne/East-Cape region has such a large Maori population active participation will prove vital if the previous problems stated are to be reversed. Values and attitudes to land and land management will prove significant in terms of shaping future land-use within the community. Large tracts of Maori land are described as being 'undeveloped' or marginal (Harmsworth et al. 2002). There is therefore, huge potential for change both economically and also in terms of positive environmental outcomes. The aim and objectives of this research within the East-Cape community, fit closely with some of the goals held by the people of the East-Cape especially in terms of sustainable land management and safeguarding of natural resources. There are soils and climatic conditions throughout the region that allow for a wide variation of land-uses and farming practices. This makes the region interesting for research in carbon sequestration potential and associated co-benefits. 


\subsection{DATA REVIEW}

New Zealand has a large inventory of soil data mainly available in the form of soil maps. The problem with much of the data is that it was collected before the introduction of computer programs, modern database protocols and simulation models were developed (Giltrap \& Hewitt, 2004). Therefore, discrepancies and the need for updated data are some key issues surrounding New Zealand's soil inventory. This chapter will first review the nationally available soil data looking at New Zealand's National Soils Database (NSD), the revised New Zealand Soil Classification (NZSC) which has replaced the old New Zealand Genetic Soil Classification (NZG) and New Zealand's Fundamental Soil Layers (FSL) available through GIS. Issues of representativeness and reliability, outlining both positive and negative aspects of the databases, will be discussed. The New Zealand Land Resource Inventory (NZLRI) which includes fundamental soil data will also be reviewed. Site selection steps and tables outlining the soil, vegetation and land-use data relevant to the Tikitiki and Willowbank case-study properties will be given. A brief discussion outlining the importance of such databases to the GIS based tool Polyscape and the wider context of terrestrial carbon budgets and modelling will then conclude the chapter.

\subsection{INTRODUCTION TO NEW ZEALAND'S SOIL CLASSIFICATION SCHEMES AND DATABASES:}

The National Soil Database (NSD) is a 'point' database containing physical and chemical information on about 1500 soil profiles throughout New Zealand 
(Wilde, 2004). The information gathered is extensive with more than 200 individual pieces of data collected for each point either in the field or through further ex-situ analysis. The New Zealand component represents about 15 million dollars worth of information and is invaluable for use with sustainable land management decisions (Wilde, 2003). However, the NSD is currently dormant with no new data being added at present.

Another valuable source of soil data is the revised New Zealand Soil Classification (NZSC) system that has evolved from the earlier New Zealand Genetic Soil Classification (NZG) (MfE, 2010). Hewitt (1992) gives a comprehensive overview of New Zealand's soil classification schemes and how these have evolved through time. The NZG was first published in 1948 (Hewitt, 1992) by its founder New Zealand soil scientist Norman Taylor, with the key underlying assumptions of this model comparing relationships between the environment, soil processes and soil morphology (Hewitt, 1992). Taylor's classification system lacked definition especially in terms of soil classes. This meant that only experts could easily recognise the correct soil class. Relationships between the environment and soils were useful for the wider context and broader sense but proved ineffective at more detailed scales (Leamy et al. 1983). The late 1970s saw a shift in focus from soil processes to soil morphology and a commitment was made to develop a soil taxonomy in New Zealand (Hewitt, 1992). This system was arguably over complex, and the decision was made by the New Zealand Soil Bureau not to adopt a soil taxonomy system as a means of soil classification in New Zealand. Instead a revised NZSC was developed (Leamy et al. 1983). Several changes occurred and new methods of soil description were also developed (Milne et al. 1991). The revised NZSC was first published in 1992 and has evolved greatly from the previous genetic classification scheme. The new classification follows a multicategorical system which uses soil properties as a way of defining class limits (Leamy et al. 1983). However, it still includes many underlying assumptions present within the older NZG scheme retaining concepts and previously defined common names. The revised NZSC follows a hierarchical structure with four levels in the hierarchy including: 
- 15 Soil Orders - the most generalised level of classification providing a national overview of New Zealand soils (refer to Appendix I),

- 73 Soil Groups - based on variation of factors such as physical and chemical properties,

- 272 Subgroups - the soil groups are then divided into subgroups providing detail into the range of soils included in each soil group,

- Soil Forms - provide information about soil parent material, texture and permeability.

The objectives of this new classification include improving communication about New Zealand soils, how they can be utilised and to draw knowledge of the properties outlining important similarities and differences among them (Hewitt, 1998). A positive aspect of the revised system is that it is considered more internationally comparable (MfE, 2010) allowing more detailed and accurate descriptions to be made for specific soils. However, although officially the revised classification system has replaced the old genetic soil classification system, $95 \%$ of published data in New Zealand still uses the old genetic system (MfE, 2010).

\subsection{NEW ZEALAND'S FUNDAMENTAL SOIL LAYER (NZFSL):}

Technological advancement has led to the development and conversion of much of New Zealand's soil data into forms that are computer compatible. New Zealand's Fundamental Soil Layer (NZFSL) is one such database. Regional soil databases and surveys were key to the formation of NZFSL. This regional data was then correlated using the NZSC with reference to the NSD and other relevant data sources, (Wilde, 2003) finally linked to the soil polygons in the New Zealand Land Resource Inventory (NZLRI). 


\section{Soil Chemical Characteristics:}

- Minimum $\mathrm{pH}$

- Maximum salinity

- Cation exchange capacity

- Total carbon

- Phosphate retention
Soil Physical Characteristics:

- Topsoil gravel content

- Rock outcrops and surface boulders

- Particle Size

- Potential rooting depth

- Soil permeability

- Depth to slowly permeable horizon

- Internal soil drainage

\section{Soil Moisture Properties:}

- Profile total available water

- Profile readily available water

- Macroporosity (0-0.6m)

- Macroporosity (0.6-0.9m)

Information in terms of identification, distribution, measurable site characteristics and chemical and physical soil properties are available. This data can then be manipulated depending on what information or output is required. The key attributes of the NZFSL fall into three main groups; soil physical properties, soil fertility/toxicity and topography. Some of these attributes are derived from exact matches with NSD records, while others originate from matches to similar soils or professional estimates (Wilde, 2003). The layer includes mapped data of widely varying quality and resolution, coupled with limited measurements of soil chemical and physical attributes (Leathwick et al. 2002). Therefore, issues of data reliability arise. Improving the accurateness and credibility of the underlying soil attribute layers involves several challenges, especially in terms of funding and manpower required for intensive data accumulation. However, with technological advancements in remote sensing and terrain analysis, such as looking at high resolution digital elevation models (DEMs), some of these challenges could be addressed. 


\section{NEW ZEALAND LAND RESOURCE INVENTORY (NZLRI):}

The New Zealand Land Resource Inventory (NZLRI) coupled together with the national soil survey data previously mentioned has been described as the most 'comprehensive spatial archive of New Zealand's physical resource information' (Newsome et al. 2008:3). The resulting national database comprising New Zealand's physical land-resource information and the improved soil data consists of two sets of data:

- an inventory of the five physical factors basic to the assessment of land resources. These are; rock type; soil; slope; present extent and severity of erosion; and vegetation,

- a Land Use Classification (LUC) rating of each map polygon based on an assessment of the ability of the inventory factors (above) together with climate, the effects of past land use, and the potential for erosion, to provide sustained agricultural production (Jessen et al. 1999).

\section{S-MAP: A NEW SOILS DATABASE:}

Landcare Research New Zealand realises the demand for adequate soil data especially for use in sustainable and environmental management decisions (Lilburne et al. 2004). Current soil data, as mentioned previously, is described as being irregular varying in age and quality. Landcare Research is however, addressing these issues with the development of S-map. S-map is a new digital soil spatial information system and a new component of the New Zealand Land Resource Information System (LRIS) database. Development and implementation of S-Map will provide higher quality soil data and will eventually replace NZFSL (Barringer et al. 2008). Funding is limited and the process of updating all of New Zealand will be a drawn out process. However, S-Map has now reached the stage where information is available for a few parts of New Zealand. Unfortunately S-Map data was not available for the 
Gisborne/East-Cape region at the time of this research. Availability is expected in the final quarter of 2010.

Information regarding S-Map is available through the following link http://smap.landcareresearch.co.nz/ which contains fact sheets on the available soil data. The most up-to-date data is available through either the National Soil Database through the Landcare Research website or NZFSL linked with the NZLRI.

The main sources of soil and land resource information for the Gisborne/EastCape region include published and unpublished Soil Bureau reports. However, the information is limited with the exception of the Poverty Bay Flats and Tolaga Bay Flats which have been more extensively researched. For the 2nd edition of the NZLRI the Gisborne/East-Cape region was mapped to the NZSC in terms of soil data. As mentioned previously the main sources of information included the NZLRI and Jessen et al. (1999) report on land-use classification. The following table (Table 4) summarises the attributes identified at each of the case-study properties. 


\begin{tabular}{|c|c|c|c|c|c|c|c|}
\hline $\begin{array}{l}\text { Sample Site } \\
\text { Identification }\end{array}$ & Soil Type (DOMNZSC) ${ }^{1}$ & Vegetation (NZLRI Ed2) & Land-use & $\begin{array}{l}\text { CARBON } \\
\text { _CLA }\end{array}$ & $\begin{array}{l}\text { CARBON } \\
\text { _MAX (\%) }\end{array}$ & $\begin{array}{l}\text { CARBON } \\
\text { MID (\%) }\end{array}$ & $\begin{array}{l}\text { CARBON } \\
\text { _MIN (\%) }\end{array}$ \\
\hline Garden & $\begin{array}{l}\text { Typic Orthic Allophanic Soils } \\
\text { (LOT) }\end{array}$ & $\begin{array}{l}\text { Gorse } 70 \% \text { / Semi- } \\
\text { Improved Pasture } 30 \% \\
\text { (Sg7gS3) }\end{array}$ & $\begin{array}{l}\text { Semi-intensive livestock } \\
\text { farming }\end{array}$ & 3 & 9.9 & 7 & 4 \\
\hline Gorse & $\begin{array}{l}\text { Typic Orthic Allophanic Soils } \\
\text { (LOT) }\end{array}$ & $\begin{array}{l}\text { Gorse } 70 \% \text { / Semi- } \\
\text { Improved Pasture 30\% } \\
\text { (Sg7gS3) }\end{array}$ & $\begin{array}{l}\text { Semi-intensive livestock } \\
\text { farming }\end{array}$ & 3 & 9.9 & 7 & 4 \\
\hline Flats & Typic Orthic Brown Soils (BOT) & $\begin{array}{l}\text { Improved Pasture } 100 \% \\
\text { (gI0) }\end{array}$ & $\begin{array}{l}\text { Intensive to semi-intensive } \\
\text { livestock farming }\end{array}$ & 3 & 9.9 & 6 & 2 \\
\hline $\begin{array}{l}\text { Bottom } \\
\text { Pasture }\end{array}$ & $\begin{array}{l}\text { Mottled-weathered Fluvial } \\
\text { Recent Soils (RFM) }\end{array}$ & $\begin{array}{l}\text { Improved Pasture } 90 \% \\
\text { / Erosion control trees - } \\
\text { Exotic broadleaf forest / } \\
\text { Maize } 10 \% \\
\text { (gI9efR*cM1) }\end{array}$ & $\begin{array}{l}\text { Semi-intensive livestock } \\
\text { farming, field cropping }\end{array}$ & 3 & 19.9 & 11 & 2 \\
\hline Top Pasture & $\begin{array}{l}\text { Pedal Immature Pallic Soils + } \\
\text { Weathered Orthic Recent Soils } \\
\text { (PID+ROW) }\end{array}$ & $\begin{array}{l}\text { Semi-improved pasture } \\
\text { 100\% / Manuka, Kanuka }\end{array}$ & $\begin{array}{l}\text { Semi-intensive livestock } \\
\text { farming }\end{array}$ & 4 & 9.9 & 6 & 2 \\
\hline River & $\begin{array}{l}\text { Weathered Fluvial Recent Soils } \\
\text { + Mottled-weathered Fluvial } \\
\text { Recent Soils (RFW+RFM) }\end{array}$ & $\begin{array}{l}\text { Semi-improved pasture } \\
100 \% \text { / Manuka, Kanuka } \\
\text { (gS0sM }{ }^{*} \text { ) }\end{array}$ & $\begin{array}{l}\text { Semi-intensive livestock } \\
\text { farming, field cropping }\end{array}$ & 3 & 19.9 & 11 & 2 \\
\hline Kanuka & $\begin{array}{l}\text { Pedal Immature Pallic Soils + } \\
\text { Weathered Orthic Recent Soils } \\
\text { (PID+ROW) }\end{array}$ & $\begin{array}{l}\text { Kanuka forest } 100 \% \\
\text { (fN0) }\end{array}$ & $\begin{array}{l}\text { Extensive to semi- } \\
\text { intensive livestock farming, } \\
\text { exotic plantation forestry, } \\
\text { undeveloped }\end{array}$ & 4 & 9.9 & 6 & 2 \\
\hline
\end{tabular}

Table 4. Soil Type (DOMNZSC), Vegetation, Land use and associated Carbon attributes at each of the seven sample sites.

\footnotetext{
${ }^{1}$ Attributes sourced from the NZLRI and FSL accessed through GIS. Further information in regards to the carbon attributes is explained in Appendix II.
} 


\subsection{SUMMARY:}

Soil data is becoming increasingly important to assist and inform sustainable management. Data scarcity issues are a problem in parts of the New Zealand landscape. These are concerns regarding how representative or suitable this data is when applied to the wider context. More specifically how well can the available data be trusted to support important decisions regarding the environment and sustainable development?

This research will test the suitability of New Zealand's nationally available data for use with decision support tools such as Polyscape and inform an additional valuation layer on both existing and potential carbon storage and emissions in rural landscapes. The previously mentioned databases and database content are crucial to this GIS based tool; reliability and consistency of the data are key to achieving meaningful output. In the chapters that follow comparisons will be made between the national scale data and research results, with the results chapter also including an application of the Polyscape tool to the catchments and properties of interest.

Unfortunately there are several issues with the available soil data in the Gisborne/East-Cape region, with key attributes missing from the sample sites of interest because of the different soil classification techniques applied. The following chapters will compare both the available national data and results from this research. A review and comparison on both the physical and chemical soil properties provides an insight in to the processes operating within the two case-study properties. 


\subsection{METHODS:}

Appropriate selection methods and sampling techniques are crucial for valid data representation. The following chapter details the processes and methodologies undertaken throughout this research, firstly looking at the initial procedures and selection of potential sites for further investigation. Explanations on the different soil sampling and analysis techniques available are presented with a brief review of the literature on soil carbon methodologies. The chosen Walkley-Black (1934) method for Soil OC determination is then explained in detail with reference to the full methods and procedures undertaken found in the appendices. A review and comparisons between the physical and chemical soil properties will hopefully provide an insight in to the processes operating within the two case-study properties.

\subsection{FIELD SAMPLING TECHNIQUES:}

After a review of national scale data and geographic information system (GIS) investigations into New Zealand's fundamental soil layers and Land Resource Inventory (NZLRI) and identification of accessible land where permission for research was granted, a total of seven sample locations were identified for further investigation. These were predominantly chosen due to differing soils, land-use and vegetation cover, however, a spread of topography and aspect were also deciding secondary factors to gain a representative sample of the landscape. Within each sample location at each of the case-study properties, five soil profiles were chosen and dug at random. A handheld Global Positioning System (GPS) was used to map the location of the soil profiles and 
sample sites. GPS data was then downloaded and converted into a GIS shape file for further analysis.

The majority of carbon within the subsurface is found in the top layers (0$20 \mathrm{~cm}$ ) of a soil profile. However, soil organic carbon stratification within a soil profile can vary quite dramatically being largely dependent on differing pedogenic properties and processes (Post et al. 2001). Taking samples from different depth intervals rather than a single measurement is more representative and allows an insight into the interacting and dominant processes within the subsurface. At each profile soil samples were taken from the following depth intervals; $0-5 \mathrm{~cm}, 5-10 \mathrm{~cm}, 10-20 \mathrm{~cm}, 20-30 \mathrm{~cm}, 30-50 \mathrm{~cm}$ and, $50 \mathrm{~cm}$ - to where possible (typically $0.7-1.0 \mathrm{~m}$ ). Samples from $0-50 \mathrm{~cm}$ were collected using a spatula after shaving a profile face flush to reduce crosscontamination. Samples at depth $(>50 \mathrm{~cm})$ were collected using a soil auger. A total of 210 soil samples were collected from the two case-study properties.

\subsection{SOIL ANALYSIS:}

\section{PRE-TREATMENT OF SAMPLES:}

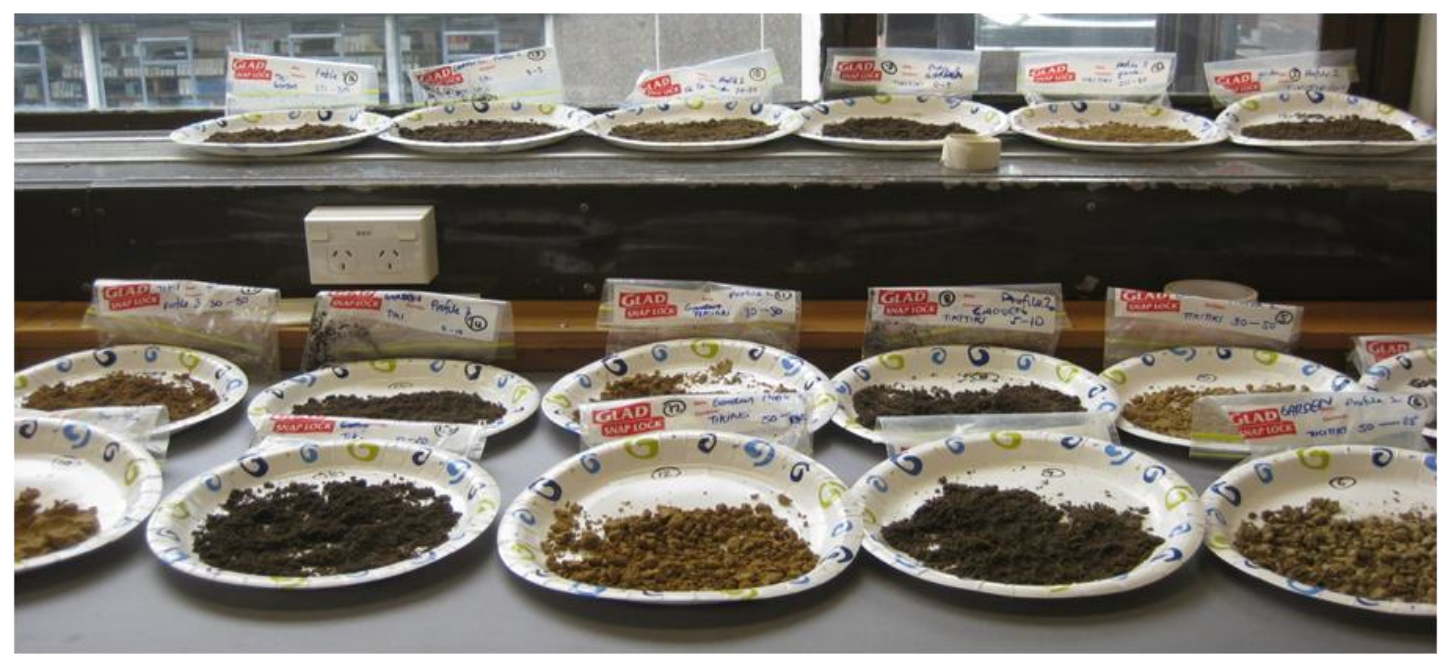

Figure 22. Soil samples in the laboratory air drying.

Samples were spread out in soil trays and air dried in a clean dust and fume free laboratory. Roots and large stones were removed by hand. The samples were 
dried for periods ranging between 5-7 days dependent on the soil. Once dried, the soils were sieved to $<0.25 \mathrm{~mm}$ with bigger clods pulverised using a mortar and pestle. The samples were then stored in airtight snap lock plastics bags until they were further needed for chemical or physical analysis.

\section{METHODS FOR SOIL CARBON ANALYSIS:}

There are several techniques that can be followed when quantifying carbon within soils. Currently the most established techniques for soil OC evaluation consist of ex-situ chemical or high temperature destruction of soil organic matter carried out in a laboratory, although, several non-destructive, in-situ methods are currently being developed (Bisutti et al. 2004; Chatterjee et al. 2009). For the scope of this research only the established (ex situ) techniques will be discussed further. Soil carbon quantification can be obtained following wet or dry combustion methods using either acids or heat at high temperatures (Schumacher, 2002). Table 5 compares both the wet and dry combustion methods.

\begin{tabular}{|l|l|l|l|}
\hline \multicolumn{1}{|c|}{ Method: } & $\mathbf{C O}_{2}$ Determination & \multicolumn{1}{|c|}{ Advantages } & \multicolumn{1}{|c|}{ Wet Combustion: } \\
\hline \multicolumn{5}{|c|}{} & $\begin{array}{l}\text { Dequantages } \\
\text { Combustion train } \\
\text { Titirimetric } \\
\text { readily available, } \\
\text { adjustable, } \\
\text { titrimetric analysis } \\
\text { less subject to } \\
\text { error }\end{array}$ & $\begin{array}{l}\text { Gravimetric } \\
\text { determination } \\
\text { requires careful } \\
\text { analytical } \\
\text { techniques, } \\
\text { titirimetric is less } \\
\text { precise }\end{array}$ \\
\hline $\begin{array}{l}\text { Van-Slyke-Neil } \\
\text { apparatus }\end{array}$ & Manometric & $\begin{array}{l}\text { Technique is } \\
\text { relatively simple to } \\
\text { conduct }\end{array}$ & $\begin{array}{l}\text { Apparatus is easily } \\
\text { damaged and } \\
\text { expensive }\end{array}$ \\
\hline Walkley-Black & Titrimetric & $\begin{array}{l}\text { Titrimetric analysis } \\
\text { less subject to } \\
\text { error }\end{array}$ & $\begin{array}{l}\text { Oxidation factor is } \\
\text { needed. Soil OC } \\
\text { recovery is variable, } \\
\text { and hazardous by- } \\
\text { products are } \\
\text { produced }\end{array}$ \\
\hline
\end{tabular}




\begin{tabular}{|l|l|l|l|}
\hline \multicolumn{1}{|c|}{ Method: } & CO $_{2}$ Determination & \multicolumn{1}{|c|}{ Advantages } & Disadvantages \\
\hline \multicolumn{3}{|c|}{ Dry Combustion: } \\
\hline $\begin{array}{l}\text { Weight-loss-on- } \\
\text { ignition (LOI) }\end{array}$ & Gravimetric & $\begin{array}{l}\text { Equipment usually } \\
\text { readily available, } \\
\text { simple procedure }\end{array}$ & $\begin{array}{l}\text { Overestimation of } \\
\text { organic matter }\end{array}$ \\
\hline Automated & $\begin{array}{l}\text { Thermal } \\
\text { conductivity, } \\
\text { gravimetric, IR } \\
\text { absorption } \\
\text { spectrometry }\end{array}$ & $\begin{array}{l}\text { Rapid with good } \\
\text { accuracy and } \\
\text { precision }\end{array}$ & $\begin{array}{l}\text { Expensive, slow } \\
\text { release of } \mathrm{CO}_{2} \text { from } \\
\text { alkaline earth } \\
\text { carbonates with a } \\
\text { resistance furnace }\end{array}$ \\
\hline
\end{tabular}

Table 5. Characteristics of soil C determination methods. Source: Altered from Chatterjee et al. 2009.

\section{COLORIMETRIC DETERMINATION OF ORGANIC CARBON:}

Soil chemical analysis was carried out using New Zealand Soil Bureau standard methods and followed methods described by Blakemore et al. (1987). Generally speaking, total carbon within a soil profile is the equivalent of the total organic carbon, exceptions include geographic areas dominated by carbonate bearing minerals where inorganic forms of carbon may be present within the soil samples (Schumacher, 2002). Negligible carbonate is present at the case-study sites.

Analysis of soil OC by wet combustion has long been the standard method since its introduction by Schollenberger (1927), it has however since been modified (Chatterjee et al. 2009). The Walkley-Black method for soil OC estimation (Walkley \& Black, 1934) is probably the most common wet oxidation method for soil $\mathrm{C}$ characterisation because of its ease of operation (Cheng \& Kimble, 2000) and minimal equipment needed (Nelson \& Sommers, 1996). The Walkley-Black method gives a quantitative measure of organic carbon by oxidation. This method involves a wet oxidation of the carbon by dichromate and subsequent measurement of the amount of reduced chromium present. Calibration is made against amounts of sucrose which have known amounts of soil carbon. The Walkley-Black procedure depends only upon the heat generated from dilution of concentrated acid for the oxidation purpose, therefore only the readily oxidizable $\mathrm{C}$ is estimated by this method (Cheng \& 
Kimble, 2000). Modifications to the Walkley-Black method now see an additional heating step (Chatterjee et al. 2009) to increase C recovery. On average $76 \%$ SOC recovery is achieved and a correction factor of 1.32 is used for quantifying total soil OC content of a particular sample (Chatterjee et al. 2009).

\section{PARTICLE SIZE DISTRIBUTION:}

A soil's textural characteristics and particle size distribution play a dominant role in many soil properties and functions (Shein, 2009). Soil organic carbon and processes surrounding stabilization and accumulation are controlled by a number of factors, one of which is soil texture. Depending on the proportion of sand, silt and clay present, the soil can be assigned to a textural class (Figure 23). Soil texture is particularly important not only in terms of its stabilizing effects but, also through its direct influence on organic matter and soil water processes (Hook \& Burke, 2000). Therefore soil texture has a dominant control over biogeochemical processes, the associated patterns and, transformations within the subsurface. Studies suggest that soil OC levels increase with silt and clay content (Telles et al. 2003) as these textural characteristics greatly influence carbon binding dynamics and turnover times within the soil. Soil

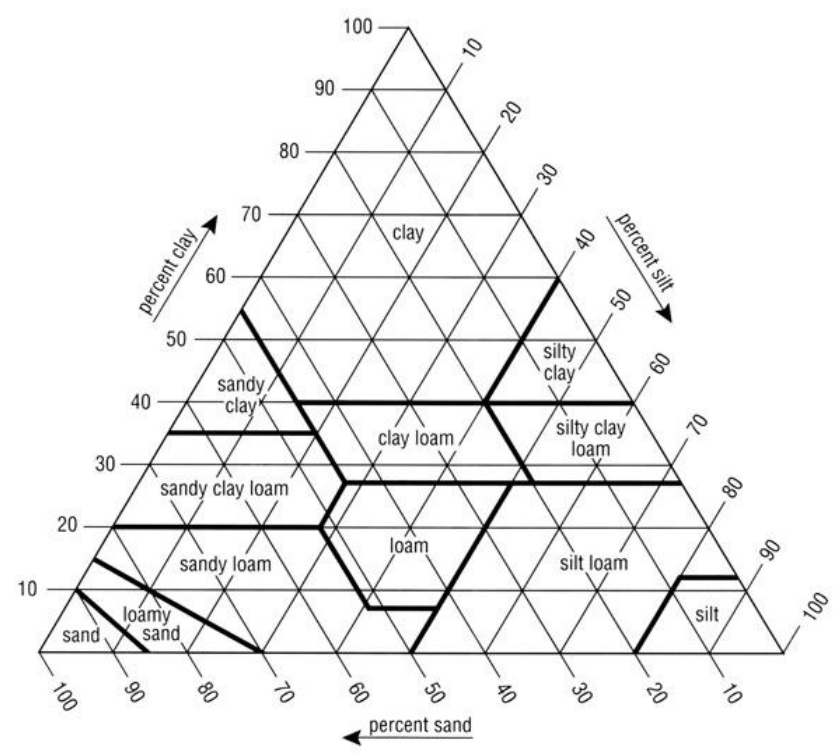

Figure 23. USDA Textural classification triangle. Source: United States Department of Agriculture, 2009. 
texture and organic matter are also key in terms of soil structure as they are principle determinants of structural characteristics such as bulk density and aggregate stability. Soil structure refers to the size, shape and stability of soil aggregates and is a key moderator of soil and plant functions also, providing the framework for water, air and nutrient flow (Blanco-Canqui \& Lal, 2004). For these reasons particle size analysis was a key component of the methodology undertaken throughout this research. Particle size distribution analysis gives a measure of the size distribution of individual particles within a particular sample (USDA, 2009). Results of particle size distribution are eventually used to define soil texture. There are several different methods that can be applied to determine particle size and distribution, these include: dry mechanical sieving, wet sieving, settling tube or pipette method, and laser diffractometry. Muggler et al. (1997) stress the potential of laser diffractometry especially in soil science, as it allows insight into the differences in aggregation that could not be assessed using other methods (Beuselinck et al. 1998). Factors determining the methods used for particle size analysis included equipment availability and the range in which the particle sizes fell.

\begin{tabular}{|c|c|c|}
\hline $\begin{array}{l}\text { Measurement } \\
\text { Technique }\end{array}$ & Model & $\begin{array}{l}\text { Advantages/ } \\
\text { Disadvantages }\end{array}$ \\
\hline Dry Mechanical Sieving & - & $\begin{array}{l}\text { Simple and easy to interpret } \\
\text { however requires a relatively } \\
\text { long time for analysis }\end{array}$ \\
\hline Wet Sieving & Archimedean principle & $\begin{array}{l}\text { Samples must also be dried - } \\
\text { time consuming }\end{array}$ \\
\hline $\begin{array}{l}\text { Settling Tube or } \\
\text { Pipette Method }\end{array}$ & $\begin{array}{l}\text { Stoke's Law for the } \\
\text { settling velocity of a } \\
\text { spherical particle in a } \\
\text { fluid medium }\end{array}$ & $\begin{array}{l}\text { Particles may partially or fully } \\
\text { dissolve in the medium. Density } \\
\text { is highly dependent of fluid } \\
\text { temperature remaining } \\
\text { constant }\end{array}$ \\
\hline $\begin{array}{l}\text { Laser Diffractometry } \\
\text { Method }\end{array}$ & $\begin{array}{l}\text { Mie Theory of light } \\
\text { scattering by a spherical } \\
\text { particle }\end{array}$ & $\begin{array}{l}\text { Require only small samples, } \\
\text { short analysis time }\end{array}$ \\
\hline
\end{tabular}

Table 6. Characteristics of the different methods followed to determine particle size distribution. 


\section{LASER PARTICLE SIZER (LPS):}

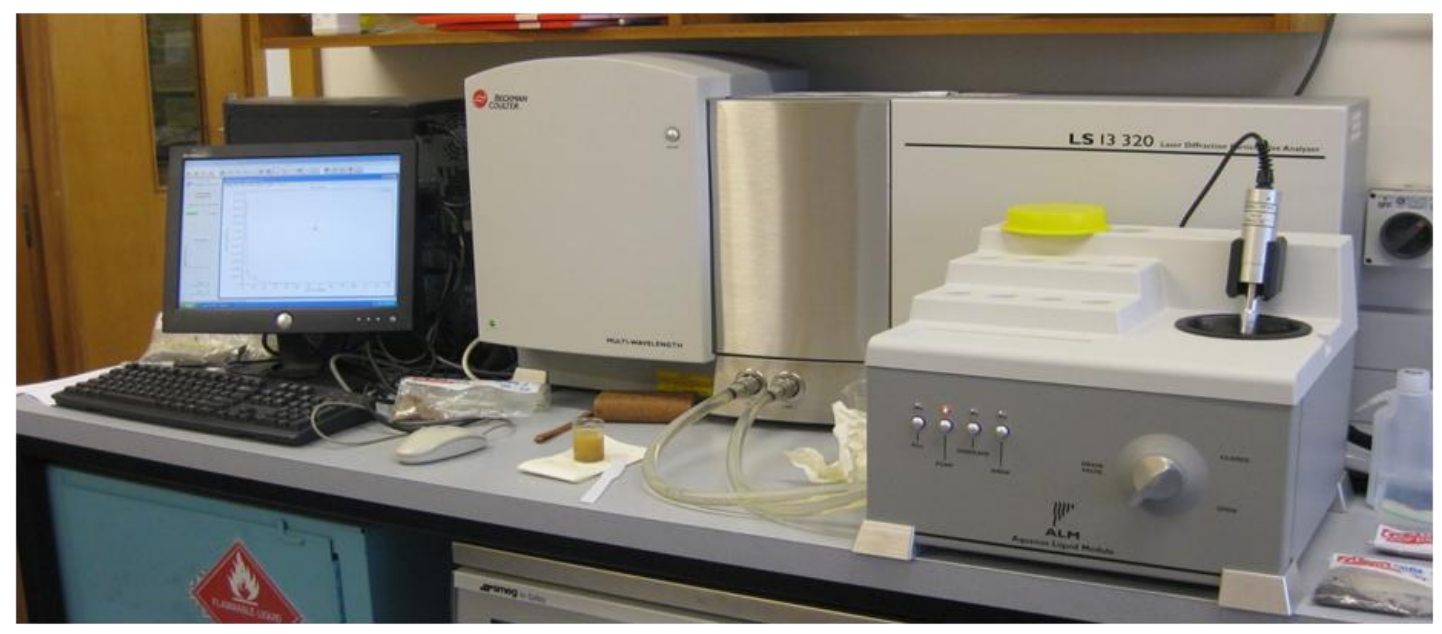

Figure 24. Beckman Coulter LS 13320 - Laser Particle Sizer Victoria University Water Quality Laboratory.

The chosen method for this research was laser diffraction, with the above image (Figure 24) showing the laser diffraction particle size analyser that was used for analysis. The benefits of using laser diffraction for particle size analysis include: relatively wide measuring range (from $\mu \mathrm{m}$ to $\mathrm{mm}$ ), samples can either be dry or wet, analysis is relatively fast, and output is immediate. Samples were left in a calgon solution overnight to reduce the likelihood of the particles clumping together. Laser diffraction was carried out on all samples taken from 5-10 cm and $30-50 \mathrm{~cm}$ at the Tikitiki property and at each of the depth intervals at the Willowbank property at each soil profile.

\section{BULK DENSITY:}

Studies of biogeochemical cycles, in both natural and managed ecosystems and their changes due to anthropogenic activities, cannot be done without reliable information on soil bulk density and its temporal and spatial variations (Lal \& Kimble, 2000). A soils bulk density is the ratio of the soil mass to its volume. Bulk density tends to increase with depth as a result of many factors such as reduced OM and root penetration (USDA, 2009). After chemical analysis, results are given in milligrams of organic carbon per gram of soil (this can then be converted to a percentage). Bulk density is required to convert this 
gravimetric soil data (e.g. \% Soil Carbon) to the volumetric form needed for decision making and carbon accounting. Therefore, bulk density combined with \%C determines the amount of soil $\mathrm{C}$ stored in that volume of soil. Such calculations are vital for estimating $\mathrm{C}$ budgets and $\mathrm{C}$ stored in a particular area. Soil bulk density was measured at each of the soil profile locations using metal cylinders. The core samples were taken from the top soil $(0-5 \mathrm{~cm})$, in the middle of each profile $(25-30 \mathrm{~cm})$ and at lower depths $(35-45 \mathrm{~cm})$. Cores were labelled and put in plastic bags then transferred to the laboratory for weight measurements.

\section{SOIL WATER HOLDING AND INFILTRATION CAPACITIES:}

Pedo-transfer function (PTF), a term used to describe predictive functions that allow an estimation of certain soil properties from other, easily measured properties. Using these readily available data can be translated into other soil functions which can often be difficult or costly to measure (Wilde, 2003). It is recognised that a soils texture has a dominant effect on soil water characteristics. Organic matter (OM) also plays a significant role with increased OM often producing soils with increased water holding capacities and conductivity (Saxton \& Rawls, 2006).

Soil hydraulic properties for this research were calculated using the Saxton and Rawls (2006) pedo-transfer relationship that statistically relates bulk density, percentage sand, percentage silt, percentage clay, and organic matter. 


\subsection{RESULTS:}

Due to the multitude of data collected for analysis, only summary results are presented in this chapter. Results are presented as mean values unless stated otherwise. The appendix includes entire datasets and further details and information on both the chemical and mechanical analysis on each of the soil samples. This results and discussion chapter is structured as follows:

- firstly results from the soil OC data at each of the properties and sample locations are presented with general trends evident between soil type, land-use and location discussed;

- particle size, textural characteristics, and soil water characteristics are then presented;

- available national soil data (in particular the associated carbon attributes) are compared with the soil sample results from the two case study properties;

- the implementation of the Polyscape tool and a discussion surrounding the results of Polyscape at both the farm and catchment scales will conclude the results chapter.

One of the main focuses and objectives of this research project was to review the suitability of the available national scale soil data for its implementation with decision support tools such as the Geographic Information Systems (GIS) based tool Polyscape, which considers the broad context of carbon sequestration potential and linkages with general sustainability. The results chapter will firstly look at the soil sample results taken from the two case study 
properties. Results include; soil OC content, particle size analysis, bulk density and associated pedo-transfer functions and hydraulic properties. As previous chapters have pointed out OM or soil OC plays a particularly important role when it comes to a soils overall physical condition and also aids with other associated subsurface functions such as structure and therefore a soils inherent strength. Increases or decreases of $\mathrm{OC}$ in soil can be largely dependent on not only inherent properties such as parent material, but also different types of land-uses and management strategies applied. Results will outline both similarities and differences between sites, and discuss these in the context of broader patterns within the landscape.

\subsection{CHEMICAL RESULTS - SOIL ORGANIC CARBON:}

\begin{tabular}{|c|c|c|c|}
\hline Sampling Depth & \multicolumn{3}{|c|}{ Average Soil OC (mg/g) } \\
\cline { 2 - 4 } Intervals (cm) & Garden & Gorse & Flats \\
\hline $0-5$ & $64.86(18.10)$ & $89.76(14.97)$ & $67.20(8.60)$ \\
\hline $5-10$ & $55.61(7.03)$ & $63.45(17.88)$ & $45.36(4.97)$ \\
\hline $10-20$ & $42.51(12.21)$ & $42.35(19.09)$ & $23.15(6.54)$ \\
\hline $20-30$ & $18.04(6.65)$ & $25.32(11.42)$ & $9.31(5.97)$ \\
\hline $30-50$ & $9.56(3.15)$ & $17.32(7.23)$ & $5.30(1.84)$ \\
\hline $50-$ & $4.66(5.02)$ & $5.41(3.37)$ & $5.22(1.75)$ \\
\hline
\end{tabular}

Table 7. Mean soil organic carbon (mg/g) (standard deviation): Tikitiki case-study property.

\begin{tabular}{|c|c|c|c|c|}
\hline \multirow{2}{*}{$\begin{array}{c}\text { Sampling Depth } \\
\text { Intervals (cm) }\end{array}$} & \multicolumn{4}{|c|}{ Average Soil OC (mg/g) } \\
\cline { 2 - 5 } & $\begin{array}{c}\text { Bottom } \\
\text { Pasture }\end{array}$ & Top Pasture & River & Kanuka \\
\hline $0-5$ & $32.60(5.87)$ & $58.20(9.82)$ & $33.34(6.99)$ & $50.94(12.65)$ \\
\hline $5-10$ & $19.40(4.71)$ & $40.74(5.05)$ & $28.12(8.47)$ & $34.18(4.38)$ \\
\hline $10-20$ & $14.92(2.61)$ & $27.50(5.21)$ & $15.89(6.06)$ & $17.31(4.28)$ \\
\hline $20-30$ & $15.43(8.06)$ & $16.10(8.89)$ & $7.91(3.11)$ & $8.88(3.79)$ \\
\hline $30-50$ & $8.58(3.11)$ & $8.84(9.57)$ & $5.33(1.82)$ & $5.18(0.96)$ \\
\hline $50-$ & $8.68(4.13)$ & $4.82(3.00)$ & $4.84(2.67)$ & $3.88(0.72)$ \\
\hline
\end{tabular}

Table 8. Mean soil organic carbon (mg/g) (standard deviation): Willobank case-study property. 


\section{PROPORTIONAL DECREASE IN SOIL OC WITH INCREASING SAMPLING DEPTH AT EACH OF THE SEVEN SAMPLE SITES:}

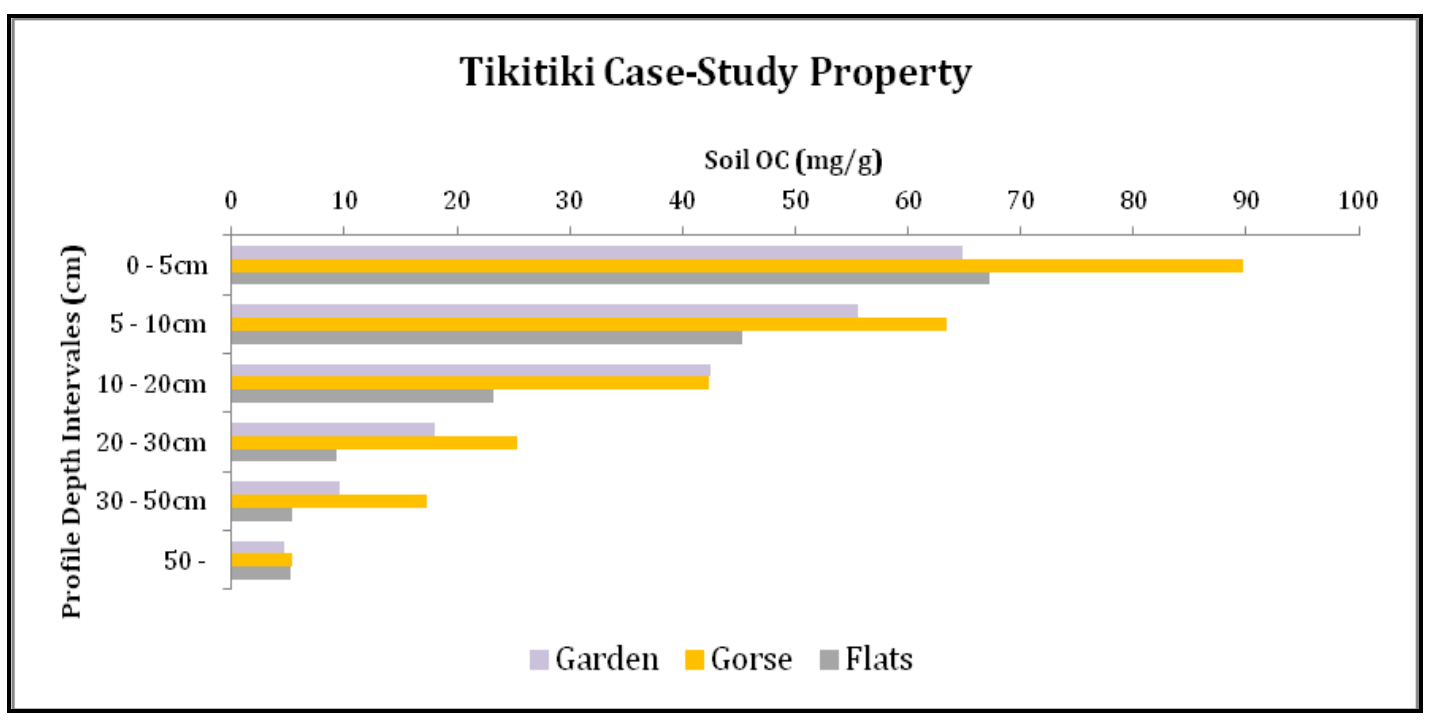

Figure $25^{2}$. Proportional decrease in soil OC (mg/g) with increasing sampling depth: Tikitiki.

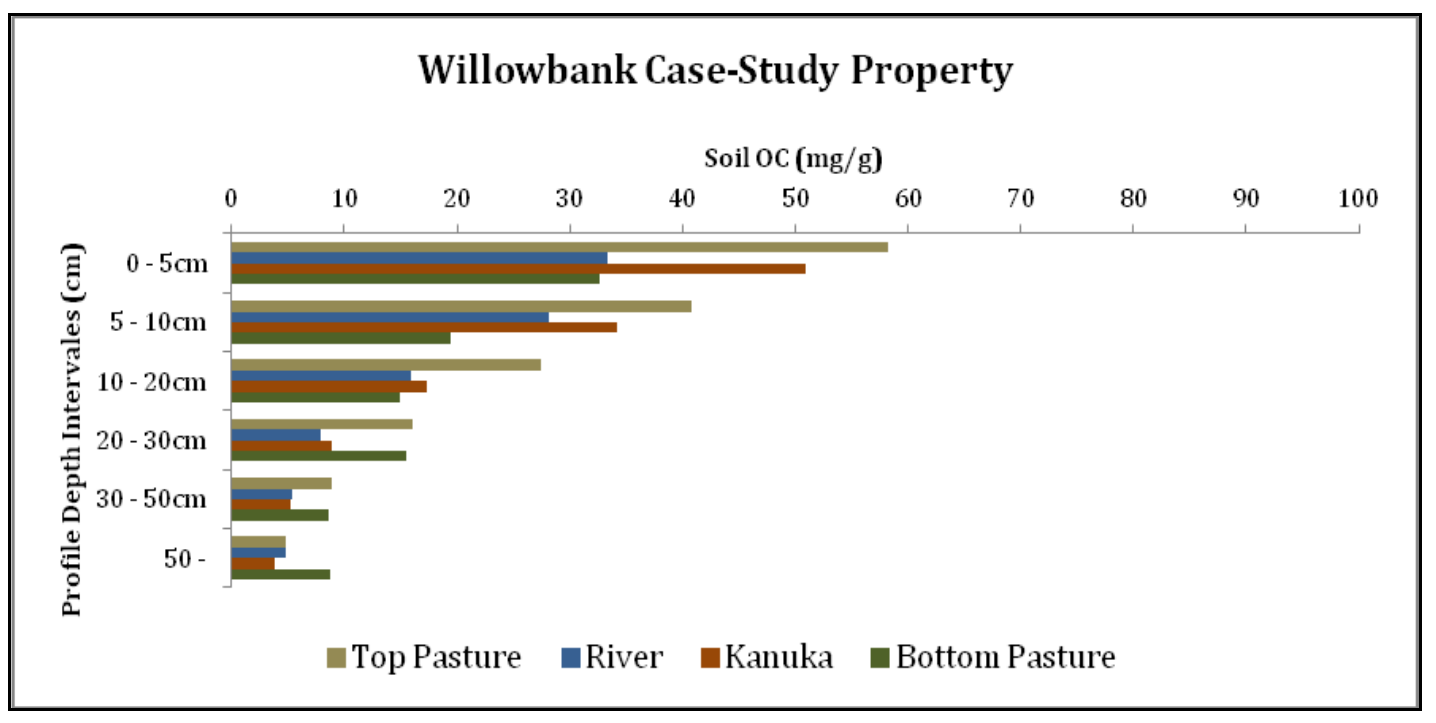

Figure 263. Proportional decrease in soil OC (mg/g) with increasing sampling depth: Willowbank.

\footnotetext{
2 The colour schemes chosen were for personal preference relating to physical characteristics at each of the sample locations. "Gorse" = yellow/orange representing the gorse flower, "Flats" = grey as the soil was quite gleyed and greyish in colour and, "Garden" = purple as it fits quite well with the other two colours

3 "Top Pasture" = light green as the grass was a lot drier "River" = blue representing water as the site was the closest to the river, "Kanuka" = brown the colour of the bark of the Kanuka tree and, "Bottom Pasture" = dark green as the site was covered in green pasture. These colour schemes will be followed throughout the results chapter.
} 
The previous two tables (Table 7 and Table 8), and the two previous graphs (Figure 25 and Figure 26), give an indication of the average amounts of soil OC (mg/g) at the two case-study properties at each of the seven sample sites ("Garden”, “Gorse”, “Flats", "Bottom Pasture”, “Top Pasture”, “Kanuka”, and "River"). The graphs highlight both similarities and notable differences between each of the seven sample sites. All seven of the sites showed a negative exponential relationship between increasing soil depth and a decrease in soil OC content. However, the rate of decrease in soil OC with depth varied significantly with especially marked differences between the two case-study properties. Similar trends are evident between the three sample sites located at the Tikitiki property ("Garden", "Gorse" and "Flats") with the first $0-5 \mathrm{~cm}$ (topsoil) containing significant amounts of soil OC ranging between $53 \mathrm{mg} / \mathrm{g}$ and $103 \mathrm{mg} / \mathrm{g}$, and decreased with increasing depth. However, there were still notable amounts of carbon being recorded at lower depths $(30-50 \mathrm{~cm}$ and $>50 \mathrm{~cm}$ ), particularly underneath the sample site referred to as "Gorse" with an average of $17 \mathrm{mg} / \mathrm{g}$ of soil OC recorded at the $30-50 \mathrm{~cm}$ depth interval. "Gorse" also showed the highest soil OC content at shallow depths and overall with $>10 \%$ soil OC being recorded within the top $0-5 \mathrm{~cm}$ at two soil profiles (profiles $4 \& 5$ at the "Gorse" sample location). At the Willowbank property, the first 0 $5 \mathrm{~cm}$ (topsoil) also contained the highest amounts of soil OC with decreasing amounts as depth increased. The sample site referred to as "Top Pasture" contained the most soil OC at each depth interval $(0-5 \mathrm{~cm}=58.2 \mathrm{mg} / \mathrm{g}, 5-10 \mathrm{~cm}=$ $40.74 \mathrm{mg} / \mathrm{g}, 10-20 \mathrm{~cm}=27.50 \mathrm{mg} / \mathrm{g}, 20-30 \mathrm{~cm}=16.10 \mathrm{mg} / \mathrm{g}$, and $30-50 \mathrm{~cm}=$ $8.84 \mathrm{mg} / \mathrm{g})$ with the exception the $50-\mathrm{cm}(4.82 \mathrm{mg} / \mathrm{g})$ measurement. The sample site "Kanuka" similar results to the "Top Pasture" site, both having the same soil type (Pallic Soils). The "Bottom Pasture" and "River" sample sites were also very similar to each other. Again both sample locations had similar underlying soils (Fluvial Recent Soils). 


\section{Stacked Averages Showing Soil OC (mg/g) at Each Soil Sample Site at Each Depth Interval}

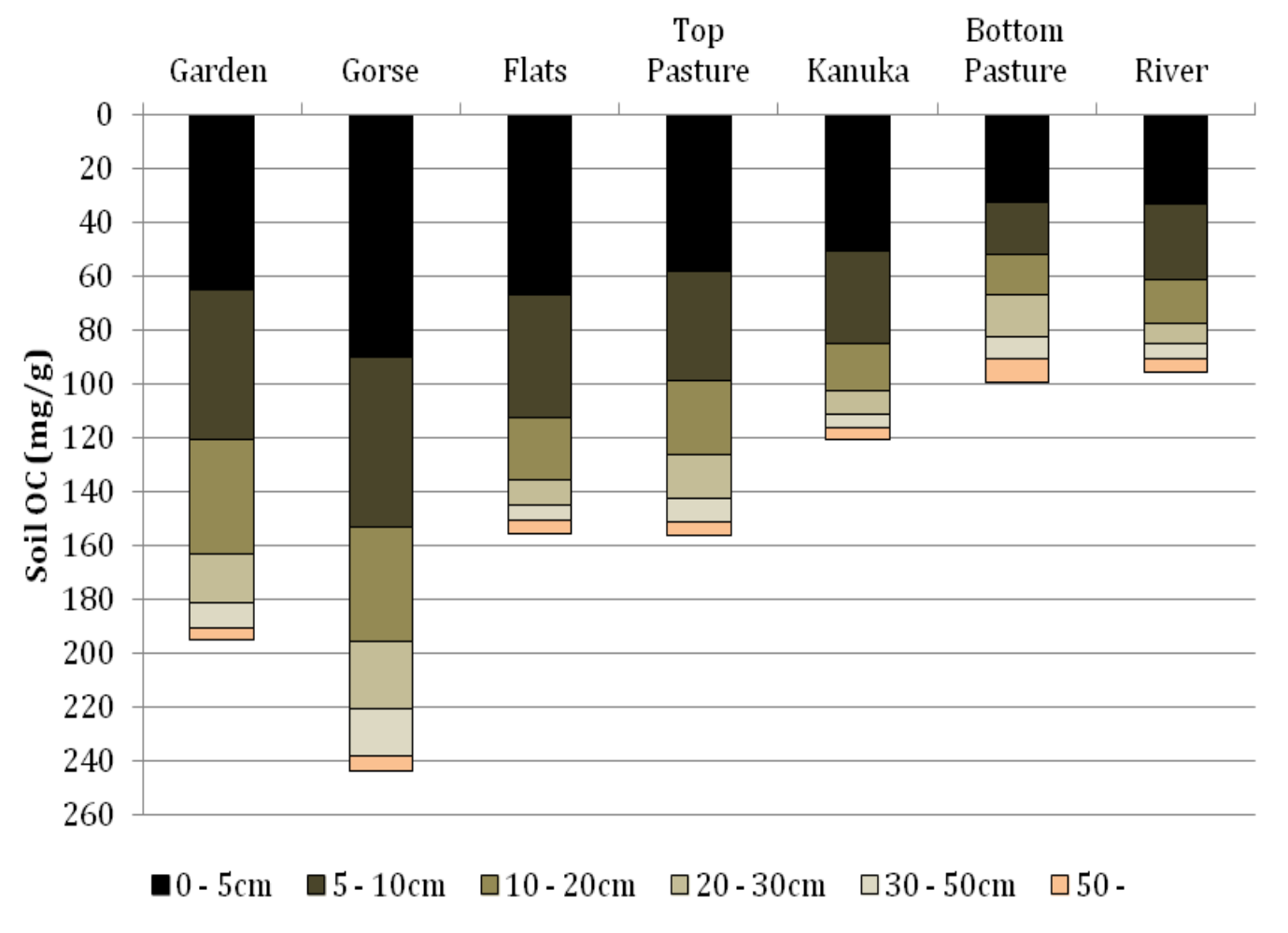

Figure 27. Stacked averages showing soil $\mathrm{OC}(\mathrm{mg} / \mathrm{g})$ at each soil sample site

Figure 27 shows the mean vertical distribution of soil OC $(\mathrm{mg} / \mathrm{g})$ at each of the seven sample sites using a stacked plot. The first three columns represent samples from the Tikitiki case-study property and the last four columns represent samples from the Willowbank case-study property. The graph again reiterates the notable difference in soil OC content between each of the seven sample sites and also notable differences between the two case-study properties. Displaying the results in a stacked form allows for a better visual representation in terms soil OC and the changes with relative depth. The graph highlights the significant amounts of soil OC found within the top of each of the soil profiles, with the majority of soil OC located within the top $0-10 \mathrm{~cm}$. 
DEPTH INTEGRATED SOIL ORGANIC CARBON $\leq 30 \mathrm{~cm}$ :

\begin{tabular}{|c|c|c|c|c|c|c|}
\hline \multirow{2}{*}{$\begin{array}{c}\text { Soil Sample } \\
\text { Locations: }\end{array}$} & $\mathbf{1}$ & $\mathbf{2}$ & $\mathbf{3}$ & $\mathbf{4}$ & $\mathbf{5}$ & $\begin{array}{c}\text { Average C } \\
\text { t/ha }\end{array}$ \\
\cline { 2 - 6 } & 95.41 & 94.35 & 121.00 & 60.68 & 95.44 & $\mathbf{9 3 . 3 8}$ \\
\hline Garden & 158.94 & 62.99 & 113.17 & 146.96 & 152.74 & $\mathbf{1 2 6 . 9 6}$ \\
\hline Gorse & 102.34 & 99.55 & 88.36 & 135.56 & 106.66 & $\mathbf{1 0 6 . 4 9}$ \\
\hline Flats & 76.17 & 91.13 & 75.20 & 55.43 & 76.75 & $\mathbf{7 4 . 9 4}$ \\
\hline Bottom Pasture & 78.03 & 111.19 & 133.25 & 101.51 & 83.27 & $\mathbf{1 0 1 . 4 5}$ \\
\hline Top Pasture & 41.44 & 87.94 & 63.33 & 80.98 & 58.95 & $\mathbf{6 6 . 5 3}$ \\
\hline River & 80.92 & 60.58 & 61.73 & 54.22 & 82.83 & $\mathbf{6 8 . 0 6}$ \\
\hline Kanuka & & & & & & \\
\hline
\end{tabular}

Table 9. Table Showing Soil OC Depth Integration Results $(\leq 30 \mathrm{~cm})$

When reporting soil carbon stocks, New Zealand follows the IPCC standard depth range of $\leq 30 \mathrm{~cm}$. Figure 28 and Figure 29 show the output when soil OC results are integrated to this specified depth $(\leq 30 \mathrm{~cm})$. Figure 28 compares soil OC $\left(\mathrm{t} / \mathrm{ha}^{-1}\right)$ at all seven of the sample locations, showing results from the individual profiles (profile one through to profile five) at each of the sample location. This figure highlights both the variation seen between the seven sample locations and also shows variation between profiles within a specific sample location. Once the results are averaged out and depth integrated (Figure 29), "Gorse" still clearly contains the highest amount of carbon with on average $126 \mathrm{t} / \mathrm{ha}^{-1}$. 


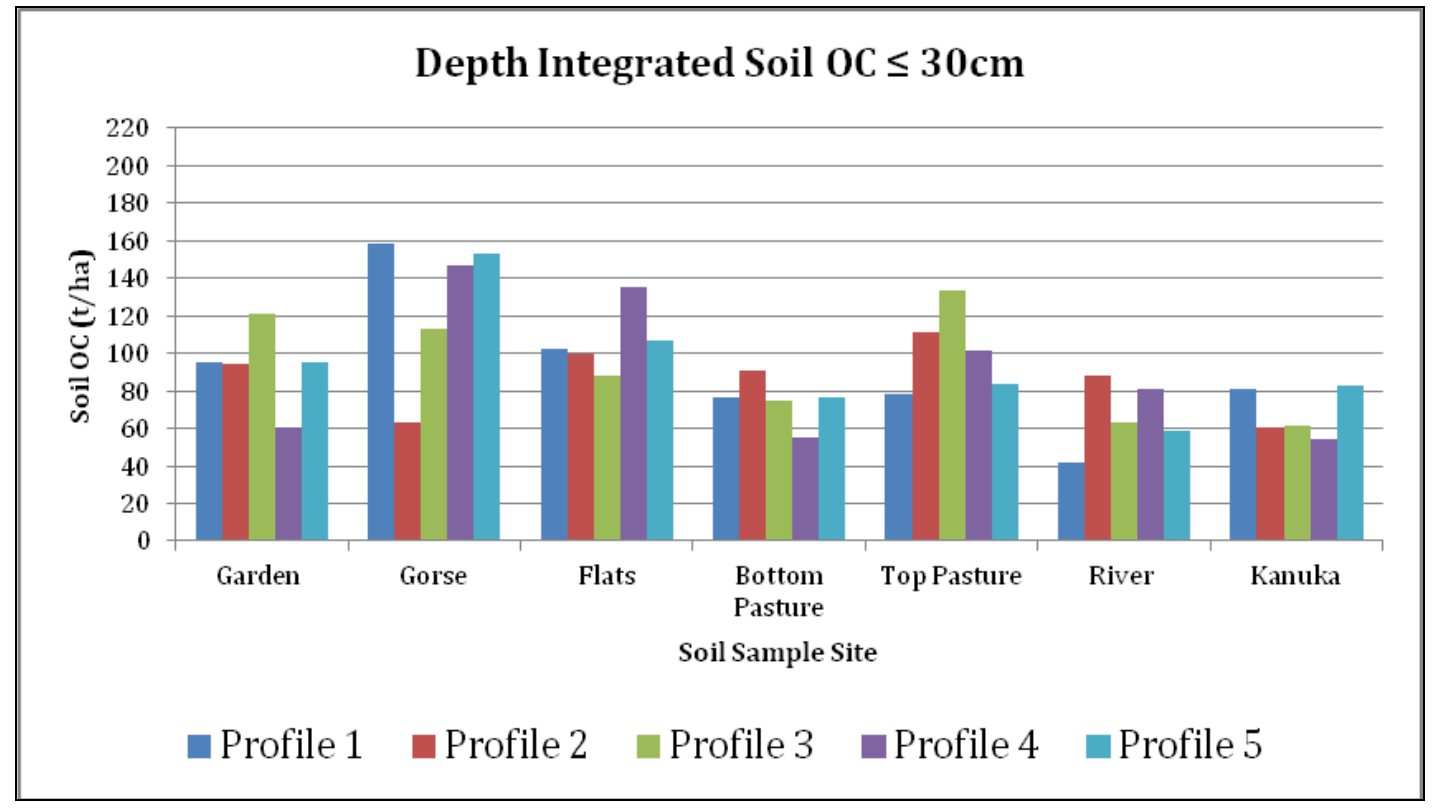

Figure 28. Depth integration results $(\leq 30 \mathrm{~cm})$

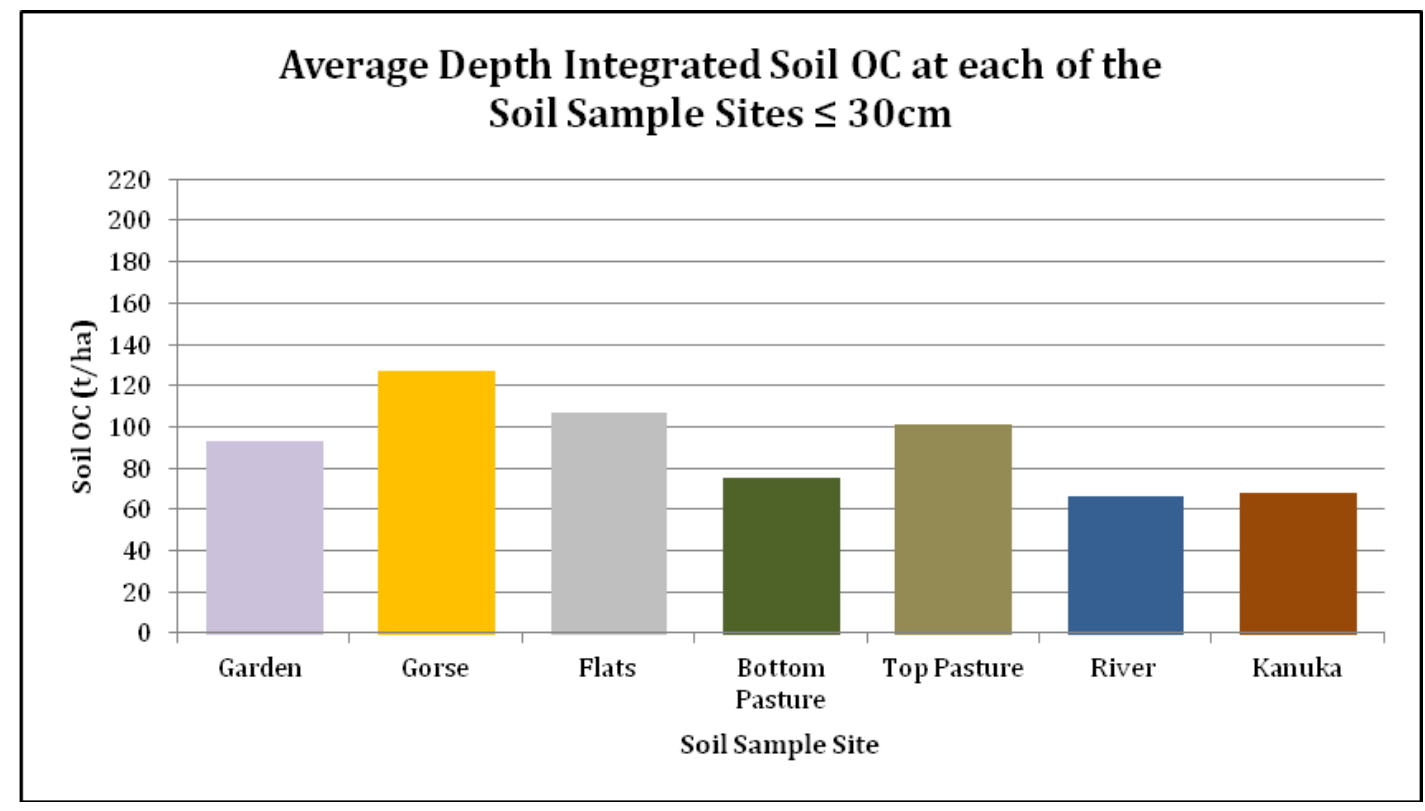

Figure 29. Averaged depth integration results $(\leq 30 \mathrm{~cm})$ 
DEPTH INTEGRATED SOIL ORGANIC CARBON $\leq 70 \mathrm{~cm}$ :

\begin{tabular}{|c|c|c|c|c|c|c|}
\hline \multirow{2}{*}{$\begin{array}{c}\text { Soil Sample } \\
\text { Locations: }\end{array}$} & \multicolumn{5}{|c|}{ Soil Profile No. } & $\begin{array}{c}\text { Average C } \\
\text { t/ha }\end{array}$ \\
\cline { 2 - 6 } & $\mathbf{1}$ & $\mathbf{2}$ & $\mathbf{3}$ & $\mathbf{4}$ & $\mathbf{5}$ & $\mathbf{1 1 7 . 8 8}$ \\
\hline Garden & 133.05 & 113.11 & 148.47 & 82.65 & 112.12 & $\mathbf{1 6 6 . 9 6}$ \\
\hline Gorse & 207.91 & 92.88 & 145.58 & 196.48 & 191.94 & $\mathbf{1 3 1 . 7 3}$ \\
\hline Flats & 129.32 & 119.16 & 109.77 & 174.17 & 126.24 & $\mathbf{1 3}$ \\
\hline $\begin{array}{c}\text { Bottom } \\
\text { Pasture }\end{array}$ & 128.66 & 126.09 & 118.37 & 108.34 & 125.11 & $\mathbf{1 2 1 . 3 1}$ \\
\hline Top Pasture & 101.26 & 132.75 & 210.57 & 113.68 & 97.85 & $\mathbf{1 3 1 . 2 2}$ \\
\hline River & 80.48 & 117.78 & 86.80 & 96.70 & 75.03 & $\mathbf{9 1 . 3 6}$ \\
\hline Kanuka & 100.91 & 80.39 & 82.56 & 67.56 & 98.57 & $\mathbf{8 6 . 0 0}$ \\
\hline
\end{tabular}

Table 10. Table showing Soil OC Depth Integration Results $(\leq 70 \mathrm{~cm})$

The topsoil and upper depth intervals $(0-5 \mathrm{~cm}$ and $5-10 \mathrm{~cm})$, and more generally the IPCC standard reporting depth of $\leq 30 \mathrm{~cm}$ of a soil profile contains most labile carbon; i.e. the carbon that is most easily gained or lost and turned over fairly rapidly (Pluske et al. 2010). Consequently the upper depths of a soil are particularly important to identify short to medium term sequestration potential. There are however, significant stocks of carbon found at lower depths, and therefore significant amounts to be protected. Figure 30, Figure 31 and Table 10 give indicative figures of the amount of carbon $\mathrm{t} / \mathrm{ha}^{-1}(\leq 70 \mathrm{~cm})$. Figure 30 shows average depth integrated soil $\mathrm{OC}\left(\mathrm{t} / \mathrm{ha}^{-1}\right)$ for each profile at each of the seven sample sites this time down to $\leq 70 \mathrm{~cm}$. It is important to consider carbon stock to greater depth than the IPCC standard as this deeper down carbon is better protected from processes such as erosion and therefore is less likely to be lost back to the atmosphere. However, it is at risk of being lost over medium to longer term timescales as soils adjust to changing land management regimes/climate drivers. Again the sample site "Gorse" produced the highest value with $166.9 \mathrm{t} / \mathrm{ha}^{-1}$ ( $\leq 70 \mathrm{~cm}$ ) of soil OC with the "Garden" and "Flats" sample sites ranged between $117 \mathrm{t} / \mathrm{ha}^{-1}(\leq 70 \mathrm{~cm})$ and $131 \mathrm{t} / \mathrm{ha}^{-1}$. $(\leq 70 \mathrm{~cm})$. Results were somewhat lower overall at the Willowbank case-study property with values ranging between $85 \mathrm{t} / \mathrm{ha}^{-1}(\leq 70 \mathrm{~cm})$ and $131 \mathrm{t} / \mathrm{ha}^{-1}$ $(\leq 70 \mathrm{~cm})$ of soil OC. 


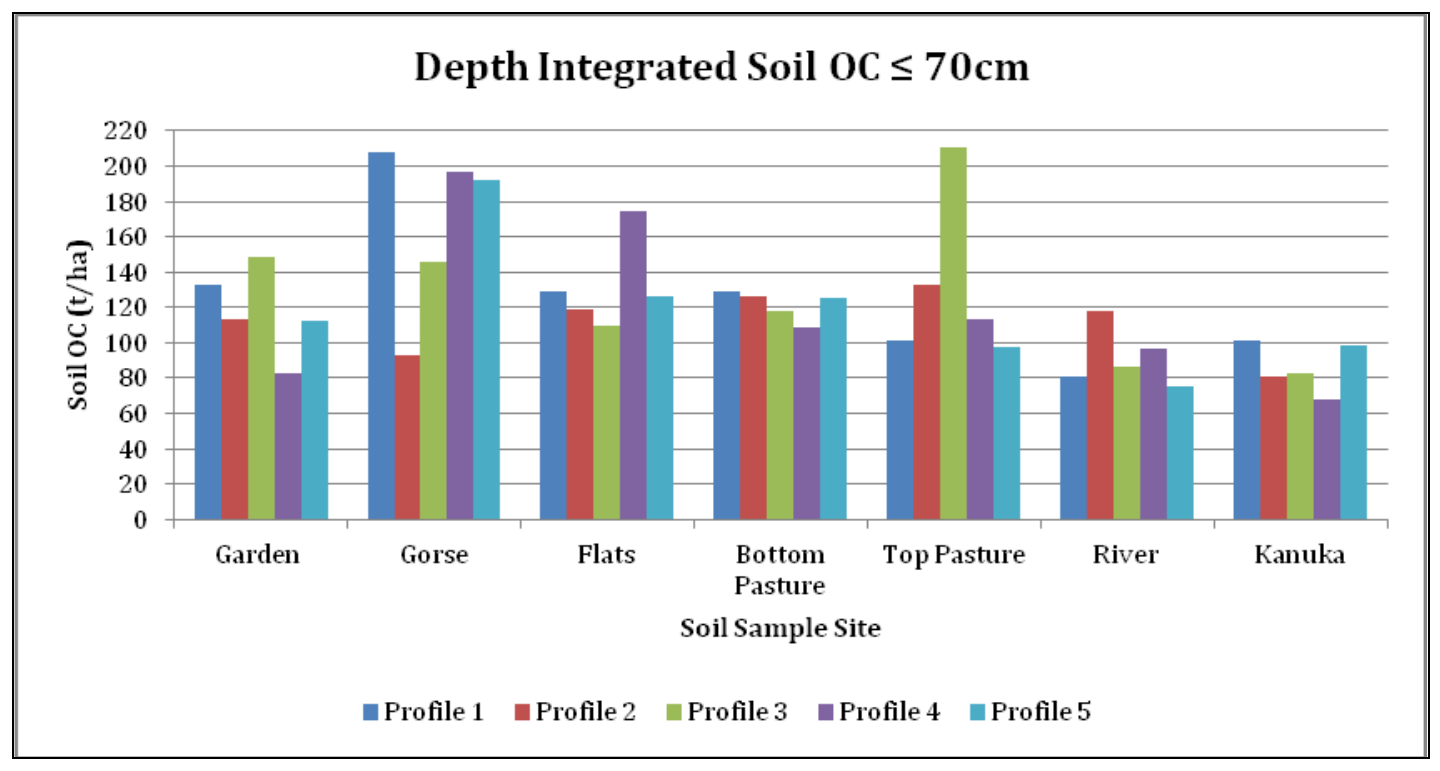

Figure 30. Depth integration results $(\leq 70 \mathrm{~cm})$

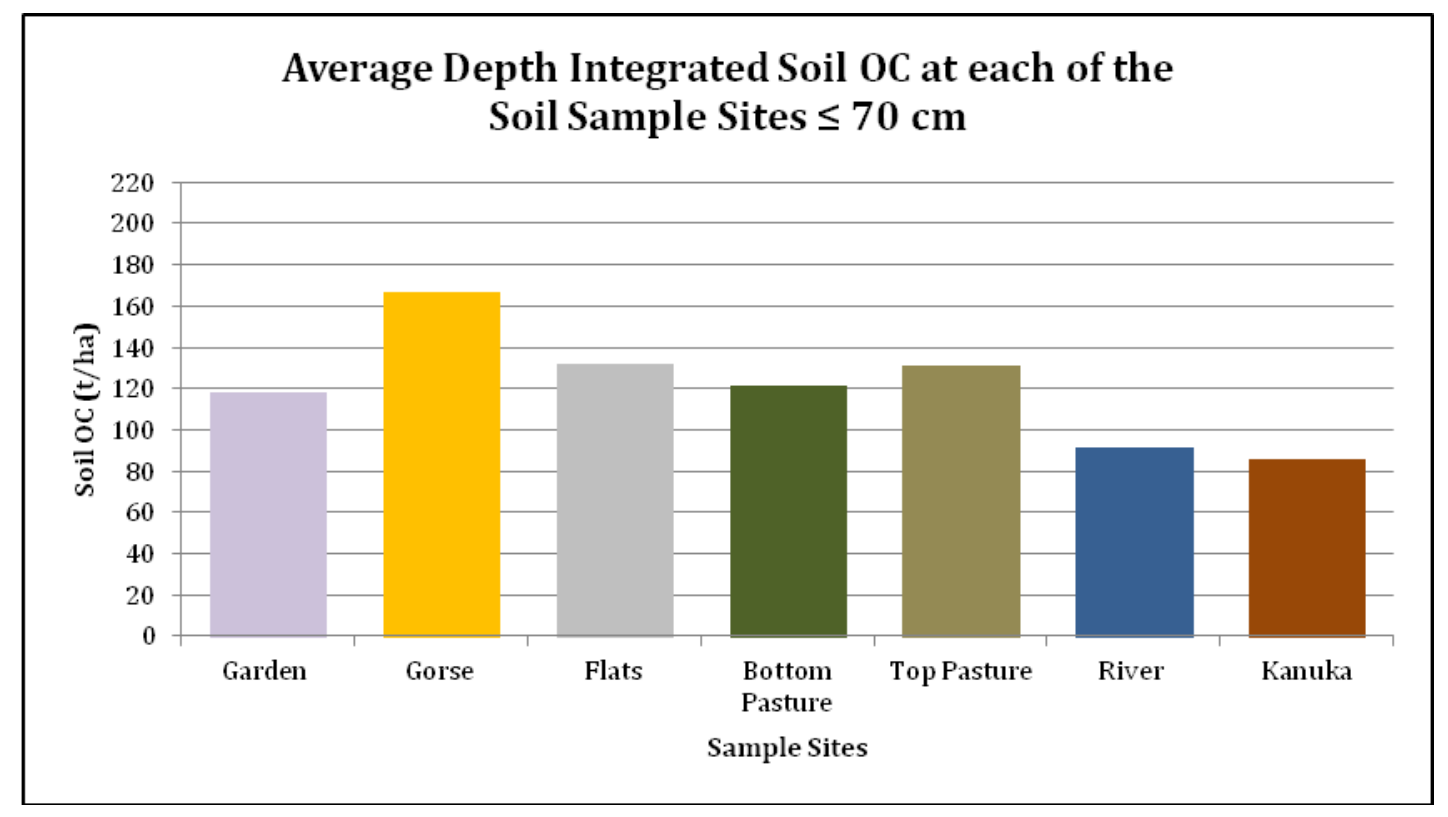

Figure 31. Averaged depth integration results $(\leq 70 \mathrm{~cm})$ 


\section{COMPARISONS WITHIN CASE-STUDY PROPERTIES:}

Figure 32 through to Figure 36 highlight the most obvious similarities and notable differences within properties and also between the two case-study properties. Differences appear to be in main a consequence of differing soil type. However, vegetation cover and land-use also appear to be responsible for some of the disparity between results. Figure 32 compares the "Gorse" and "Garden" sample sites. According to New Zealand's fundamental soil layer (NZFSL) the sites are both located on the same soil classified as Typic Orthic Allophanic Soil (LOT), but are under different vegetation cover with the "Garden" having been cleared of gorse in the past to allow for the plantation of organic crop vegetables. Figure 32 shows "Gorse" to be consistently greater in $\%$ soil OC (excluding $10-20 \mathrm{~cm}$, where it is equal) at each of the depth intervals. Results show \% soil OC to be markedly greater in the top $0-5 \mathrm{~cm}$ at the "Gorse" sample site with $8.9 \%$ soil OC recorded, compared to only $6.5 \%$ soil OC at the "Garden" site. Results are consistent with expectations as both sample sites are located on the same soil and in the (near) past both would have been under gorse. Therefore they should show similar results. A potential explanation for the lower \% soil OC at the "Garden" site could be an effect of the vegetation having been cleared for agricultural purposes. It is unlikely that the soil has fully adjusted to the new land-use regime and carbon may show a decreasing trend in the "Garden" site in the near future.

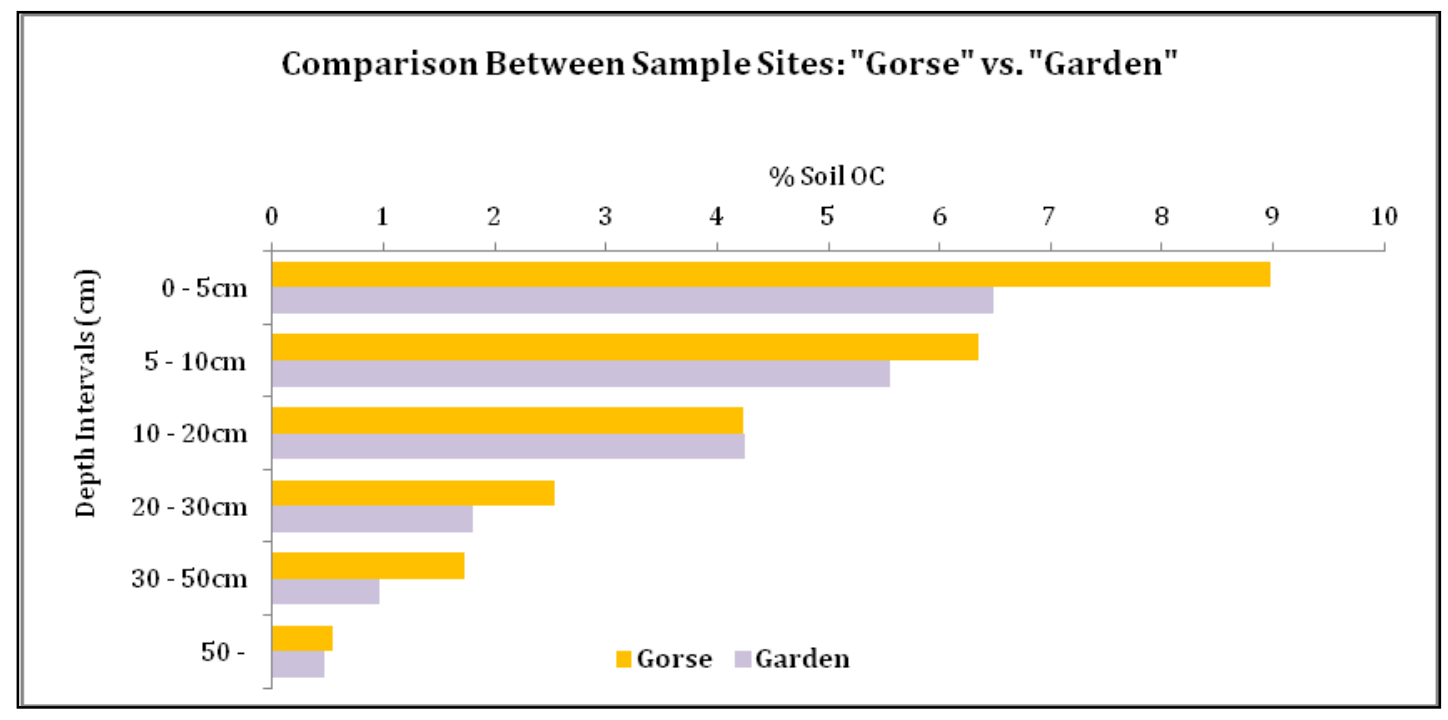

Figure 32. \% soil OC comparison between "Gorse” vs. "Garden". 
Figure 33 compares the "Kanuka" and "Top Pasture" sites. Both are located on a combination of the same two soils according to NZFSL, classified as Pedal Immature Pallic Soils and Weathered Orthic Recent Soils (PID+ROW). The sites differ in terms of land-use and vegetation cover. Results are fairly similar however "Top Pasture" consistently shows more \% soil OC compared to the "Kanuka" site at all depths. Reasons for differences between the two sample sites again could largely be attributed to the differing vegetation with the "Kanuka" site being under permanent Kanuka forest and the "Top Pasture" site semi-improved pasture. Results are consistent with other research suggesting pasture to have greater amounts of soil carbon than other types of vegetation or land-uses (Savage, 2006; Tate et al. 2005).

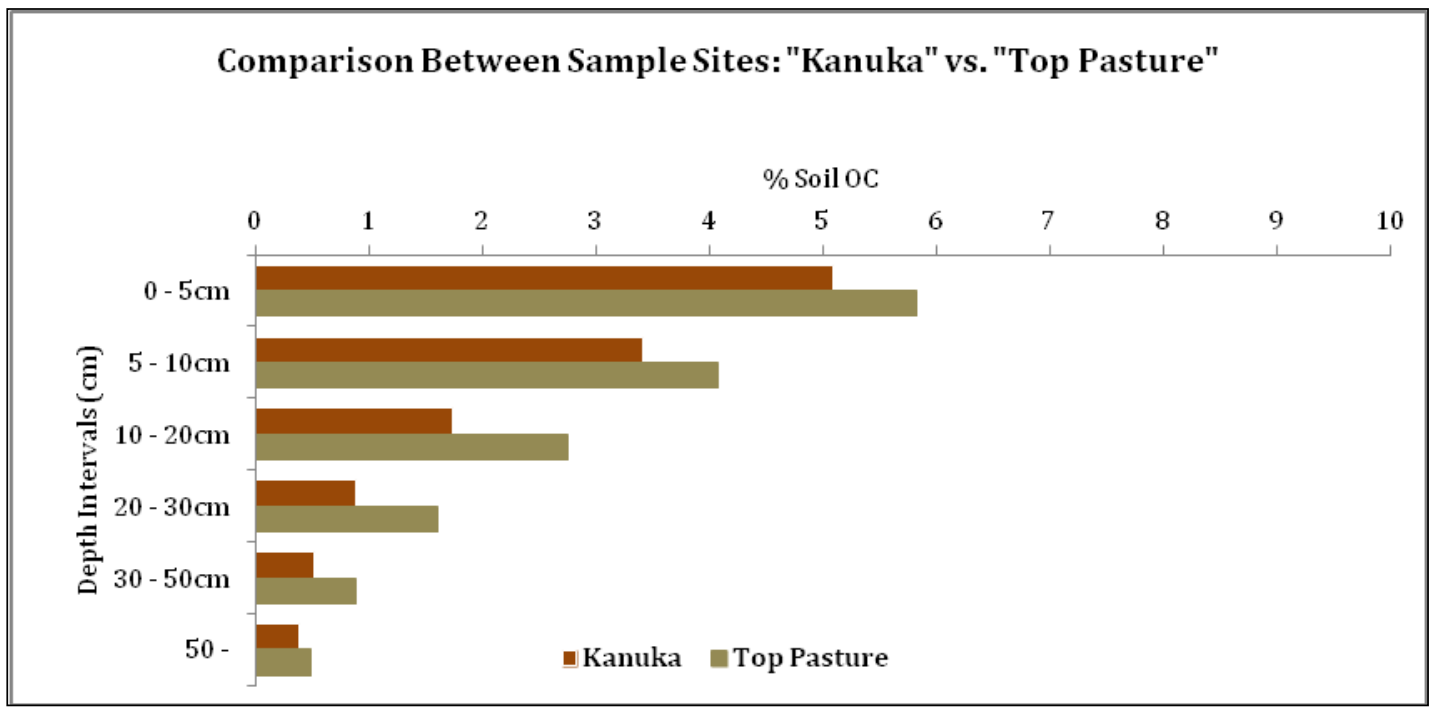

Figure 33. \% soil OC comparison between "Kanuka" vs. "Top Pasture".

Figure 34 compares the "Top Pasture" and "Bottom Pasture" samples sites. Both are identified as having the same vegetation cover according to the NZLRI, classified as being improved pasture or semi-improved pasture. However, there are notable differences in \% soil OC between the two sites. This could suggest that the underlying soils (Pedal Immature Pallic Soils + Weathered Orthic Recent Soils and Mottled-weathered Fluvial Recent Soils) may have more of an influence rather than vegetation or land-use. The "Top Pasture" site has significantly more \% OC in the upper $20 \mathrm{~cm}$ of the soil profile but evens out with depth and is more comparable to the "Bottom Pasture" site at depths greater 
than $20 \mathrm{~cm}$. Results follow expectations and with vegetation having more of an influence in the top layers and then a switch to soil type having the influence at depth. Other reasons for differing results could include location within the landscape. The location of the "Bottom Pasture" site could be an area of carbon accumulation with it being located at the bottom of a slope close to the river (with no evidence of erosion present). However results show the "Bottom Pasture" site to have less \% soil OC than the "Top Pasture" site suggesting position in the landscape in this case is less influential than soil type.

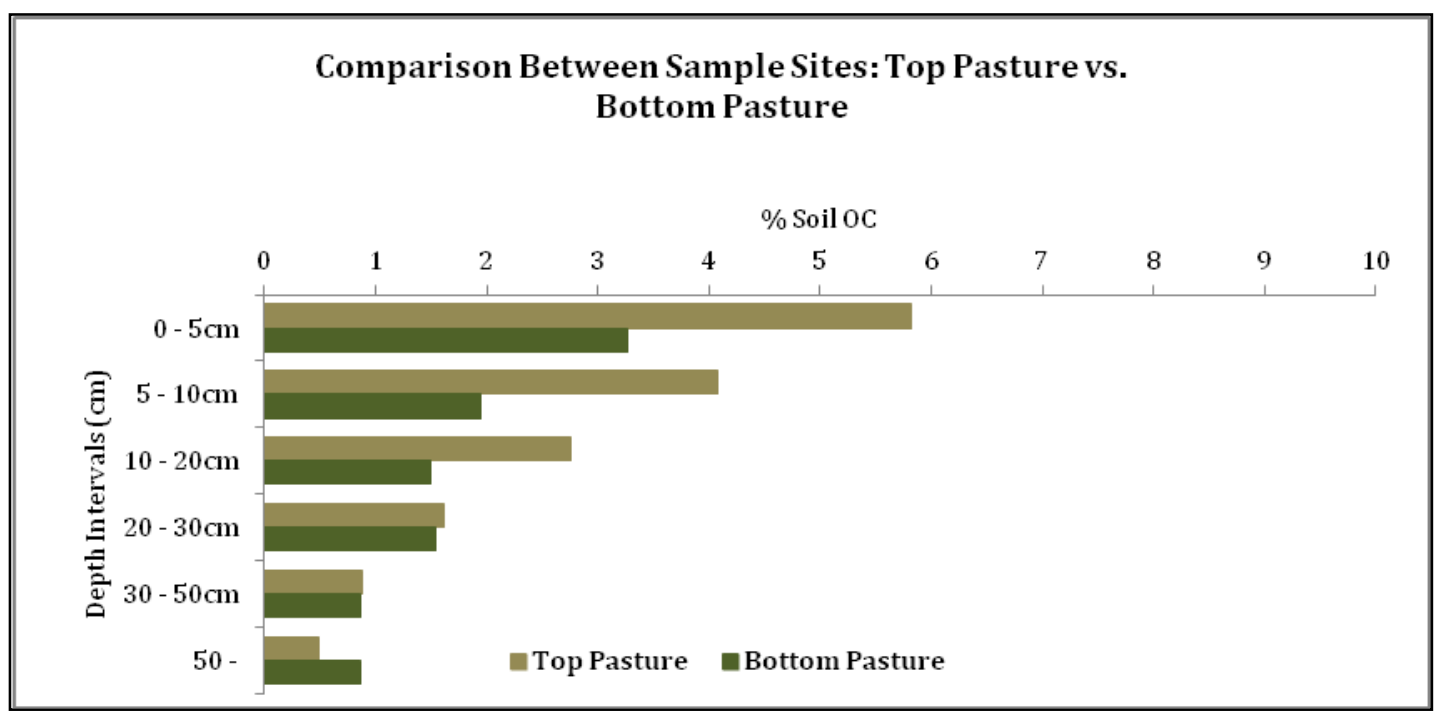

Figure 34. \% soil OC comparison between “Top Pasture” vs. "Bottom Pasture”.

\section{COMPARISONS BETWEEN CASE-STUDY PROPERTIES:}

Figure 35 compares the two sample sites "Flats" located at the Tikitiki casestudy property and "Bottom Pasture" located at the Willowbank case-study property. According to the NZLRI and field observations these sites are both classified as being 'Improved Pasture'. Figure 35 shows a large disparity between \% soil OC at the two different sites. The sites were subject to differing soil, climate and land-use characteristics, this once again reiterates the notable differences overall in soil OC between the two case-study properties and associated regions. 


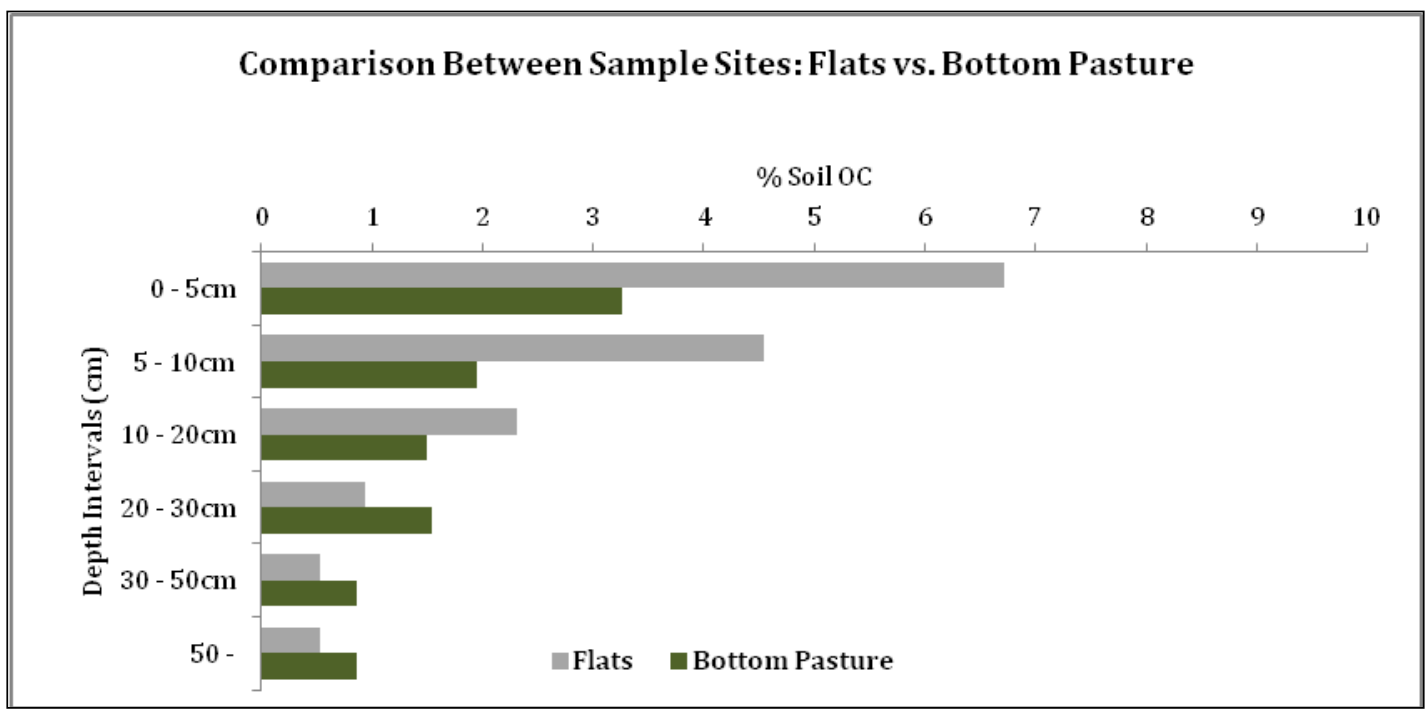

Figure 35. \% soil OC comparison between "Flats" vs. "Bottom Pasture".

Figure 36 compares the "Kanuka" and "Gorse" sample sites. Again they are located at different properties and both have different soil types, however both can be classified as being a type of scrub (dependent on age according to the NZLRI) so for carbon accounting may be treated similarly. "Gorse" at all depth intervals had significantly more \% soil OC with more than three times the "Kanuka" amount at the 30-50 cm depth. Differences between the two sites ("Kanuka" and "Gorse") will largely be attributed to the fact that they are located within different properties and are therefore subjected to differing conditions. However it is important to note that varying types of scrub (one land-use regime according to the NZLRI) can show notable differences in soil OC. 


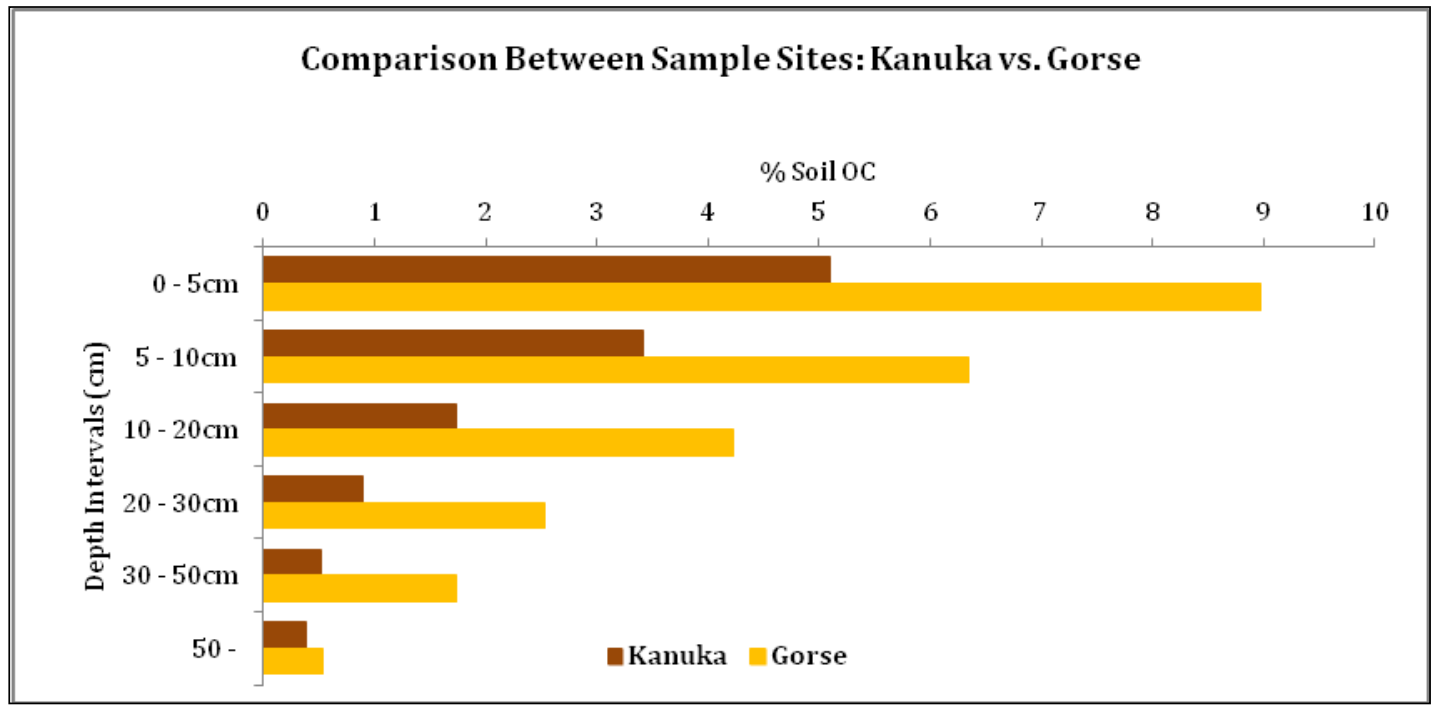

Figure 36. \% soil OC comparison between "Kanuka" vs. "Gorse".

\section{SOIL OC SUMMARY:}

From the soil OC results several preliminary conclusions can be drawn. The highest \% soil OC was recorded underneath gorse compared to any other landuse or vegetation type. Results strongly suggest that overall the Tikitiki casestudy property has significantly more soil OC within the subsurface compared to the lower results shown at the Willowbank case-study property. Both properties followed what was expected in terms of vertical distribution with the majority of soil OC being located in the top $20 \mathrm{~cm}$ of the soil profile and a substantial decline in content with increasing depth however, carbon at depth was still significant. Results showed that both soil type and vegetation/landuse can play differing roles on carbon within soil, the next section of this chapter will discuss particle size, results and associated functions that can also play a dominant role when it comes to soil $\mathrm{C}$ accumulation or loss within the subsurface. 


\subsection{MECHANICAL RESULTS - PARTICLE SIZE ANALYSIS AND TEXTURAL CHARACTERISTICS:}

The particle-size fractions (Table 11) used in the following soil descriptions are based on the Standards Association of New Zealand (1986) soil testing methods. Particle-size distribution refers to the proportions of both the coarse fraction (gravels) and the fine-earth (sand, silt and clay) fraction (Milne et al. 1991) however when dealing with soils the fine-earth fraction is dominant. The fineearth fraction was analysed using a Laser Particle Sizer (LPS) (refer to methods chapter and Appendix III) with the following figures displaying average textural proportions at each of the seven sample sites. All sample depths were processed for the Willowbank case-study property. At the Tikitiki case-study property only the $5-10 \mathrm{~cm}$ and $30-50 \mathrm{~cm}$ depth intervals were processed, results however still provide some information about relative textural composition.

\begin{tabular}{|c|c|}
\hline \multicolumn{2}{|c|}{ Particle-size fractions (mm) (Fine-earth fraction) } \\
\hline Clay & $<0.002$ \\
\hline Silt & $0.06-0.002$ \\
\hline Sand & $2.0-0.06$ \\
\hline
\end{tabular}

Table 11. Particle-size fractions according to the Standards Association of New Zealand (1986). Source: Milne $e t$ al. 1991. 
AVERAGE TEXTURAL PROPORTIONS TIKITIKI CASE-STUDY PROPERTY:

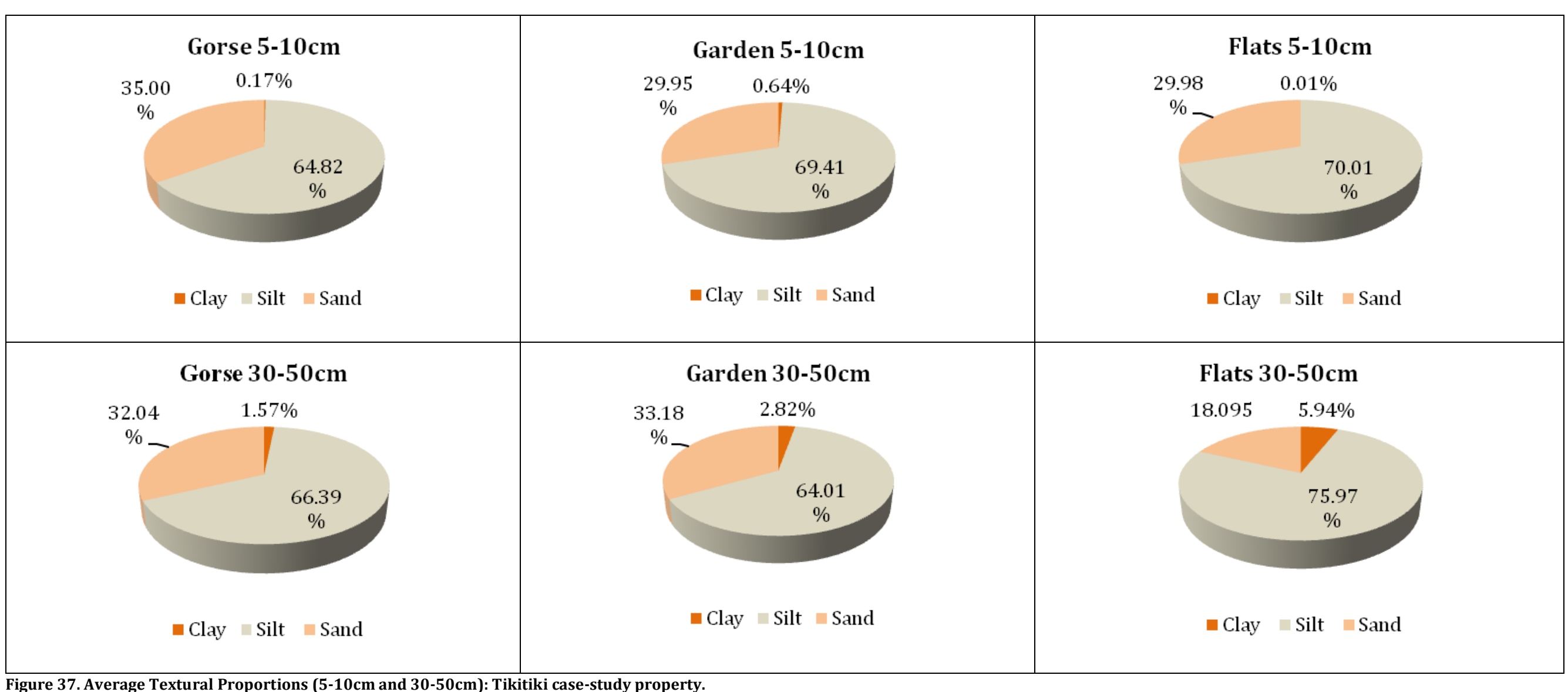




\section{AVERAGE TEXTURAL PROPORTIONS WILLOWBANK CASE-STUDY PROPERTY:}

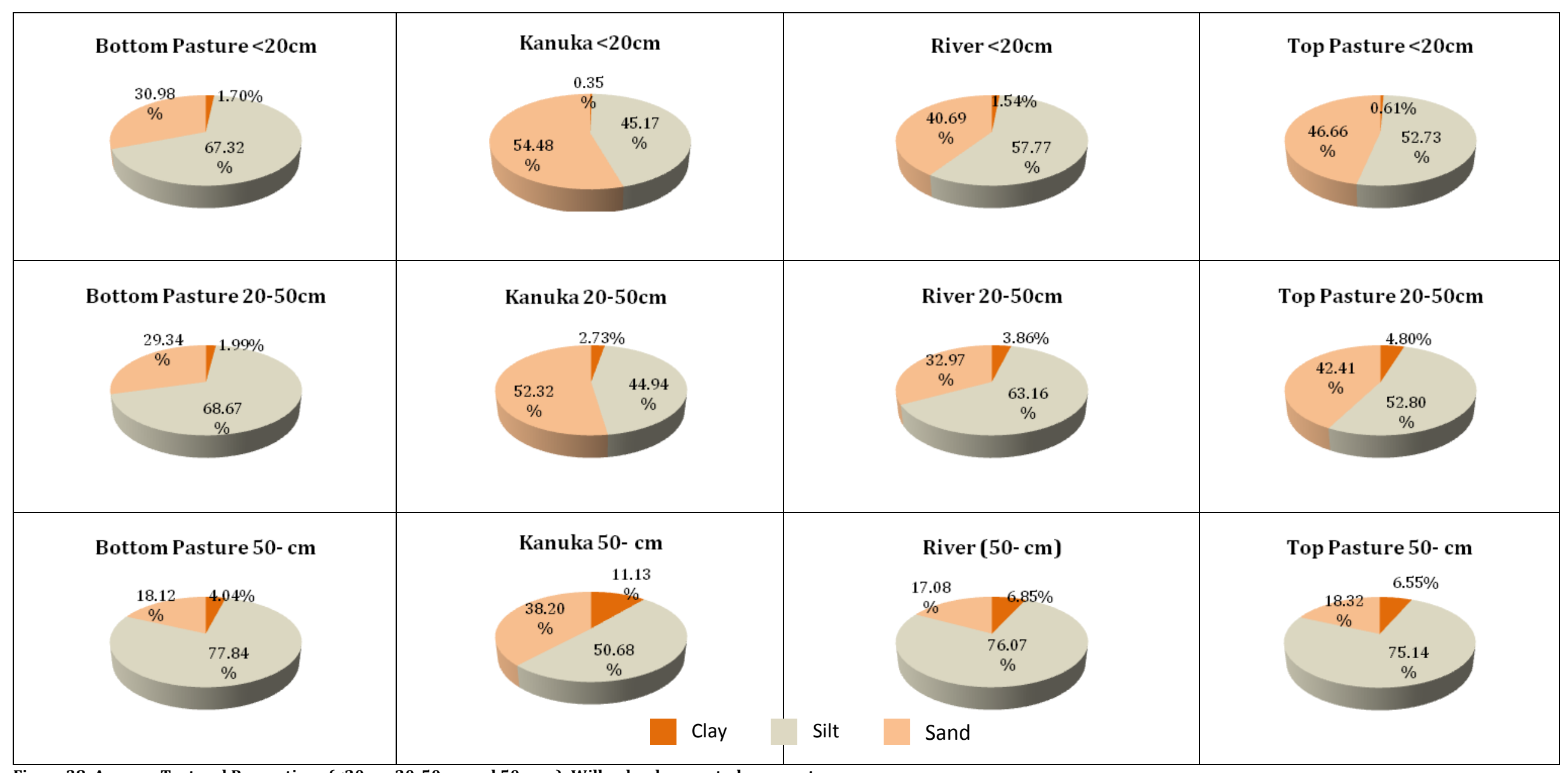

Figure 38. Average Textural Proportions $(<20 \mathrm{~cm}, 20-50 \mathrm{~cm}$ and $50-\mathrm{cm})$ : Willowbank case-study property. 
Overall results show a distinct range of particle sizes, however the majority of the sample sites are dominated by the silt fraction at all depth intervals. According to Milne et al. (1995) the previous particle size results all fall into the Loamy silt (LZ) texture class containing less than 18\% clay and between $40 \%$ and $82 \%$ silt. Samples of such soils contain subordinate amounts of clay, but sufficient silt to still give a smooth soapy feel (Milne et al. 1995). Loamy soils are often considered more favourable for growth compared to coarse sands or fine clays (Schipper \& Sparling, 2009) and therefore could prove favourable for soil OC sequestration potential. There are mixed opinions about the correlation between soil $\mathrm{OC}$ and clay content. Some research suggests clay content relates poorly to long-term soil organic C accumulation (Percival et al. 2000) where other research showed increases in soil OC with increasing clay content (Jobbagy \& Jackson, 2000). Results from this research showed no substantial evidence favouring either argument. Only small fractions of clay were recorded at both of the properties. When comparing the soil OC results with the textural proportions, no one site showed higher soil OC with increasing clay content.

\section{PARTICLE SIZE DISTRIBUTION/CLASSIFICATIONS:}

This section of the results chapter will look at the particle sizes and textural characteristics of the seven sample sites in forms suitable for use with established pedo-transfer functions allowing associated hydraulic characteristics to be estimated. These results follow the standards set out by the United States Department of Agriculture (USDA) and are as follows:

\begin{tabular}{|c|c|}
\hline \multicolumn{2}{|c|}{ Particle-size fractions $(\mathbf{m m})$ (Fine-earth fraction) } \\
\hline Clay & $<0.002$ \\
\hline Silt & $0.05-0.002$ \\
\hline Sand & $2.0-0.06$ \\
\hline
\end{tabular}

Table 12. Particle size fractions following the USDA soil standards 


\section{TERNARY PLOTS:}
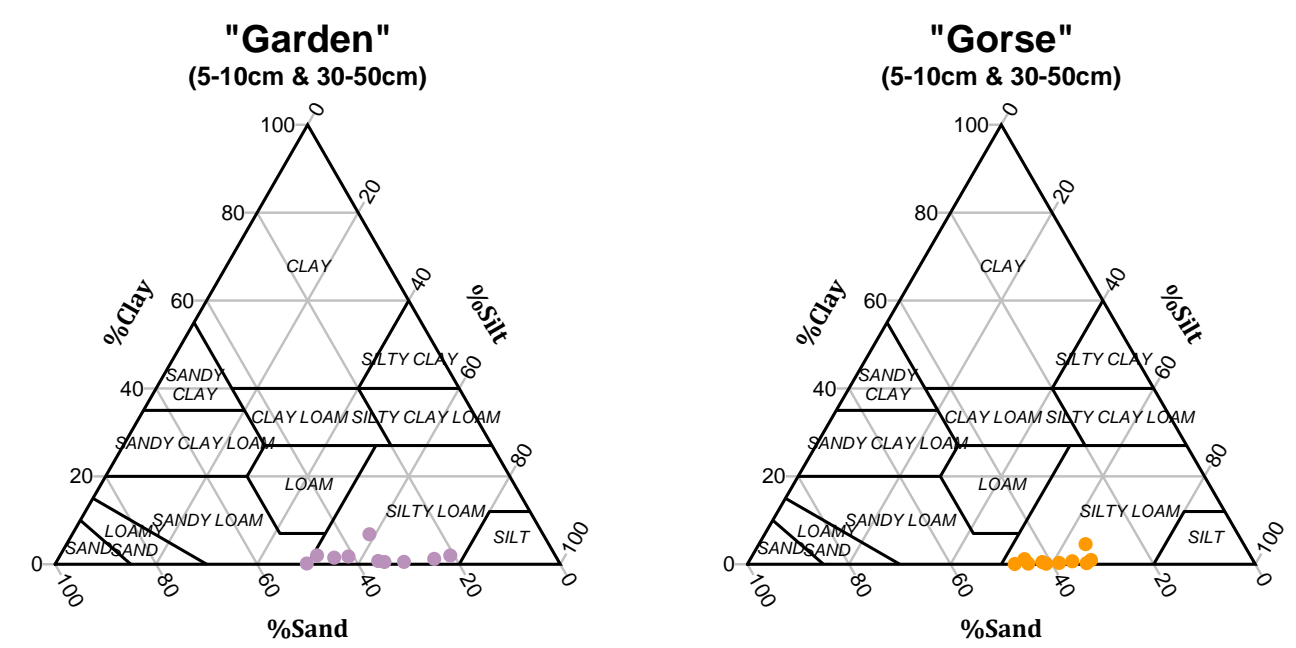

"Flats"

$(5-10 \mathrm{~cm} \& 30-50 \mathrm{~cm})$

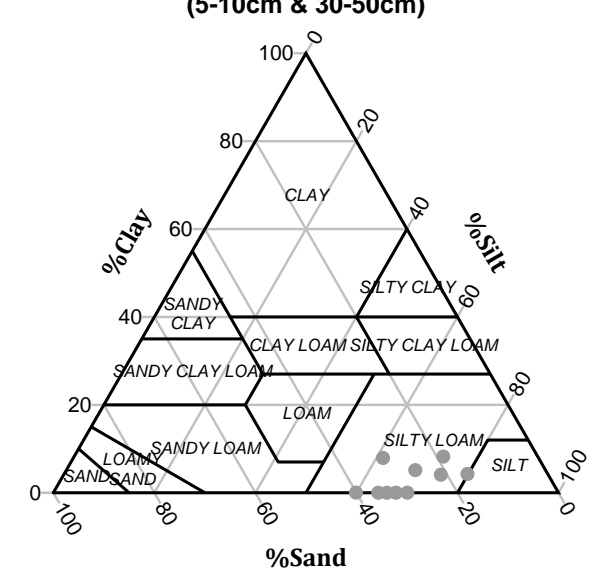

"Bottom Pasture"

$(0-5 \mathrm{~cm}, 5-10 \mathrm{~cm}, 10-20 \mathrm{~cm}, 20-30 \mathrm{~cm}, 30-50 \mathrm{~cm} \& 50-\mathrm{cm})$

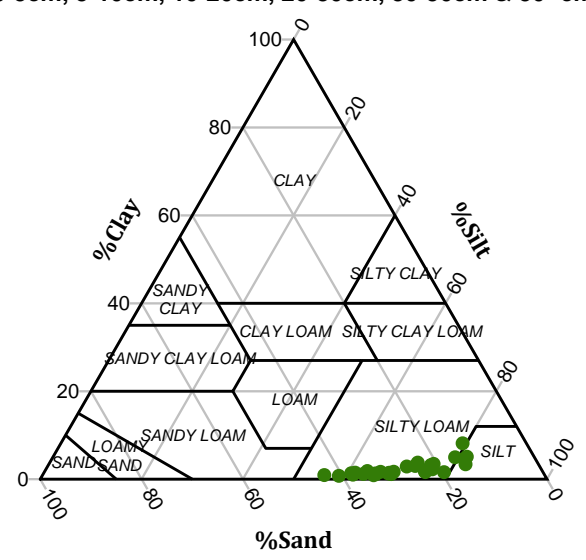

"Top Pasture"

$(0-5 \mathrm{~cm}, 5-10 \mathrm{~cm}, 10-20 \mathrm{~cm}, 20-30 \mathrm{~cm}, 30-50 \mathrm{~cm} \& 50-\mathrm{cm})$

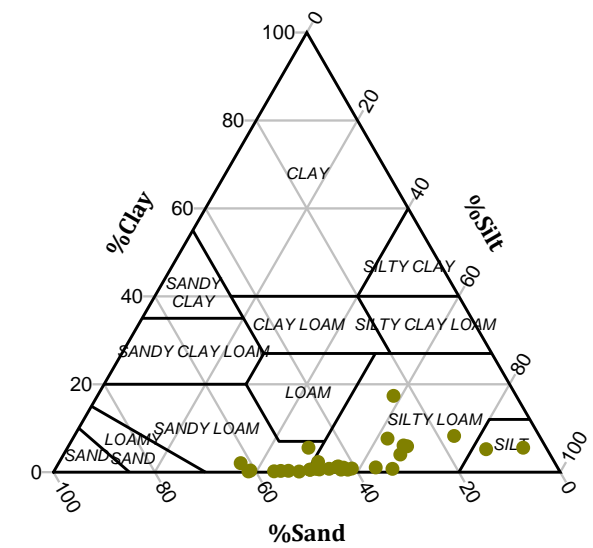

"Kanuka"

$(0-5 \mathrm{~cm}, 5-10 \mathrm{~cm}, 10-20 \mathrm{~cm}, 20-30 \mathrm{~cm}, 30-50 \mathrm{~cm} \& 50-\mathrm{cm})$

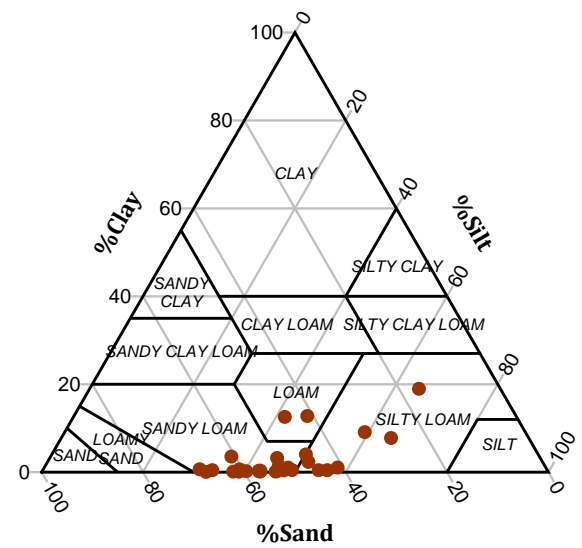

"River"

(0-5cm, $5-10 \mathrm{~cm}, 10-20 \mathrm{~cm}, 20-30 \mathrm{~cm}, 30-50 \mathrm{~cm}, \& 50-\mathrm{cm})$

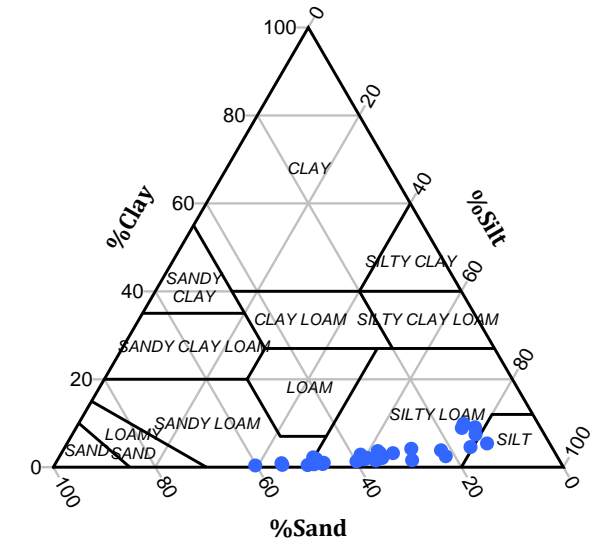

Figure 39. Ternary plots showing USDA textural classifications at each of the seven sample sites. 
Figure 39 show the grain-size results from the sampled soil. The graphs display the samples relative to the USDA soil classifications, dividing the plot into the 12 regions of USDA specified soil textures. The LPS results were again split into specified fractions according to the USDA definitions (sand, silt, and clay). Again, sediment sizes were largely silt dominated at both properties. Samples are classified as silty loams according to the USDA textural classification scheme.

Results showed little difference between the New Zealand standard soil testing methods (1986) or the USDA textural classification scheme in terms of describing the particle sizes and textural results. The only difference being the silt and sand fractions between the two systems. Samples were either classified as Loamy Silts (New Zealand standard) or Silty Loams (USDA) dependent on the classification followed.

\section{SOIL-WATER CHARACTERISTICS:}

The determination of a soils texture is particularly important for understanding soil hydraulic properties and can have a huge influence on functions such as porosity, infiltration, and available water holding capacities. Textural proportions (\% sand, \% silt, and \% clay), soil OC, and bulk density were used as input for the Saxton \& Rawls (2006) pedo-transfer function subsequently providing estimated available water capacities (appendix IV) and saturated hydraulic conductivity as output (see appendix IV for further details). 

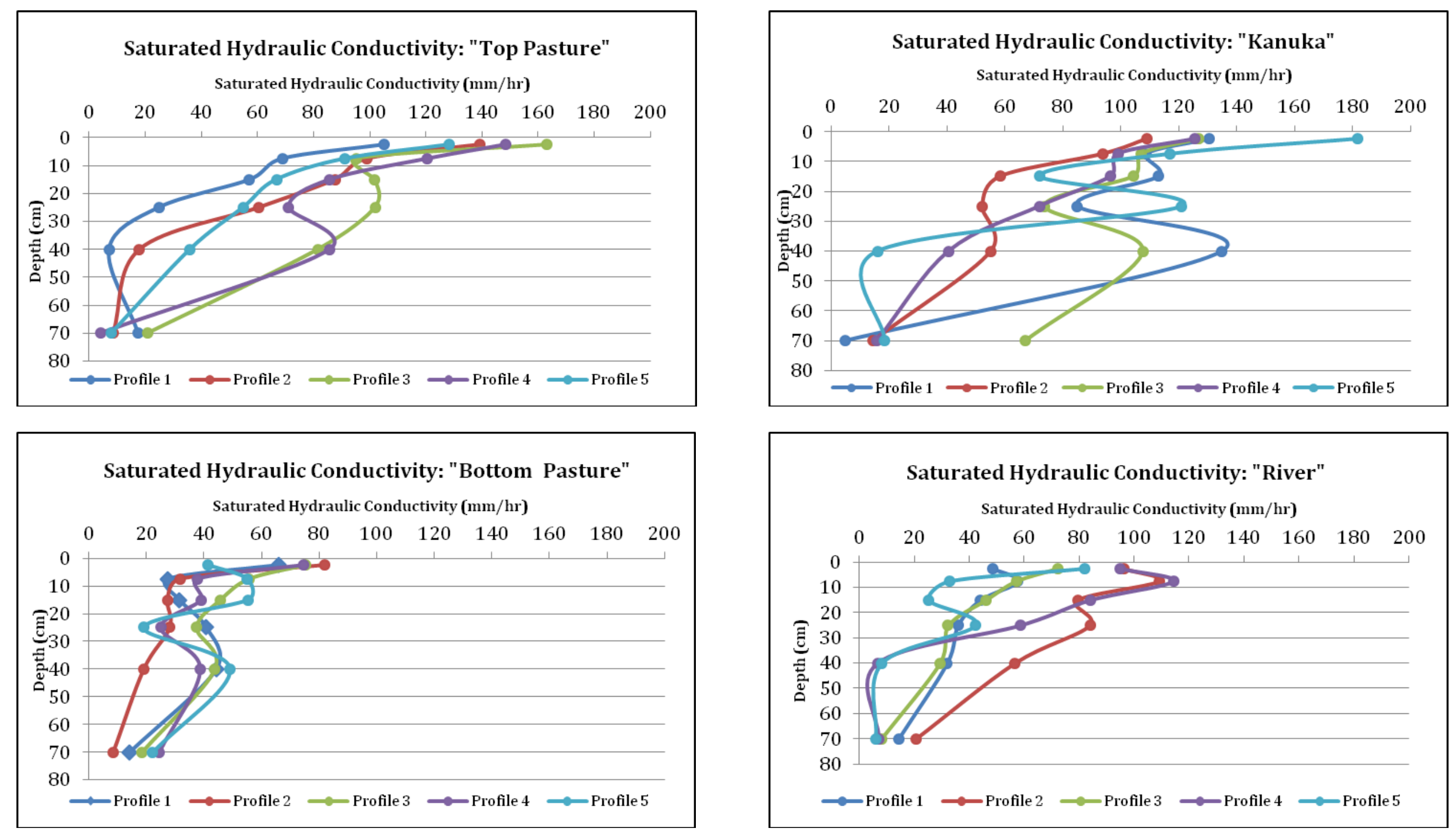

Figure 40. Saturated Hydraulic Conductivity: Willowbank case-study property 
Soil water retention depends largely on the proportion of textural components and the amount of soil OC present, although other properties such as bulk density and structure also have an influence. Increases in carbon content generally lead to an increase in water retention if all else is close to equal (Rawls et al. 2003). On average textural results were similar within and between the two case-study properties, therefore we could expect differences in soil OC at each of the sites to correlate well with changes in saturated hydraulic conductivity. At the Tikitiki case-study property (sampling of the pedo-transfer measurements only take place at two depths due to time constrains in the field, refer to appendix IV for further information), the Saxton and Rawls (2006) relationship suggested sample sites "Garden" and "Gorse" had higher saturated conductivity results compared to the lower "Flats" samples. The "Garden" and "Gorse" samples sites were also higher in overall soil OC compared to the "Flats" sample site. At the Willowbank case-study property samples sites "Top Pasture" and "Kanuka" showed relatively similar saturated conductivity results, with results being higher (particularly in the upper profile) than results at the bottom two sites "Bottom Pasture" and "River". Once again the two upper sites ("Top Pasture" and "Kanuka") showed higher overall soil OC results compared to the two bottom sites ("Bottom Pasture" and "River").

\section{NZFSL COMPARISIONS:}

Results from New Zealand's fundamental soil layer (NZFSL) report organic matter content down to $20 \mathrm{~cm}$. It is important to note that organic matter $(\mathrm{OM})$ and organic carbon (OC) are often confused and used interchangeably (Pluske et al. 2010). For the purpose of making the results from this research more comparable with the attributes present within the NZFSL a conversion equation was applied to convert soil OC to soil OM. Soil OC results were multiplied by a factor of 1.72 (Pluske et al. 2010).

After integrating the top three depth intervals from this research $(0-5 \mathrm{~cm}, 5$ $10 \mathrm{~cm}$ and $10-20 \mathrm{~cm}$ ) results show average soil $O C \leq 20 \mathrm{~cm}$. Table 13 and Table 
14 show that all seven sample sites fall between the CARBON_MIN and CARBON_MAX values given under the NZFSL. Blakemore et al. (1987) however, point out that some New Zealand soils exhibit substantial nutrient enrichment of their top-soils largely as a result of the active organic cycle evident under forest and permanent pasture systems. Because of this ranges of the ratings are sometimes over-weighted (Blakemore et al. 1987). This may be the reason for the low to mid range results evident at the two case-study properties.

\begin{tabular}{|c|c|c|c|c|c|}
\hline \multicolumn{2}{|c|}{} & \multicolumn{3}{c|}{ According to NZFSL } \\
\hline $\begin{array}{c}\text { Sample Site } \\
\text { Identification }\end{array}$ & $\begin{array}{c}\text { \% } \\
\text { OC_AVERAGE } \\
(<20 \mathrm{~cm})\end{array}$ & $\begin{array}{c}\text { \% OM } \\
(\text { OC } \times 1.72)\end{array}$ & $\begin{array}{c}\text { CARBON_MAX } \\
(0-0.2 \mathrm{~m})\end{array}$ & $\begin{array}{c}\text { CARBON } \\
\text { _MIN } \\
(0-0.2 \mathrm{~m})\end{array}$ & $\begin{array}{c}\text { CARBON_ } \\
\text { CLA }\end{array}$ \\
\hline Garden & & & & & \\
\hline$\leq 20 \mathrm{~cm}$ & $\mathbf{5 . 1 4}$ & $\mathbf{8 . 8}$ & 9.9 & 4 & Medium (3) \\
\hline Gorse & & & & & \\
\hline$\leq 20 \mathrm{~cm}$ & $\mathbf{5 . 9 5}$ & $\mathbf{1 0 . 2}$ & 9.9 & 4 & Medium (3) \\
\hline Flats & & & & & \\
\hline$\leq 20 \mathrm{~cm}$ & $\mathbf{3 . 9 7}$ & $\mathbf{6 . 8}$ & 9.9 & 2 & Medium (3) \\
\hline
\end{tabular}

Table 13. Integrated soil OC $(\leq 20 \mathrm{~cm})$ results compared with attributes from the NZFSL: Tikitiki case-study property.

\begin{tabular}{|c|c|c|c|c|c|}
\hline \multirow[b]{2}{*}{$\begin{array}{l}\text { Sample Site } \\
\text { Identification }\end{array}$} & \multirow[b]{2}{*}{$\begin{array}{c}\text { OC_AVERAGE } \\
(<20 \mathrm{~cm})\end{array}$} & \multirow[b]{2}{*}{$\begin{array}{c}\text { \% OM } \\
\text { (OC x 1.72) }\end{array}$} & \multicolumn{3}{|c|}{ According to NZFSL } \\
\hline & & & $\begin{array}{c}\text { CARBON_MAX } \\
(0-0.2 \mathrm{~m})\end{array}$ & $\begin{array}{c}\text { CARBON_ } \\
\text { MIN } \\
(0-0.2 \mathrm{~m})\end{array}$ & $\begin{array}{l}\text { CARBON } \\
\text { _CLA }\end{array}$ \\
\hline \multicolumn{6}{|l|}{$\begin{array}{l}\text { Bottom } \\
\text { Pasture }\end{array}$} \\
\hline$\leq 20 \mathrm{~cm}$ & 2.05 & 3.5 & 19.9 & 2 & Medium \\
\hline \multicolumn{6}{|l|}{ Top Pasture } \\
\hline$\leq 20 \mathrm{~cm}$ & 3.85 & 6.6 & 9.9 & 2 & Low (4) \\
\hline \multicolumn{6}{|l|}{ River } \\
\hline$\leq 20 \mathrm{~cm}$ & 2.33 & 4.0 & 19.9 & 2 & Medium \\
\hline \multicolumn{6}{|l|}{ Kanuka } \\
\hline$\leq 20 \mathrm{~cm}$ & 2.99 & 5.1 & 9.9 & 2 & Low (4) \\
\hline
\end{tabular}

Table 14. Integrated soil $0 \mathrm{C}(\leq 20 \mathrm{~cm})$ results compared with attributes from the NZFSL: Willowbank case-study property.

${ }^{4}$ Carbon attributes (CARBON_MAX, CARBON_MIN reported in OM not OC, \& CARBON_CLA) defined in Appendix II. 
From Table 13 and Table 14, the national scale data suggests the two case-study properties are comparable in terms of soil OC or OM content within the soil. According to the NZLRI and the NZFSL each of the sites within the two properties are classified as having either a low or a medium carbon class. However, this generalisation is very coarse, previous results showed significant differences between and across the two case-study properties, and also variation within sample sites. These differences are not picked up by the often extrapolated broad scale national data available through GIS. A major discrepancy between the NZFSL and the results of this research is that the sites "Top Pasture" and "Kanuka" are classified as having a low carbon class (according to the NZFSL) and "Bottom Pasture" and "River" are classified as having a medium carbon class (according to the NZFSL), hence the last two are assigned a higher maximum value to their range. However, results from this research show the sample sites "Top Pasture" and "Kanuka" overall are higher in soil OC than the sample sites "Bottom Pasture" and "River". How these differences affect decision support tools such as Polyscape will be discussed further on in the chapter.

\section{POLYSCAPE OUTPUT:}

Polyscape, a GIS based decision support toolbox, aims to look at spatial impacts of landscape changes and decisions from several different environmental and social perspectives (Jackson et al. 2010). For the purposes of this research we consider the Polycape layers looking at farm

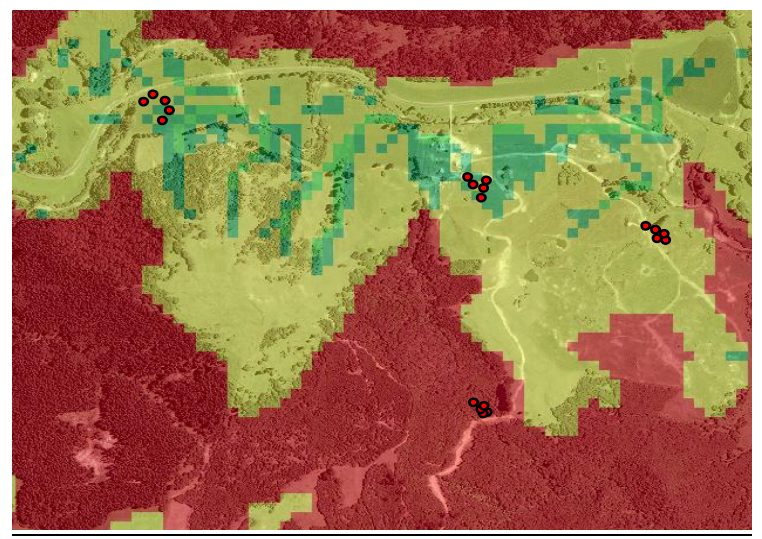
Figure 41. Colour scheme produced using the polyscape tool (colours become altered once overlaid on aerial photographs etc...) impact and hydrological impact of land-use change. These are viewed alongside carbon stocks and opportunity suggested by the national scale data. Polyscape has largely been designed to consider impacts on biodiversity, hydrology (e.g. 
risk of flood and droughts), erosion and socio-economic impacts of changes in land-use and management structures and can be implemented at several spatial scales. Algorithms within Polyscape are designed to include explicit consideration of the spatial location of various soils and land cover types within a specified catchment. Polyscape is computationally efficient with scenario impacts able to be generated within a few minutes (Jackson et al. 2010). Polyscape operates on a traffic light system which is outlined below, colours include:

- Green which highlights high opportunities for positive change,

- Red highlights existing utility (be wary of change) and,

- Orange represents marginal services or identifies one or more tradeoffs between ecosystem services (there are also options for 3 and 5 colour displays with the addition of dark red/green) (Jackson et al. 2010).

The following figures (Figure 42 through to Figure 49) is the output generated using the tool Polyscape. These figures and associated layers were created using New Zealand's underlying national scale soil, vegetation, and land-use data specific to the two case-study properties. Jackson et al. (2010) include further information surrounding the application of Polyscape and in particular underlying data and assumptions used to produce the presented output. 
POLYSCAPE OUTPUT: SOIL CARBON OPTIONS LAYER

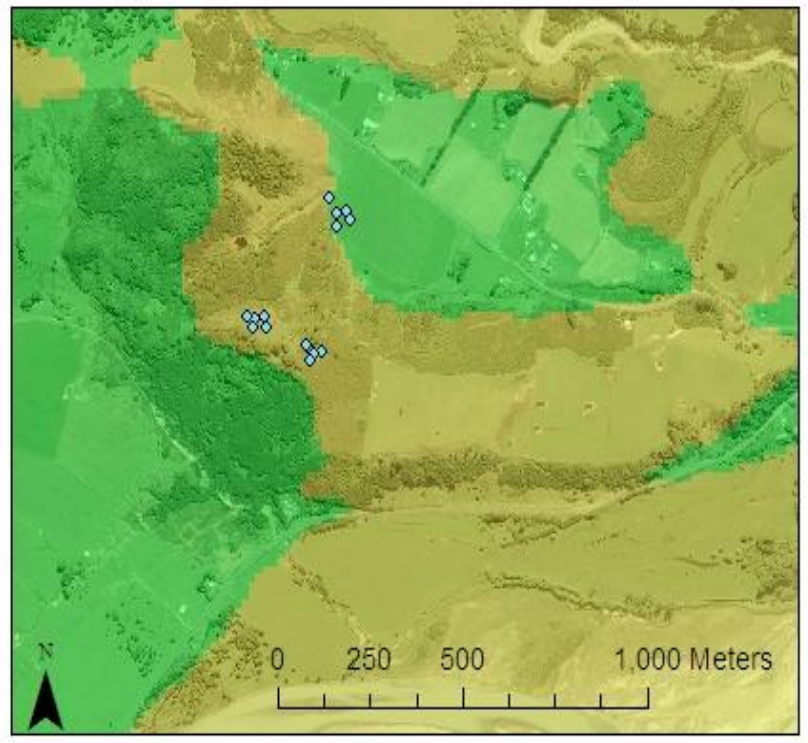

Legend

- Sample Locations

Moderate existing carbon stock

Lowexisting carbon stock

Figure 42. Soil carbon options layer Tikitiki case-study property

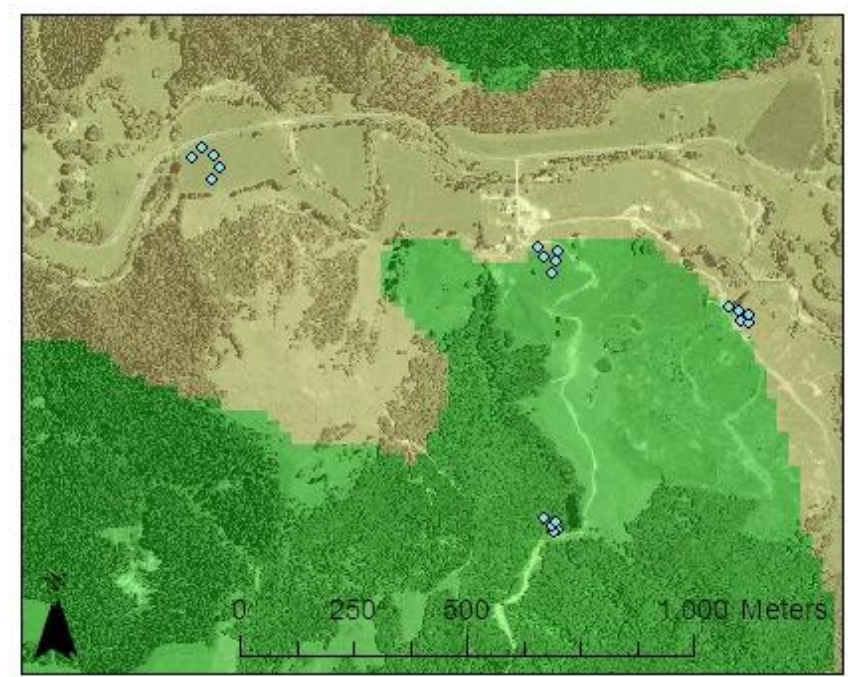

Legend

Sample Locations

- Sample Locations

High existing carbon stock

Moderate existing carbon stock

Low existing carbon stock

Figure 43. Soil carbon options layer Willowbank case-study property. 


\section{SOIL CARBON OPTIONS LAYER:}

Figure 42 represents the soil carbon options layer for the Tikitiki case study property. This layer highlights both high carbon stocks where preservation should be focus and also areas with high opportunity for more carbon. The colours green and yellow represent carbon mid-point values between CARBON_MIN and CARBON_MAX values according to NZFSL. Spatial information from the carbon output layer is rudimentary however due to the coarse underlying data; but does highlight differences in soil carbon at the Tikitiki case-study property in keeping with results from the field research. The colour yellow represents areas that already have moderate amounts of carbon within the soil. The colour green highlights areas in the landscape that have potential for more carbon to be stored within the soil. Both the "Garden" and "Gorse" sample sties were located within the yellow area identified by Polyscape and the "Flats" samples located within the green area. Overall the "Flats" samples had less soil OC compared to the "Garden" and "Gorse" samples and therefore have more potential to sequester additional carbon.

Figure 43 represents the soil carbon options layer for the Willowbank casestudy property. Like the Tikitiki property the colours green and yellow represent mid-point carbon values (Total upper-profile carbon) between CARBON_MIN and CARBON_MAX according to NZFSL. "Bottom Pasture" and "River" showed less soil OC compared to the other two samples sites "Top Pasture" and "Kanuka". According to the national scale data the green areas have higher opportunity for change or opportunity for additional carbon. "Top Pasture" and "Kanuka" sample sites had more soil carbon but they also have more potential to add additional carbon than the two lower sites ("Bottom Pasture" and River"). 


\section{POLYSCAPE OUTPUT: FARM IMPACT/PRODUCTIVITY LAYER}

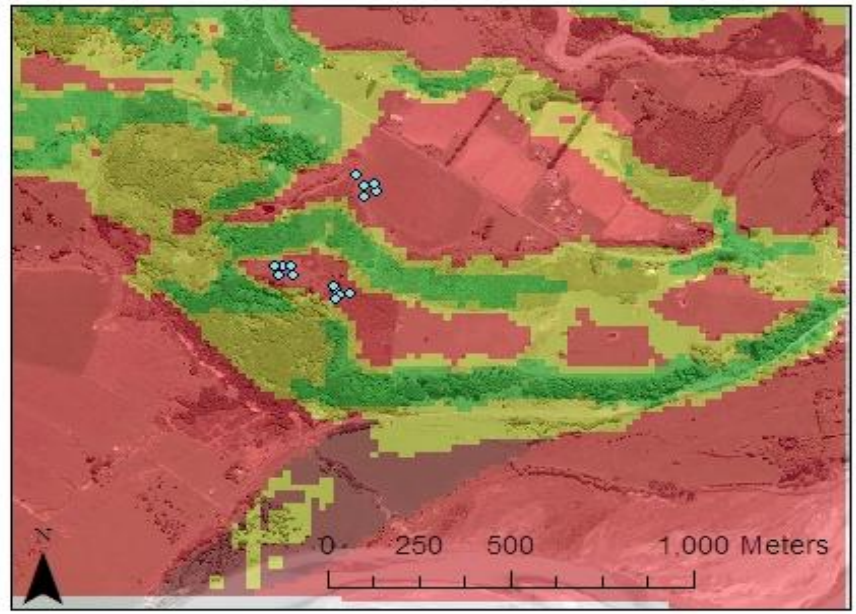

Legend

- Sample Locations

very high agricultural value

High agricultura I value

$M$ arginal agricultural value

No agricultural value

Figure 44. Farm impact/productivity layer Tikitiki case-study property.

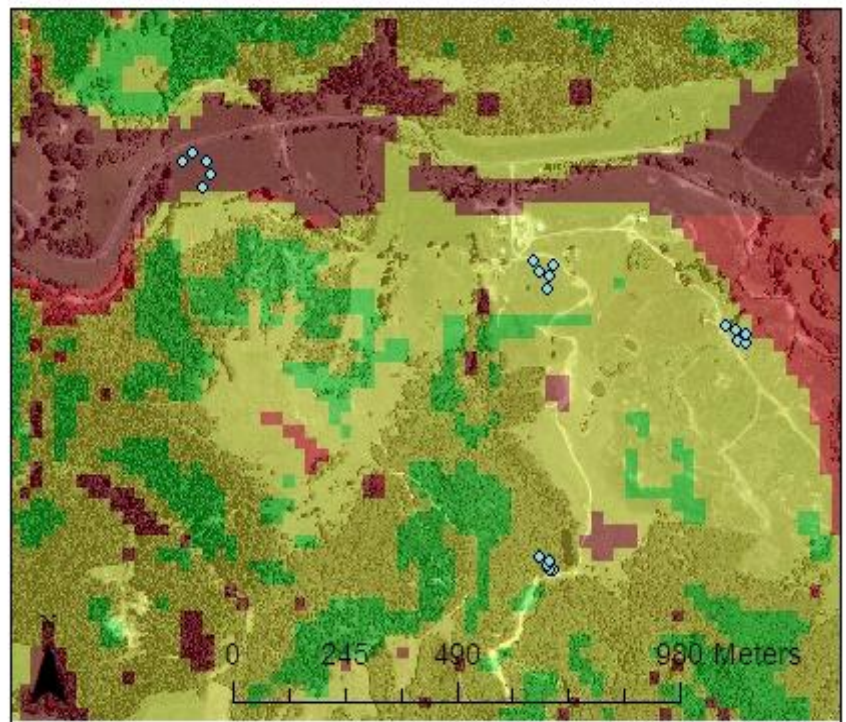

Legend

- Sample Locations

Very high agricultural value

High agricultural value

Marginal agricultural value

No agricultural value

Figure 45. Farm impact/productivity layer Willowbank case-study property. 


\section{FARM IMPACT/PRODUCTIVITY LAYER:}

Figure 44 is an example of the farm impact or productivity layer produced by Polyscape. This layer follows simple rules based on slope, land-use and water regime (Jackson et al. 2010) and the identification of areas where interventions or a change may provide multiple benefits are highlighted by the different colour schemes (red, orange and green). This layer indicates (using the colour red) areas that are clearly undesirable for a change (i.e. planting or other interventions) due to the agricultural value at present. At the Tikitiki casestudy property the land that has been cleared at the top of the property and is now used for organic cropping is clearly indicated in red as are the bottom flats, indicating high existing value. Orange suggests marginal opportunity for change with the green areas representing a high opportunity for positive change and therefore should be targeted first.

Figure 45 is the output for the farm impact or productivity layer for the Willowbank case-study property. This shows the "Bottom Pasture" and flat areas in close proximity to the river as areas of high agricultural value (indicated in red) with smaller patches of red scattered throughout the rest of the property. These areas have been identified (according to the Polyscape tool) as areas with the most productivity potential, the impact of land management change on productivity to be considered alongside carbon sequestration and other ecosystem service impacts. 
POLYSCAPE OUTPUT: FLOOD MITIGATION LAYER

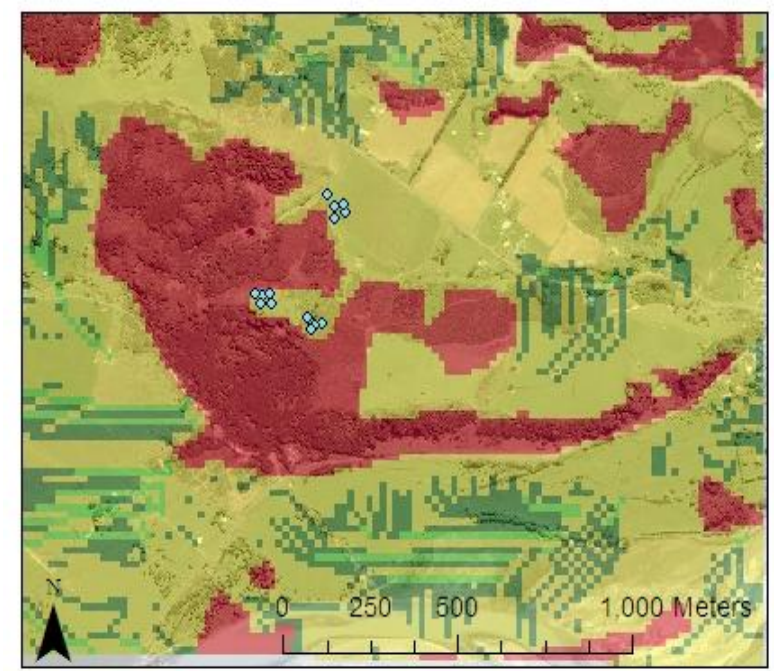

Legend

- Sample Locations

Flood mitigating features

Negligible impact

Flood generating land

Severe flood generating land

Figure 46. Flood mitigation layer Tikitiki case-study property.

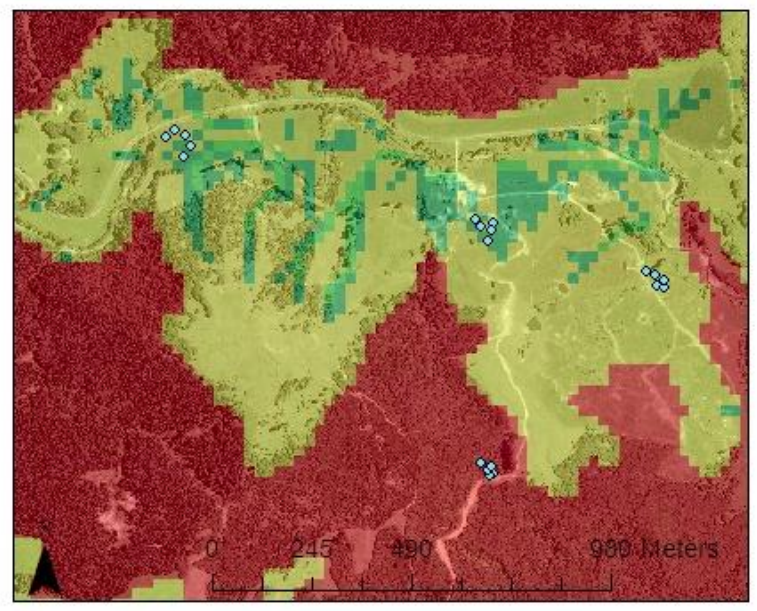

Legend

- Sample Locations

Flood mitigating features

Negligible impact

Flood generating land

Severe flood generating land

Figure 47. Flood mitigation layer Willowbank case-study property. 


\section{FLOOD MITIGATION LAYER:}

The hydrological or flood mitigation output layer of the Polyscape tool predominantly looks at flood mitigation using a flow accumulation algorithm that is modified by soil type and land cover (Jackson et al. 2010). Figure 46, shows the results of the hydrological output layer for the Tikitiki case-study property. The areas in red are already providing some sort of benefit with the red indicating some sort of flood mitigating function (for example the presence of trees or other flow sinks). Yellow indicates areas that may be flood generating but not concentrating with green suggesting areas of saturation showing the occurrence of flow paths and bottlenecking where these flow paths meet. Therefore the areas of high priority (because of high flows) that should be targeted are the areas shown in light green.

Figure 47 shows the results of the hydrological output layer for the Willowbank case-study property. As at the Tikitiki property, the areas already with trees or other flow sinks and are therefore providing some sort of hydrological benefit are shown in red. Yellow indicates areas that maybe flood generating but not concentrating. Finally green suggests areas of saturation showing the occurrence of preferential flow paths and bottlenecking where these flow paths meet. These green areas are the areas that should be targeted for change and are considered high priority because of high flows and the likeliness of excess saturation. Therefore targeting these green areas for additional carbon storage would be most beneficial in terms of flood mitigation and increasing carbon sequestration potential. 
POLYSCAPE OUTPUT: HYDROLOGICAL WORST CASE SCENARIO

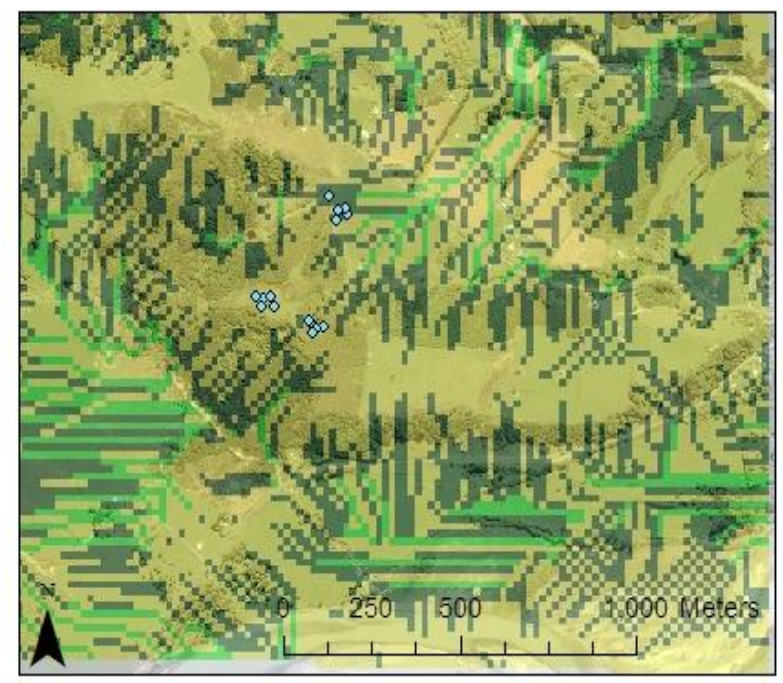

Legend

- Sample Locations

Negligible impact

Flood generating land

severe flood generating land

Figure 48. Hydrological worst case scenario layer Tikitiki case-study property.

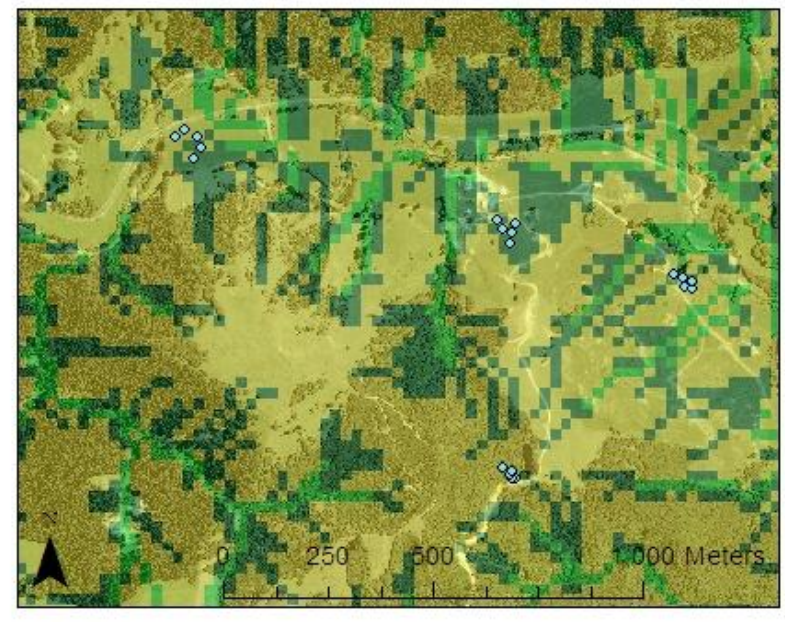

Legend

- Sample Locations

Neg ligible impact

Flood generating land

severe flood generating land

Figure 49. Hydrological worst case scenario layer Willowbank case-study property. 


\section{HYDROLOGICAL WORST CASE SCENARIO LAYER:}

Figure 48, shows the hydrological worst case scenario output of Polyscape at the Tikitiki case-study property. This layer indicates what would happen if all mitigating elements (e.g. trees, farm dams etc) are removed. Figure 48 shows existing landscape features are providing a benefit in terms of flood mitigation capacity. If existing utilities were removed i.e. trees or farm dams, the likeliness of excess saturation and flooding potential would increase.

Figure 49, like the results from the Tikitiki output looks at what would happen when all mitigating elements are removed at the Willowbank case-study property. The hydrological worst case scenario output gives an indication of how important the existing utilities are and what role they are playing in terms of flood mitigating functions and capacity. Clearly the existing utilities (trees or farm dams) are providing some sort of benefit with Figure 48 and Figure 49 highlighting the major preferential flow paths and areas of saturation if these utilities were removed.

\section{SUMMARY:}

The previous output looked not only at results from carbon sequestration potential but also other spatially explicit outcomes (hydrology and agricultural productivity). Decision support tools such as Polyscape that have the capacity to 'trade-off' certain elements against one-another will prove extremely powerful in the context of sustainable management and approaching land management more holistically. Polyscape was able to identify areas of the landscape where carbon sequestration might be particularly beneficial, particularly in areas that are less productive and therefore have 'less to lose' and more to gain and where flood mitigation capabilities might be enhanced. Once tradeoffs between other options are made a more target focused approach to planting or the positioning of specific utilities means that the user gains the best possible benefit from the decided change. 
This idea of multiple co-benefits and the use of decision support tools such as Polyscape that can be used in the wider context of sustainable management decisions will be discussed throughout the next chapter. 


\subsection{INTERPRETATION, DISCUSSION AND CONCLUSIONS:}

The preceding chapters have presented a review of nationally available soil data and results from both chemical (soil OC) and physical (particle size and hydraulic properties) analysis of the soil samples taken from the two case-study properties (Tikitiki and Willowbank). The previous chapter discussed spatial distribution and quantification of soil OC at each of the case study properties. Notable trends and relationships evident are summarised further within this chapter.

This research focused on soil carbon stocks and soil hydraulic properties within several different soil types and vegetation covers/land-uses in two significantly different case-study properties in the Gisborne/East-Cape region of New Zealand. Differences in results, along with interactions between soil type, vegetation and land-use were explored and discussed in the broader scale context of carbon sequestration potential, environmental co-benefits of increased carbon in the soil and overall sustainability.

This chapter summarises research outcomes and observed trends, firstly looking at soil OC trends within and between the two properties and the relationships surrounding differences in vegetation cover and land-uses. Soil textural and structural differences and corresponding hydraulic properties will also be discussed. Comparisons between New Zealand's available soil data relevant to the two case study properties and the results from this research will be then be reviewed. Reintroduction of the aim, objectives and associated conclusions will then conclude the chapter.

Distribution of soil carbon is not random and to some extent can be predicted or estimated, being influenced by factors such as underlying parent material, 
inherent soil properties (texture and structure), soil management, and vegetation cover/land-use. This generalisation holds true at both the Tikitiki and Willowbank case-study properties. If we can better understand the factors that contribute to carbon fate within soil we can better identify and predict areas of opportunity for increased sequestration or areas with high carbon stocks that may merit protection.

\section{DIFFERENCES/SIMILARITES IN SOIL OC, VEGETATION AND LAND USES:}

Both differences and similarities were evident within and between the two case-study properties. Increasing depth at both the Tikitiki and Willowbank properties saw a decline in soil OC, in line with expectations. However, the Tikitiki case study property had notably higher soil OC results overall and at depth compared to results from the Willowbank case-study property. This is thought to largely be a result of the underlying parent material at each of the properties. Within the Tikitiki property two of the sample sites ("Garden" and "Gorse") were identified as Typic Orthic Allophanic (LOT) soils. These soils are typically derived from North Island volcanic ash (Allophanic) and from the weathering products of other volcanic rocks. Typic Orthic Allophanic soils commonly have significant amounts of organic matter (8- 15\%) (Schipper \& Sparling, 2009) and therefore higher soil OC concentrations. Samples taken from locations ("Garden" and "Gorse") underlain by Typic Orthic Allophanic soils gave the highest soil OC results out of all of the seven sample sites from this research. However, the "Flats" sample site at the Tikitiki property was located on what is classified as Typic Orthic Brown Soils (according to NZFSL) and therefore it was expected that the "Flats" site would be lower in soil OC (because of the differing soil types) compared to neighbouring "Garden" and "Gorse" sites. This was in fact the case however, the "Flats" site still showed higher soil OC results compared to results from the sites at the Willowbank property. This suggests the Tikitiki case-study property's physical characteristics contribute to a predisposition of overall higher soil OC. 
Parent material and underlying soils are not solely responsible for differences in soil carbon accumulation. Vegetation/land-use also has a significant effect on the amount of carbon being stored within the subsurface. Differences in landuse or vegetation cover affect decomposition rates and organic matter break down, and consequently play a dominant role in determining soil organic carbon stocks under a variety of different vegetation types/land-uses or management strategies. An aspect of soil OC dynamics still poorly understood is the vertical distribution of soil OC and the differences seen as a result of differing vegetation (Jobbagy \& Jackson, 2000). Agricultural soils or soils under pasture tend to experience particularly significant and more frequent external stimulus and are often mechanically mixed or turned over (Post \& Kwon, 2000). Soils that are under permanent forest are often subject to less disturbance and may be less likely to lose carbon from the soil as a result of being lost back to the atmosphere or mobilised and washed away. Carbon therefore, may accumulate more easily in these sorts of systems compared to a system that is constantly being reworked (i.e. such as intensive cropping). This research compared a variety of vegetation covers and land-uses within the two casestudy properties. The effects of vegetation and the aboveground biomass played a role on $\mathrm{C}$ within the subsurface at both of the case-study properties. How big of an impact vegetation cover/land-use played is still questionable with results favouring more strongly relationships between soil type rather than vegetation/land-use. However, significant results surrounded the "Gorse' sample site which showed overall the highest soil carbon content out of all of the seven sample sites and also high hydraulic conductivity at depth, subsequently providing more ecosystem benefits than we currently acknowledge.

At the Willowbank case-study property samples underneath Kanuka forest although slightly lower than the "Top Pasture" samples were higher in soil OC than the two lower samples sites ("Bottom Pasture" and "River") at higher depth intervals. However at lower depth intervals samples underneath pasture gave higher soil OC results ("Bottom Pasture" and "Top Pasture"). Pasture is the dominant land-use in New Zealand and it is estimated that soil carbon under 
grassland accounts for over $50 \%$ of New Zealand's total soil OC stocks (Tate et al. 2005). This makes pastoral land-use an area of great importance. Changes in soil $\mathrm{C}$ under pasture could be significant in a range of ecosystem services but also particularly important with New Zealand's commitment to the Kyoto Protocol (Baisden et al. 2001).

Overall results showed the Tikitiki case-study property to have notably higher amounts of soil OC. Therefore the Tikitiki property has more to lose meaning the protection of what is there is fundamental for future management. It can also be assumed that the Willowbank case-study property has the most potential to sequester more carbon however, current management and landuses alter decisions especially surrounding a potential change at both properties. One area may have more potential for carbon sequestration (in the case the Willowbank property) but whether or not a change is viable is determined by the current situation and what is ultimately wanted to be achieved. The Tikitiki property is higher in overall soil OC lending more potential for a change. However, at present Tikitiki is to a large extent economically dormant compared to the Willowbank case-study property. Change is inevitable and dependent on what sort of change is to occur, come the potential to increase or decrease carbon stocks at both case-study properties.

\section{DIFFERENCES/SIMILARITIES IN TEXTURE, STRUCTURE AND SATURATED HYDRAULIC CONDUCTIVITY:}

Differences in soil type and vegetation cover/land-use were the dominant reasons why sample sites were chosen for further investigation. Along with these differences come differences in soil texture and structure. Soil composition and structure fundamentally defines a soils hydraulic capacity and a change in soil OC can also modify a soils textural and structural form (Lal, 1998). Increases in soil OC/OM often result in increased infiltration capacities and hence give soil a greater resistance to processes such as erosion (Rawls et al. 2003). 
Results showed that the dominant texture was largely silt at the Tikitiki casestudy property and both silt and sand at the Willowbank case-study property. Tikitiki results showed remarkably low levels of clay and high organic carbon for all land-uses/soils measured. Although still quite low in general the clay fractions from the Willowbank property samples were higher than those samples taken from the Tikitiki property. Soil OC results neither increased nor decreased with increasing clay content in this research.

Estimates of saturated hydraulic conductivity (from pedo-transfer functions) varied across the seven sample sites. Sites "Top Pasture" and "Kanuka" at the Willobank property had higher hydraulic conductivity than sites "Bottom Pasture" and "River". A correlation between soil OC and hydraulic capacity is evident with the two upper sites ("Top Pasture" and "Kanuka") being higher in soil OC, clay content and hydraulic capacity compared to the lower sites ("Bottom Pasture" and "River"). This was also evident at the Tikitiki property with sites "Garden" and "Gorse" showing higher soil OC and overall hydraulic capacity compared to the lower "Flats" site that had less soil OC and lower saturated hydraulic conductivity results. The low levels of clay and the overall high soil OC results from the Tikitiki property appear to be providing a higher level of carbon sequestration and flood mitigation functionality.

\section{DISCREPENCIES BETWEEN RESULTS AND NATIONAL SCALE DATA:}

The sometimes complicated and often missing soil data presented a significant challenge in terms of finding relevant up-to-date data. However, from the previous results it has been shown that to some extent (specifically larger spatial scales) the national scale data can be trusted for the implementation with decision support tools such as Polyscape. Results did however show discrepancies between the often extrapolated data from national inventories and databases and point measurements from this research. The problem with the national scale data is that in many regions the records are insufficient or extremely outdated. Though many properties such as nutrient status, bulk density and water-holding capacity can be assumed or estimated from soil data, 
heterogeneity of soils means that these values can vary quite dramatically in space resulting in issues with representativeness. Farm scale changes are not easily distinguished or detected. This research showed that variations in soil type and vegetation resulted in large differences in overall soil OC and its vertical distribution within the subsurface. The New Zealand land resource inventory (NZLRI) and New Zealand's fundamental soil layer (NZFSL), more particularly the carbon attributes suggest that the two case-study properties were quite comparable in terms of carbon within the soil. Results from this research showed that this was largely not the case with soil OC very much contrasting within and between sample sites.

\subsection{CONCLUSIONS:}

The stated aim of this research was to investigate the issues surrounding general sustainability of rural land-use within the Gisborne/East-Cape, region, North Island, New Zealand with a particular emphasis on soil carbon sequestration and the associated co-benefits of increased carbon within the subsurface. To support this aim a number of objectives were established. The results and supporting evidence presented in chapter six and discussed further here were used to develop the following conclusions.

OBJECTIVE ONE: Determine both the environmental and socioeconomic sustainability issues the Gisborne/East-Cape region is facing at present, with a particular focus on the major erosion and flooding issues.

Among the major sustainability issues surrounding the Gisborne/East-Cape at present are managing impacts of flooding and associated erosional processes. Erosion problems within the region can be attributed to both anthropogenic and natural causative mechanisms. Flooding and erosion issues, with soil carbon redistribution/loss, will continue to hamper the region unless action is taken to mitigate these negative environmental impacts. Erosion can be and is a 
major limiting factor affecting land-use and productivity in many rural communities throughout New Zealand. The consequences of erosion and flooding can have also have huge influence on community dynamics often damaging economic potential and community 'spirit' if such processes are continually occurring.

The Gisborne/East-Cape region as a whole is known for its scarred and unstable landscape. Many consider the land to be marginal, and as being (in its current management state) environmentally and economically unsustainable. Though future management may prove difficult (particularly given the issues surrounding (Maori-owned land) in some instances the people of the East-Cape are extremely proactive in seeking multiple co-beneficial outcomes. This was evident and expressed by the landowners and other stakeholders encountered throughout this research.

A greater understanding of terrestrial and fluvial systems that takes a more holistic approach to management decisions could potentially reduce the likelihood of negative environmental and socio-economic impacts in the future. If management decisions are properly thought through sustainability and resource management with multiple co-benefits is likely to be achieved

OBJECTIVE TWO: Quantify soil OC and its variation with depth across a range of different soil types and land-uses within the Gisborne/East-Cape region.

To fulfil the second objective soil chemical analysis (OC determination following the Walkley Black Method) was undertaken on 220 soil samples taken from the two case-study properties. Both properties had a variety of different soils and vegetation/land-uses and were contrasting in many aspects.

C content within the subsurface appeared to depend predominantly on the underlying soil type. Results also showed that the $\mathrm{C}$ content and associated characteristics can vary greatly with depth, vegetation and land-use, largely reflecting differences in inputs of $\mathrm{C}$ and therefore, overall carbon. Results 
suggested that the Tikitiki property has a predisposition of higher soil OC within the soil compared to the Willowbank property. This could be a result of the underlying soils present at each of the properties and to a large extent was. Other factors such as vegetation (particularly gorse) also contributed to this predisposition of higher soil OC at the Tikitiki case-study property.

Overall the range of soil types and vegetation/land uses tested throughout this research gave a variety of results from which several conclusions could be drawn regarding soil OC quantification.

OBJECTIVE THREE: Review the available national scale soil data, both in a stand-alone sense and in comparison with the data collected in objective two. Then comment on data reliability and representativeness to inform its application with spatially explicit land management tools, using the geographic information system tool Polyscape as a "test case".

Objective three primarily involved a review of the underlying nationally available soil data for its application with decision support tools. The initial implementation of Polyscape within the New Zealand landscape seems to be correct. After reviewing and discussing the output generated by Polyscape with the landowners involved results seemed to match what was going on at the smaller farm spatial scale. National scale data was used to identify areas that had the greatest potential for a change or potential for carbon sequestration. Polycapes hydrological and farm productivity algorithms meant that areas that were more or less valuable, prone to flooding and/or subject to excess saturation were also able to be identified. By identifying features in the landscape that are providing high carbon and/or flood protection, decisions surrounding removal or a change to such utilities should be wary. Rather select areas to accumulate carbon that also provide flood mitigation benefits without removing previous utilities or taking productive land out of use. 
OBJECTIVE FOUR: Comment on the results of objectives two and three with regards to how these results can be used to inform strategies to address the sustainability issues outlined in objective one. Objective four also looks at the application of results to the wider context of data support systems and assisting with overall sustainable land management decisions.

Results suggested that variability in soil properties and the interaction between a soils inherent properties and external factors such as vegetation or landuse/land management strategies, largely determine soil OC, transport and potential. However, results also suggest that there may be other important characteristics influencing carbon within the soil at the two properties. Possible influences could also include differences in climate or geological effects that were not clearly differentiated by soil textural characteristics alone. Locking up more carbon in the soil generally leads to improvements in overall soil quality and increases a soils capacity to mitigate floods. Changes in land-use management can substantially increase (or decrease) soil carbon and with this change soil hydraulic properties. This has important implications for the global carbon and climate cycles, but also for flooding and erosion - key sustainability issues in the East Cape. Land-use changes and unfortunate management decisions in the past have significantly increased erosion and with this the rate at which carbon is mobilised/lost.

In order for steps to be taken to implement mitigation strategies that prove cobeneficial local knowledge and requirements must be integrated into the decision making processes. It is at this smaller scale where local knowledge and input becomes vital in the decision making process. But it is these smaller scale decisions and changes that will ultimately have larger scale impacts and hopefully potential for positive gains. 


\subsection{IMPLICATIONS AND CONCLUDING STATEMENT:}

The initial research aim was to investigate issues surrounding general sustainability of the Gisborne/East-Cape region with a particular emphasis on soil carbon sequestration potential and the associated environmental and socioeconomic gains. Increasing the amount of carbon provides the soil with increased infrastructural features and therefore enhanced flood and erosion mitigation potential. Knowledge of the spatial and temporal heterogeneity of soil properties, the surrounding environmental conditions, past practices and present management options are crucial to monitor carbon stocks and estimate potential future changes in soil carbon. While (in some regions) there is great potential to increase sequestration of carbon in soil, it is necessary to consider impacts of vegetation and land-use that may result in carbon being lost from the soil and therefore play a dominant role in determining carbon fate in the terrestrial environment. Findings of this research showed that the differing soils, vegetation and land-uses tested at the two case-study properties were responsible for quite contrasting results within and between the two properties.

With the introduction of policy such as the Kyoto Protocol and as carbon becomes more widely recognised for both its direct and indirect environmental or economic value, the need for increased confidence in monitoring systems and data will become crucial. Trotter et al. (2004) reiterates the strong need for continued development of models that can provide reliable and accurate estimates of carbon accumulation at several spatial scales.

Comparisons with national scale data and the application of results with the test-case tool Polyscape allowed the user to examine differing land management scenarios. Polyscape is an example of a decision support system that focuses largely on the idea of multiple co-benefits. Such tools are important in identifying potential areas for change where the location of specific features (such as a riparian strip) will have the greatest benefit for several other services. Decision support tools such as Polyscape that seek multiple cobeneficial outcomes surrounding sustainable change will prove to be powerful 
in our volatile environment. The utilisation of such tools however, is limited unless appropriate data to support farm-scale decisions can be obtained.

To conclude; the direct and indirect benefits in terms of both the environment and socio-economic aspects that potentially result from having more carbon within the subsurface and the identification of potential carbon sink areas at different spatial scales through data support tools such as Polyscape are heavily dependent on underlying data reliability. Data support tools along with a holistic viewpoint towards the environment will hopefully provide some incentives for better land-use and sustainable land management practices with positive steps towards flooding and erosion alleviation particularly in the East Cape region. 


\subsection{FURTHER RECOMMENDATIONS AND KEY RESEARCH OPPORTUNITIES:}

Factors such as vegetation/land-use or soil structural characteristics that regulate where $\mathrm{OC}$ is likely to accumulate or be lost can be extremely unpredictable and therefore provide continual opportunities for research. The two case-study properties located on the East-Cape of North Island New Zealand provided insight into both the physical and cultural/socio-economic aspects surrounding soil carbon dynamics at each of the properties. Differing soil types, vegetation and land-uses provided both similar and quite contrasting results representative across many situations. Other areas of investigation that were not covered thoroughly throughout this research and should continue to be areas of investigation are stated below.

- Focus should be given to protecting the stocks and stores of carbon we already have. For example more carbon cannot be sequestered if internal and external stimuli remain constant resulting in carbon reaching a point of equilibrium. Research should focus on ensuring stimuli to high existing stock is managed correctly so that carbon remains sequestered.

- Carbon can be mobilised or lost back into the atmosphere often more easily that it is sequestered. More research is needed in this area to identify which of New Zealand's soils are most vulnerable to processes such as erosion and carbon remobilisation. A major implication is the effect erosion and resultant mobilisation of carbon from high to low topography has on the presented results. Research surrounding carbon turnover within the subsurface should continue to be of primary focus. We know that organic matter accumulates relatively slowly in soils, however it is the rate of decline and loss that can be rapid and therefore the biggest issue. Therefore there is potential for more research on turnover times, especially those for soil carbon at greater depths 
- Due to the other variations being considered (e.g. soil type and vegetation/land-use) and sample/time limitations topographical effects could not be fully disentangled. Further research could focus solely on the differing position in the landscape researching marked differences between geomorphic units i.e. ridges or slopes or valley floor etc, and investigate the effect such differences have on carbon accumulation.

- A need for more specific data on soil carbon, requiring investment in soil monitoring is another key priority. The continuation of data being added and the validity of the New Zealand's soil data and databases will be critical for its application and implementation with data support tools used to make sustainable management decisions. 


\section{REFERENCES:}

Asher, G., \& Naulls, D. (1987) Maori Land. New Zealand Planning Council, Wellington. Barlow, C. 1991. Tikanga whakaaro: Key concepts in Maori culture. Auckland, New Zealand: Oxford University Press.

Batjes, N.H. (1996) The total C and N in soils of the world. European Journal of Soil Science 47, 151-163.

Barringer, J., Hewitt, A., Lynn, I., \& Schmidt, J. (2008) National Mapping of Landform Elements in Support of S-Map, A New Zealand Soils Database. Lecture Notes in Geoinformation and Cartography.

Beckman Coulter. (n.d.). LS ${ }^{\mathrm{TM}} 13320$ Series Laser Diffraction Particle Size Analyzers. Retrieved January 31, 2010 from http://www.beckmancoulter.com/coultercounter/product_LS13320.jsp.

Beuselinck, L., Govers, G., Poesen, J., Degraer, G., \& Froyen, L. (1998) Grain-size analysis by laser diffractometry: comparison with the sieve-pipette method. Catena, 32, 193-208.

Bisutti, I., Hilke, I., \& Raessler, M. (2004) Determination of total organic carbon - an overview of current methods, Trends Anal. Chem. 23, 716-726.

Blakemore, L.C., Searle, P.L., \& Daly, B.K. (1987) Methods for Chemical Analysis of Soils. New Zealand Soil Bureau Scientific Report 80.103p.

Blanco-Canqui, H., \& Lal, R (2004) Mechanisms of Carbon Sequestration in Soil Aggregates, Critical Reviews in Plant Sciences, 2,(6), 481-504.

Cheng, H.H., \& Kimble, J. (2000) Methods of Analysis for Soil Carbon: An Overview. In R. Lal, J.M. Kimble, \& B.A. Stewart (Eds.), Advances in Soil Science: Global Climate Change and Tropical Ecosystems. Lewis Publishers.

Chatterjee, A., Lal, R., Wielopolski, L., Martin, M.Z., \& Ebinger, M.H. (2009) Evaluation of Different Soil Carbon Determination Methods. Critical Reviews in Plant Sciences, 28(3), 164 - 178.

Denman, K.L., G. Brasseur, A. Chidthaisong, P. Ciais, P.M. Cox, R.E. Dickinson, D. Hauglustaine, C. Heinze, E. Holland, D. Jacob, U. Lohmann, S Ramachandran, P.L. da Silva Dias, S.C. Wofsy \& X. Zhang, (2007) Couplings Between Changes in the Climate System and Biogeochemistry. In: Climate Change 2007: The Physical Science Basis. Contribution of Working Group I to the Fourth Assessment Report of the Intergovernmental Panel on Climate Change [Solomon, S., D. Qin, M. Manning, Z. Chen, M. Marquis, K.B. Averyt, M.Tignor and H.L. Miller (eds.)]. Cambridge University Press, Cambridge, United Kingdom and New York, NY, USA. 
Deurer, M., Sivakumaran, S., Ralle, S., Vogeler, I., Clothier, B., Green, S., and Bachmann, J. (2008). A New Method to Quantify the Impact of Soil Management on Biophysical Soil Properties: The Example of Two Apple Orchard Systems in New Zealand. Journal of Environmental Quality. (37)915-924.

Dunn, S.M., \& Mackay, R. (1995) Spatial variation in evapotranspiration and the influence of land use on catchment hydrology. Journal of Hydrology 171, 49-73

Durie, M.H. (1998) Te Mana, Te Kawanatanga. The politics of Māori selfdetermination. Oxford University Press, Auckland. 280p.

Ekanayake, J.C., \& Phillips, C.J. (1999) A model for determining thresholds for initiation of shallow landslides under near-saturated conditions in the East Coast region, New Zealand. Journal of Hydrology (NZ) 38(1): 1-28.

Falkowski, P., Scholes, R.J., Boyle, E., Canadell, J., Canfield, D., Elser, J., et al. (2000) The Global Carbon Cycle: A Test of Our Knowledge of Earth asa System. Science 290.291-296.

Falloon, P.D., Smith, P., Smith, J.U., Szabo, J., Coleman, K., \& Marshall, S., (1998) Regional estimates of carbon sequestration potential: linking the Rothamsted Carbon Model to GIS databases.

Feller, C., Balesdent, J., Nicolardot, B., and Cerri, C. (2000) Approaching "Functional" Soil Organic Matter Pools through Particle-Size Fractionation: Examples for Tropical Soils. In: Assessment Methods for Soil Carbon. / [Edited by] R. Lal .... [et al.]. Advances in Soil Science. Lewis Publishers.

Food and Agriculture Organization (FAO) of the United Nations. (2001) Soil Carbon Sequestration for Improved Land Management. World Soils Resources Report 96.

Funk, J. \& Kerr, S. (2007) "Restoring forests through carbon farming on Maori land in New Zealand/Aotearoa." Mountain Research and Development 27(3): 202-205.

Gerald, L. (2006) The Influence of Land Use Change on Catchment Soil Erosion and Biogeochemical Characteristics: Waipaoa River Case Study. MSCI 698 Final Paper.

Ghani, A., Mackay, A., Clothier, B., Curtin, D., and Sparling, G. (2009). A literature review of soil carbon under pasture, horticulture and arable land uses. Report prepared for AGMARDT. Agresearch.

Gibbs, H.S. (1959) Soils of the Gisborne/East Coast District and their problems for pastoral use. Proc. 21 Conf. N.Z. Grass Ass., 9-18. 
Giltrap D.J., and Hewitt, A.E. (2004) Spatial variability of soil quality indicators in New Zealand soils and land uses. NZ Journal of Agricultural Research 47:167-177

Gregg, P. (2009) Soil Erosion and Conservation - Natural and human causes of erosion', Te Ara - the Encyclopedia of New Zealand, updated 1-Mar-09 URL: http://www.TeAra.govt.nz/en/soil-erosion-and-conservation/2

Harmsworth, G. (2002) Indigenous concepts, values and knowledge for sustainable development: New Zealand case studies. 7th Joint Conference: "Preservation of Ancient Cultures and the Globalization Scenario". School of Maori and Pacific Development \& International Centre for Cultural Studies (ICCS), India, 22-24 November 2002. Te Whare Wananga o Waikato, University of Waikato, Hamilton, New Zealand.

Harmsworth, G., Barclay-Kerr, K., \& Reedy, T., (2002) Maori sustainable development in the 21st Century: The importance of Maori values, strategic planning and information systems. Journal of Maori and Pacific Development, 3(2).

Harris, C.S., McKee, J.G., O’Bryne, T.N. (1964) Land Use Capability Survey Gisborne - East Coast Region. Unpublished.

Heimann, M. and Reichstein, M. (2008) Terrestrial ecosystem carbon dynamics and climate feedbacks. Year of Planet Earth Feature. NATURE, 451(17).

Hessell, J.W.D. (1980) The Climate and Weather of the Gisborne Region. New Zealand Meteorological Service. Misc. Pub. 115(8).

Hewitt, A.E. (1998) New Zealand Soil Classification. 2nd Edition. Manaaki Whenua - Landcare Research New Zealand.

Hewitt, A.E. (1992) Soil classification in New Zealand: legacy and lessons. Australian Journal of Soil Research, 30, 843-854.

Hicks, D.M., Gomez, B. \& Trustrum, N.A. (2004) Event suspended sediment characteristics and the generation of hyperpycnal plumes at river mouths: East Coast Continental Margin, North Island, New Zealand. J. Geol., 112, 471-485.

Hook, P.B., and Burke, I.C. (2000) Biogeochemistry in a Shortgrass Landscape: Control by Topography, Soil Texture, and Microclimate. Ecology 81:2686-2703.

ICF International. (2008) Final Report: Voluntary Carbon Market Opportunities - Soil Carbon Management in New Zealand. Submitted to: Ministry of Agriculture and Forestry. Retrieved June 10, 2010 
http://www.maf.govt.nz/climatechange/reports/voluntary-carbon-mktopps/voluntary-carbon-market-opportunities.pdf

Intergovernmental Panel on Climate Change (IPCC.) (1996) Land-use change and forestry. Pages 5.6-5.75 in Intergovernmental Panel for Climate Change. Revised 1996 guidelines for national greenhouse gas inventories: reference manual.

Isaac, M.J. (1977) Mesozoic geology of the Matawai district, Raukumara Peninsula. Unpulished Phd Thesis. University of Auckland, New Zealand.

Jackson, B., Pagella, T., Sinclair, F., Orellana, B., Reynolds, B., Henshaw, A., Wheater, H., and Eycott, A. (in press) Polyscape: a mapping toolbox providing efficient and spatially explicit valuation of multiple ecosystem services.

Jackson, B., Pagella, T., and Orellana, B. (2010). Polyscape manual v1.1, Victoria University of Wellington, New Zealand.

James, B. (1993) The Maori Relationship with the Environment. Policy and Planning Department, Wellington Regional Council. Published by Department of Conservation. Publication No. WRC/PP-G-93/29.

Jessen, M.R., Crippen, T.F., Page, M.J., Rijkse, W.C., Harmsworth, G.R., \& McLeod, M. (1999) Land use capability classification of the Gisborne - East Coast region: a report to accompany the second-edition New Zealand Land Resource Inventory. Landcare Research science series, No. 21, Manaaki Whenua Press, Lincoln, Canterbury, N.Z.

Jobbagy, E.G. \& Jackson, R.B. (2000) The Vertical Distribution of Soil Organic Carbon and its Relation to Climate and Vegetation. Belowground Processes and Global Change. Ecological Applications, 10(2), 423-436.

Kingi, T. (2008) Case Study 7: Maori landownership and land management in New Zealand. In: Making Land Work. Reconciling Customary Ownership and Development. Institute of Natural Resources, Massey University, Palmerston North, New Zealand.

Lal, R. (2004) Soil Carbon Sequestration Impacts on Global Climate Change and Food Security. Soils - The Final Frontier. Viewpoint, Special Section. Science (304). Lal, R. (2004) Soil carbon sequestration to mitigate climate change. Geoderma 123, 1-22.

Lal, R. (2003) Global Potential of Soil Carbon Sequestration to Mitigate the Greenhouse Effect. Critical Reviews in Plant Sciences, Volume 22(2), 151-184. 
Lal, R. (1999) Global carbon pools and fluxes and the impact of agricultural intensification and judicious land use in: prevention of land degradation, enhancement of carbon, sequestration and conservation of biodiversity through land use change and sustainable land management with a focus on Latin America and the Caribbean. World soil resources report No. 86. FAO, Rome, Italy, $45-52$.

Lal, R. \& Kimble, J.M. (2000) Chapter Three. Importance of Soil Bulk Density and Methods of Its Measurements. In: Assessment Methods for Soil Carbon. / [Edited by] R. Lal .... [et al.]. Advances in Soil Science. Lewis Publishers

Le Quéré, C., Raupach, M.R., Canadell, J.G., Marland, G., Bopp, L., Ciais, P., Conway, Doney, S.C., Feely, R.A., Foster, P., Friedlingstein, P., Gurney, K., Houghton, R.A., House, J.I., Huntingford, C., Levy, P.E., Lomas, M.R., Majkut, J., Metzl, N., Ometto, J.P., Peters, G.P., Prentice, I.C., Randerson, J.T., Running, S.W., Sarmiento, J.L., Schuster, U., Sitch, S., Takahashi, T., Viovy, N., Van Der Werf, G.R., and Woodward, I.F. (2009) Trends in the sources and sinks of carbon dioxide. Nature Geoscience 2.

Leamy, M.L., Clayden, B., \& Hewitt, A.E. (1983) Soil Classification in the N.Z. Soil Bureau. N.Z. Soil News 31, 183-5.

Leathwick, J., Morgan, F., Wilson, G., Rutledge, D., Malcom, M., \& Johnston, K. (2002) Land Environments of New Zealand: A Technical Guide. Landcare Research Ltd.

Lettens, S., DeVos, B., Quataert, P., Van Wesemael, B., Muys, B., \& Van Orshoven, J. (2007) Variable carbon recovery of Walkley-Black analysis and implications for national soil organic carbon accounting. European Journal of Soil Science, 58 (6) 1244-1253(10)

Lilburne, L., Hewitt, A., Webb, T., \& Carrick, S. (2004) S-map - a new soil database for New Zealand. Landcare Research Ltd. Proceedings of the International Soil Science Conference 2004. Sydney, Australia.

Mazengarb, C., \& Speden, I.G. (2000) Geology of the Raukumara area. Institute of Geological \& Nuclear Sciences 1:250 000 geological map 6. 1 sheet + 60p. Lower Hutt, New Zealand.

McLeod, M., Rijkse, W.C., Jessen, M.R. (1999) Available water capacities of key soil layers in the Gisborne - East Coast region, New Zealand. New Zealand Journal of Agricultural Research 42(2), 195-203.

McLeod, M., Rijkse, W.C., \& Dymond, J.R. (1995) A Soil-landscape Model for Close-jointed Mudstone, Gisborne-East Cape, North Island, New Zealand. Australian Journal of Soil Research. 
McMillan, H., Jackson, B., and Poyck, S. (2010) Flood Risk Under Climate Change: A framwork for assessing the impacts of climate change on river flow and floods, using dynamically-downscaled climate scenarios. A case study for the Uawa (East Cape) and Waihou (Northland) catchments. NIWA Client Report prepared for Ministry of Agriculture and Forestry.

Metson, A.J. (1956) Methods of chemical analysis for soil survey samples. Soil Bureau bulletin, 12. New Zealand. Dept. of Scientific and Industrial Research.

Milne, E. (2008) Soil organic carbon. In: Encyclopaedia of Earth. Eds. Cutler J. Cleveland. Washington, D.C. Environmental Information Coalition, National Council for Science and the Environment. Retrieved March 11, 2009, from: http://www.eoearth.org/article/Soil_organic_carbon

Milne, J.D.G., Clayden, B., Singleton, P.L., \& Wilson, A.D. (1995) Soil Description Handbook Revised Edition. Published by Manaaki Whenua Press, Landcare Research New Zealand, 156 p.

Milne, J.D.G., Clayden, B., Singleton, P.L., and Wilson, A. D. (1991) Soil description handbook. DSIR Land Resources. 133p.

Ministry for the Environment. (MfE) (2010) Metadata Reports. 13.1 National Soils Database. Retrieved April 28, 2010, from http://www.mfe.govt.nz/publicaitons/ser/metadata/landrep/page38.html

Ministry for the Environment. (2007) Preparing for and adapting to climate change. Look ahead to the future. Climate Change Publications. Retrieved March 11, 2009, from: http://www.mfe.govt.nz/publications/climate/

Ministry of Agriculture and Forestry (MAF). (2008) Carbon Sequestration Rates. Retrieved November 8, 2008, from: http://www.maf.govt.nz/mafnet/

Ministry of Agriculture and Forestry (MAF). (1998) MAF Policy Technical Paper 98/9 Land Use Change and Response in the Gisborne District of Waipaoa: Summary of a Case Study Using a Multistakeholder Approach.

Molloy, L. (1988) Soils in the New Zealand Landscape: the living mantle. 2nd Edition. Mallinson Rendel Publishers Ltd. 239p

Moore, P.R., \& Mazengarb C. (1992) Geology and landforms of Raukumara Peninsula. In Soons, J.M and Selby, M.J. (Eds.) Landforms of New Zealand. 2nd edition. Longman Paul, 334-343.

Morad, M. \& Jay, M. (1997) Cadastral Reform of Indigenous Land Information and Environmental Sustainability in New Zealand. Surveying and Land Information Systems, 57(2), 120-123. 
Muggler, C.C., Pape, Th., \& Buurman, P. (1997) Laser grain-size determination in soil genetic studies: 2. Clay content, clay formation, and aggregation in some Brazilian Oxisols. Soil Science. 162 (3), 219-228.

Nelson, D., \& L. Sommers. (1996) Total carbon, organic carbon, and organic matter. In Methods of Soil Analysis: Chemical Methods, edited by D. L. Sparks, A. Page, P. Helmke, R. Loeppert, P. Soltanpour, M. Tabatabai, C. Johnston and M. Summer. Madison: American Society of Agronomy.

Newsome, P.F.J., Wilde, R.H., and Willoughby, E.J. (2008) Land Resource Information System Spatial Data Layers - Data Dictionary. Landcare Research New Zealand Ltd.

New Zealand Biodiversity Strategy (2007) Maori View of Biodiversity. Retrieved February 2, 2009, from http://www.biodiversity.govt.nz

New Zealand Climate Change Centre (NZCCC) (2010) Climate change adaptation in New Zealand: Future scenarios and some sectoral perspectives. Nottage, R.A.C., Wratt, D.S., Bornman, J.F., Jones, K. (eds), Wellington, $136 \mathrm{p}$.

One News (2010) Gisborne region mops up after flood. Article published: July 2010. Retrieved August 3, 2010, from http://tvnz.co.nz/nationalnews/gisborne-region-mops-up-after-floods-3632389

Ota, Y., Hull, A.G., Iso, N., Ikeda, I., Moriya, Yoshikawa, T., (1992). Holocene marine terraces on the northeast coast of North Island, New Zealand, and their tectonic significance. N.Z. J. Geol. Geophys. 192, 273-288.

Page, M.J., Trustrum, N.A., \& Gomez, B. (2000) Implications of a century of anthropogenic erosion for future land use in the Gisborne-East Coast region of New Zealand. New Zealand Geographer, 56 (2), 13-24.

Percival, H.J., Parfitt, R.L., Scott, N.A. (2000) Factors controlling soil carbon levels in New zealand grasslands : Is clay content important? Soil Science Society of America. Volume 64(5), 1623-1630.

Pluske, W., Murphy, D., and Sheppard, J. (2010) Soil Health. Organic carbon. Available at: http://www.soilquailty.org.au. New South Wales Government. Namoi Catchment Management Authority.

Post, W. M., Izaurralde, R. C., Mann, L. K., \& Bliss, N. (2001) Monitoring and Verifying Changes of Organic Carbon in Soil. Climatic Change 51, 73-99.

Post, W. M., \& Kwon, K.C. (2000) Soil Carbon Sequestration and Land-Use Change: Processes and Potential. Global Change Biology 6 (3), 317-327.

Preston, N.J., Trustrum, N.A., Sidorchuk, A.Y., Hicks, D.M., Baisden, W.T., Giltrap, D.J., Scott, D.T., Page, M.J., Tate, K.R. (2004) Estimating national erosion- 
related soil carbon losses in New Zealand : an indicator for Kyoto compliance and sustainability assessment. In: Francaviglia, R. Agricultural impacts on soil erosion and soil biodiversity: developing indicators for policy analysis: proceedings from an OECD Expert Meeting, Rome, Italy, March 2003. Rome, Istituto Sperimentale per la Nutrizione delle Piante. 301-310.

Raich, J.W., \& Schlesinger, W.H. (1992) The global carbon dioxide flux in soil respiration and its relationship to vegetation and climate. Tellus, 44:8199.

Rawls, W.J., Pachepsky, Y.A,. Ritchie, J.C., sobecki, T.M., \& Bloodworth, H. (2003) Effect of soil organic carbon on soil water retention. Geoderma 116, 6176.

Rhodes, D. (2001) Rehabilitation of deforested steep slopes on the East Coast of New Zealand's North Island. Unasylva Food and Agriculture Organization of the United Nations. 52(207), 21-29.

Rijkse, W.C. (1980) Soils and agriculture of Waiapu Valley, East Coast, North Island, New Zealand. N.Z. Soil Survey Report 60.

Robertson, B. (2004) Maori Land Tenure: Issues and Opportunities. A paperprepared for the New Zealand Institute of Surveyors Annual Conference, Auckland, October, 2004

Rosell, R.A., Gasparoni, J.C. \& Galatini, J.A. (2000) Soil Organic Matter Evaluation. In: Assessment Methods for Soil Carbon. / [Edited by] R. Lal .... [et al.]. Advances in Soil Science. Lewis Publishers.

Savage, L. (2009) An update on Climate Change: New developments since 2006 in climate science and legislation. Prepared for Gisborne District Council.

Savage, L. (2006) An Overview of Climate change and Possible Consequences for Gisborne District. Prepared for Gisborne Civil Defence and Emergency Management Group.

Saxton, K.E., and Rawls, W.J. (2006) Soil Water Characteristics Estimates by Texture and Organic Matter for Hydrologic Solutions. Soil \& Water Management \& Conservation, Soil Physics. Soil Science. Society. Of America. 70:1569-1578.

Schimel, D.S. (1995) Terrestrial ecosystems and the carbon cycle. Global Change Biology. 1, 77-91.

Schipper, L. \& Sparling, G. (2009). Carbon in soils. NZ Science Teacher, 120, 1315. 
Schlesinger, W.H. and Andrews, J.A. (2000) Soil respiration and the global carbon cycle. Biogeochemistry. 48, 7-20. Kluwer Academic Publishers. Printed in the Netherlands.

Schlesinger, W.H. (1998) An Overview of the Carbon Cycle. In Soil Processes and the Carbon Cycle, edited by R. Lal, J. M. Kimble, R. F. Follett and B. A. Stewart. Boston: CRC Press.

Schlesinger, W.H. (1984) Soil Organic Matter: a Source of Atmospheric $\mathrm{CO}_{2}$. In The Role of Terrestrial Vegetation in the Global Carbon Cycle: Measurement by Remote Sensing. Edited by G.M. Woodwell. John and Wiley Sons Ltd.

Schollenberger, C.J. (1927) A rapid approximate method for determining soil organic matter. Soil Science, 24, 65-68.

Schumacher, B.A. (2002) Methods for the Determination of Total Organic Carbon (TOC). Ecological Risk Assessment Support Center Office of Research and Development. United States Environmental Protection Agency Environmental Sciences Division National Exposure Research Laboratory.

Scott, N.A., Tate, K.R., Giltrap, D.J., Tattersall Smith, C., Wilde, R.H., Newsome, P.F.J, \& Davis, M.R. (2002) Monitoring land-use change effects on soil carbon in New Zealand: quantifying baseline soil carbon stocks. Environmental Pollution 116.

Shein, E.V. (2009) The Particle-Size Distribution in Soils: Problems of the Methods of Study, Interpretation of the Results, and Classification. Eurasian Soil Science 42(3), $284-291$.

Smale, M.C., McLeod, M., \& Smale, P.N. (1997) Vegetation and Soil Recovery on Shallow Landslide Scars in Tertiary Hill Country, East Cape Region, New Zealand. New Zealand Journal of Ecology 21(1) 31-41.

Sparling, G., Lilburne, L., and Vojvodić-Vuković, M. (2008) Provisional Targets for Soil Quality Indicators in New Zealand. Landcare Research Science Series No. 34. Manaaki Whenua Press.

Standards Association of New Zealand. (1986) NZS4402 Methods of testing soils for civil engineering purposes. Part 1. Preliminary and general. Standards Association of NZ, Wellington.

Statistics New Zealand Publication. (1999) New Zealand - A Regional Profile. Gisborne. Statistics New Zealand Te Tari Tatau, Wellington, New Zealand. Catalogue Number 01.707.IN98.

Tate, K., Wilde, R.H., Giltrap, D.J., Baisden, W.T., Saggar, S., Trustrum, N.A., and Scott,N.A., \& Barton, J.P. (2005) Soil organic carbon stocks and flows in 
New Zealand: System development, measurement and modelling. Canadian Journal of Soil Science. 85, 481-489.

Tate, K., Wilde, R.H., Giltrap, D.J., Baisden, W.T., Saggar, S., Trustrum, N.A., \& Scott, N.A. (2004) Soil carbon changes and uncertainties with New Zealand land-use change. SuperSoil 2004 Published by The Regional Institute Ltd. Retrieved March 17, 2009 from http://www.regional.org.au/au/asssi/supersoil2004/s10/oral/1428_ta tek.htm - 17/03/09

Tate, K.R., Scott, N.A., Saggar, S., Giltrap, D.J., Baisden, W.T., Newsome, P.F., Trotter, C.M., \& Wilde, R.H. (2003a) Land-use change alters New Zealand's terrestrial carbon budget: uncertainties associated with estimates of soil carbon change between 1990-2000. Tellus 55B, 364377.

Tate, K.R., Barton, J.P., Trustrum, N.A., Baisden, W.T., Sagger, S., Wilde, R.H., Giltrap, D. J., and Scott, N.A. (2003b) Monitoring and modelling soil organic carbon stocks and flows in New Zealand. Pages 253-268 in C.A. Scott-Smith, ed. Soil organic carbon and agriculture: Developing indicators for policy analysis, Proceedings of an OECD Expert Meeting, Ottawa, ON. October 2002. Agriculture and Agri-Food Canada and Organisation for Economic Co-operation and Development.

Tate, K.R., Wilde, R.H., Giltrap, D.J., Baisden, W.T., Saggar, S., Trustrum, N.A., Scott, N.A. (2003c.) Current Approaches to Soil Carbon Monitoring in New Zealand. In: Proceedings of Carbon Measurement and Monitoring Forum (CASGMS). Manhattan: Kansas. 15-17 October 2003.

Tate, K.R., Scott, N.A., Parshotam, A., Brown, L., Wilde, R.H., Giltrap, D.J., Trustrum, N.A., Gomez, B., \& Ross, D.J. (2000) A multi-scale analysis of a terrestrial carbon budget: Is New Zealand a source or sink of carbon? Agriculture, Ecosystems and Environment 82, 229-246.

Tate, K.R., Giltrap, D.J., Claydon, J.J., Newsome, P.F., Atkinson, I.A.E., Taylor, M.D., \& Lee, R. (1997) Organic Carbon Stocks in New Zealand's Terrestrial Ecosystems. Journal of The Royal Society of New Zealand, 27(3), 315335.

Taylor, N.H. (1970) Wise Land Use and Community Development. Report of Technical Committee of Inquiry into the problems of the Poverty BayEast Cape District of New Zealand. Water and Soil Division, Ministry of Works, Wellington, $120 \mathrm{p}$.

Tisdall, J.M. (1996) Formation of soil aggregates and accumulation of soil organic matter. In: Structure and Organic Matter Storage in Agricultural Soils. pp.57-96, Carter, M. R. and Stewart B. A., Eds., CRC Press, Boca Raton, FL. 
Trotter, C.M., Tate, K.R., Saggar, S., Scott, N.A., Sutherland, M.A. (2004) A MultiScale Analysis of a National Terrestrial Carbon Budget and the Effects of Land-Use Change. Global Environmental Change in the Ocean and on Land, Eds., M. Shiyomi et al., 311-341. by TERRAPUB, 2004.

Trumbore, S.E. (1997) Potential responses of soil organic carbon to global environmental change. Proceedings of the National Academy of Sciences of the United States of America. 94(16) 8284-8291.

United Nations Framework Convention on Climate Change (UNFCCC) (2009). New Zealand. Report of the individual review of the annual submission of New Zealand submitted in 2009. United Nations Office at Geneva

United States Department of Agriculture (USDA) (2009) Natural Resources Conservation Service. National Soil Survey Handbook. Available online at: http://soils.usda.gov/technical/handbook/

United States Department of Energy (1999) Publication: Carbon Sequestration Research and Development. Chapter 4: Carbon Sequestration in Terrestrial Ecosystems, and Chapter 10: Findings and Recommendations. Retrieved July 28, 2008, from http://fossil.energy.gov/

Walkley, A., \& Black, I.A. (1934) An examination of Degtjareff method for determining soil organic matter and a proposed modification of the chromic acid titration method, Soil Science, 37, 29-37.

Watts, L.F., \& Hawke, R.M. (2003) The effects of urbanization on hydrologic response: a study of two coastal catchments. Journal of Hydrology (NZ) 42 (2) 125-143, 2003.

Webb, T.H., \& Wilson, A. D. (1995) A manual of land characteristics for evaluation of rural land. Landcare Research Science Series 10. Linsoln, New Zealand, Manaaki Whenua Press. 32p.

Whangapirita, L., Awatere, S., \& Nikora, L. (2003) Maori Perspectives of the Environment. A Review of Environment Waikato Iwi Environmental Management Plans. Technical Report No. 2. Environment Waikato Internal Series 2004/01.

White, R. E. (2006) Principles and Practice of Soil Science: The Soil as a Natural Resource. Fourth Edition. Blackwell Science Ltd.

Wilde, R.H., Davis, M., Tate, K., \& Giltrap, D.J. (2004) Testing the representativeness of soil carbon data held in the databases underpinning the New Zealand Soil Carbon Monitoring System. SuperSoil 2004: 3rd Australian New Zealand Soils Conference, 5-9 December 2004, University of Sydney, Australia. 
Wilde, R.H. (2003) Manual for National Soils Database. Landcare Research New Zealand Ltd. 
APPENDIX I:

NZSC SOIL ORDERS 


\begin{tabular}{|c|c|}
\hline \multicolumn{2}{|c|}{ ORDERS OF THE NEW ZEALAND SOIL CLASSIFICATION: } \\
\hline Allophanic Soils (L) & Dominated by short-range-order minerals \\
\hline Anthropic Soils (A) & Soils substantially modified by man \\
\hline Brown Soils (B) & $\begin{array}{l}\text { Yellow-brown B horizon, low base } \\
\text { saturation }\end{array}$ \\
\hline Gley Soils (G) & Reductimorphic from near surface to depth \\
\hline Granular Soils (N) & $\begin{array}{l}\text { Strongly weathered, moderately active clay, } \\
\text { pedal cutanic horizon }\end{array}$ \\
\hline Melanic Soils (E) & $\begin{array}{l}\text { Low colour values, pedal A horizon and } \\
\text { pedal high-base-status B horizon }\end{array}$ \\
\hline Organic Soils (O) & Organic soil material, including thick litters \\
\hline Oxidic Soils (X) & $\begin{array}{l}\text { Strongly weathered, low activity clay, fine } \\
\text { polyhedral structure, friable failure }\end{array}$ \\
\hline Pallic Soils (P) & $\begin{array}{l}\text { Pale colours, weakly weathered high base } \\
\text { status, low sequioxides, high slaking } \\
\text { potential, high subsoil density }\end{array}$ \\
\hline Podzols (Z) & $\begin{array}{l}\text { An E horizon, and a sesquioxidic/organic } \\
\text { illuvial horizon }\end{array}$ \\
\hline Pumice Soils (M) & Dominated by pumiceous or glassy skeleton \\
\hline Raw Soils (W) & $\begin{array}{l}\text { Topsoil absent or with fluid subsurface } \\
\text { horizons }\end{array}$ \\
\hline Recent Soils (R) & $\begin{array}{l}\text { Distinct topsoil, absent or very thin B } \\
\text { horizon, no fluid subsurface horizon }\end{array}$ \\
\hline Semiarid Soils (S) & $\begin{array}{l}\text { Semi-arid soil moisture regime, very weakly } \\
\text { weathered and weakly leached }\end{array}$ \\
\hline Ultic Soils (U) & $\begin{array}{l}\text { Strongly weathered, acid, clayey illuvial } \\
\text { horizon }\end{array}$ \\
\hline
\end{tabular}

Source: Hewitt, 1998 
NZSC SOIL ORDERS FURTHER DESCRIBED:

\section{ALLOPHANIC SOILS - L}

Allophanic Soils are dominated by allophane (also imogolite or ferrihydrite) minerals. These stiff, jelly-like minerals coat the sand and silt grains and maintain porous, low density structure with weak strength. The soils are identified by a distinctly greasy feel when moistened and rubbed firmly between the fingers. The soil is easy to dig and samples crumble easily when crushed in the hand.

Occurrence: These soils occur predominantly in the North Island volcanic ash, and in the weathering products of other volcanic rocks. They also occur in the weathering products of greywacke and schist in the South Island high country. These are common soils in the stable easier hill country, rolling land, and on terraces in the eastern and northern parts of the GEC region, where the influence of Taupo Pumice is not great. They cover $5 \%$ of New Zealand

Physical Properties: Because bulk density is very low and there is little resistance to root growth, topsoil and subsoil horizons are very friable. Topsoils are stable and resist the impact of machinery or grazing animals in wet weather. Erosion rates are generally low except on steep slopes or exposed sites.

Chemical properties: The ability to retain phosphorous is high. Natural fertility is low.

Biological properties: Soils contain large populations of soil organisms, particularly in A horizons.

Climate: Soils are usually moist with more than $1000 \mathrm{~mm} / \mathrm{yr}$ rainfall.

\section{Soil groups of the Allophanic Soils order:}

Perch-gley Allophanic Soils (LP) - periodic wetness caused by a perched watertable

Gley Allophanic Soils (LG) - periodic wetness caused by a groundwater-table Impeded Allophanic Soils (LI) - have a hard layer that impedes roots and water Orthic Allophanic Soils (LO) - other Allophanic Soils

\section{Nearest equivalent New Zealand Genetic Soil Classification classes:}

Perch-gley Allophanic Soils (LP) - gley soils

Gley Allophanic Soils (LG) - gley soils

Impeded Allophanic Soils (LI) - yellow-brown loams

Orthic Allophanic Soils (LO) - yellow-brown loams 


\section{BROWN SOILS - B}

Brown Soils have a brown or yellow-brown subsoil below a dark grey-brown topsoil. The brown colour is caused by thin coatings of iron oxides weathered from the parent material.

Occurrence: Brown Soils occur in places where summer drought is uncommon (except in some stony and sandy sites) and which are not waterlogged in winter. They are the most extensive soils covering $43 \%$ of New Zealand. Brown Soils are common in the hill country of the GEC region: in particular, where erosion is not severe and where older weathered tephric soil material (if present) is not thick enough; or if thick enough, the P-retention values are too low to qualify soils as Allophanic.

Physical properties: They have relatively stable topsoils with well-developed polyhedral or spheroidal structure.

Chemical properties: Soils have low to moderate base saturation. Clay minerals are dominantly mica/illite and vermiculite, with allophane in Allophanic Brown Soils.

Biological properties: Soils contain large, active populations of soil organisms, particularly earthworms.

Climate: Rainfall is more than $1000 \mathrm{~mm} / \mathrm{yr}$. Soils are rarely dry except for some stony and sandy soils.

\section{Soil groups of the Brown Soils order:}

Allophanic Brown Soils $(\mathrm{BL})$ - have an horizon with soil properties dominated by allophonic material

Sandy Brown Soils (BS) - dominated by sand or loamy sand to depth

Oxidic Brown Soils $(B X)$ - similar to Oxidic Soils but with significant weatherable minerals

Mafic Brown Soils (BM) - in materials from dark igneous rocks or sediments

Acid Brown Soils (BA) - strongly or extremely acid

Firm Brown Soils (BF) - strong, apedal subsurface horizon

Orthic Brown Soils (BO) - other Brown Soils

\section{Nearest equivalent New Zealand Genetic Soil Classification classes:}

Allophanic Brown Soils (BL) - yellow-brown earths (upland and high country)

Sandy Brown Soils (BS) - yellow-brown sands

Oxidic Brown Soils (BX) - yellow-brown earths (northern)

Mafic Brown Soils (BM) - brown granular loams and clays

Acid Brown Soils (BA) - podzolised yellow-brown earths, yellow-brown shallow and stony soils

Firm Brown Soils (BF) - yellow-brown earths, yellow-brown shallow and stony soils Orthic Brown Soils (BO) - yellow-brown earths, yellow-brown shallow and stony soils 
Gley Soils are strongly affected by waterlogging and have been chemically reduced. They have light grey subsoils, usually with reddish brown or brown mottles. The grey colours usually extend to more than $90 \mathrm{~cm}$ depth. Waterlogging occurs in winter and spring, and some soils remain wet all year.

Occurrence: Gley Soils occur throughout New Zealand in low parts of the landscape where there are high groundwater-tables, or in places where there are seepages. Large areas of Grey Soils have been artificially drained to form productive agricultural land on flood plains, such as on the Poverty Bay and Tolaga Bay flats. They cover $3 \%$ of New Zealand.

Physical properties: These soils have high groundwater-tables, shallow potential rooting depth and relatively high bulk density. Trafficability is limited when soils are wet. Drainage is necessary for most agricultural development.

Chemical properties: Soils have common segregated iron and manganese oxide mottles, concretions or nodules. Organic matter content is usually high.

Biological properties: Many soil organisms are restricted because of anaerobic conditions.

\section{Soil groups of the Gley Soils order:}

Sulphuric Gley Soils (GU) - sulphuric acid or the mineral jarosite in marine estuarine soils

Sandy Gley Soils (GS) - dominated by sand or loamy sand to depth

Acid Gley Soils (GA) - strongly or extremely acid

Oxidic Gley Soils $(G X)$ - similar to Oxidic Soils but with less iron oxide

Recent Gley Soils (GR) - on young land surfaces, mainly alluvial or estuarine

Orthic Gley Soils (GO) - other Gley Soils

Nearest equivalent New Zealand Genetic Soil Classification classes:

Sulphuric Gley Soils (GU) - gley soils

Sandy Gley Soils (GS) - gley soils

Acid Gley Soils (GA) - gley soils

Oxidic Gley Soils (GX) - gley soils

Recent Gley Soils (GR) - gleyed recent soils

Orthic Gley Soils (GO) - gleyed recent soils 


\section{ORGANIC SOILS - 0}

Organic Soils are formed in the partly decomposed remains of wetland plants (peat) or forest litter. Some mineral material may be present but the soil is dominated by organic matter.

Occurrence: Organic Soils occur in wetlands in most parts of New Zealand, or under forests that produce acid litter in areas with high precipitation. They cover $1 \%$ of New Zealand.

Physical properties: Organic Soils have very low bulk densities, low bearing strength, high shrinkage potential when dried, very low thermal conductivity and high total available-water capacity.

Chemical properties: Organic Soils have high cation exchange capacities, are usually strongly or extremely acid, and nutrient deficiencies are common.

Biological properties: High carbon/nitrogen ratios indicate slow decomposition rates. Many soil organisms are restricted because of anaerobic conditions.

\section{Soil groups of the Organic Soils order:}

Litter Organic Soils $(\mathrm{OL})$ - thick litter that has accumulated under forest

Fibric Organic Soils (OF) - in peat with plant fibres that are only weakly decomposed

Mesic Organic Soils $(\mathrm{OM})$ - in peat that is moderately decomposed

Humic Organic Soils $(\mathrm{OH})$ - in peat that is strongly decomposed

Nearest equivalent New Zealand Genetic Soil Classification classes:

Litter Organic Soils (OL) - unclassified

Fibric Organic Soils (OF) - organic soils

Mesic Organic Soils (OM) - organic soils

Humic Organic Soils $(\mathrm{OH})$ - organic soils 


\section{PALLIC SOILS - P}

Pallic Soils have pale coloured subsoils, due to low contents of iron oxides. The soils have weak structure and high density in subsurface horizons. Pallic Soils become dry in summer and wet in winter

Occurrence: Pallic Soils occur predominantly in the seasonally dry eastern part of the North and South Islands, and in the Manawatu. They cover $12 \%$ of New Zealand, but are relatively poorly represented in the GEC region, being confined to lower rainfall areas such as the eastern coastal areas and around the margins of the Poverty Bay flats. Parent materials are commonly loess derived from schist or greywacke.

Physical properties: Soils have slow permeability with limited rooting depth, and medium to high bulk density. They are susceptible to erosion because of high potential for slaking and dispersion. Pallic Soils of the GEC region developed on mudstones have perched watertables.

Chemical properties: Soils have medium to high nutrient content (except for sulphur), high base saturation, low concentrations of secondary oxides, and low organic matter contents. Phosphorus-retention values are less than $30 \%$.

Biological properties: Soils are strongly worm-mixed, at the boundary of the A and B horizons.

Climate: Annual precipitation usually between 500 and $1000 \mathrm{~mm}$ and the climate is typically droughty in summer, and moist or wet in winter.

\section{Soil groups of the Pallic Soils order:}

Perch-gley Pallic Soils (PP) - periodic wetness caused by a perched water table Duric Pallic Soils (PU) - silica-cemented pan in the subsoil

Fragic Pallic Soils (PX) - a compact pan in the subsoil

Laminar Pallic Soils (PL) - clay accumulation as thin subsoil bands subsoil Argillic Pallic Soils (PJ) - clay accumulation as thin coatings on peds or in pores Immature Pallic Soils $(\mathrm{PI})$ - Weakly expressed pallic soil features 


\section{PODZOLS - Z}

Podzol soils are strongly acid soils that usually have a bleached horizon immediately beneath the topsoil. This horizon is the source of aluminium and iron oxides that have accumulated, in association with organic matter, in an underlying dark or reddish coloured horizon.

Occurrence: Podzol Soils occur in areas of high rainfall and are usually associated with forest trees with an acid litter. They are most common in Northland, the North Island high country, and the West Coast and high country of the South Island. The soils occur mainly in materials from silica-rich rocks such as granite, greywacke, schist, ryholite, or rhyolitic ash. They cover $13 \%$ of New Zealand, and are found in upland areas (>550 $\mathrm{m}$ a.sl.) of the GEC region. Sandy Taupo and Waimihia tephric soil materials are prone to processes that result in the formation of Podzols.

Physical properties: Cemented or compacted B horizons are common, with associated slow permeability and limited root depth. E and B horizons are weakly pedal or lack pedality.

Chemical properties: Podzol soils have low natural fertility, low base saturation, and are strongly acid. Secondary oxides and other clay minerals are strongly differentiated with depth.

Biological properties: Podzols have low biological activity. The vegetation comprises plants that deposit a mor-forming acid litter.

Climate: The soils are moist throughout the year with annual rainfall more than about $1500 \mathrm{~mm}$ (and in the GEC region, more than about $1800 \mathrm{~mm} / \mathrm{yr}$ ).

\section{Soil groups of the Podzol Soils order:}

Densipan Podzol Soils (ZD) - high density, pale coloured, pan just beneath the topsoil

Perch-gley Podzol Soils (ZP) - periodic wetness caused by a perched watertable Groundwater-gley Podzol Soils (ZG) - periodic wetness caused by a groundwatertable

Pan Podzol Soils $(Z X)$ - with a subsoil cemented pan

Orthic Podzol Soils (ZO) - other Podzols

\section{Nearest equivalent New Zealand Genetic Soil Classification classes:}

Densipan Podzol Soils (ZD) - podzols

Perch-gley Podzol Soils (ZP) - gley-podzols

Groundwater-gley Podzol Soils (ZG) - gley-podzols

Pan Podzol Soils $(Z X)$ - podzols

Orthic Podzol Soils (ZO) - podzols 


\section{PUMIC SOILS - M}

Pumice Soils are sandy or gravelly soils dominated by pumice, or pumice sand with a high content of natural glass. Drainage of excess water is rapid but the soils are capable of storing large amounts of water for plants. They occur in tephras ranging from 700 to 3500 years old.

Occurrence: Pumice Soils occur predominantly in the central North Island, particularly in the Volcanic Plateau. They cover $7 \%$ of New Zealand.

Physical properties: Clay contents are low, generally less than $10 \%$. They have low soil strengths, high macroporosity, and deep rooting depth. Soils have low strength when disturbed, but are generally resistant to livestock treading damage.

Chemical properties: The pumice is fresh or only moderately weathered with low reserves of major nutrient elements. Trace elements are likely to be deficient. Clay minerals are dominated by allophane.

Biological properties: Soil animal populations are low with most species concentrated in the topsoil. Earthworm populations are limited by droughtiness and coarse texture.

\section{Soil groups of the Pumice Soils order:}

Perch-gley Pumic Soils (MP) - periodic wetness caused by a perched watertable Impeded Pumice Soils $(\mathrm{M})$ - with a subsoil layer that restricts water movement and roots

Orthic Pumice Soils (MO) - other Pumice Soils

\section{Nearest equivalent New Zealand Genetic Soil Classification classes:}

Perch-gley Pumic Soils (MP) - gley soils

Impeded Pumice Soils (M) - yellow-brown pumice soils

Orthic Pumice Soil (MO) - yellow-brown pumice soils 


\section{RAW SOILS - W}

Raw Soils are very young soils. They lack distinct topsoil development or are fluid at a shallow depth. They occur in environments where the development of topsoils is prevented by rockiness, by active erosion, or deposition.

Occurrence: Raw Soils are scattered throughout New Zealand, particularly in association with high mountains (alpine rock areas and active screes), braided rivers, beaches and tidal estuaries. They cover 3\% of New Zealand.

Physical properties: Raw Soils have no B horizon, and a topsoil is either absent or less than $5 \mathrm{~cm}$ thick. Most occur in environments with active erosion or deposition. Fluid soils have a continuously high water-table.

Chemical properties: Fertility is limited by lack of organic matter and nitrogen deficiency.

Biological properties: Vegetation cover is sparse and often consists of ephemeral herbaceous plants, mosses, or lichens.

\section{Soil groups of the Raw Soils order:}

Gley Raw Soils (WG) - periodically wet

Hydrothermal Raw Soils (WH) - soils naturally warmed by geothermal activity

Rocky Raw Soils (WX) - rock at shallow depths

Sandy Raw Soils (WS) - dominated by sand or loamy sand to depth

Fluvial Raw Soils (WF) - in sediments deposited by flowing water

Tephric Raw Soils (WT) - in sediments originating as volcanic ejecta

Orthic Raw Soils (WO) - other Raw Soils

Nearest equivalent New Zealand Genetic Soil Classification classes:

Gley Raw Soils (WG) - unclassified

Hydrothermal Raw Soils $(\mathrm{WH})$ - hydrothermal soils

Rocky Raw Soils (WX) - unclassified

Sandy Raw Soils (WS) - unclassified

Fluvial Raw Soils (WF) - unclassified

Tephric Raw Soils (WT) - unclassified

Orthic Raw Soils (WO) - unclassified 


\section{RECENT SOILS - R}

Recent Soils are weakly developed, showing limited signs of soil-forming processes. $A$ distinct topsoil is present but a $B$ horizon is either absent or only weakly expressed.

Occurrence: Recent soils occur throughout New Zealand on young land surfaces, including alluvial floodplains, unstable steep slopes, and slopes mantled by young volcanic ash. Their age varies depending on the environment and soil materials, but most are less than 1000 to 2000 years old. They cover 6\% of New Zealand.

Physical properties: The soils have variable soil texture, with common stratification of contrasting materials, and spatial variability is high. They are generally deep rooting and have high plant-available water capacity.

Chemical Properties: Natural fertility is usually high with high base saturation. The clay mineralogy is usually dominated by illite.

Biological Properties: A continuous cover of vascular plants is normally well established.

\section{Soil groups of the Recent Soils order:}

Hydrothermal Recent Soils $(\mathrm{RH})$ - soils naturally warmed by geothermal activity Rocky Recent Soils (RX) - rock at shallow depths

Sandy Recent Soils (RS) - dominated by sand or loamy sand to depth

Fluvial Recent Soils (RF) - in sediments deposited by flowing water

Tephric Recent Soils (RT) - in sediments originating as volcanic ejecta

Orthic Recent Soils (RO) - other Recent Soils, most commonly on slopes

Nearest equivalent New Zealand Genetic Soil Classification classes:

Hydrothermal Recent Soils $(\mathrm{RH})$ - recent soils

Rocky Recent Soils (RX) - lithosols

Sandy Recent Soils (RS) - recent soils

Fluvial Recent Soils (RF) - recent soils

Tephric Recent Soils (RT) - recent soils

Orthic Recent Soils $(\mathrm{RO})$ - recent soils

Source: Jessen et al.1999 


\section{APPENDIX II:}

EXPLANATION OF ATTRIBUTE DATA FROM NZFSL AND THE NZLRI: 


\section{TOTAL CARBON:}

Total carbon (organic matter content) is represented by four data fields: CARBON_CLASS, CARBON_MIN, CARBON_MAX and CARBON_MID. CARBON_CLASS is a 1-character alphanumeric field corresponding to the minimum and maximum values of carbon in the upper part of the soil profile within the depths of 0-0.2 $\mathrm{m}$ (expressed as a percentage). Values are weighted averages over the specified control section $(0-20 \mathrm{~cm})$. CARBON_MIN, CARBON_MAX, and CARBON_MID are numeric fields representing the minimum, maximum and mid-values of carbon. The classes used here are those given in Table 21 of Webb and Wilson (1995) and Blakemore et al. (1987). Two alphanumeric reliability fields (CARB_VAR and CARB_EST) are associated with total carbon. Total carbon classes and their corresponding values and description are as follows:

\begin{tabular}{|l|l|l|l|l|}
\hline CARBON_CLASS & $\begin{array}{l}\text { CARBON_MIN } \\
(\%)\end{array}$ & $\begin{array}{l}\text { CARBON_MAX } \\
(\%)\end{array}$ & $\begin{array}{l}\text { CARBON_MID } \\
(\%)\end{array}$ & Description \\
\hline 1 & 20 & 60 & 40 & Very high \\
\hline 2 & 10 & 19.9 & 15 & High \\
\hline 3 & 4 & 9.9 & 7 & Medium \\
\hline 4 & 2 & 3.9 & 3 & Low \\
\hline 5 & 0 & 1.9 & 1 & Very low \\
\hline
\end{tabular}


APPENDIX III:

METHODS 


\section{COLORIMETRIC DETERMINATION OF ORGANIC CARBON:}

Derived from the original Walkley and Black (1934) paper, and Metson (1956).

Set out in Blakemore et al. (1987).

CAUTION: This method uses very toxic and very corrosive reagents. It is potentially hazardous.

Reagents:

- - Chromium trioxide 3M.

- - Sulphuric acid 98\%w/w

- - Sucrose

\section{Standard preparation:}

Soils with $<\mathbf{1 0} \%$ Carbon: Weigh out sucrose standards which are equivalent to $0,20,40,60,80$ and $100 \mathrm{mg}$ soil carbon, using the following table.

\begin{tabular}{|l|l|l|l|}
\hline For 1g soil samples & \multicolumn{5}{|l|}{} \\
\hline Soil Carbon \% & Soil Carbon (mg) & $\begin{array}{l}\text { Sucrose carbon } \\
\text { equivalent }(\mathrm{mg})\end{array}$ & Sucrose (g) \\
\hline 0 & 0 & 0 & 0 \\
\hline 2 & 20 & 19.6 & 0.0465 \\
\hline 4 & 40 & 39.0 & 0.0926 \\
\hline 6 & 60 & 58.4 & 0.1386 \\
\hline 8 & 80 & 77.9 & 0.1849 \\
\hline 10 & 100 & 97.4 & 0.2312 \\
\hline
\end{tabular}

Soils with $>\mathbf{1 0} \%$ Carbon: Weigh out sucrose standards using the table below:

\begin{tabular}{|l|l|l|l|}
\hline For 0.2g soil samples & \multicolumn{3}{l|}{} \\
\hline Soil Carbon \% & Soil Carbon (mg) & $\begin{array}{l}\text { Sucrose carbon } \\
\text { equivalent }(\mathrm{mg})\end{array}$ & Sucrose (g) \\
\hline 0 & 0 & 0 & 0 \\
\hline 2 & 20 & 20.8 & 0.0494 \\
\hline 4 & 40 & 41.6 & 0.0988 \\
\hline 6 & 60 & 62.4 & 0.1481 \\
\hline 8 & 80 & 83.2 & 0.1974 \\
\hline 10 & 100 & 104.0 & 0.2469 \\
\hline
\end{tabular}


(note: accuracy only needs to be to 2 decimal places, as long as exact measurement is recorded)

\section{Procedure:}

1. Weigh out standards and soil into $250 \mathrm{ml}$ volumetric flasks. Record weights (g).

2. Add $12 \mathrm{ml}$ of concentrated sulphuric acid $\mathrm{H}_{2} \mathrm{SO}_{4}$

3. Stand 10 mins

4. $\quad$ Add $6 \mathrm{ml}$ Chromium trioxide $3 \mathrm{M}\left(\mathrm{CrO}_{3}\right)$

5. Stand 10mins EXACTLY

6. Dilute nearly to $250 \mathrm{ml}$

7. Leave overnight for $18-24 \mathrm{hrs}$

8. Make up to $250 \mathrm{ml}$

9. Centrifuge an aliquot (about $40 \mathrm{ml}$ ) for $10-15 \mathrm{mins}$ and $2000 \mathrm{rpm}$

10. Read at $600 \mathrm{~nm}$ on spectrometer

11. Corrections:

TWO corrections must be applied:

- Soil carbon (mg)/ Weight of soil sample = Soil carbon in $1 \mathrm{~g}$ of sample (express as $\mathrm{mg} / \mathrm{g}$ )

- $\quad$ Correct for MF (Soil carbon x MF). 


\section{BULK DENSITY:}

\section{Description:}

The bulk density is the ratio of the soil mass to its volume. Which can be expressed as:

$$
\text { BulkDensity }=\frac{\text { weight }}{\text { volume }}
$$

\section{Procedure:}

1. Obtain a sample in a core tube - trim the ends.

2. Calculate the volume of this soil sample $\left(V=\pi r^{2} h\right)$

3. Weigh the core (soil plus tube)

4. Dry core in oven at $105^{\circ} \mathrm{C}$ for $24 \mathrm{hrs}$. Remove and cool in a desiccator

5. Weigh the oven dried core

6. Remove the soil from the core, weigh the core tube alone

\section{Calculations:}

Weight of soil alone $(\mathrm{W})=\mathrm{W}_{2}-\mathrm{W}_{3}$

Bulk density $\left(D_{b}\right)=W / V$

Water content of soil $\left(\mathrm{W}_{\mathrm{s}}\right)=\left(\frac{W_{1}-W_{2}}{W}\right) \times 100$ 


\section{SOIL MOISTURE FACTOR:}

\section{Description:}

Analysis are carried out on 'air dried' samples, but should be expressed as oven dried weights. Water content can be corrected for using a moisture factor correction. If you are undertaking LOI analysis, moisture factor is included, and can be derived for all other analyses from there.

\section{Procedure:}

1. Weigh soil moisture can (beaker, crucible or soil can that is lidded)

= Weight (a)

2. Weigh $\sim 10 \mathrm{~g}$ air dried soil

= Weight $(b)$

3. Heat soil at $105^{\circ} \mathrm{C}$ for about $24 \mathrm{hrs}$ with the lid uncovered from the sample

4. Remove can, replace lid, and cool in a dessicator, weigh as quickly as possible after removing from dessicator

= Weight $(\mathrm{c})$

\section{Calculation:}

$M F=(b-a) /(c-a)=$ air dry weight of soil/oven dry weight of soil.

For all analyses, the final calculation is multiplied by the moisture factor, which converts from air-dry to oven dry basis. 
CONVERSION CALCULATIONS:

\section{$\% \mathrm{C} / 100 * \mathrm{BD}^{*}$ Depth$^{*} 100=$ Carbon $\mathrm{t} \mathrm{ha}{ }^{-1}$}

Where:

$\% \mathrm{C}$, is the percentage of carbon by weight determined by previous methods,

$\mathrm{BD}$, is bulk density,

D, depth is the soil depth over which carbon is measured and calculated in centimetres

Multiplying by 100 converts from grams per square centimetre to tons per hectare.

A conversion factor of 1.72 is commonly used to convert organic carbon to organic matter:

Organic Matter (\%) = Organic Carbon (\%) x 1.72

This conversion factor assumes organic matter contains 58\% organic carbon. However this can vary with the type of organic matter, soil type and soil depth (Pluske et al. 2010). 


\section{APPENDIX IV:}

\section{TEXTURAL CLASSIFICATIONS AND SOIL WATER CHARACTERISTICS:}

Soil hydraulic properties are inferred from particle size and organic carbon using Saxton and Rawls (2006) pedo-transfer relationships (properties statistically related to \%Sand, \%Silt, \%Clay, soil OM and, bulk density ( $\rho b$.) 


\begin{tabular}{|c|c|c|c|c|c|c|c|c|}
\hline \multicolumn{9}{|c|}{ Garden } \\
\hline $\begin{array}{l}\text { Sample } \\
\text { No. }\end{array}$ & $\begin{array}{l}\text { Depth } \\
\text { (cm) }\end{array}$ & \%Clay & \%Silt & \%Sand & $\% O C$ & BD & $\begin{array}{l}\text { Plant } \\
\text { Available } \\
\text { Water }\end{array}$ & $\begin{array}{l}\text { Saturated } \\
\text { hydraulic } \\
\text { conductivity } \\
\text { (mm/hr) }\end{array}$ \\
\hline 2 & $5-10 \mathrm{~cm}$ & 0.539 & 68.782 & 30.679 & 5.539 & 0.72 & 22.290 & 101.69694 \\
\hline 5 & $30-50 \mathrm{~cm}$ & 1.495 & 54.491 & 44.013 & 1.024 & 0.80 & 14.923 & 57.07979 \\
\hline 8 & $5-10 \mathrm{~cm}$ & 0.735 & 63.575 & 35.690 & 6.119 & 0.72 & 21.264 & 117.72959 \\
\hline 11 & $30-50 \mathrm{~cm}$ & 1.772 & 57.175 & 41.053 & 0.934 & 0.80 & 15.586 & 49.73675 \\
\hline 14 & $5-10 \mathrm{~cm}$ & 0.158 & 49.746 & 50.096 & 6.335 & 0.72 & 17.373 & 143.96557 \\
\hline 17 & $30-50 \mathrm{~cm}$ & 1.990 & 77.219 & 20.791 & 1.441 & 0.80 & 21.465 & 26.94928 \\
\hline 20 & $5-10 \mathrm{~cm}$ & 1.225 & 74.418 & 24.357 & 4.583 & 0.72 & 23.178 & 73.16403 \\
\hline 23 & $30-50 \mathrm{~cm}$ & 6.817 & 58.809 & 34.374 & 0.604 & 0.80 & 16.305 & 22.11538 \\
\hline 26 & $5-10 \mathrm{~cm}$ & 0.521 & 64.921 & 34.558 & 5.231 & 0.72 & 20.862 & 100.87508 \\
\hline 29 & $30-50 \mathrm{~cm}$ & 2.009 & 50.848 & 47.143 & 0.775 & 0.80 & 13.909 & 57.07322 \\
\hline \multicolumn{9}{|c|}{ Gorse } \\
\hline 32 & $5-10 \mathrm{~cm}$ & 0.15062 & 55.2117 & 44.63766 & 7.9801 & 0.86 & 20.452 & 173.116 \\
\hline 35 & $30-50 \mathrm{~cm}$ & 0.96131 & 67.1614 & 31.87731 & 2.36 & 0.90 & 19.208 & 53.41457 \\
\hline 38 & $5-10 \mathrm{~cm}$ & 0.2967 & 61.2096 & 38.4937 & 3.9427 & 0.86 & 18.688 & 86.79539 \\
\hline 41 & $30-50 \mathrm{~cm}$ & 4.57098 & 64.2989 & 31.13017 & 0.5767 & 0.90 & 17.489 & 23.83935 \\
\hline 44 & $5-10 \mathrm{~cm}$ & 0.24703 & 66.6711 & 33.0818 & 4.9526 & 0.86 & 21.118 & 95.76606 \\
\hline 47 & $30-50 \mathrm{~cm}$ & 0.49121 & 57.8041 & 41.7047 & 1.5864 & 0.90 & 16.043 & 64.66556 \\
\hline 50 & $5-10 \mathrm{~cm}$ & 0.05513 & 52.6065 & 47.33839 & 7.3757 & 0.86 & 19.107 & 162.90472 \\
\hline 53 & $30-50 \mathrm{~cm}$ & 1.15718 & 53.9611 & 44.88177 & 2.3076 & 0.90 & 15.582 & 71.06188 \\
\hline 56 & $5-10 \mathrm{~cm}$ & 0.12025 & 58.762 & 41.11776 & 7.4745 & 0.86 & 21.033 & 158.17251 \\
\hline 59 & $30-50 \mathrm{~cm}$ & 0.67735 & 63.6188 & 35.70383 & 1.8312 & 0.90 & 17.803 & 55.32979 \\
\hline \multicolumn{9}{|c|}{ Flats } \\
\hline 62 & $5-10 \mathrm{~cm}$ & 0.02381 & 59.892 & 40.0842 & 4.5787 & 1.15 & 18.799 & 100.70701 \\
\hline 65 & $30-50 \mathrm{~cm}$ & 7.91476 & 61.2918 & 30.79345 & 0.5829 & 1.37 & 17.022 & 17.61189 \\
\hline 68 & $5-10 \mathrm{~cm}$ & 0.03258 & 70.0348 & 29.93168 & 3.9411 & 1.15 & 21.234 & 76.15942 \\
\hline 71 & $30-50 \mathrm{~cm}$ & 4.28595 & 79.8239 & 15.89012 & 0.4912 & 1.37 & 21.651 & 11.78529 \\
\hline 74 & $5-10 \mathrm{~cm}$ & 0.01664 & 67.7969 & 32.18643 & 4.1732 & 1.15 & 20.766 & 82.99763 \\
\hline 77 & $30-50 \mathrm{~cm}$ & 8.24841 & 73.0562 & 18.6954 & 0.3541 & 1.37 & 19.945 & 9.27589 \\
\hline 80 & $5-10 \mathrm{~cm}$ & 0 & 64.3123 & 35.68773 & 5.1983 & 1.15 & 20.612 & 105.30245 \\
\hline 83 & $30-50 \mathrm{~cm}$ & 4.1037 & 74.6419 & 21.25438 & 0.82 & 1.37 & 20.419 & 17.988 \\
\hline 86 & $5-10 \mathrm{~cm}$ & 0.00042 & 66.0215 & 33.9781 & 4.7885 & 1.15 & 20.764 & 95.71885 \\
\hline 89 & $30-50 \mathrm{~cm}$ & 5.1474 & 69.0644 & 25.7882 & 0.4008 & 1.37 & 18.686 & 17.04691 \\
\hline
\end{tabular}




\begin{tabular}{|c|c|c|c|c|c|c|c|c|}
\hline \multicolumn{9}{|c|}{ Top Pasture } \\
\hline $\begin{array}{l}\text { Sample } \\
\text { No. }\end{array}$ & Depth & \%Clay & \%Silt & \%Sand & $\% O C$ & BD & $\begin{array}{l}\text { Plant } \\
\text { Available } \\
\text { Water }\end{array}$ & $\begin{array}{l}\text { Saturated } \\
\text { hydraulic } \\
\text { conductivity }\end{array}$ \\
\hline 91 & $0-5 \mathrm{~cm}$ & 0.566 & 57.779 & 41.656 & 4.945 & 0.93 & 18.546 & 104.92494 \\
\hline 92 & $5-10 \mathrm{~cm}$ & 0.751 & 66.513 & 32.736 & 3.439 & & 19.847 & 68.82815 \\
\hline 93 & $10-20 \mathrm{~cm}$ & 1.076 & 63.042 & 35.881 & 2.235 & & 17.974 & 57.144 \\
\hline 94 & $20-30 \mathrm{~cm}$ & 4.024 & 66.422 & 29.554 & 0.733 & 1.03 & 18.107 & 24.76736 \\
\hline 95 & $30-50 \mathrm{~cm}$ & 17.351 & 58.419 & 24.230 & 0.519 & 1.25 & 17.016 & 7.08223 \\
\hline 96 & $50-\mathrm{cm}$ & 7.638 & 62.085 & 30.277 & 0.546 & & 17.175 & 17.43991 \\
\hline 97 & $0-5 \mathrm{~cm}$ & 0.545 & 50.384 & 49.071 & 6.347 & 0.93 & 17.607 & 139.35097 \\
\hline 98 & $5-10 \mathrm{~cm}$ & 1.152 & 55.367 & 43.481 & 4.688 & & 17.715 & 99.08835 \\
\hline 99 & $10-20 \mathrm{~cm}$ & 0.623 & 52.165 & 47.212 & 3.150 & & 15.627 & 87.58231 \\
\hline 100 & $20-30 \mathrm{~cm}$ & 1.314 & 55.509 & 43.177 & 1.533 & 1.03 & 15.49 & 60.49247 \\
\hline 101 & $30-50 \mathrm{~cm}$ & 5.894 & 66.820 & 27.286 & 0.542 & 1.25 & 18.247 & 17.8865 \\
\hline 102 & $50-\mathrm{cm}$ & 5.225 & 82.748 & 12.027 & 0.447 & & 22.503 & 8.50541 \\
\hline 103 & $0-5 \mathrm{~cm}$ & 0.312 & 46.200 & 53.488 & 7.210 & 0.93 & 17.132 & 163.23269 \\
\hline 104 & $5-10 \mathrm{~cm}$ & 1.024 & 56.718 & 42.258 & 4.476 & & 17.912 & 95.10136 \\
\hline 105 & $10-20 \mathrm{~cm}$ & 0.144 & 48.395 & 51.461 & 3.423 & & 14.758 & 101.7321 \\
\hline 106 & $20-30 \mathrm{~cm}$ & 0.282 & 44.698 & 55.020 & 2.959 & 1.03 & 13.501 & 101.85801 \\
\hline 107 & $30-50 \mathrm{~cm}$ & 0.757 & 51.468 & 47.776 & 2.590 & 1.25 & 15.071 & 81.50897 \\
\hline 108 & $50-\mathrm{cm}$ & 6.067 & 66.038 & 27.895 & 0.957 & & 18.332 & 20.801 \\
\hline 109 & $0-5 \mathrm{~cm}$ & 0.168 & 38.385 & 61.447 & 5.709 & 0.93 & 13.738 & 148.34029 \\
\hline 110 & $5-10 \mathrm{~cm}$ & 0.371 & 38.674 & 60.955 & 3.834 & & 12.536 & 120.56253 \\
\hline 111 & $10-20 \mathrm{~cm}$ & 0.577 & 50.296 & 49.127 & 2.634 & & 14.773 & 85.68522 \\
\hline 112 & $20-30 \mathrm{~cm}$ & 0.766 & 54.000 & 45.234 & 1.907 & 1.03 & 15.282 & 70.99536 \\
\hline 113 & $30-50 \mathrm{~cm}$ & 2.049 & 35.916 & 62.035 & 0.359 & 1.25 & 10.172 & 85.54121 \\
\hline 114 & $50-\mathrm{cm}$ & 5.560 & 89.895 & 4.545 & 0.199 & & 24.399 & 4.1046 \\
\hline 115 & $0-5 \mathrm{~cm}$ & 0.192 & 43.436 & 56.372 & 4.887 & 0.93 & 14.485 & 128.36488 \\
\hline 116 & $5-10 \mathrm{~cm}$ & 0.588 & 56.443 & 42.969 & 3.933 & & 17.367 & 91.24139 \\
\hline 117 & $10-20 \mathrm{~cm}$ & 0.825 & 58.463 & 40.712 & 2.311 & & 16.752 & 66.75255 \\
\hline 118 & $20-30 \mathrm{~cm}$ & 2.312 & 51.057 & 46.631 & 0.919 & 1.03 & 14.079 & 54.90514 \\
\hline 119 & $30-50 \mathrm{~cm}$ & 5.567 & 47.530 & 46.903 & 0.408 & 1.25 & 13.284 & 35.98202 \\
\hline 120 & $50-\mathrm{cm}$ & 8.238 & 74.929 & 16.833 & 0.260 & & 20.38 & 8.02194 \\
\hline
\end{tabular}




\begin{tabular}{|c|c|c|c|c|c|c|c|c|}
\hline \multicolumn{9}{|c|}{ Kanuka } \\
\hline $\begin{array}{l}\text { Sample } \\
\text { No. }\end{array}$ & Depth & \%Clay & \%Silt & \%Sand & $\% O C$ & BD & $\begin{array}{l}\text { Plant } \\
\text { Available } \\
\text { Water }\end{array}$ & $\begin{array}{l}\text { Saturated } \\
\text { hydraulic } \\
\text { conductivity }\end{array}$ \\
\hline 121 & $0-5 \mathrm{~cm}$ & 0.163 & 43.090 & 56.747 & 4.974 & 0.83 & 14.453 & 130.4893 \\
\hline 122 & $5-10 \mathrm{~cm}$ & 0.132 & 46.099 & 53.769 & 3.679 & & 14.326 & 108.76972 \\
\hline 123 & $10-20 \mathrm{~cm}$ & 0.133 & 37.737 & 62.129 & 2.347 & & 11.38 & 112.84723 \\
\hline 124 & $20-30 \mathrm{~cm}$ & 0.408 & 47.586 & 52.006 & 1.500 & 0.84 & 13.348 & 84.9741 \\
\hline 125 & $30-50 \mathrm{~cm}$ & 0.656 & 30.847 & 68.496 & 0.557 & 1.29 & 8.999 & 134.79965 \\
\hline 126 & $50-\mathrm{cm}$ & 18.961 & 64.959 & 16.079 & 0.453 & & 18.51 & 4.72455 \\
\hline 127 & $0-5 \mathrm{~cm}$ & 0.461 & 56.112 & 43.427 & 4.996 & 0.83 & 18.103 & 108.97122 \\
\hline 128 & $5-10 \mathrm{~cm}$ & 0.478 & 49.181 & 50.341 & 3.131 & & 14.804 & 93.69762 \\
\hline 129 & $10-20 \mathrm{~cm}$ & 1.054 & 57.870 & 41.076 & 1.472 & & 16.043 & 58.42786 \\
\hline 130 & $20-30 \mathrm{~cm}$ & 2.331 & 51.458 & 46.211 & 0.584 & 0.84 & 13.983 & 52.12266 \\
\hline 131 & $30-50 \mathrm{~cm}$ & 3.234 & 44.844 & 51.922 & 0.588 & 1.29 & 12.479 & 55.16755 \\
\hline 132 & $50-\mathrm{cm}$ & 7.774 & 65.043 & 27.183 & 0.412 & & 17.858 & 14.52969 \\
\hline 133 & $0-5 \mathrm{~cm}$ & 0.162 & 38.892 & 60.946 & 4.201 & 0.83 & 12.805 & 126.91903 \\
\hline 134 & $5-10 \mathrm{~cm}$ & 0.202 & 42.799 & 56.999 & 3.037 & & 13.055 & 107.00152 \\
\hline 135 & $10-20 \mathrm{~cm}$ & 0.232 & 40.252 & 59.515 & 1.892 & & 11.748 & 104.32139 \\
\hline 136 & $20-30 \mathrm{~cm}$ & 1.034 & 48.126 & 50.841 & 0.724 & 0.84 & 13.103 & 73.71132 \\
\hline 137 & $30-50 \mathrm{~cm}$ & 0.631 & 38.721 & 60.647 & 0.599 & 1.29 & 10.769 & 107.56816 \\
\hline 138 & $50-\mathrm{cm}$ & 3.539 & 35.669 & 60.792 & 0.453 & & 10.324 & 66.98972 \\
\hline 139 & $0-5 \mathrm{~cm}$ & 0.163 & 38.745 & 61.092 & 4.073 & 0.83 & 12.682 & 125.62398 \\
\hline 140 & $5-10 \mathrm{~cm}$ & 0.417 & 46.780 & 52.803 & 3.179 & & 14.2 & 98.92507 \\
\hline 141 & $10-20 \mathrm{~cm}$ & 0.335 & 42.981 & 56.683 & 1.221 & & 12.053 & 96.42527 \\
\hline 142 & $20-30 \mathrm{~cm}$ & 1.456 & 46.074 & 52.470 & 0.630 & 0.84 & 12.6 & 71.9429 \\
\hline 143 & $30-50 \mathrm{~cm}$ & 4.039 & 50.111 & 45.851 & 0.369 & 1.29 & 13.713 & 40.58805 \\
\hline 144 & $50-\mathrm{cm}$ & 12.781 & 46.024 & 41.195 & 0.305 & & 13.704 & 15.82596 \\
\hline 145 & $0-5 \mathrm{~cm}$ & 0.070 & 32.403 & 67.527 & 7.224 & 0.83 & 13.279 & 181.5617 \\
\hline 146 & $5-10 \mathrm{~cm}$ & 0.319 & 42.704 & 56.976 & 4.063 & & 13.722 & 117.06793 \\
\hline 147 & $10-20 \mathrm{~cm}$ & 0.463 & 54.414 & 45.122 & 1.722 & & 15.237 & 71.99913 \\
\hline 148 & $20-30 \mathrm{~cm}$ & 0.454 & 33.443 & 66.104 & 1.001 & 0.84 & 9.739 & 120.87135 \\
\hline 149 & $30-50 \mathrm{~cm}$ & 9.104 & 59.191 & 31.704 & 0.477 & 1.29 & 16.539 & 16.01516 \\
\hline 150 & $50-\mathrm{cm}$ & 12.575 & 41.681 & 45.744 & 0.318 & & 12.715 & 18.56381 \\
\hline
\end{tabular}




\begin{tabular}{|c|c|c|c|c|c|c|c|c|}
\hline \multicolumn{9}{|c|}{ Bottom Pasture } \\
\hline $\begin{array}{l}\text { Sample } \\
\text { No. }\end{array}$ & Depth & \%Clay & \%Silt & \%Sand & $\% O C$ & BD & $\begin{array}{l}\text { Plant } \\
\text { Available } \\
\text { Water }\end{array}$ & $\begin{array}{l}\text { Saturated } \\
\text { hydraulic } \\
\text { conductivity }\end{array}$ \\
\hline 151 & $0-5 \mathrm{~cm}$ & 1.468 & 68.155 & 30.377 & 3.713 & 1.331 & 20.6 & 65.87112 \\
\hline 152 & $5-10 \mathrm{~cm}$ & 3.471 & 75.883 & 20.645 & 1.904 & & 21.533 & 27.41003 \\
\hline 153 & $10-20 \mathrm{~cm}$ & 1.610 & 75.178 & 23.212 & 1.515 & & 20.905 & 31.35665 \\
\hline 154 & $20-30 \mathrm{~cm}$ & 1.324 & 67.990 & 30.687 & 1.403 & 1.262 & 18.763 & 40.73623 \\
\hline 155 & $30-50 \mathrm{~cm}$ & 0.900 & 65.320 & 33.780 & 0.970 & 1.390 & 17.683 & 44.20299 \\
\hline 156 & $50-\mathrm{cm}$ & 4.981 & 79.359 & 15.660 & 1.003 & & 21.934 & 14.04197 \\
\hline 157 & $0-5 \mathrm{~cm}$ & 0.747 & 58.556 & 40.697 & 3.580 & 1.331 & 17.701 & 82.0114 \\
\hline 158 & $5-10 \mathrm{~cm}$ & 2.880 & 70.873 & 26.247 & 1.611 & & 19.851 & 31.62451 \\
\hline 159 & $10-20 \mathrm{~cm}$ & 3.013 & 72.466 & 24.522 & 1.355 & & 20.119 & 27.2846 \\
\hline 160 & $20-30 \mathrm{~cm}$ & 5.108 & 81.614 & 13.278 & 2.902 & 1.262 & 24.039 & 28.09081 \\
\hline 161 & $30-50 \mathrm{~cm}$ & 3.759 & 72.596 & 23.645 & 0.596 & 1.390 & 19.667 & 19.02358 \\
\hline 162 & $50-\mathrm{cm}$ & 8.158 & 79.254 & 12.587 & 0.718 & & 21.853 & 8.36712 \\
\hline 163 & $0-5 \mathrm{~cm}$ & 1.477 & 61.393 & 37.129 & 3.760 & 1.331 & 18.706 & 75.07841 \\
\hline 164 & $5-10 \mathrm{~cm}$ & 1.847 & 63.614 & 34.539 & 2.631 & & 18.497 & 55.66029 \\
\hline 165 & $10-20 \mathrm{~cm}$ & 1.175 & 65.616 & 33.209 & 1.491 & & 18.156 & 45.73762 \\
\hline 166 & $20-30 \mathrm{~cm}$ & 1.673 & 66.302 & 32.025 & 0.968 & 1.262 & 18.022 & 37.37925 \\
\hline 167 & $30-50 \mathrm{~cm}$ & 1.296 & 65.464 & 33.240 & 1.318 & 1.390 & 18.004 & 43.69866 \\
\hline 168 & $50-\mathrm{cm}$ & 2.253 & 76.228 & 21.519 & 0.304 & & 20.353 & 18.41347 \\
\hline 169 & $0-5 \mathrm{~cm}$ & 0.926 & 55.582 & 43.492 & 2.696 & 1.331 & 16.257 & 74.42997 \\
\hline 170 & $5-10 \mathrm{~cm}$ & 1.676 & 68.902 & 29.422 & 1.427 & & 19.066 & 37.74783 \\
\hline 171 & $10-20 \mathrm{~cm}$ & 1.156 & 68.665 & 30.179 & 1.197 & & 18.787 & 39.14118 \\
\hline 172 & $20-30 \mathrm{~cm}$ & 1.950 & 75.002 & 23.048 & 0.909 & 1.262 & 20.425 & 25.06456 \\
\hline 173 & $30-50 \mathrm{~cm}$ & 1.211 & 65.610 & 33.179 & 0.550 & 1.390 & 17.505 & 38.71734 \\
\hline 174 & $50-\mathrm{cm}$ & 3.211 & 75.474 & 21.315 & 1.438 & & 21.046 & 24.48095 \\
\hline 175 & $0-5 \mathrm{~cm}$ & 1.772 & 74.995 & 23.233 & 2.552 & 1.331 & 21.675 & 41.3658 \\
\hline 176 & $5-10 \mathrm{~cm}$ & 1.188 & 63.172 & 35.640 & 2.128 & & 17.943 & 55.09338 \\
\hline 177 & $10-20 \mathrm{~cm}$ & 1.349 & 60.684 & 37.967 & 1.899 & & 17.117 & 55.35526 \\
\hline 178 & $20-30 \mathrm{~cm}$ & 3.393 & 82.219 & 14.389 & 1.531 & 1.262 & 23.077 & 19.07949 \\
\hline 179 & $30-50 \mathrm{~cm}$ & 1.033 & 61.178 & 37.789 & 0.856 & 1.390 & 16.508 & 49.08053 \\
\hline 180 & $50-\mathrm{cm}$ & 1.590 & 78.874 & 19.536 & 0.875 & & 21.484 & 22.14781 \\
\hline
\end{tabular}




\begin{tabular}{|c|c|c|c|c|c|c|c|c|}
\hline \multicolumn{9}{|c|}{ River } \\
\hline $\begin{array}{l}\text { Sample } \\
\text { No. }\end{array}$ & Depth & \%Clay & \%Silt & \%Sand & $\% O C$ & BD & $\begin{array}{l}\text { Plant } \\
\text { Available } \\
\text { Water }\end{array}$ & $\begin{array}{l}\text { Saturated } \\
\text { hydraulic } \\
\text { conductivity }\end{array}$ \\
\hline 181 & $0-5 \mathrm{~cm}$ & 3.193 & 64.982 & 31.824 & 2.777 & 1.18 & 19.103 & 48.43592 \\
\hline 182 & $5-10 \mathrm{~cm}$ & 1.339 & 58.759 & 39.902 & 1.841 & & 16.558 & 57.76318 \\
\hline 183 & $10-20 \mathrm{~cm}$ & 1.793 & 60.057 & 38.151 & 0.760 & & 16.226 & 43.99218 \\
\hline 184 & $20-30 \mathrm{~cm}$ & 2.854 & 58.807 & 38.339 & 0.328 & 1.14 & 15.736 & 35.85266 \\
\hline 185 & $30-50 \mathrm{~cm}$ & 3.179 & 62.459 & 34.362 & 0.666 & 1.34 & 16.932 & 31.87529 \\
\hline 186 & $50-\mathrm{cm}$ & 4.581 & 79.485 & 15.934 & 0.934 & & 21.897 & 14.22927 \\
\hline 187 & $0-5 \mathrm{~cm}$ & 0.708 & 52.459 & 46.834 & 3.938 & 1.18 & 16.286 & 96.19069 \\
\hline 188 & $5-10 \mathrm{~cm}$ & 0.519 & 44.632 & 54.849 & 3.866 & & 14.117 & 109.33587 \\
\hline 189 & $10-20 \mathrm{~cm}$ & 0.656 & 50.793 & 48.551 & 2.134 & & 14.583 & 79.5617 \\
\hline 190 & $20-30 \mathrm{~cm}$ & 0.914 & 44.275 & 54.811 & 1.172 & 1.14 & 12.403 & 84.01817 \\
\hline 191 & $30-50 \mathrm{~cm}$ & 2.229 & 49.827 & 47.944 & 0.770 & 1.34 & 13.677 & 56.73862 \\
\hline 192 & $50-\mathrm{cm}$ & 4.191 & 68.085 & 27.724 & 0.453 & & 18.378 & 20.74399 \\
\hline 193 & $0-5 \mathrm{~cm}$ & 1.696 & 59.206 & 39.098 & 3.433 & 1.18 & 17.864 & 72.10805 \\
\hline 194 & $5-10 \mathrm{~cm}$ & 2.086 & 63.423 & 34.491 & 2.862 & & 18.639 & 57.14291 \\
\hline 195 & $10-20 \mathrm{~cm}$ & 1.516 & 62.450 & 36.033 & 1.251 & & 17.161 & 45.98826 \\
\hline 196 & $20-30 \mathrm{~cm}$ & 1.577 & 69.550 & 28.873 & 0.792 & 1.14 & 18.781 & 32.35413 \\
\hline 197 & $30-50 \mathrm{~cm}$ & 3.662 & 61.776 & 34.562 & 0.498 & 1.34 & 16.691 & 29.26128 \\
\hline 198 & $50-\mathrm{cm}$ & 8.929 & 75.621 & 15.450 & 0.464 & & 20.737 & 7.9767 \\
\hline 199 & $0-5 \mathrm{~cm}$ & 1.004 & 52.505 & 46.490 & 4.054 & 1.18 & 16.418 & 95.07293 \\
\hline 200 & $5-10 \mathrm{~cm}$ & 0.387 & 39.391 & 60.221 & 3.379 & & 12.431 & 114.3007 \\
\hline 201 & $10-20 \mathrm{~cm}$ & 0.477 & 49.615 & 49.908 & 2.198 & & 14.3 & 84.10591 \\
\hline 202 & $20-30 \mathrm{~cm}$ & 1.868 & 50.563 & 47.568 & 0.724 & 1.14 & 13.793 & 58.67846 \\
\hline 203 & $30-50 \mathrm{~cm}$ & 9.844 & 75.491 & 14.665 & 0.337 & 1.34 & 20.665 & 6.72143 \\
\hline 204 & $50-\mathrm{cm}$ & 7.445 & 79.051 & 13.504 & 0.307 & & 21.482 & 7.22999 \\
\hline 205 & $0-5 \mathrm{~cm}$ & 0.800 & 50.270 & 48.930 & 2.469 & 1.18 & 14.682 & 81.94869 \\
\hline 206 & $5-10 \mathrm{~cm}$ & 2.489 & 75.687 & 21.824 & 2.111 & & 21.574 & 32.93975 \\
\hline 207 & $10-20 \mathrm{~cm}$ & 3.842 & 74.091 & 22.067 & 1.603 & & 20.82 & 25.20984 \\
\hline 208 & $20-30 \mathrm{~cm}$ & 2.120 & 60.494 & 37.385 & 0.939 & 1.14 & 16.491 & 42.31884 \\
\hline 209 & $30-50 \mathrm{~cm}$ & 5.390 & 82.332 & 12.278 & 0.396 & 1.34 & 22.356 & 8.26557 \\
\hline 210 & $50-\mathrm{cm}$ & 9.085 & 78.130 & 12.785 & 0.263 & & 21.282 & 6.06282 \\
\hline
\end{tabular}


APPENDIX V:

SOIL CHEMICAL ANALYSIS: ORGANIC CARBON RESULTS 


\section{"GARDEN":}

\begin{tabular}{|c|c|c|c|c|c|c|c|}
\hline $\begin{array}{l}\text { Sample } \\
\text { No. }\end{array}$ & $\begin{array}{l}\text { Profile } \\
\text { No. }\end{array}$ & $\begin{array}{l}\text { Depth } \\
\text { Intervals }\end{array}$ & $\begin{array}{l}\text { Soil } \\
\text { Weight } \\
\text { (g) }\end{array}$ & Absorbance & $\begin{array}{l}\text { Moisture } \\
\text { Factor }\end{array}$ & $\begin{array}{l}\text { Soil OC } \\
\text { (mg/g) }\end{array}$ & Error \\
\hline 1 & 1 & $0-5 \mathrm{~cm}$ & 1.0072 & 0.391 & 1.0550 & 53.7322 & 2.0552 \\
\hline 2 & 1 & $5-10 \mathrm{~cm}$ & 1.0042 & 0.401 & 1.0565 & 55.3888 & 2.0559 \\
\hline 3 & 1 & $10-20 \mathrm{~cm}$ & 1.0071 & 0.372 & 1.0564 & 51.1200 & 2.0552 \\
\hline 4 & 1 & $20-30 \mathrm{~cm}$ & 1.0001 & 0.117 & 1.0537 & 15.0950 & 2.2092 \\
\hline 5 & 1 & $30-50 \mathrm{~cm}$ & 1.0034 & 0.083 & 1.0555 & 10.2445 & 2.2496 \\
\hline 6 & 1 & $50-$ & 0.9966 & 0.107 & 1.0424 & 13.5737 & 2.2207 \\
\hline 7 & 2 & $0-5 \mathrm{~cm}$ & 0.9941 & 0.395 & 1.0552 & 55.0229 & 2.0555 \\
\hline 8 & 2 & $5-10 \mathrm{~cm}$ & 1.0076 & 0.444 & 1.0548 & 61.1871 & 2.0639 \\
\hline 9 & 2 & $10-20 \mathrm{~cm}$ & 0.9951 & 0.31 & 1.0533 & 42.7290 & 2.0667 \\
\hline 10 & 2 & $20-30 \mathrm{~cm}$ & 1.0049 & 0.143 & 1.0476 & 18.5924 & 2.1812 \\
\hline 11 & 2 & $30-50 \mathrm{~cm}$ & 1.0015 & 0.077 & 1.0480 & 9.3445 & 2.2571 \\
\hline 12 & 2 & $50-$ & 1.0055 & 0.029 & 1.0365 & 2.5286 & 2.3219 \\
\hline 13 & 3 & $0-5 \mathrm{~cm}$ & 1.0000 & 0.654 & 1.0656 & 92.4762 & 2.2184 \\
\hline 14 & 3 & $5-10 \mathrm{~cm}$ & 1.006 & 0.457 & 1.0585 & 63.3455 & 2.0680 \\
\hline 15 & 3 & $10-20 \mathrm{~cm}$ & 1.0059 & 0.361 & 1.0561 & 49.6070 & 2.0560 \\
\hline 16 & 3 & $20-30 \mathrm{~cm}$ & 0.9978 & 0.191 & 1.0529 & 25.6526 & 2.1364 \\
\hline 17 & 3 & $30-50 \mathrm{~cm}$ & 1.0008 & 0.112 & 1.0563 & 14.4087 & 2.2149 \\
\hline 18 & 3 & $50-$ & 0.9989 & 0.032 & 1.0404 & 2.9766 & 2.3176 \\
\hline 19 & 4 & $0-5 \mathrm{~cm}$ & 1.0024 & 0.531 & 1.0550 & 73.8700 & 2.1055 \\
\hline 20 & 4 & $5-10 \mathrm{~cm}$ & 1.0015 & 0.336 & 1.0461 & 45.8292 & 2.0598 \\
\hline 21 & 4 & $10-20 \mathrm{~cm}$ & 1.0095 & 0.165 & 1.0388 & 21.4073 & 2.1596 \\
\hline 22 & 4 & $20-30 \mathrm{~cm}$ & 1.0045 & 0.072 & 1.0322 & 8.4826 & 2.2635 \\
\hline 23 & 4 & $30-50 \mathrm{~cm}$ & 1.0031 & 0.054 & 1.0399 & 6.0396 & 2.2872 \\
\hline 24 & 4 & $50-$ & 1.0077 & 0.021 & 1.0261 & 1.3987 & 2.3334 \\
\hline 25 & 5 & $0-5 \mathrm{~cm}$ & 1.004 & 0.358 & 1.0540 & 49.1756 & 2.0563 \\
\hline 26 & 5 & $5-10 \mathrm{~cm}$ & 1.0041 & 0.38 & 1.0545 & 52.3130 & 2.0550 \\
\hline 27 & 5 & $10-20 \mathrm{~cm}$ & 1.0052 & 0.348 & 1.0537 & 47.6876 & 2.0576 \\
\hline 28 & 5 & $20-30 \mathrm{~cm}$ & 1.0075 & 0.17 & 1.0497 & 22.3772 & 2.1549 \\
\hline 29 & 5 & $30-50 \mathrm{~cm}$ & 1.0055 & 0.066 & 1.0471 & 7.7532 & 2.2713 \\
\hline 30 & 5 & $50-$ & 1.0067 & 0.031 & 1.0365 & 2.8035 & 2.3190 \\
\hline
\end{tabular}

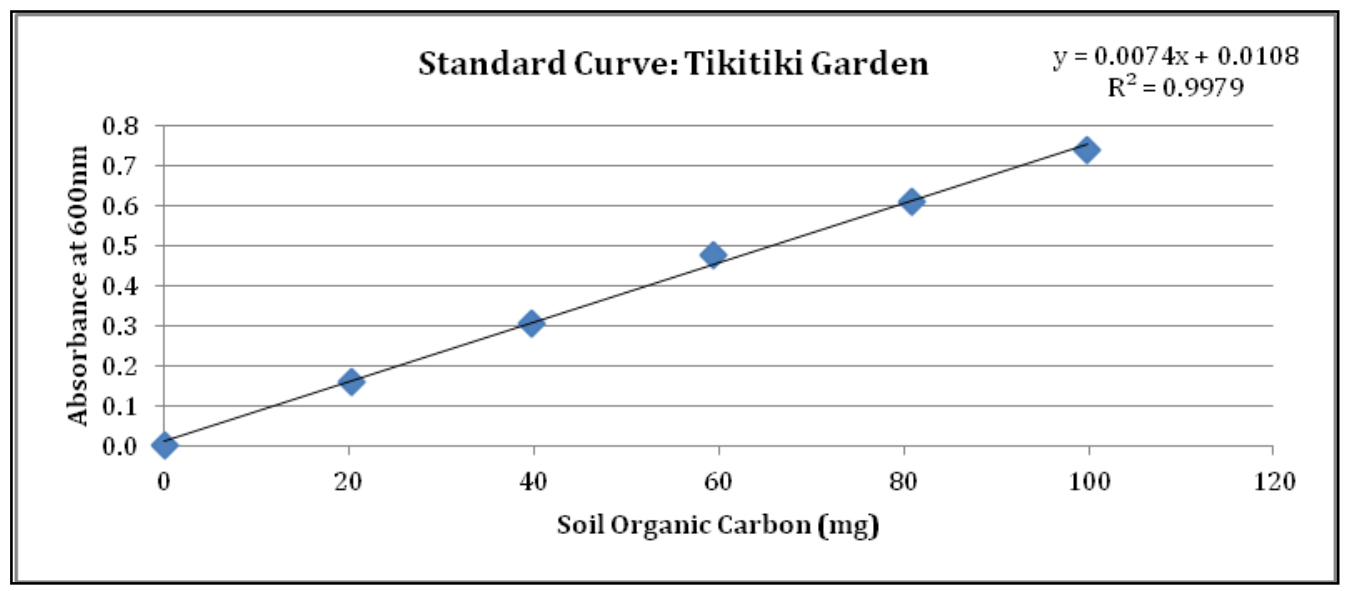


“GORSE”

\begin{tabular}{|c|c|c|c|c|c|c|c|}
\hline $\begin{array}{l}\text { Sample } \\
\text { No. }\end{array}$ & $\begin{array}{l}\text { Profile } \\
\text { No. }\end{array}$ & $\begin{array}{l}\text { Depth } \\
\text { Intervals }\end{array}$ & $\begin{array}{l}\text { Soil } \\
\text { Weight } \\
\text { (g) }\end{array}$ & Absorbance & $\begin{array}{l}\text { Moisture } \\
\text { Factor }\end{array}$ & $\begin{array}{l}\text { Soil OC } \\
\text { (mg/g) }\end{array}$ & Error \\
\hline 31 & 1 & $0-5 \mathrm{~cm}$ & 1.0075 & 0.727 & 1.0691 & 97.3086 & 1.3856 \\
\hline 32 & 1 & $5-10 \mathrm{~cm}$ & 1.0084 & 0.601 & 1.0666 & 79.8006 & 1.3079 \\
\hline 33 & 1 & $10-20 \mathrm{~cm}$ & 1.0037 & 0.437 & 1.0608 & 57.3775 & 1.2614 \\
\hline 34 & 1 & $20-30 \mathrm{~cm}$ & 1.0018 & 0.271 & 1.0569 & 34.6787 & 1.2828 \\
\hline 35 & 1 & $30-50 \mathrm{~cm}$ & 1.0048 & 0.19 & 1.0577 & 23.6004 & 1.3176 \\
\hline 36 & 1 & $50-$ & 0.9968 & 0.047 & 1.0611 & 4.2276 & 1.4139 \\
\hline 37 & 2 & $0-5 \mathrm{~cm}$ & 1.0021 & 0.535 & 1.0607 & 70.8416 & 1.2813 \\
\hline 38 & 2 & $5-10 \mathrm{~cm}$ & 1.0096 & 0.309 & 1.0538 & 39.4274 & 1.2718 \\
\hline 39 & 2 & $10-20 \mathrm{~cm}$ & 1.0002 & 0.087 & 1.0485 & 9.5729 & 1.3828 \\
\hline 40 & 2 & $20-30 \mathrm{~cm}$ & 0.9999 & 0.067 & 1.0481 & 6.8678 & 1.3980 \\
\hline 41 & 2 & $30-50 \mathrm{~cm}$ & 1.0002 & 0.059 & 1.0451 & 5.7674 & 1.4042 \\
\hline 42 & 2 & $50-$ & 1.0016 & 0.1 & 1.0396 & 11.2193 & 1.3734 \\
\hline 43 & 3 & $0-5 \mathrm{~cm}$ & 1.0053 & 0.577 & 1.0631 & 76.5105 & 1.2971 \\
\hline 44 & 3 & $5-10 \mathrm{~cm}$ & 1.0066 & 0.382 & 1.0564 & 49.5257 & 1.2608 \\
\hline 45 & 3 & $10-20 \mathrm{~cm}$ & 0.9996 & 0.283 & 1.2326 & 42.4413 & 1.2789 \\
\hline 46 & 3 & $20-30 \mathrm{~cm}$ & 1.002 & 0.188 & 1.0462 & 23.1404 & 1.3187 \\
\hline 47 & 3 & $30-50 \mathrm{~cm}$ & 1.0007 & 0.133 & 1.0536 & 15.8636 & 1.3510 \\
\hline 48 & 3 & $50-$ & 1.0004 & 0.035 & 1.0543 & 2.5539 & 1.4237 \\
\hline 49 & 4 & $0-5 \mathrm{~cm}$ & 1.0026 & 0.747 & 1.0723 & 100.8404 & 1.4008 \\
\hline 50 & 4 & $5-10 \mathrm{~cm}$ & 1.0063 & 0.555 & 1.0678 & 73.7571 & 1.2883 \\
\hline 51 & 4 & $10-20 \mathrm{~cm}$ & 1.0016 & 0.398 & 1.0640 & 52.3227 & 1.2601 \\
\hline 52 & 4 & $20-30 \mathrm{~cm}$ & 1.0067 & 0.218 & 1.0587 & 27.3772 & 1.3039 \\
\hline 53 & 4 & $30-50 \mathrm{~cm}$ & 1.0061 & 0.186 & 1.0599 & 23.0759 & 1.3198 \\
\hline 54 & 4 & $50-$ & 1.0059 & 0.054 & 1.0444 & 5.0613 & 1.4082 \\
\hline 55 & 5 & $0-5 \mathrm{~cm}$ & 1.0043 & 0.764 & 1.0752 & 103.2855 & 1.4144 \\
\hline 56 & 5 & $5-10 \mathrm{~cm}$ & 1.0045 & 0.559 & 1.0722 & 74.7445 & 1.2898 \\
\hline 57 & 5 & $10-20 \mathrm{~cm}$ & 0.9977 & 0.38 & 1.0632 & 50.0123 & 1.2609 \\
\hline 58 & 5 & $20-30 \mathrm{~cm}$ & 1.0073 & 0.271 & 1.0584 & 34.5393 & 1.2828 \\
\hline 59 & 5 & $30-50 \mathrm{~cm}$ & 1.0025 & 0.151 & 1.0557 & 18.3125 & 1.3397 \\
\hline 60 & 5 & $50-$ & 1.0015 & 0.046 & 1.0330 & 3.9636 & 1.4147 \\
\hline
\end{tabular}

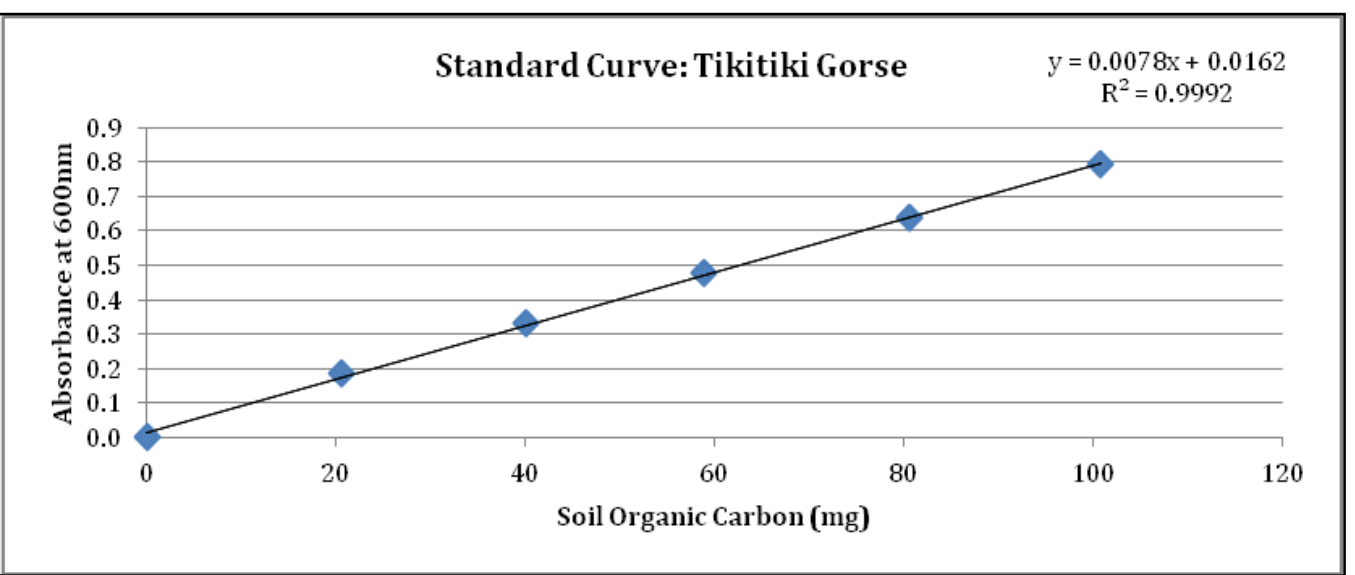


"FLATS":

\begin{tabular}{|c|c|c|c|c|c|c|c|}
\hline $\begin{array}{l}\text { Sample } \\
\text { No. }\end{array}$ & $\begin{array}{l}\text { Profile } \\
\text { No. }\end{array}$ & $\begin{array}{l}\text { Depth } \\
\text { Intervals }\end{array}$ & $\begin{array}{l}\text { Soil } \\
\text { Weight } \\
\text { (g) }\end{array}$ & Absorbance & $\begin{array}{l}\text { Moisture } \\
\text { Factor }\end{array}$ & $\begin{array}{l}\text { Soil OC } \\
\text { (mg/g) }\end{array}$ & Error \\
\hline 61 & 1 & $0-5 \mathrm{~cm}$ & 1.0604 & 0.507 & 1.0457 & 63.4861 & 0.5869 \\
\hline 62 & 1 & $5-10 \mathrm{~cm}$ & 1.0283 & 0.359 & 1.0382 & 45.7867 & 0.5801 \\
\hline 63 & 1 & $10-20 \mathrm{~cm}$ & 0.9997 & 0.187 & 1.0281 & 23.8921 & 0.6041 \\
\hline 64 & 1 & $20-30 \mathrm{~cm}$ & 1.0477 & 0.06 & 1.0252 & 6.7539 & 0.6419 \\
\hline 65 & 1 & $30-50 \mathrm{~cm}$ & 1.0096 & 0.051 & 1.0244 & 5.8290 & 0.6452 \\
\hline 66 & 1 & $50-$ & 1.0274 & 0.048 & 1.0380 & 5.4144 & 0.6463 \\
\hline 67 & 2 & $0-5 \mathrm{~cm}$ & 0.8973 & 0.412 & 1.0451 & 60.7547 & 0.5796 \\
\hline 68 & 2 & $5-10 \mathrm{~cm}$ & 1.0418 & 0.314 & 1.0378 & 39.4113 & 0.5831 \\
\hline 69 & 2 & $10-20 \mathrm{~cm}$ & 1.014 & 0.177 & 1.0308 & 22.3087 & 0.6065 \\
\hline 70 & 2 & $20-30 \mathrm{~cm}$ & 1.0064 & 0.087 & 1.0254 & 10.5693 & 0.6326 \\
\hline 71 & 2 & $30-50 \mathrm{~cm}$ & 1.0218 & 0.052 & 0.8545 & 4.9117 & 0.6448 \\
\hline 72 & 2 & $50-$ & 1.0064 & 0.031 & 1.0328 & 3.2562 & 0.6527 \\
\hline 73 & 3 & $0-5 \mathrm{~cm}$ & 1.022 & 0.477 & 1.0467 & 61.9861 & 0.5835 \\
\hline 74 & 3 & $5-10 \mathrm{~cm}$ & 1.0433 & 0.333 & 1.0365 & 41.7316 & 0.5815 \\
\hline 75 & 3 & $10-20 \mathrm{~cm}$ & 1.0054 & 0.136 & 1.0286 & 17.0586 & 0.6174 \\
\hline 76 & 3 & $20-30 \mathrm{~cm}$ & 1.0239 & 0.043 & 1.0243 & 4.7179 & 0.6481 \\
\hline 77 & 3 & $30-50 \mathrm{~cm}$ & 1.0681 & 0.035 & 1.0258 & 3.5411 & 0.6511 \\
\hline 78 & 3 & $50-$ & 1.0092 & 0.047 & 1.0375 & 5.3769 & 0.6467 \\
\hline 79 & 4 & $0-5 \mathrm{~cm}$ & 0.9944 & 0.51 & 1.0441 & 67.9987 & 0.5873 \\
\hline 80 & 4 & $5-10 \mathrm{~cm}$ & 0.9984 & 0.395 & 1.0385 & 51.9834 & 0.5794 \\
\hline 81 & 4 & $10-20 \mathrm{~cm}$ & 0.9955 & 0.26 & 1.0312 & 33.7877 & 0.5898 \\
\hline 82 & 4 & $20-30 \mathrm{~cm}$ & 1.0173 & 0.154 & 1.0278 & 19.1843 & 0.6124 \\
\hline 83 & 4 & $30-50 \mathrm{~cm}$ & 0.9949 & 0.068 & 1.0287 & 8.1998 & 0.6391 \\
\hline 84 & 4 & $50-$ & 0.9987 & 0.066 & 1.0268 & 7.8894 & 0.6398 \\
\hline 85 & 5 & $0-5 \mathrm{~cm}$ & 1.0019 & 0.614 & 1.0485 & 81.7735 & 0.6074 \\
\hline 86 & 5 & $5-10 \mathrm{~cm}$ & 1.0017 & 0.367 & 1.0343 & 47.8850 & 0.5798 \\
\hline 87 & 5 & $10-20 \mathrm{~cm}$ & 0.9976 & 0.148 & 1.0252 & 18.7206 & 0.6141 \\
\hline 88 & 5 & $20-30 \mathrm{~cm}$ & 1.003 & 0.047 & 1.0225 & 5.3321 & 0.6467 \\
\hline 89 & 5 & $30-50 \mathrm{~cm}$ & 1.0076 & 0.037 & 1.0238 & 4.0077 & 0.6504 \\
\hline 90 & 5 & $50-$ & 1.0074 & 0.038 & 1.0272 & 4.1529 & 0.6500 \\
\hline
\end{tabular}

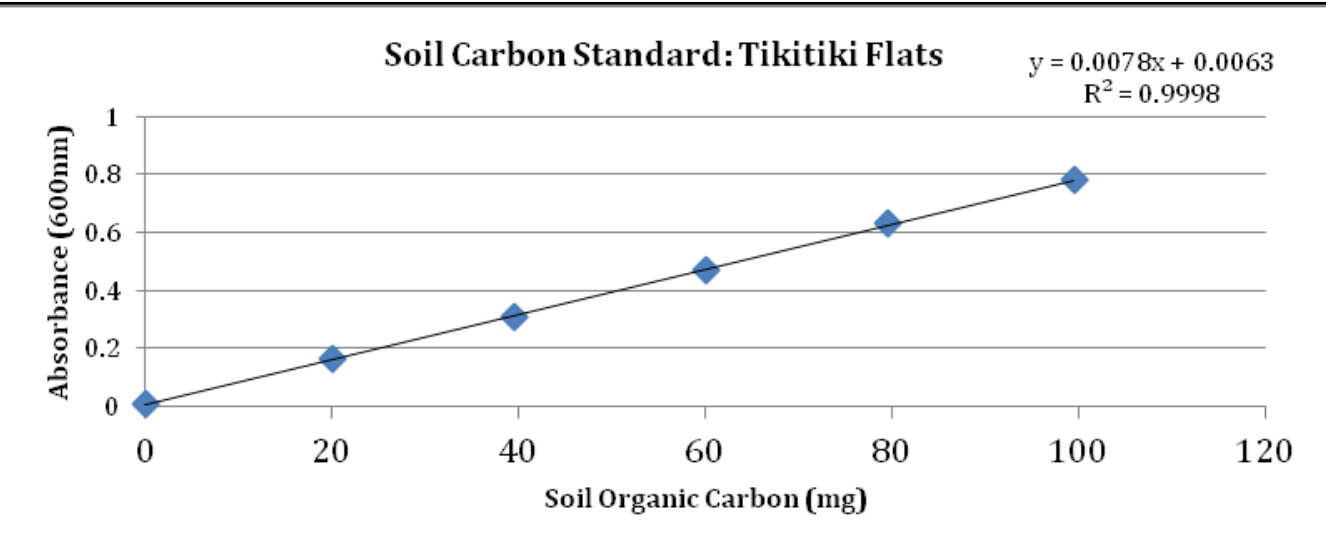


“TOP PASTURE”:

\begin{tabular}{|c|c|c|c|c|c|c|c|}
\hline $\begin{array}{l}\text { Sample } \\
\text { No. }\end{array}$ & $\begin{array}{l}\text { Profile } \\
\text { No. }\end{array}$ & $\begin{array}{l}\text { Depth } \\
\text { Intervals }\end{array}$ & $\begin{array}{l}\text { Soil } \\
\text { Weight } \\
\text { (g) }\end{array}$ & Absorbance & $\begin{array}{l}\text { Moisture } \\
\text { Factor }\end{array}$ & $\begin{array}{l}\text { Soil OC } \\
\text { (mg/g) }\end{array}$ & Error \\
\hline 91 & 1 & $0-5 \mathrm{~cm}$ & 0.9981 & 0.352 & 1.0414 & 49.4455 & 1.6477 \\
\hline 92 & 1 & $5-10 \mathrm{~cm}$ & 1.0038 & 0.25 & 1.0374 & 34.3938 & 1.6752 \\
\hline 93 & 1 & $10-20 \mathrm{~cm}$ & 0.9955 & 0.165 & 1.0335 & 22.3458 & 1.7272 \\
\hline 94 & 1 & $20-30 \mathrm{~cm}$ & 1.0007 & 0.061 & 1.0269 & 7.3261 & 1.8233 \\
\hline 95 & 1 & $30-50 \mathrm{~cm}$ & 1.0049 & 0.046 & 1.0305 & 5.1936 & 1.8399 \\
\hline 96 & 1 & $50-$ & 1.0022 & 0.047 & 1.0514 & 5.4585 & 1.8387 \\
\hline 97 & 2 & $0-5 \mathrm{~cm}$ & 0.9989 & 0.45 & 1.0404 & 63.4743 & 1.6587 \\
\hline 98 & 2 & $5-10 \mathrm{~cm}$ & 1.0081 & 0.339 & 1.0367 & 46.8849 & 1.6490 \\
\hline 99 & 2 & $10-20 \mathrm{~cm}$ & 0.9964 & 0.229 & 1.0332 & 31.4988 & 1.6857 \\
\hline 100 & 2 & $20-30 \mathrm{~cm}$ & 0.9963 & 0.117 & 1.0260 & 15.3288 & 1.7674 \\
\hline 101 & 2 & $30-50 \mathrm{~cm}$ & 0.9971 & 0.047 & 1.0391 & 5.4222 & 1.8387 \\
\hline 102 & 2 & $50-$ & 1.0048 & 0.04 & 1.0600 & 4.4675 & 1.8466 \\
\hline 103 & 3 & $0-5 \mathrm{~cm}$ & 1.0071 & 0.512 & 1.0445 & 72.0976 & 1.6844 \\
\hline 104 & 3 & $5-10 \mathrm{~cm}$ & 1.0043 & 0.323 & 1.0364 & 44.7639 & 1.6515 \\
\hline 105 & 3 & $10-20 \mathrm{~cm}$ & 1.0026 & 0.249 & 1.0355 & 34.2302 & 1.6757 \\
\hline 106 & 3 & $20-30 \mathrm{~cm}$ & 1.0082 & 0.218 & 1.0337 & 29.5853 & 1.6918 \\
\hline 107 & 3 & $30-50 \mathrm{~cm}$ & 1.0071 & 0.192 & 1.0327 & 25.9012 & 1.7080 \\
\hline 108 & 3 & $50-$ & 1.0005 & 0.075 & 1.0546 & 9.5666 & 1.8085 \\
\hline 109 & 4 & $0-5 \mathrm{~cm}$ & 0.9977 & 0.404 & 1.0436 & 57.0936 & 1.6490 \\
\hline 110 & 4 & $5-10 \mathrm{~cm}$ & 1.0027 & 0.278 & 1.0347 & 38.3389 & 1.6637 \\
\hline 111 & 4 & $10-20 \mathrm{~cm}$ & 1.0059 & 0.195 & 1.0321 & 26.3417 & 1.7060 \\
\hline 112 & 4 & $20-30 \mathrm{~cm}$ & 0.9974 & 0.143 & 1.0291 & 19.0677 & 1.7447 \\
\hline 113 & 4 & $30-50 \mathrm{~cm}$ & 1.0054 & 0.035 & 1.0185 & 3.5895 & 1.8524 \\
\hline 114 & 4 & $50-$ & 0.998 & 0.023 & 1.0570 & 1.9949 & 1.8664 \\
\hline 115 & 5 & $0-5 \mathrm{~cm}$ & 0.9988 & 0.348 & 1.0422 & 48.8699 & 1.6480 \\
\hline 116 & 5 & $5-10 \mathrm{~cm}$ & 0.9991 & 0.284 & 1.0346 & 39.3328 & 1.6617 \\
\hline 117 & 5 & $10-20 \mathrm{~cm}$ & 1.0023 & 0.172 & 1.0297 & 23.1057 & 1.7220 \\
\hline 118 & 5 & $20-30 \mathrm{~cm}$ & 0.9959 & 0.074 & 1.0243 & 9.1919 & 1.8095 \\
\hline 119 & 5 & $30-50 \mathrm{~cm}$ & 1.0059 & 0.038 & 1.0366 & 4.0791 & 1.8489 \\
\hline 120 & 5 & $50-$ & 0.9961 & 0.027 & 1.0647 & 2.6044 & 1.8617 \\
\hline
\end{tabular}

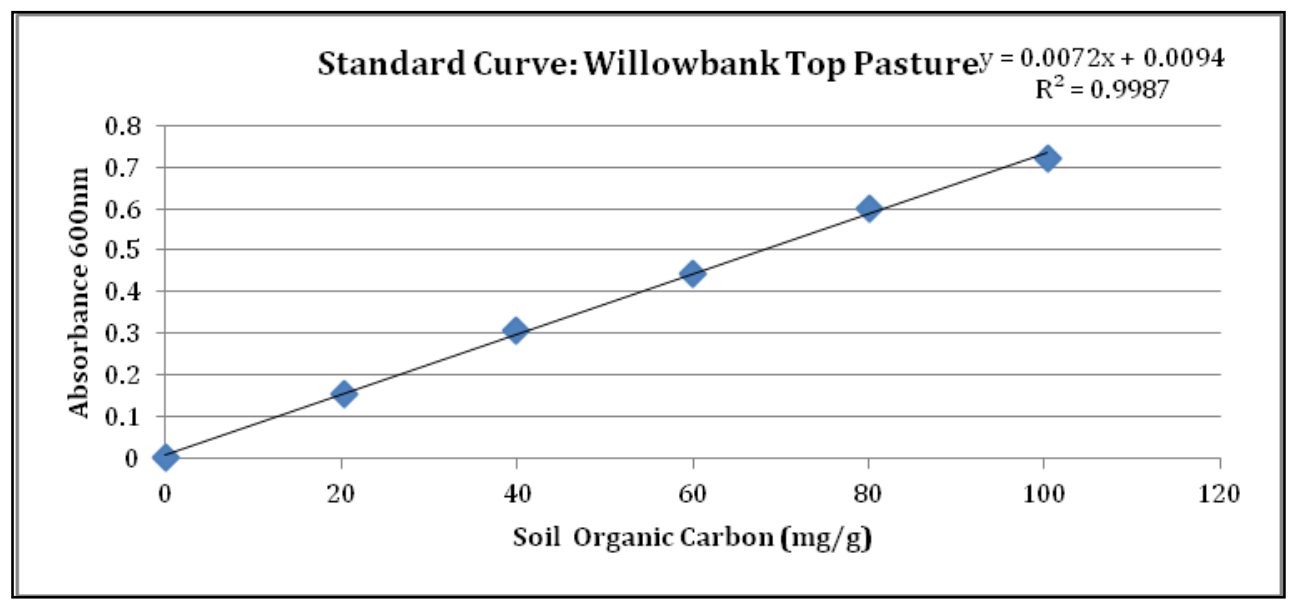


“KANUKA":

\begin{tabular}{|c|c|c|c|c|c|c|c|}
\hline $\begin{array}{l}\text { Sample } \\
\text { No. }\end{array}$ & $\begin{array}{l}\text { Profile } \\
\text { No. }\end{array}$ & $\begin{array}{l}\text { Depth } \\
\text { Intervals }\end{array}$ & $\begin{array}{l}\text { Soil } \\
\text { Weight } \\
\text { (g) }\end{array}$ & Absorbance & $\begin{array}{l}\text { Moisture } \\
\text { Factor }\end{array}$ & $\begin{array}{l}\text { Soil OC } \\
\text { (mg/g) }\end{array}$ & Error \\
\hline 121 & 1 & $0-5 \mathrm{~cm}$ & 1.0062 & 0.389 & 0.9847 & 49.7443 & 2.0210 \\
\hline 122 & 1 & $5-10 \mathrm{~cm}$ & 0.9992 & 0.272 & 1.0327 & 36.7862 & 2.0460 \\
\hline 123 & 1 & $10-20 \mathrm{~cm}$ & 1.0009 & 0.174 & 1.0293 & 23.4744 & 2.1096 \\
\hline 124 & 1 & $20-30 \mathrm{~cm}$ & 1.0065 & 0.112 & 1.0237 & 15.0020 & 2.1683 \\
\hline 125 & 1 & $30-50 \mathrm{~cm}$ & 1.0023 & 0.041 & 1.0142 & 5.5667 & 2.2515 \\
\hline 126 & 1 & $50-$ & 1.0018 & 0.033 & 1.0166 & 4.5250 & 2.2619 \\
\hline 127 & 2 & $0-5 \mathrm{~cm}$ & 1.0014 & 0.37 & 1.0346 & 49.9604 & 2.0212 \\
\hline 128 & 2 & $5-10 \mathrm{~cm}$ & 1.0008 & 0.232 & 1.0315 & 31.3130 & 2.0674 \\
\hline 129 & 2 & $10-20 \mathrm{~cm}$ & 1.0003 & 0.109 & 1.0254 & 14.7201 & 2.1715 \\
\hline 130 & 2 & $20-30 \mathrm{~cm}$ & 1.0033 & 0.043 & 1.0161 & 5.8353 & 2.2490 \\
\hline 131 & 2 & $30-50 \mathrm{~cm}$ & 0.9945 & 0.043 & 1.0156 & 5.8839 & 2.2490 \\
\hline 132 & 2 & $50-$ & 1.0056 & 0.03 & 1.0187 & 4.1215 & 2.2658 \\
\hline 133 & 3 & $0-5 \mathrm{~cm}$ & 0.9957 & 0.311 & 1.0285 & 42.0114 & 2.0314 \\
\hline 134 & 3 & $5-10 \mathrm{~cm}$ & 1.0009 & 0.226 & 1.0269 & 30.3693 & 2.0712 \\
\hline 135 & 3 & $10-20 \mathrm{~cm}$ & 1.0082 & 0.142 & 1.0222 & 18.9176 & 2.1382 \\
\hline 136 & 3 & $20-30 \mathrm{~cm}$ & 1.0072 & 0.054 & 1.0137 & 7.2409 & 2.2351 \\
\hline 137 & 3 & $30-50 \mathrm{~cm}$ & 0.9956 & 0.044 & 1.0122 & 5.9901 & 2.2477 \\
\hline 138 & 3 & $50-$ & 0.9995 & 0.033 & 1.0162 & 4.5337 & 2.2619 \\
\hline 139 & 4 & $0-5 \mathrm{~cm}$ & 1.0063 & 0.305 & 1.0274 & 40.7252 & 2.0332 \\
\hline 140 & 4 & $5-10 \mathrm{~cm}$ & 1.0055 & 0.238 & 1.0257 & 31.7894 & 2.0638 \\
\hline 141 & 4 & $10-20 \mathrm{~cm}$ & 1.0005 & 0.091 & 1.0169 & 12.2110 & 2.1912 \\
\hline 142 & 4 & $20-30 \mathrm{~cm}$ & 1.0091 & 0.047 & 1.0120 & 6.3012 & 2.2439 \\
\hline 143 & 4 & $30-50 \mathrm{~cm}$ & 1.0078 & 0.027 & 1.0104 & 3.6873 & 2.2698 \\
\hline 144 & 4 & $50-$ & 1.0082 & 0.022 & 1.0154 & 3.0480 & 2.2765 \\
\hline 145 & 5 & $0-5 \mathrm{~cm}$ & 1 & 0.53 & 1.0439 & 72.2370 & 2.0664 \\
\hline 146 & 5 & $5-10 \mathrm{~cm}$ & 1.0007 & 0.3 & 1.0362 & 40.6307 & 2.0349 \\
\hline 147 & 5 & $10-20 \mathrm{~cm}$ & 1.0024 & 0.128 & 1.0255 & 17.2219 & 2.1519 \\
\hline 148 & 5 & $20-30 \mathrm{~cm}$ & 1.0086 & 0.075 & 1.0166 & 10.0086 & 2.2097 \\
\hline 149 & 5 & $30-50 \mathrm{~cm}$ & 1.0016 & 0.035 & 1.0121 & 4.7693 & 2.2593 \\
\hline 150 & 5 & $50-$ & 1.0055 & 0.023 & 1.0140 & 3.1833 & 2.2751 \\
\hline
\end{tabular}

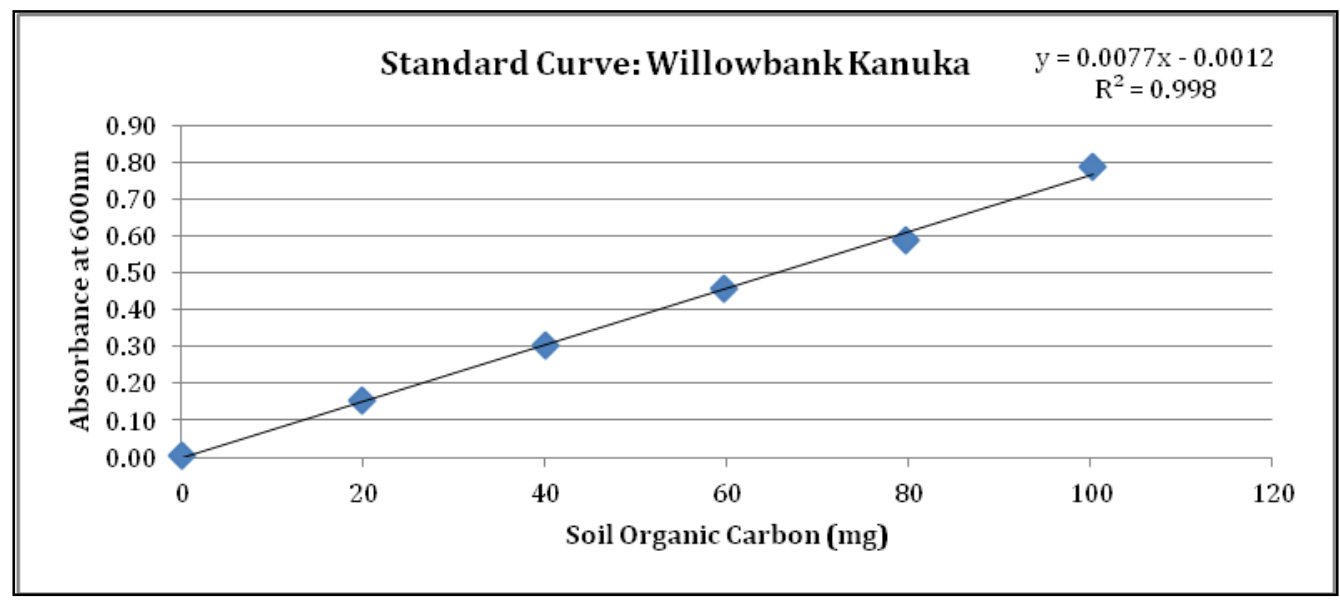


“BOTTOM PASTURE”:

\begin{tabular}{|c|c|c|c|c|c|c|c|}
\hline $\begin{array}{l}\text { Sample } \\
\text { No. }\end{array}$ & $\begin{array}{l}\text { Profile } \\
\text { No. }\end{array}$ & $\begin{array}{l}\text { Depth } \\
\text { Intervals }\end{array}$ & $\begin{array}{l}\text { Soil } \\
\text { Weight } \\
\text { (g) }\end{array}$ & Absorbance & $\begin{array}{l}\text { Moisture } \\
\text { Factor }\end{array}$ & $\begin{array}{l}\text { Soil OC } \\
\text { (mg/g) }\end{array}$ & Error \\
\hline 151 & 1 & $0-5 \mathrm{~cm}$ & 1.0018 & 0.273 & 1.0344 & 37.1322 & 0.6691 \\
\hline 152 & 1 & $5-10 \mathrm{~cm}$ & 1.0041 & 0.142 & 1.0409 & 19.0444 & 0.7008 \\
\hline 153 & 1 & $10-20 \mathrm{~cm}$ & 1.0036 & 0.114 & 1.0409 & 15.1548 & 0.7104 \\
\hline 154 & 1 & $20-30 \mathrm{~cm}$ & 1.004 & 0.106 & 1.0406 & 14.0310 & 0.7133 \\
\hline 155 & 1 & $30-50 \mathrm{~cm}$ & 1.0052 & 0.075 & 1.0404 & 9.7031 & 0.7254 \\
\hline 156 & 1 & $50-$ & 1.0009 & 0.077 & 1.0407 & 10.0270 & 0.7246 \\
\hline 157 & 2 & $0-5 \mathrm{~cm}$ & 1.0083 & 0.264 & 1.0386 & 35.7971 & 0.6705 \\
\hline 158 & 2 & $5-10 \mathrm{~cm}$ & 1.0091 & 0.122 & 1.0361 & 16.1052 & 0.7075 \\
\hline 159 & 2 & $10-20 \mathrm{~cm}$ & 1.0032 & 0.103 & 1.0349 & 13.5491 & 0.7144 \\
\hline 160 & 2 & $20-30 \mathrm{~cm}$ & 1.0073 & 0.215 & 1.0375 & 29.0162 & 0.6803 \\
\hline 161 & 2 & $30-50 \mathrm{~cm}$ & 1.0023 & 0.048 & 1.0389 & 5.9595 & 0.7367 \\
\hline 162 & 2 & $50-$ & 1.0075 & 0.057 & 1.0404 & 7.1848 & 0.7328 \\
\hline 163 & 3 & $0-5 \mathrm{~cm}$ & 0.9977 & 0.274 & 1.0393 & 37.5986 & 0.6689 \\
\hline 164 & 3 & $5-10 \mathrm{~cm}$ & 0.9953 & 0.193 & 1.0383 & 26.3091 & 0.6857 \\
\hline 165 & 3 & $10-20 \mathrm{~cm}$ & 0.9966 & 0.112 & 1.0358 & 14.9066 & 0.7111 \\
\hline 166 & 3 & $20-30 \mathrm{~cm}$ & 1.0032 & 0.075 & 1.0361 & 9.6824 & 0.7254 \\
\hline 167 & 3 & $30-50 \mathrm{~cm}$ & 1.0032 & 0.1 & 1.0388 & 13.1839 & 0.7156 \\
\hline 168 & 3 & $50-$ & 1.0025 & 0.027 & 1.0413 & 3.0429 & 0.7461 \\
\hline 169 & 4 & $0-5 \mathrm{~cm}$ & 0.9991 & 0.199 & 1.0350 & 26.9585 & 0.6842 \\
\hline 170 & 4 & $5-10 \mathrm{~cm}$ & 1.0037 & 0.108 & 1.0375 & 14.2704 & 0.7126 \\
\hline 171 & 4 & $10-20 \mathrm{~cm}$ & 1.006 & 0.091 & 1.0452 & 11.9719 & 0.7190 \\
\hline 172 & 4 & $20-30 \mathrm{~cm}$ & 1.0034 & 0.071 & 1.0324 & 9.0929 & 0.7270 \\
\hline 173 & 4 & $30-50 \mathrm{~cm}$ & 1.0035 & 0.045 & 1.0331 & 5.5041 & 0.7380 \\
\hline 174 & 4 & $50-$ & 1.0016 & 0.096 & 1.1815 & 14.3841 & 0.7171 \\
\hline 175 & 5 & $0-5 \mathrm{~cm}$ & 1.0069 & 0.19 & 1.0355 & 25.5213 & 0.6865 \\
\hline 176 & 5 & $5-10 \mathrm{~cm}$ & 1.0038 & 0.16 & 1.0276 & 21.2802 & 0.6951 \\
\hline 177 & 5 & $10-20 \mathrm{~cm}$ & 1.0089 & 0.144 & 1.0280 & 18.9930 & 0.7001 \\
\hline 178 & 5 & $20-30 \mathrm{~cm}$ & 1.0034 & 0.116 & 1.0325 & 15.3118 & 0.7097 \\
\hline 179 & 5 & $30-50 \mathrm{~cm}$ & 1.0024 & 0.067 & 1.0342 & 8.5637 & 0.7286 \\
\hline 180 & 5 & $50-$ & 1.0054 & 0.061 & 1.1734 & 8.7475 & 0.7312 \\
\hline
\end{tabular}

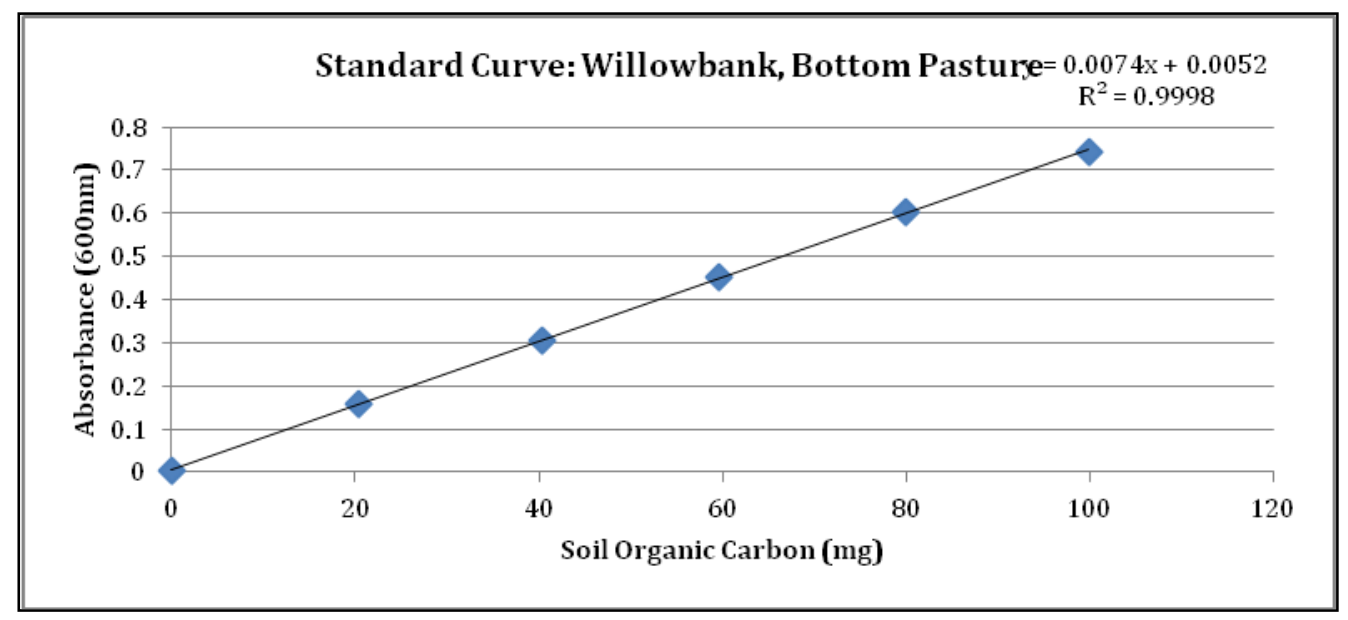


"RIVER":

\begin{tabular}{|c|c|c|c|c|c|c|c|}
\hline $\begin{array}{l}\text { Sample } \\
\text { No. }\end{array}$ & $\begin{array}{l}\text { Profile } \\
\text { No. }\end{array}$ & $\begin{array}{l}\text { Depth } \\
\text { Intervals }\end{array}$ & $\begin{array}{l}\text { Soil } \\
\text { Weight } \\
\text { (g) }\end{array}$ & Absorbance & $\begin{array}{l}\text { Moisture } \\
\text { Factor }\end{array}$ & $\begin{array}{l}\text { Soil OC } \\
\text { (mg/g) }\end{array}$ & Error \\
\hline 181 & 1 & $0-5 \mathrm{~cm}$ & 0.997 & 0.201 & 1.04164 & 27.7715751 & 2.565 \\
\hline 182 & 1 & $5-10 \mathrm{~cm}$ & 0.9933 & 0.132 & 1.038641 & 18.4105173 & 2.638 \\
\hline 183 & 1 & $10-20 \mathrm{~cm}$ & 0.9971 & 0.053 & 1.033001 & 7.59555398 & 2.746 \\
\hline 184 & 1 & $20-30 \mathrm{~cm}$ & 1.0054 & 0.021 & 1.04094 & 3.28148816 & 2.797 \\
\hline 185 & 1 & $30-50 \mathrm{~cm}$ & 0.999 & 0.046 & 1.035495 & 6.65568588 & 2.757 \\
\hline 186 & 1 & $50-$ & 1.0064 & 0.066 & 1.042131 & 9.34276803 & 2.727 \\
\hline 187 & 2 & $0-5 \mathrm{~cm}$ & 1.0031 & 0.289 & 1.038782 & 39.3799453 & 2.505 \\
\hline 188 & 2 & $5-10 \mathrm{~cm}$ & 0.9974 & 0.282 & 1.038848 & 38.6591924 & 2.508 \\
\hline 189 & 2 & $10-20 \mathrm{~cm}$ & 1.006 & 0.156 & 1.03574 & 21.3411929 & 2.61 \\
\hline 190 & 2 & $20-30 \mathrm{~cm}$ & 1.0048 & 0.084 & 1.036474 & 11.7218462 & 2.701 \\
\hline 191 & 2 & $30-50 \mathrm{~cm}$ & 1.0076 & 0.054 & 1.039329 & 7.69660616 & 2.745 \\
\hline 192 & 2 & $50-$ & 1.0011 & 0.03 & 1.045228 & 4.53135507 & 2.782 \\
\hline 193 & 3 & $0-5 \mathrm{~cm}$ & 0.9999 & 0.249 & 1.045717 & 34.3286685 & 2.527 \\
\hline 194 & 3 & $5-10 \mathrm{~cm}$ & 0.9998 & 0.208 & 1.04092 & 28.6225685 & 2.559 \\
\hline 195 & 3 & $10-20 \mathrm{~cm}$ & 1.0002 & 0.104 & 0.896118 & 12.5117519 & 2.673 \\
\hline 196 & 3 & $20-30 \mathrm{~cm}$ & 0.9964 & 0.055 & 1.039777 & 7.92220256 & 2.743 \\
\hline 197 & 3 & $30-50 \mathrm{~cm}$ & 0.9959 & 0.033 & 1.047559 & 4.97561464 & 2.777 \\
\hline 198 & 3 & $50-$ & 1.0023 & 0.031 & 1.041242 & 4.64379164 & 2.781 \\
\hline 199 & 4 & $0-5 \mathrm{~cm}$ & 1.0007 & 0.296 & 1.041904 & 40.5409614 & 2.501 \\
\hline 200 & 4 & $5-10 \mathrm{~cm}$ & 1.0077 & 0.248 & 1.041449 & 33.7895018 & 2.528 \\
\hline 201 & 4 & $10-20 \mathrm{~cm}$ & 1.0008 & 0.16 & 1.035021 & 21.9752447 & 2.606 \\
\hline 202 & 4 & $20-30 \mathrm{~cm}$ & 1.002 & 0.05 & 1.045058 & 7.23966042 & 2.751 \\
\hline 203 & 4 & $30-50 \mathrm{~cm}$ & 1.0031 & 0.021 & 1.066813 & 3.37076238 & 2.797 \\
\hline 204 & 4 & $50-$ & 1.0045 & 0.019 & 1.059913 & 3.06980859 & 2.8 \\
\hline 205 & 5 & $0-5 \mathrm{~cm}$ & 1.0058 & 0.18 & 1.041148 & 24.6881989 & 2.585 \\
\hline 206 & 5 & $5-10 \mathrm{~cm}$ & 0.9943 & 0.152 & 1.038584 & 21.1081733 & 2.614 \\
\hline 207 & 5 & $10-20 \mathrm{~cm}$ & 0.9994 & 0.115 & 1.040761 & 16.0328478 & 2.659 \\
\hline 208 & 5 & $20-30 \mathrm{~cm}$ & 0.9997 & 0.066 & 1.039921 & 9.3854366 & 2.727 \\
\hline 209 & 5 & $30-50 \mathrm{~cm}$ & 1.0062 & 0.026 & 1.042749 & 3.9585309 & 2.789 \\
\hline 210 & 5 & $50-$ & 0.9992 & 0.016 & 1.043657 & 2.63120042 & 2.805 \\
\hline
\end{tabular}

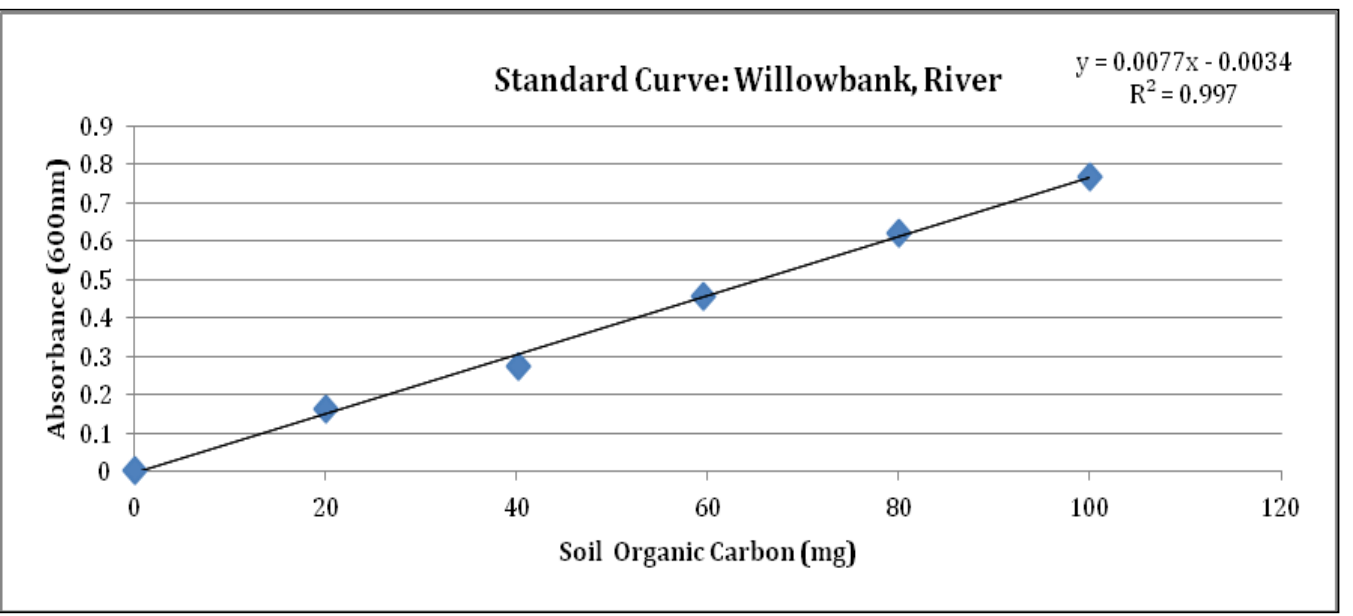

